\title{
SOY-BASED FILLERS FOR THERMOSET COMPOSITES
}

\author{
A Dissertation \\ Presented to \\ The Graduate Faculty of The University of Akron
}

In Partial Fulfillment

of the Requirements for the Degree

Doctor of Philosophy

Paula Watt

August, 2015 


\title{
SOY-BASED FILLERS FOR THERMOSET COMPOSITES
}

\author{
Paula Watt \\ Dissertation
}

Approved:

Advisor

Dr. Coleen Pugh

Committee Member

Dr. Toshikazu Miyoshi

Committee Member

Dr. Ali Dhinojwala

Committee Member

Dr. Lu-Kwang Ju

Committee Member

Dr. Mark Soucek
Accepted:

Department Chair

Dr. Coleen Pugh

Dean of the College

Dr. Eric Amis

Interim Dean of the Graduate School

Dr. Rex Ramsier

Date 


\begin{abstract}
Considerable work has been done with bio-based fillers in thermoplastics. Wood dust has been used for decades in wood plastic composites in conjunction with recycled high HDPE and PET. In recent years rapidly renewable fillers derived from dried distillery grains and from wood have been introduced commercially for thermoset polymers. These fillers provide bio-content and weight reduction to thermoset molding compounds but issues with moisture absorption and polymerization inhibition have limited their commercial acceptance.
\end{abstract}

The intent of this research was to develop a bio-based filler suitable for thermoset composites. This filler would provide a low density alternative to mined mineral filler, such as $\mathrm{CaCO}_{3}$ or clay. Composites made with these fillers would be lighter in weight, which is desirable for many markets, particularly transportation. Cost parity to the mineral fillers, on a volume basis, was desirable and the use of green chemistry principles was a key objective of the project.

This work provides a basis from which further development of modified soy flours as fillers for thermoset composites will continue. Biomass has been evaluated as fillers for thermoset composites since the early 1980s but failed to gain commercial acceptance due to excessive water absorption and inhibition issues with free radical curing. Biomass, with a large percentage of carbohydrates, are very hydrophilic due to 
their abundance of hydroxyl groups, while biomass, high in lignin, resulted in inhibition of the free radical cure of the unsaturated styrenated polyester matrix systems. Generally protein use as a filler is not desirable due to its food value.

Torrefaction has proved to be a good, cost effective, process to reduce hydrophilicity of high cellulose feedstock. Surprising, however, some levels of torrefaction were found to induce the inhibition effect of the filler. Scientific inquiry into this problem proved that aromatics form during the torrefaction process and can become problematic when threshold levels are reached. Studies to determine suitable levels and appropriate processes provided options for manufacture of suitable fillers. 


\section{DEDICATION}

This dissertation is dedicated to my parents, Carol and Harry, who always taught me that I could achieve anything I worked for. It is also dedicated to my husband, Tom, whose support made it possible to complete this work. Finally, I want to dedicate this

dissertation to my exceptional children, Carlie and John, who are my life's greatest achievement and most precious blessings. 


\section{ACKNOWLEDGEMENTS}

I would like to begin by thanking my parents, Carol and Harry, for being such wonderful role models and loving parents. I also want to thank my husband, Tom, for his support during my graduate studies. I am also very grateful for my wonderful children, Carlie and John, with whom I sat beside at the dining room table for many hours doing school work. I appreciate them supporting their weird mom who went back to school at such an age.

I cannot properly convey how very grateful I am to my doctoral advisor and mentor, Dr. Coleen Pugh. Quite honestly, I would not have finished this work without her encouragement and support. Her belief in me has provided me opportunities that I never would have dreamed of having. She is an incredibly intelligent researcher and personally, to be affiliated with her makes me extremely proud.

I acknowledge my doctoral dissertation committee members, Dr. Toshikazu Miyoshi, Dr. Ali Dhinojwala, Dr. Mark Soucek and Dr. Lu-Kwang Ju. I also want to thank Dean Eric Amis and the DPS staff, Melissa Bowman and Jacqui Clark, for all their support. In addition, I would like to thank Sue Dollinger, and others in the UA Office of Tech Transfer, for their guidance and support. I thank the USB and Premix Inc. for funding of my research. In particular, I wish to thank Dwight Russ of Omni-Tech, as well as Mike Gruskiewicz and Casey Blabolil at Premix. I also want to thank Union Process, Agritech and EarthCare for their assistance in the research. 


\section{TABLE OF CONTENTS}

Page

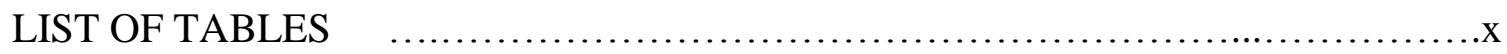

LIST OF FIGURES ….............................................................

CHAPTER

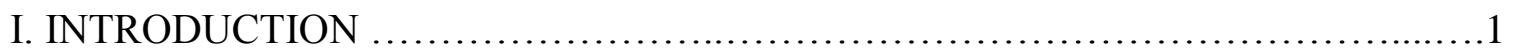

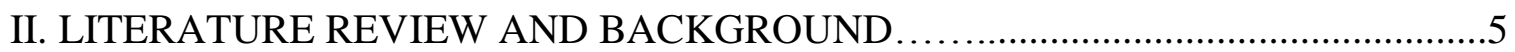

2.1 The Soy Flour Precursor....................................................

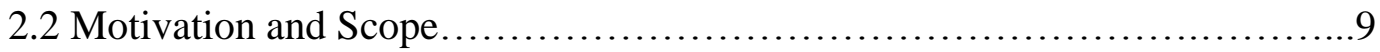

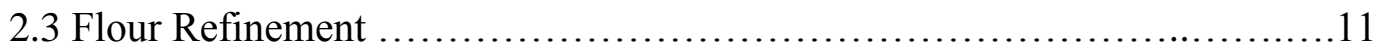

2.4 Chemical Surface Modifications..........................................20

2.5 Characterizaton of Modified Soy Flours...................................28

2.6 Moldified Milled Biomass as a Composite Filler............................33

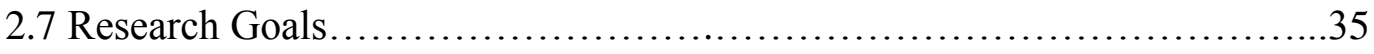

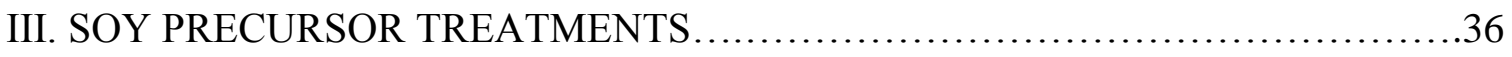

3.1 Converting Soy to a Useful Polymer Filler .................................36

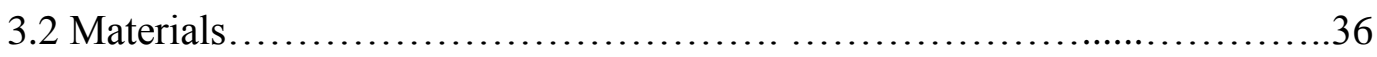

3.3 Refinement Methods................................................... 40

3.4 Thermal Treatment........................................................ 40

3.5 Chemical Modifications..............................................47

vii 
3.6 Esterifications.................................................... 51

3.7 Combined Treatments..............................................56

IV. CAST RESIN WATER ABSORPTION STUDIES .........................................60

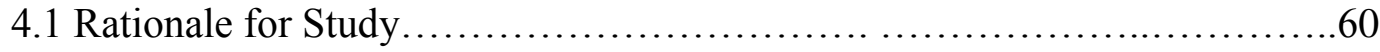

4.2 Materials.....................................................60

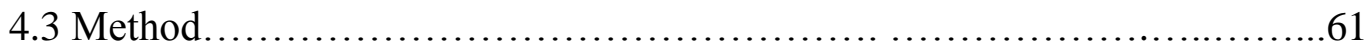

4.4 Method Uncertainty Assessment....................................66

4.5 Discussion....................................................... 73

4.6 Conclusions..................................................... 80

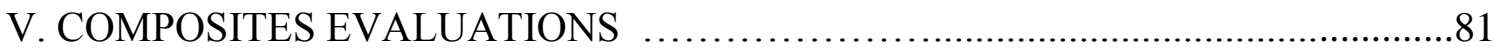

5.1 Requirements for a Composite Filler....................................81

5.2 Discontinuous Glass Molding Compounds .............................82

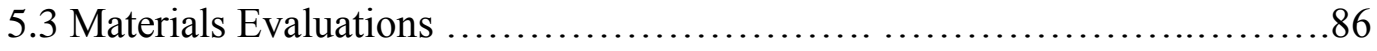

5.4 Bulk Molding Compound Evaluations..............................92

5.5 Sheet Molding Compound Evaluations...............................107

VI. ANALYTICAL EVALUATIONS OF PREFERRED TREATMENTS.................125

6.1 Purpose of Analytical Evaluations................................... 125

6.2 Instrumentation and Default Parameters...............................125

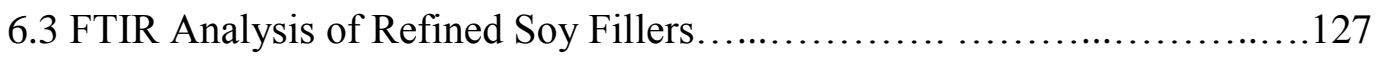

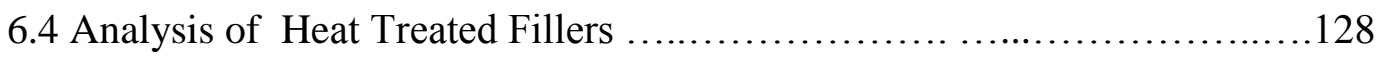

6.5 FTIR Analysis of OTES Treated Fillers .............................156

6.6 FTIR Analysis of Esterified Fillers and Filtrates......................... 157 
VII. SUMMARY AND FUTURE DIRECTION ................................... 166

7.1 Scope of the Dissertation............................................ 166

7.2 Precursors and Modifications......................................167

7.Water Absorption Experiments...................................... 167

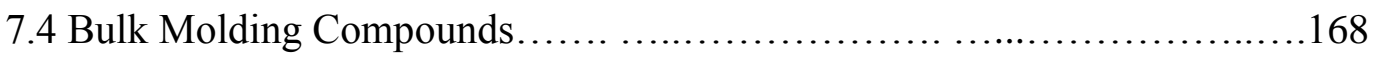

7.5 Cost Assessment : Torrefaction of Soy Hulls............................ 168

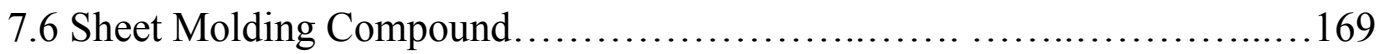

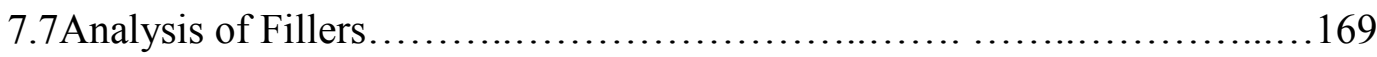

7.8 Unique Contribution and Future Direction.............................. 170 


\section{LIST OF TABLES}

Table

Page

2.1 Composition of Defatted Soy Meal and Flour .................................6

2.2 Composition of Biomass.................................................. 19

3.1 Silanes used for Treatments .............................................. 39

3.2 Muffle Furnace Experiments..........................................43

3.3 ECP Torrefaction Series.................................................... 47

4.1 Resin Casting Water Absorption Specimen..................................62

4.2 Resin Only and Precursor Weight Gain.....................................69

4.3 Weight Gain Data for Treated Fillers.......................................... 70

4.4 Refined Sample Normalized Weight Gain....................................74

4.5 Summary of Heat Treated Soy Fillers...................................... 75

4.6 Summary of Chemically Treated Soy Fillers................................ 77

4.7 Summary of Acetylated Soy Fillers........................................ 79

5.1 SMC Squeeze Flow Equations.......................................... 89

5.2 BMC Composition....................................................93

5.3 BMC Formula for Torrefaction Development.................................99

5.4 Comparison of BMC with Torrefacted Filler to Reinforced Nylon.................107

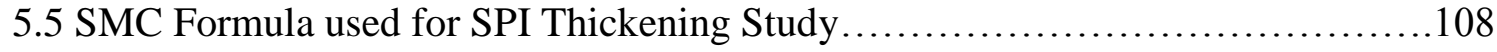

5.6 SMC Formula for PPT Samples......................................... 112 
5.7 Calculated Values from PPT Curves.....................................114

5.8 Values from Cure Studies at $3.2 \mathrm{~mm}$ Thick....................................119

5.9 Values from Cure Studies at $6.4 \mathrm{~mm}$ Thick................................119

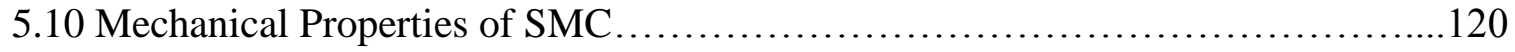

5.11 Meal and Hull Filled SMC Formulas.....................................122

5.12 SMC Mechanical Properties........................................... 123

6.1 : Elemental Analysis (EA) Data........................................ 134

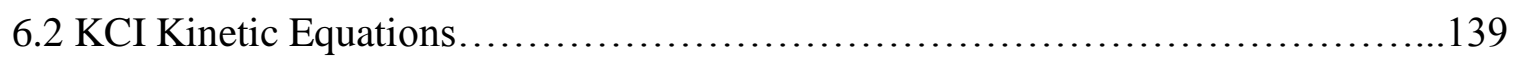

6.3 Data from DSC Analysis............................................. 147

6.4 Modified KCI Derived Kinetic Parameters.................................149

6.5 Comparison to Literature Results..................................... 151 


\section{LIST OF FIGURES}

Figure $\quad$ Page

2.1 Typical Composition of Soy Bean................................................ 5

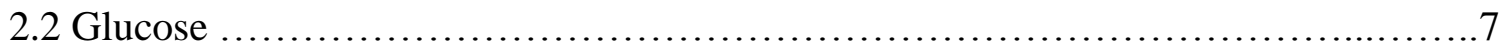

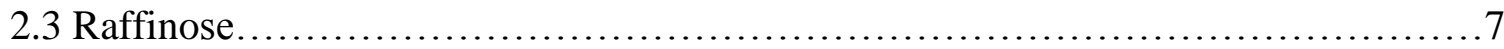

2.4 Cellulose ...........................................................................

2.5 Hemi-Cellulose..................................................................

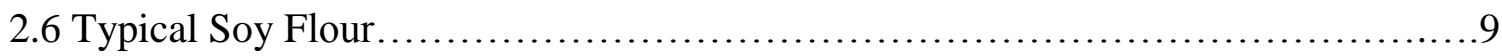

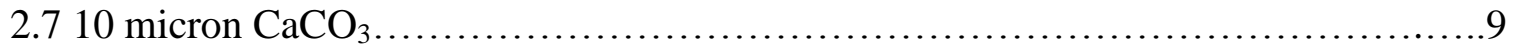

2.8 Property Loss with Water Absorption......................................... 10

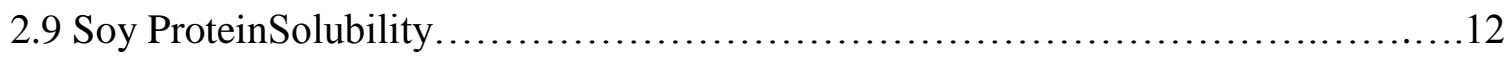

2.10 SEM of Mercerized Sisal Fibers...............................................13

2.11 Tensile Strength of Henequen Fibers with Treatments............................15

2.12 Enzymatic Digestion..................................................... 17

2.13 Ju Enzymatic Digestion Foam Fractionation Proces...............................18

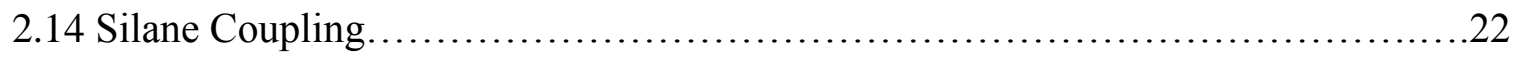

2.15 Epoxy Compatible and Reactive Silanes...................................... 23

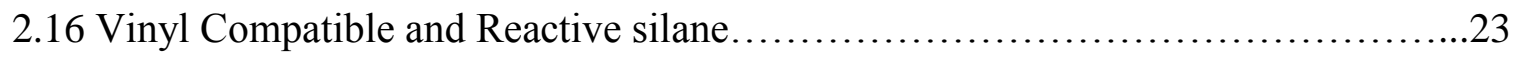

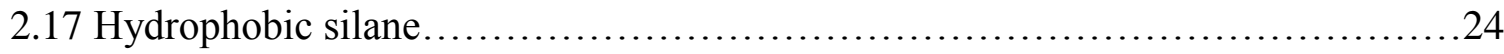

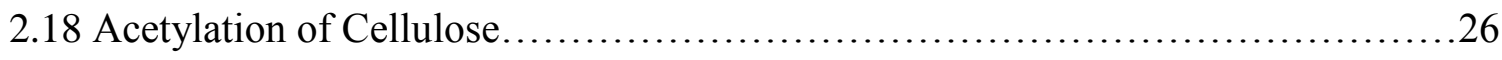


3.1 Muffle Furnace Bench Apparatus..............................................42

3.2 ATP/NCSU Continuous Self-Fueling Torrefactor Design.........................44

3.3 ECP Prototype Pilot Torrefactor..............................................46

4.1 Structure for Ashland MR 642 Polyester.....................................60

4.2 Structure for AOC S905 Polyester.........................................61

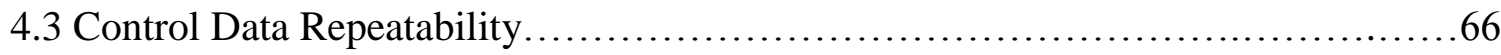

4.4 Average Weight Gain per Day.............................................67

4.5 Water Weight Gain with Time................................................68

4.6 Distribution for all Precursor Samples........................................69

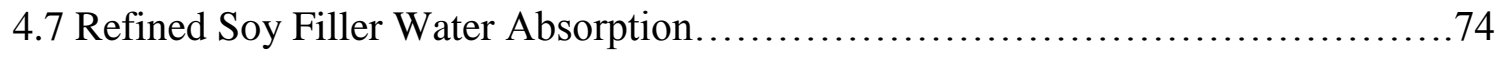

4.8 Normalized Weight Gain v. Time-Temperature for Heat Treated Fillers..............76

4.9 Normalized Water Absorption for Chemically Treated Fillers.......................78

4.10 Normalized Water Absorption for Acetylated Fillers..............................8 80

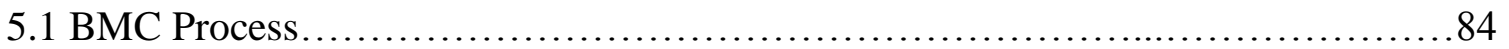

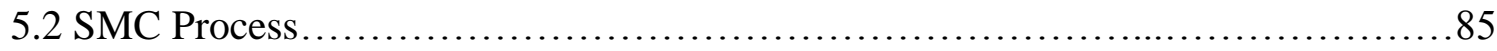

5.3 PPT 1000 Squeeze Flow Rheometer.......................................... 87

5.4 Geometry for Squeeze Flow Rheometer...................................... 88

5.5 Typical Squeeze Flow Raw Data.......................................... 88

5.6 DEA Instrumented Mold and SmarTrac ${ }^{\circledR}$ Analyzer.................................90

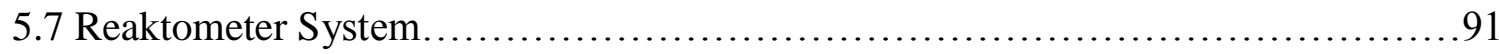

5.8 Flexural Properties of BMC with Refined Fillers................................94

5.9 Flexural Properties of BMC with Treated Fillers...................................95 
5.10 Water Absorption for BMC ................................................... 97

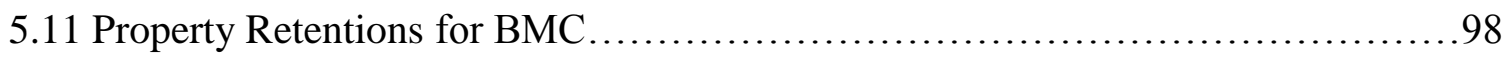

5.12 Effect of Water Absorption on Property Retentions............................... 98

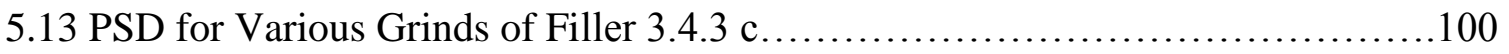

5.14 DEA Evidence of Cure Effects with Filler 3.4 .3 c..............................101

5.15 Flexural Properties of BMC with Torrefacted Filler..............................102

5.16 Density and Water Abs of BMC with Torrefacted Filler.........................103

5.17 DEA Curves for Non-inhibiting Torrefacted Fillers.............................104

5.18 Flexural Properties of BMC with Torrefacted Fillers and Clay Control............105

5.19 Water Absorption of BMC with Torrefacted Fillers and Clay Control..............106

5.20 Water Absorption of BMC with Torrefacted Fillers and Clay Control..............106

5.21 Thickening Profile with SPI Filled SMC Paste...................................109

5.22 Thickening Profile with $204{ }^{\circ} \mathrm{C}$ Torrefacted Filler...............................110

5.23 Thickening Profile with $249{ }^{\circ} \mathrm{C}$ Torrefacted Filler...............................111

5.24 PPT Data for $\mathrm{CaCO} 3$ and Soy Filler SMCs..................................112

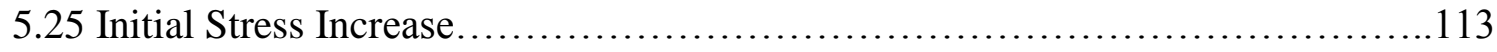

5.26 Viscosity vs. Shear Rate Curves...........................................113

5.27 Normalized Stress Relaxation Curves........................................114

5.28 Signature ${ }^{\circledR}$ DEA Curves ...................................................... 116

5.29 Reaktometer Temperature (pink) and Pressure (green) for $3.2 \mathrm{~mm}$ Panels.........117

5.30 Reaktometer Impedance (blue) and Displacement (black) for $3.2 \mathrm{~mm}$ Panels......117

5.31 Reaktometer Temperature (pink) and Pressure (green) for $6.4 \mathrm{~mm}$ Panels..........118 
5.32 Reaktometer Impedance (blue) and Displacement (black) for $6.4 \mathrm{~mm}$ Panels......118

5.33 SMC Molded Valve Covers..............................................121

6.1 ATR FTIR of SPI and UTSF........................................... 127

6.2 SPI spectra match to soy compound.................................... 128

6.3 ATR FTIR of Untreated and Torrefacted Soy Meal............................129

6.4 FTIR of Untreated and Torrefacted Soy Hulls.............................. 130

6.5 : FTIR of UTSH and EarthCare ${ }^{\circledR}$ Torrefacted Fillers..........................131

6.6 Spectra Match for Inhibiting Filler Extract................................ 132

6.7 Spectra Comparison of Tar and Oil Extracted from Inhibiting Filler...............133

6.8 Molar Ratios of Elements in Meal Fillers..................................... 134

6.9 : Molar Ratios of Elements in Hull Fillers..................................... 135

6.10 Elemental Mapping of Hydrogen vs. Carbon.................................136

6.11 TGA for Meal Fillers..................................................... 137

6.12 TGA for Hull Fillers.................................................. 138

6.13 Total Polymerization Exotherm Comparisons of $\mathrm{CaCO} 3$ and Inhibiting Heat Treated Soy Filler in a Resin Master.................................... 140

6.14 Isothermal Polymerization Comparisons of $\mathrm{CaCO} 3$ and Inhibiting Heat Treated Soy Filler in a Resin Master.................................... 140

6.15 Isothermal Polymerization of a Resin Master with and without Extracts...........141

6.16 DSC Temperature Ramp Data of Unsaturated Polyester Master...................144

6.17 Isotherms for Unsaturated Polyester with Styrene Blank at $85{ }^{\circ} \mathrm{C}$,

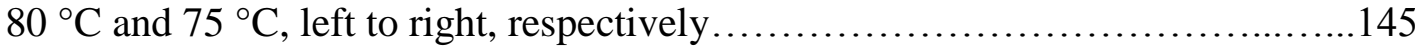

6.18 Isotherms for Unsaturated Polyester with Tar-spiked Styrene at $85{ }^{\circ} \mathrm{C}$, $80{ }^{\circ} \mathrm{C}$ and $75^{\circ} \mathrm{C}$, left to right, respectively... 
6.19 Isotherms for Unsaturated Polyester with Oil-spiked Styrene at $85{ }^{\circ} \mathrm{C}$,

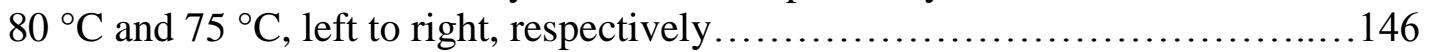

6.20 Regression Curves for Time to Isothermal Rate Maximum for Resin Master with and without Extracts........................................... 148

6.21 Regression Curves for the Isothermal Rate Maximum Maximum for Resin Master with and without Extracts................................. 148

6.22 Arrhenius Regression for Propagation Kinetic................................ 150

6.23 : SS 13C NMR Spectra of Torrified Fillers...................................152

6.24 Composition of Various Torrefied Fillers by NMR Integrations...................153

6.25 Baseline Adjusted Cellulose Region of SS ${ }^{13} \mathrm{C}$ NMR

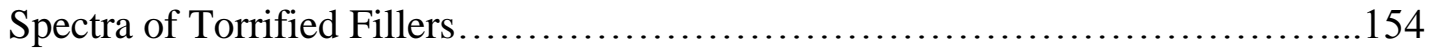

6.26 : Baseline Adjusted Aliphatic Region Region of SS

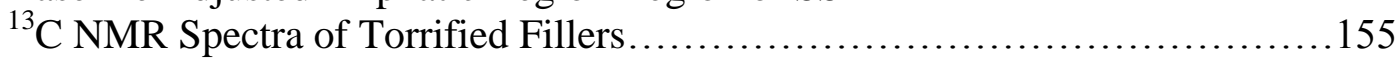

6.27 Baseline Adjusted Carboxyl Region Region of SS

${ }^{13} \mathrm{C}$ NMR Spectra of Torrified Fillers....................................... 155

6.28 Baseline Adjusted Aromatic Region Region of SS

${ }^{13} \mathrm{C}$ NMR Spectra of Torrified Fillers..........................................156

6.29 ATR FTIR Spectra of UTSH, OTES Treated Hulls \& OTES Silane................157

6.30 FTIR Match of Acetylated 3.6.1a Filtrate and Cellulose Acetate...................158

6.31 FTIR Match of Subtracted [3.6.1 a] Filtrate Spectra to Soy Protein................158

6.32 ATR FTIR of UTSF and Acetylated Soy Flour 3.6.2 a..........................160

6.33 FTIR Spectra Match for Filtrate 3.6.2a Residue to Cellulose Acetate................160

6.34 FTIR Spectra of UTSF and Slurry Acetylated Flour at Different Scales...........161

6.35 Different Areas of Acetylated Flour 6.6.3a with Different Coloration...............162

6.36 FTIR Spectra of the UTSF and Sludge Ttreated Acetylated Flours................163

6.37 FTIR Spectra of UTSH, ASA 2024 Treated Hulls and ASA 2024 Liquid...........164 
6.38 FTIR Spectra of UTSH, Acetylated Flour, ASA 2024

Treated Hulls and Mixed Treatment Hulls.......................................165 


\section{CHAPTER I}

\section{INTRODUCTION}

An accelerating trend in polymer research has been emerging in the area of green chemistry with facets including, but not limited to, reduction in chemical hazards, solventless processing, waste elimination, reduced pollution, increased energy efficiency, use of renewable feedstocks, atom economy, avoidance of unnecessary derivatizations, use of advantageous catalysis, designing for recyclability and/or low-hazard degradation, and increased safety of processes. These are among the principles of Green Chemistry framed by Anastas and Warner in the late 1990s. ${ }^{1}$

Around that time period, there was increased recycling activity and an escalation in awareness of the potential for bio-degradable polymers due to burgeoning landfills, as more and more disposable products were popularized. In the polymer literature there are several good overview publications that highlight concentrations of research and

subsequent commercialization of the biodegradable / biocompostable technologies. ${ }^{2.3 .4}$ While these polymers are of immense interest in the packaging and medical fields, environmental degradation is not necessarily a favorable attribute for durable goods. At the turn of the century another green polymer initiative was taking off, albeit with less fanfare. Although seed oil polymers had been commercialized widely in drying oils for 
coatings and linoleum ${ }^{\circledR}$ flooring, there had been decades of intellectual and commercial disinterest in the field. In the late 1990s, a few researchers began publishing on the use of plant oils as precursors for durable polymers. In subsequent years, the volume of publications on the topic mushroomed. A number of review articles in scientific journals, authored between 2007 and 2011, summarize this work. ${ }^{5,6,7,8}$ In the last few years, the interest has grown beyond academia and bio-polymers are now touted, in industry trade journals, as a promising market trend. ${ }^{9.10,11}$ The commercialization of plant oil resins, along with plant based fuels, cleaners, lubricants, etc. results in a large side stream of meal that is roughly 3.5 times the mass of the oils that are gleaned.

In addition to bio-based resin technology, there has been considerable work with bio-based reinforcements and fillers. Wood dust has been used for decades in wood plastic composites (WPCs) in conjunction with recycled high density polyethylene (HDPE) and polyethylene terephthalate (PET). ${ }^{12}$ Egg shells $^{13}$, chicken feathers ${ }^{14}$ and periwinkle shells ${ }^{15}$, amongst others, have been evaluated as fillers in polymers. In recent years a number of rapidly renewable plant-based fillers have been introduced for polymers. Lignotech ${ }^{\circledR}$ filler is produced from dry distillery grains (DDGs) using a steam explosion process. ${ }^{16}$ Laurel BioComposite's Bio-Res® is also made from DDGs utilizing a microwave treatment. ${ }^{17}$ NeroPlast ${ }^{\circledR}$, offered by New Polymer Systems, Inc., is a torrefacted lignocellulosic filler from wood and other sources. ${ }^{18}$ Advances in green polymer chemistry methods that could be used in modification of the plant meals include emulsion processing, streamlining of chemical pathways, waste minimization, efficient catalytic reactions, and enzyme catalyzed modifications and polymerizations. Recent 
advances in the latter offer the potential of particularly mild process conditions and regioselective control that is unattainable using conventional chemical reactions. An extensive review by Kobayashi and Makino describes a wide range of enzyme catalyzed polymerizations and functionalizations. ${ }^{19}$

The two largest industries in Ohio are polymers and agriculture. ${ }^{20}$ With over 220 million bushels harvested annually, soy is a major crop for the state, which is ranked seventh in the US for soybean production. ${ }^{21}$ Therefore in Ohio, use of soy as a precursor for polymer products provides the advantages of local sourcing and reduced reliance on imported raw materials, along with the renewable resource benefits.

An advantageous feature of soy flour is that it has a specific gravity of roughly $1 \mathrm{~g} / \mathrm{cm}^{3}$, which is considerably lower than inorganic mineral powders that are typically used in polymers as fillers. Calcium Carbonate $\left(\mathrm{CaCO}_{3}\right)$ for example has a specific gravity of $2.6 \mathrm{~g} / \mathrm{cm}^{3}$. The use of a lighter weight filler means that components manufactured from the compound will have a lower density. This is a benefit for many applications where fuel mileage, freight costs, and/or ergonomics are important.

In this dissertation, the performance of soy flour as filler for polymer compounds is studied. Modification of the flour to impart the required wetting and adhesion, as well as hydrophobicity, are explored with application of green chemistry. Composites are manufactured and compared to benchmark mineral filled composites.

This dissertation is organized in Chapters. CHAPTER II is a literature review, along with an introduction of other background information. CHAPTER III describes 
various treatments to convert the soy precursors to useful polymer filler. CHAPTER IV is a review of water absorption screening experiments to identify promising treatments. CHAPTER V describes the manufacture of composites using the fillers and the resulting performance relative to mineral filled composites. In CHAPTER VI, promising treatments are studied analytically to understand changes in the chemical composition and to characterize performance. CHAPTER VII presents a summary of the work. 


\section{CHAPTER II}

\section{LITERATURE REVIEW AND BACKGROUND}

\subsection{The Soy Flour Precursor}

To understand how a soy-based powder will interact with polymers and perform as a filler, it is necessary to understand the precursor and post-modification compositions and characteristics. A soybean, as harvested, has a complex composition comprised of proteins, carbohydrates, lipids, minerals, and moisture. Figure 2.1 depicts the approximate composition of a representative soybean.

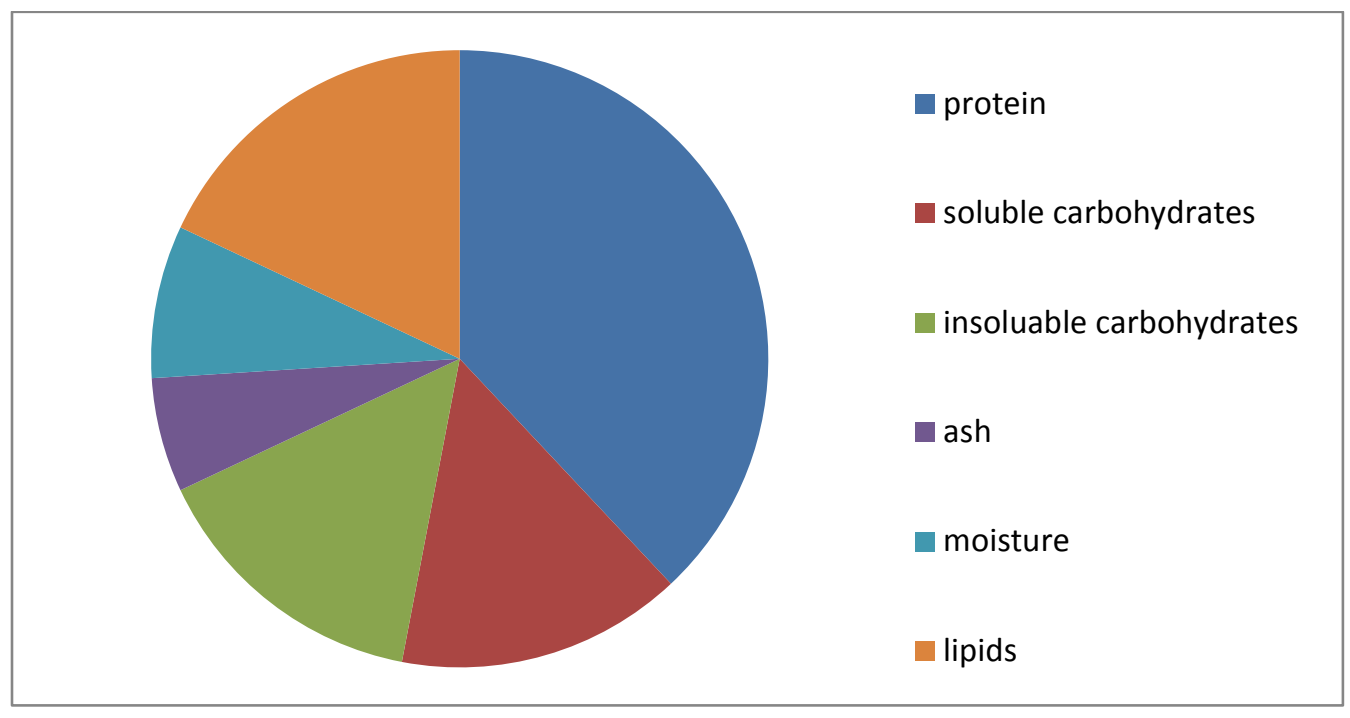

Figure 2.1: Typical Composition of Soy Bean 
For this dissertation, defatted soy meal or flour, which is a ground from the solids left after dehulling, crushing and extraction of the bean oils, was used as a precursor. A typical composition of defatted soy flour is seen in Table $2.1 .^{22}$

Table 2.1: Composition of Defatted Soy Meal and Flour ${ }^{22}$

\begin{tabular}{|c|c|c|}
\hline Defatted Soy Flour & Minimum & Maximum \\
\hline \% Protein & 50 & \\
\hline \% Carbohydrates & 30 & \\
\hline \% Indigestible Fiber & & 3.5 \\
\hline \% Moisture & & 9 \\
\hline \% Lipids & & 1.5 \\
\hline \% Ash & & 7 \\
\hline
\end{tabular}

American Oil Chemists' Society (AOCS) specifications stipulate that a soy meal or flour must contain a minimum of $48 \%$ protein. The protein contains nineteen different residues with varying charge distributions and affinities for hydrogen bonding and water binding. The interactions between residue segments results in a quaternary structure, which assays indicate have 41 moles of free amino groups per $10^{5} \mathrm{~g}$ of protein. ${ }^{23}$ The free amino groups are available for reaction with the environment and reagents. The 3-D structure of the folded proteins can be denatured or unraveled into more linear arrangements by thermal or chemical treatments. This changes the presentation of the residue distribution to the overall environment, presumably unfolding more hydrophobic functional groups in the process. 
Protein solubility is dependent not only on temperature but also on $\mathrm{pH}$. At neutral and alkaline conditions the proteins are largely soluble and bind large quantities of water. Water solubility goes through a minimum at $\mathrm{pH} \sim 4.5$. Process conditions will dictate what portion of the protein is carried away with filtrate and what is retained in the flour after treatment. This will impact both the characteristics of the treated flour as a filler, as well as yields of filler per mass of precursor material and reagents.

Carbohydrates are the second most abundant compounds in defatted soy flour at roughly $30 \%$. Carbohydrates include simple sugars, such as sucrose seen in Figure 2.2, oligosaccharides, like stachyose seen Figure 2.3, and other soluble polysaccharides such as starch. $^{24}$

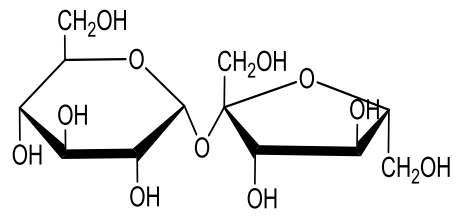

Figure 2.2: Sucrose

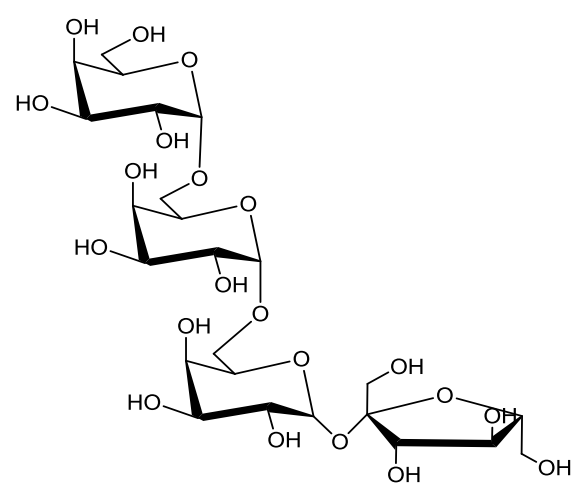

Figure 2.3: Stachyose

Indigestible fibers also contain cellulose, seen in Figure 2.4, along with hemicellulose, seen in Figure 2.5.

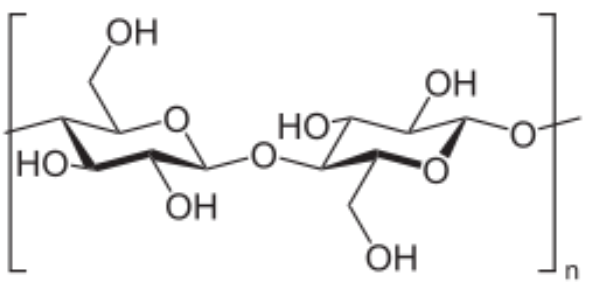

Figure 2.4: Cellulose

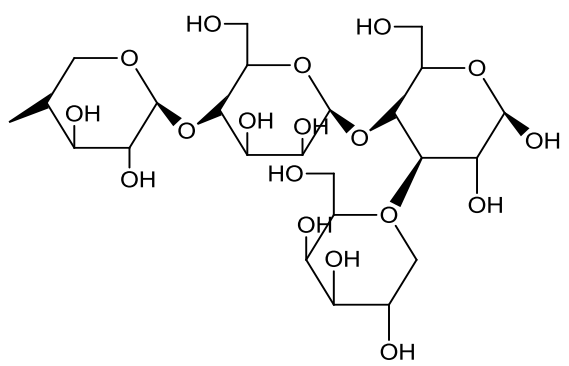

Figure 2.5: Hemi-Cellulose 
Roughly half of the carbohydrates are soluble in neutral ambient temperature water; however cellulose and much of the hemicellulose are not soluble, although they can be digested to soluble constituents under harsh conditions. The carbohydrates in soy contribute significant hydroxyl functionality, imparting high water absorption and hydrogen bonding. In fact, the flour will swell in water, rather than disperse, resulting in an engorged sludge. This contributes significantly to the hydrophilic nature of soy flour, which is the major concern in performance for a composite filler. The remainder of the defatted soy flour composition is minerals (referred to as ash), moisture, fat, and indigestible fiber.

To be recognized as a flour, as opposed to a meal or grit, the particle size is reduced, such that $97 \%$ of the flour will sift through a 100 mesh sieve. ${ }^{25}$ This indicates that $97 \%$ have a particle diameter of less than 149 microns. Detailed particle size distributions of these flours are not typically characterized. Most mineral fillers, used in composites and molding compounds, are 10 micron or smaller in median diameter, with maximum diameters of roughly 100 microns. Fine particulates are typically removed through classification. Figure 2.6 shows a typical soy flour particle size distribution and Figure 2.7 shows the target distribution based on analysis of nominal 10 micron $\mathrm{CaCO}_{3}$. Note the broader distribution of the soy flour. To work effectively in a reinforced composite, filler with similar particle size ranges may be required. This is questionable, however, due to the differences in the deformability of the soy filler and mineral fillers. It may be possible to use a broader particle size distribution due to the ability of the filler to elongate and compress. 


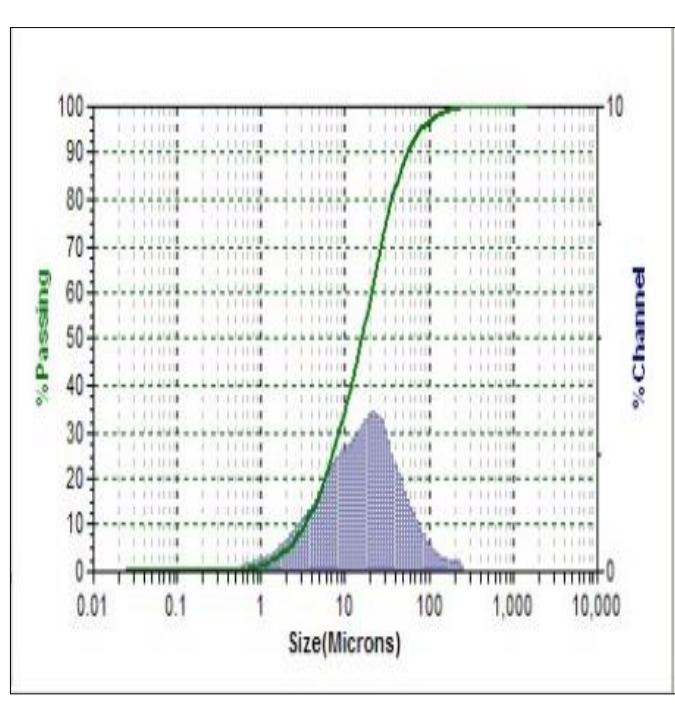

Figure 2.6: Typical Soy Flour ${ }^{26}$

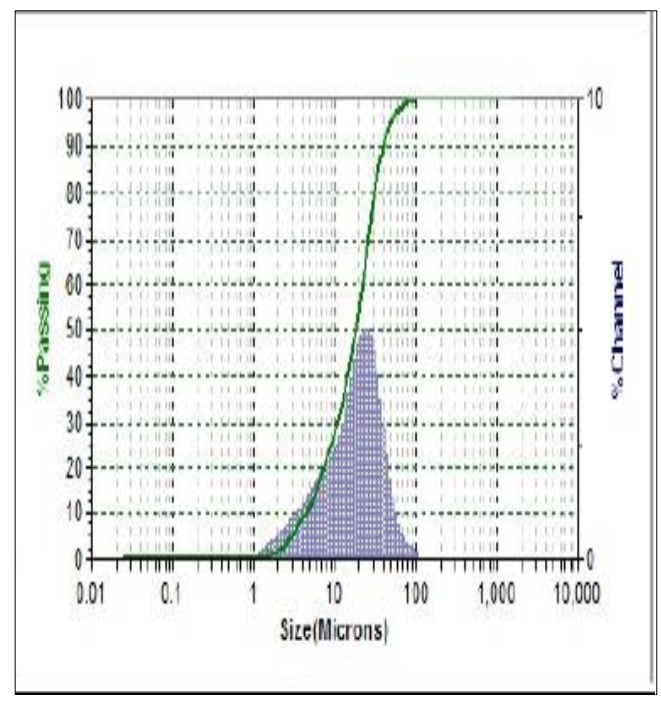

Figure 2.7: 10 micron $\mathrm{CaCO}_{3}{ }^{27}$

\subsection{Motivation and Scope}

A growing demand for soy oil derivatives in industrial products is driving the consumption of millions of bushels of soybeans annually. For each ton of oil yielded, over 3.5 tons of meal is left behind. Finding uses for this side stream is a priority to the American soybean farmers and processors. Plant biomass has been widely explored as fillers for composite materials but, with the exception of Wood Plastic Composites (WPC) made from wood flour and thermoplastic matrices, very limited composite products have been commercialized. The number one recognized challenge for the use of defatted soy flour is its highly hydrophilic nature. Moisture uptake results in dimensional stresses, plasticization, hydrolysis, and microbial attack, all of which are detrimental to a composite's performance. ${ }^{28} \mathrm{An}$ example of modulus loss of a glass reinforced thermoset composite is seen in Figure 2.8. ${ }^{29}$ 


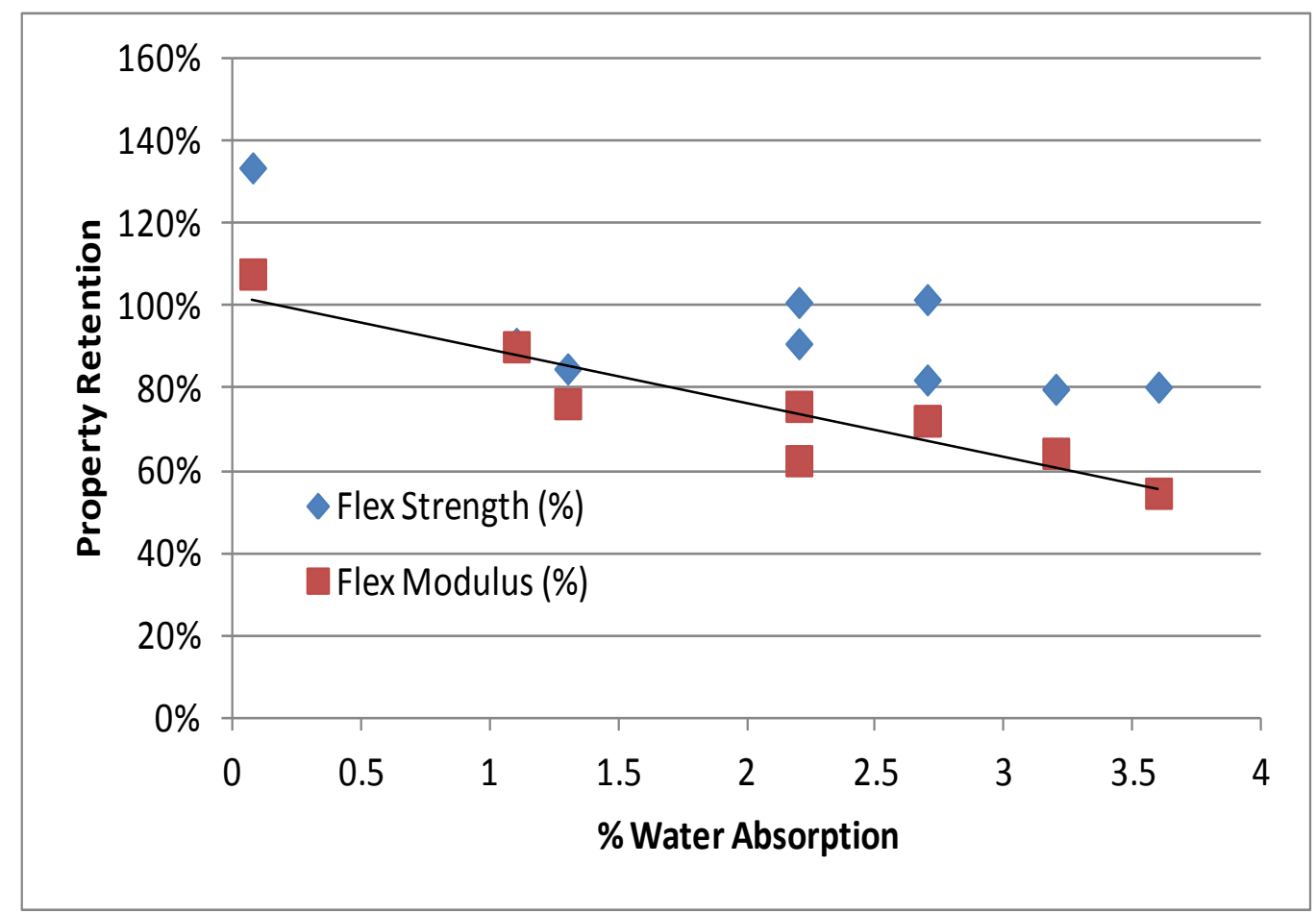

Figure 2.8: Property Loss with Water Absorption ${ }^{29}$

The present work, in preparation of this dissertation, includes investigation into the effects of various modifications to the defatted soy flour in terms of water absorption when dispersed into a polymer matrix. This is dependent on contributions from the hydrophilicity of the modified flour filler and the wetting at the interface between the matrix and filler, with both contributing to the ingress of water. Further, when effective modifications are identified, the chemical compositions and characteristics are explored in an attempt to decouple the various contributors to the hydrophobic shift.

Ideally two general approaches to reducing hydrophilicity are suggested: 1) elimination of highly hydrophilic content (i.e. carbohydrates, soluble protein) and 2) chemical modification. In practice, often a clean distinction between the approaches does 
not exist due to the conditions of the treatments, which draw out some species that are then separated from the solid filler with the liquid reactants and/or wash solvents. In addition, reaction chemicals or temperatures can denature the protein content and modify the carbohydrate crystallinity of the system, adding a further level of complexity to the effectiveness of the functionalizations.

Various approaches, as well as combined strategies, including both selective removal and chemical modification, are assessed with a focus on industrial feasibility and environmental impact. Cost consideration, as well as green attributes including worker and consumer safety, waste, renewable resource content, etc., are scrutinized.

\subsection{Flour Refinement}

Schultz and Mehta reported that soy protein isolates exhibited 65\% less water absorption than defatted soy flour when cast into unsaturated polyester (UPE) resin. ${ }^{30}$ This supports the premise that the carbohydrates in the system are the major contributor to the hydrophilic nature of the flour.

Processes for abstraction of carbohydrates, to concentrate and isolate soy proteins, are well established in the food industry. Concentrates, which by specification contain a minimum of $70 \%$ protein, are prepared by several methods. ${ }^{31}$ One method takes advantage of the fact that the protein is not soluble in alcohol. Using alcohol / water mixtures the carbohydrates are extracted, leaving the protein behind. Another method is to denature the protein, which makes it insoluble, followed by washing with water. The most common means of denaturing is through steam exposure. 
Further protein purification to isolates, with greater than $90 \%$ protein content, is also a mature technology. The isoelectric precipitation method manipulates the solubility behavior of the protein, as a function of $\mathrm{pH}$, seen in Figure 2.9. ${ }^{32}$ Soluble protein and carbohydrates are extracted at a $\mathrm{pH}$ of 7-9 in water. In the absence of salts, the protein is insoluble in water at a $\mathrm{pH}$ of 4.5 , therefore with the addition of acid, the protein can be selectively precipitated from the aqueous solution.

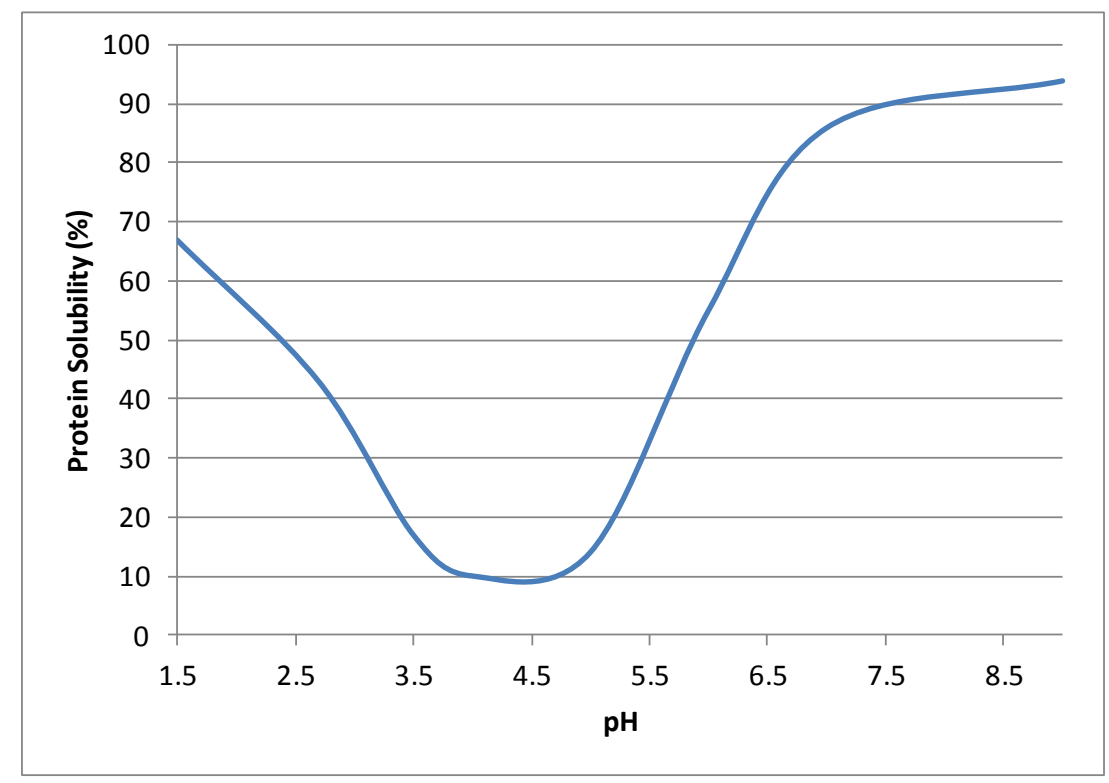

Figure 2. 9: Soy Protein Solubility in Water ${ }^{32}$

\subsubsection{Alkali Treatment}

While the chemical methods of protein isolation are suitable, if not ideal, for production of expensive soy isolates, their cost would not be feasible for the manufacture of a filler, which must sell for no more than $\$ 0.30 / \mathrm{lb}$. A number of publications describe simple alkali pretreatments of cellulosic fillers and fibers to promote adhesion with polymeric resins. A slurry wash of our soy flour will carry away the base-soluble 
carbohydrates and protein, leaving the less hydrophilic portion in the solid form. This is a mild mercerization, which also swells the cellulose, as $\mathrm{H}^{+}$ions are exchanged with the larger $\mathrm{Na}^{+}$ions. This allows for rearrangements of a portion of the crystal structures, from cellulose I to cellulose II, with reduced overall crystallinity, from $52 \%$ to $43 \%$, as reported by Liu and Wang. ${ }^{33}$

Mercerization also solvates and removes lignin and hemicellulose, leaving a coarse surface topography that creates opportunity for matrix ingress and enhancement of adhesion through mechanical interlocks, as Rong et al. reports in Figure $2.10 .^{34}$
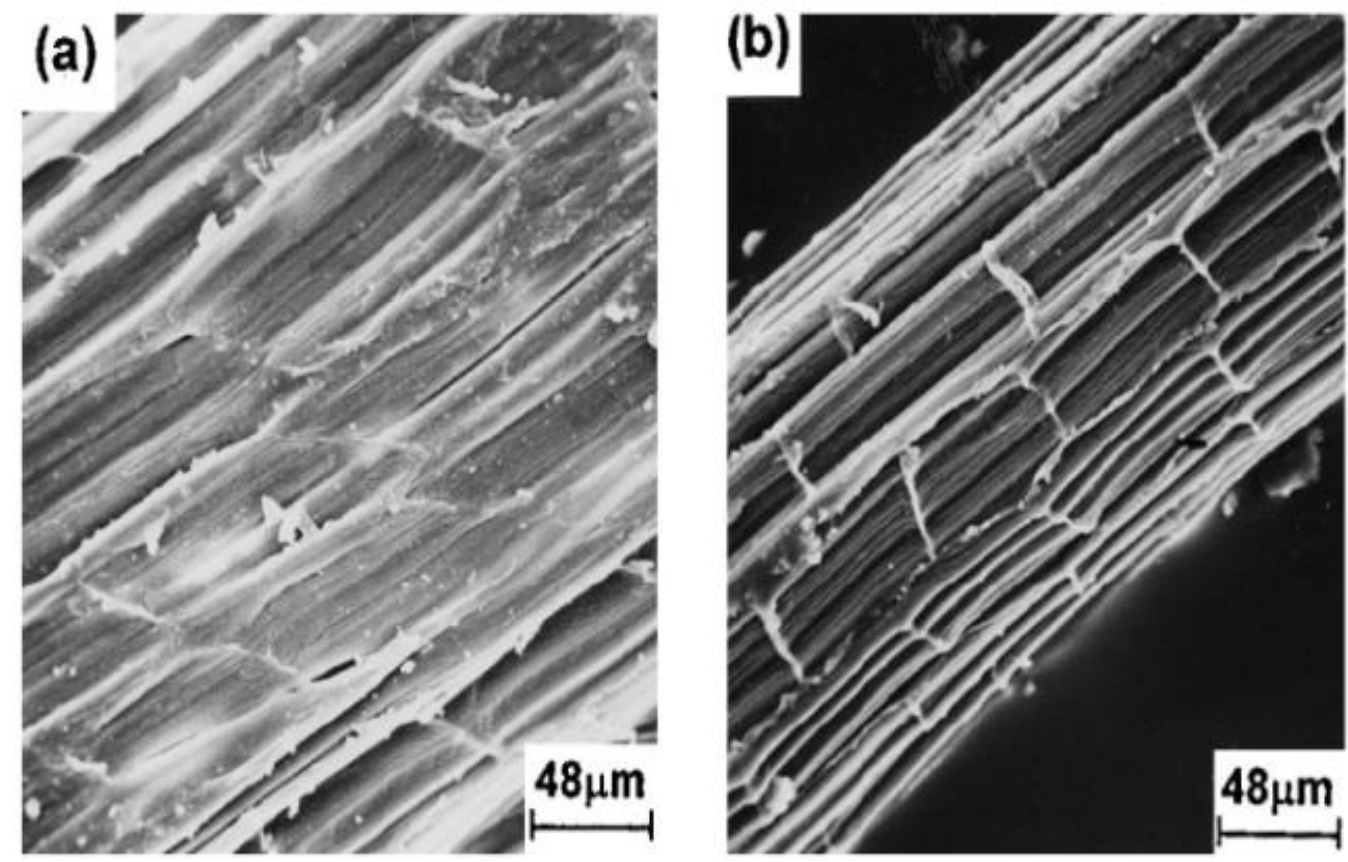

Figure 2.10: SEM of Mercerized Sisal Fibers ${ }^{34}$. Reprinted with Permission from reference 34 .

The sisal fibers were immersed in a $60{ }^{\circ} \mathrm{C}, 2 \% \mathrm{NaOH}$ solution for 4 hours, followed by water washes and air drying at $80{ }^{\circ} \mathrm{C}$. They reported a $13.5 \%$ weight loss and a slight 
reduction in cellulose crystallinity. Tensile strength was increased, from $391 \mathrm{MPa}$ to 496 $\mathrm{MPa}$, with the treatment. They attributed this to epoxy penetration into the etched flaws in the fiber, resulting in improved distribution of load.

Van der Weyenberg et al. employed immersions at ambient temperature in three $\mathrm{NaOH}$ solution concentrations $(1,2,3 \%)$ for 20 min to modify flax fibers. ${ }^{35}$ They used a cold water, acidified water (20 drops $\mathrm{HCl} 0.1 \mathrm{M}$ in $1 \mathrm{~L}$ of water), cold water wash sequence, followed by oven drying at $80{ }^{\circ} \mathrm{C}$ for $8 \mathrm{~h}$. Improvements in longitudinal strength, which increased with higher concentration, and transverse strength, not trending with concentration, were reported in epoxy composites. The former was attributed to removal of pectins, rich in galacturonic acid, and the latter to improved mechanical adhesion to the etched surface of the treated fibers.

Valadez-Gonzalez et al. described a $1 \mathrm{~h}, 25^{\circ} \mathrm{C}$ alkaline treatment of henequen fibers with $2 \% \mathrm{w} / \mathrm{v} \mathrm{NaOH}$ aqueous solutions with a water wash to neutral $\mathrm{pH}$ and drying at $60{ }^{\circ} \mathrm{C}$ for $24 \mathrm{~h} .{ }^{36}$ No enhancement in tensile strength of henequen / HDPE composites was observed with only the alkali treatment. This is likely due to the thermoplastic's inability to penetrate into surface features, in contrast to the lower viscosity thermosets. An improvement was observed; however, when alkali treated fibers were compared to untreated fibers as substrates for silane grafting, as seen in Figure $2.11^{36}$. They attributed this to an increase in reactive sites due to partial extraction of alkali soluble compounds, including lignin, from the fiber. 


\begin{tabular}{ll}
\hline Keyword & Surface treatment \\
\hline FIB & Untreated henequén \\
FIBNA & Henequén fiber treated with an aqueous alkaline solution \\
FIBSIL & Henequén fiber treated with a silane coupling agent \\
FIBNASIL & $\begin{array}{l}\text { Henequén fiber treated first with alkaline solution and } \\
\text { then with a silane coupling agent }\end{array}$ \\
\hline
\end{tabular}

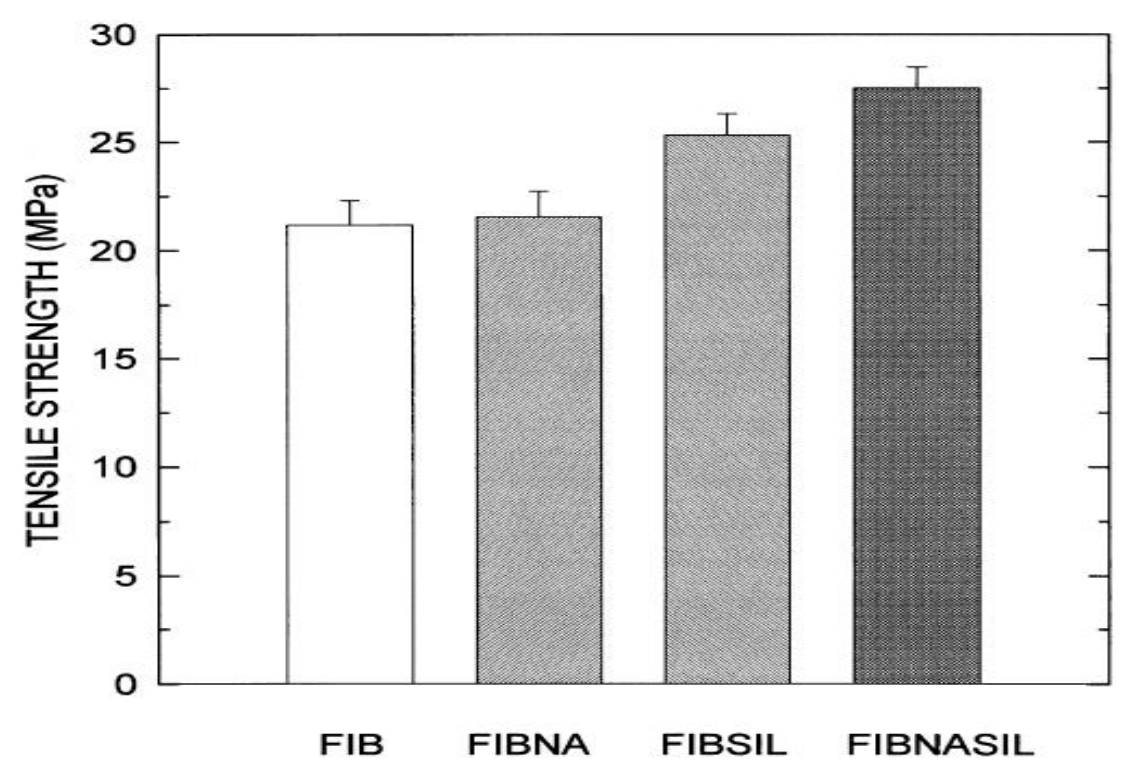

Figure 2.11: Tensile Strength of Heneguen Fibers with Treatments ${ }^{36}$.

Reprinted with permission from reference 36 .

Schultz and Mehta treated soy flour using a ambient temperature, $15 \mathrm{~min}, 5 \mathrm{~N}$ $\mathrm{NaOH}$ slurry, followed by filtering and vacuum drying for $16 \mathrm{~h}$ at $60{ }^{\circ} \mathrm{C} .{ }^{30}$ Their findings did not indicate any improvement in mechanical properties with the treatment, although they did report a $45 \%$ decrease in water absorption in polyester composites.

Agrawal et al. used a $48 \mathrm{~h}$ ambient $5 \% \mathrm{NaOH}$ solution soak of palm fiber, followed by a water wash containing a few drops of acetic acid, then a final fresh water wash before drying. ${ }^{37}$ They ascribed improved adhesion to phenol formaldehyde resin in 
a composite, to an increase in surface roughness and anchoring features created via removal of natural and artificial impurities.

Rangel-Vazquez and Leal-Garcia reports rice husk treatment in $0.5 \mathrm{~N} \mathrm{NaOH}$ ambient temperature solution for $2 \mathrm{~h}$, followed by fresh water rinses, dilute $\mathrm{HCl}$ rinses to a neutral $\mathrm{pH}$, and a final water rinse. ${ }^{38}$ The fibers were dried for $24 \mathrm{~h}$ at $70{ }^{\circ} \mathrm{C}$. No mechanical properties were reported in this study.

\subsubsection{Enzymatic Refinement}

Alkali extraction / treatment and other chemical processes to refine the flour result in a significant waste stream of non-neutral water solutions that must be treated. The filler yield is also compromised because of the hazardous content of the waste stream, which makes the extracted materials non-usable.

Motivated by the prospect of bio-fuel as a replacement for petroleum, biomass conversion to usable feedstock has been aggressively researched in the last decade. In light of the growing interest in green technology, significant work demonstrating the use of enzymes to refine biomass, as an alternative to harsh chemical treatments, has been underway. Insoluble cellulose, along with oligosaccharides and soluble cellulose, can be hydrolyzed using cellulose as seen in Figure 2.12. The resulting extractable sugars, which are not made toxic with chemicals, are a valuable by-product of the flour refinement. A review of much of the science behind enzymatic refinement has been documented by Yang et al in a review paper. ${ }^{39}$ 

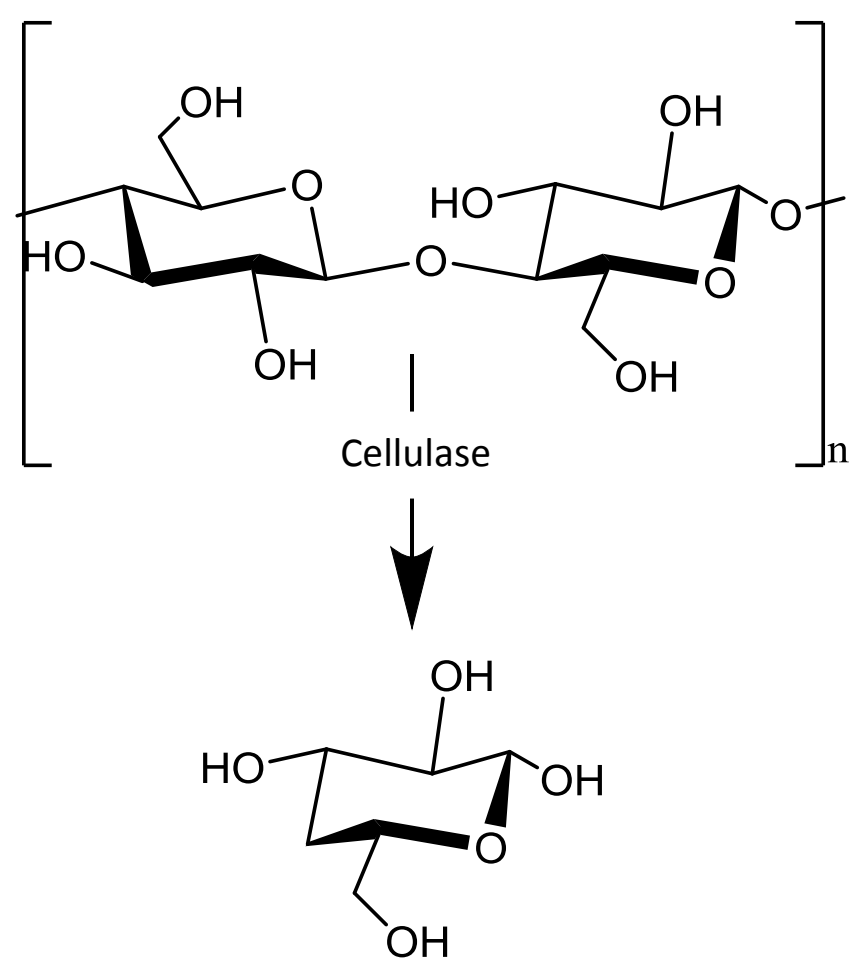

Figure 2.12: Enzymatic Digestion

The efficiency of enzymatic hydrolysis of bio-mass has been established, although cost effectiveness has not been demonstrated. The major cost component of the process is the enzyme production, primarily due to its low yields. The concentration dependence of the enzyme reproduction, having both induction and repression effects, results in the low yields. Ju pioneered a foam fractionation method, by which the enzyme can be removed from the reaction vessel continuously, to maintain the optimum concentration. ${ }^{40}$ The method, depicted in Figure 2.13, employs substrate materials that preferentially bind to the generated enzymes. Because the complex is less hydrophilic than the enzymes and precursor materials, they separate from the broth, rise with the foam and are harvested. This approach substantially improves the yields and the enzyme cost becomes industrially feasible. 


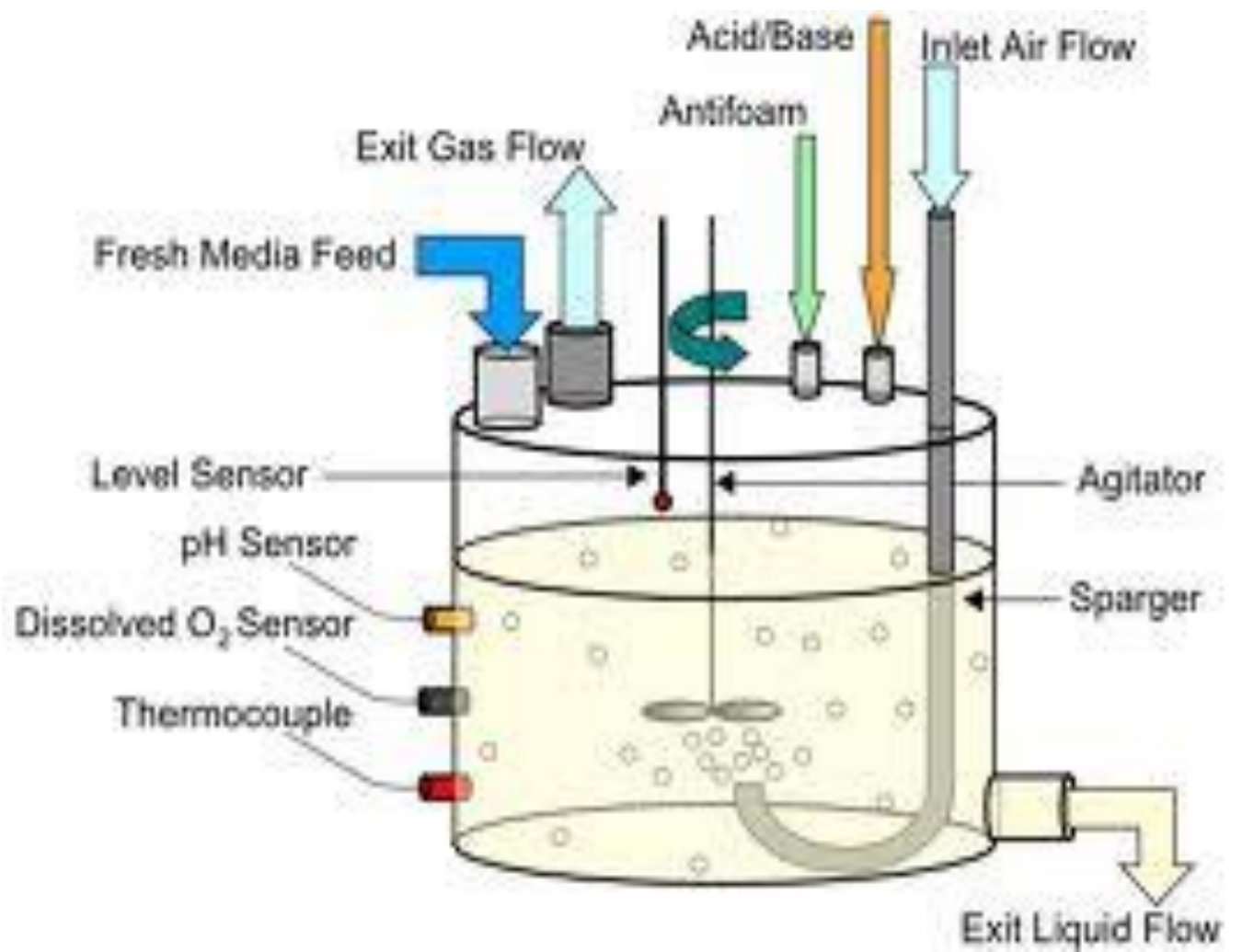

Figure 2.13: Ju Enzymatic Digestion Foam Fractionation Process ${ }^{40}$. Reprinted with permission from reference 40 .

\subsubsection{Thermal Treatments}

Some pioneers of biomass fillers have introduced products for plastics and composites, claiming improved hydrophobicity relative to lignocellulosic precursor flour. LignoTech Developments introduced a filler manufactured by steam explosion of dried distillery grains (DDGs), which are then ground to flour. ${ }^{16}$ A known result of this treatment is denaturing of the protein in the grains, which reduces the solubility and hydrophilicity of the flour. New Polymer Systems Inc. markets their NeroPlast ${ }^{\circledR}$ fillers, which are produced by torrefaction of wood flour from rapidly renewable yellow pine. ${ }^{18}$ 
Torrefaction, a process used to increase the calorific value of bio-mass, is used in the production of pellets for wood burning stoves and furnaces. It is widely reported that the hemicellulose disintegration is the main result of the anaerobic thermal treatment at 225 ${ }^{\circ} \mathrm{C}$ to $300{ }^{\circ} \mathrm{C}$, for time scales on the order of minutes to one hour. ${ }^{41,42,43}$ The result of the treatment is a loss of mass, densification, and a reduction in the hydrophilic nature of the wood flour. Since soy flour is compositionally different from wood flour, it is not certain that the benefits seen in wood flour would be manifested. Table 2.2 compares the relative quantities of constituents of the two flours. ${ }^{44,45}$

Table 2.2 Composition of Biomass ${ }^{44,45}$

\begin{tabular}{|c|c|c|c|c|c|c|c|}
\hline \multicolumn{8}{|c|}{ \% atter dehulling, defatting and drying } \\
\hline \multicolumn{3}{|c|}{ carbohydrates } & total & & & & \\
\hline$\%$ & cellulose & non-cellulose & carbohydrates & protein & lignin & ash & other \\
\hline yellow pine flour & 44 & 15 & 59 & & 30 & 0.4 & 10.6 \\
\hline soy flour & 16 & 16 & 32 & 53 & & 7 & 8 \\
\hline
\end{tabular}

The yellow pine flour's major constituents are carbohydrates, with $44 \%$ of the total flour being cellulose and $15 \%$ simple sugars and oligomeric polysaccharides. The flour also contains $30 \%$ lignin. While protein is not reported for yellow pine flour, it is the major component of the soy flour at 53\%. In soy flour, carbohydrates are evenly split between cellulose and non-cellulose with $32 \%$ total. Lignin, a major component of yellow pine flour, is not even listed as a constituent for soy flour. With these compositional differences, the material will respond differently to thermal exposure. It is expected, that with soy, the protein will denature and crystallinity changes may occur. 


\subsection{Chemical Surface Modifications}

Surface modification of particulate filler and fibers has been used in composites since their inception. In particular, fiberglass sizing plays a critical role in resin wetting, compatibility, coupling, strength and hydrolytic stability of composites. Some mineral fillers are also surface modified to impart ease of manufacture and improved composite performance. It follows, that the surface characteristics of the soy filler could be modified for enhanced composite processing and performance.

\subsubsection{Wax Emulsion Coating}

A simple treatment of soy flour with a wax emulsion is described by Schultz and Mehta. ${ }^{30}$ Dilute solutions (2\% and $10 \%$ ) of a paraffin-polyethylene emulsion were used to slurry treat or were sprayed onto soy flour. Although the results varied between multiple specimen forms, in most cases the treatments reduced moisture absorption by 10 to $20 \%$.

\subsubsection{Triglyceride Treatment}

Dankovich and Hsieh treated cotton with triglycerides to impart hydrophobicity. ${ }^{46}$ After ambient temperature solution coating, followed by ambient drying and heating at $120{ }^{\circ} \mathrm{C}$ for $1 \mathrm{~h}$, they reported the emergence of a small ester absorption in infrared spectra and concluded that transesterification had occurred. Whether acting as a functionalizer or simply as a coating, the contact angle of the fabric increased and the water absorption decreased from $1.8 \mathrm{uL} / \mathrm{mg}$ to $0.8 \mathrm{uL} / \mathrm{mg}$. It is also possible that the triglyceride is 
functioning as a plasticizer and altering the morphology of the proteins. Chen and Zhang studied the effect of water and glycerol on soy protein morphology formation in compounded thermoplastic composites. ${ }^{47,48}$ They found that the use of the plasticizing additives converted the proteins from functioning as a discrete rigid filler to a percolated interpenetrating network within the thermoplastic matrix. This structure evolution with increasing additive content resulted in increased modulus of the composites.

\subsubsection{Organosilane Grafting}

Organosilanes are used in a wide variety of applications to aid in coupling organic and inorganic materials. In composites, their primary use is as part of a sizing package for fiberglass reinforcements. Some fillers are also treated to impart better wetting or bonding and in some formulas the organosilane is added to the resin system, rather than as a filler sizing. ${ }^{49}$ Although our filler is organic rather than inorganic, organosilanes have the potential to provide the same coupling benefit. This is due to the dominant hydroxyl functionality of the carbohydrate portion of the flour. The organosilane coupling reactions are depicted in Figure 2.14.

The structure of an organosilane includes a silicon atom with three alkoxy groups and an organic functional group, $\mathrm{R}$. In the presence of water, the silanes hydrolyze and condense onto the surface hydroxyl functionalities, resulting in a grafted pendant organic group. Condensation between side oriented alkoxy groups results in formation of an integral film. 


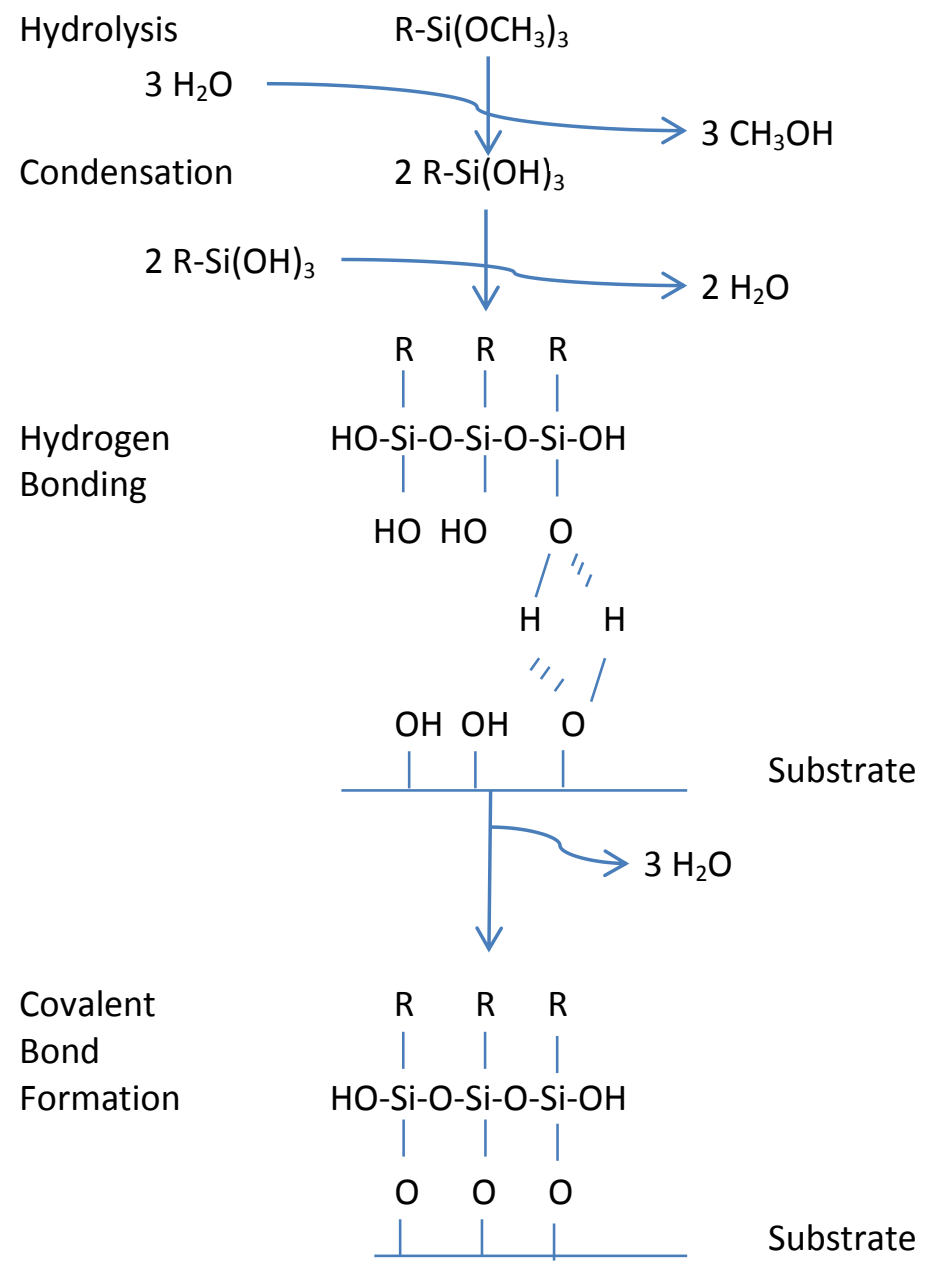

Figure 2.14: Silane Coupling

The choice of organosilane is determined by the kinetic requirements of the treatment process, environmental, health and safety (EHS) concerns, and the functional groups presented by the resin. The primary choice, to impact the kinetics, in most cases is whether the alkoxy group is methoxy or ethoxy. The smaller methoxy group hydrolyses faster than its ethoxy analogs. There are also versions with more alkyl carbons but these are very slow to hydrolyze and find only limited utility. ${ }^{50}$ When the alkoxy groups 
hydrolyze, alcohol is released. In general, ethanol is considered less hazardous than methanol and therefore is favored in sensitive environments. The volatility of ethanol is also lower than methanol which can provide enhanced working life for reactants. The organic functional groups are chosen to provide a minimum affinity for the matrix, and quite often to co-react with the matrix. For example, if an epoxy matrix is used, the organic group would likely be an amine or an epoxide as seen in Figure 2.15

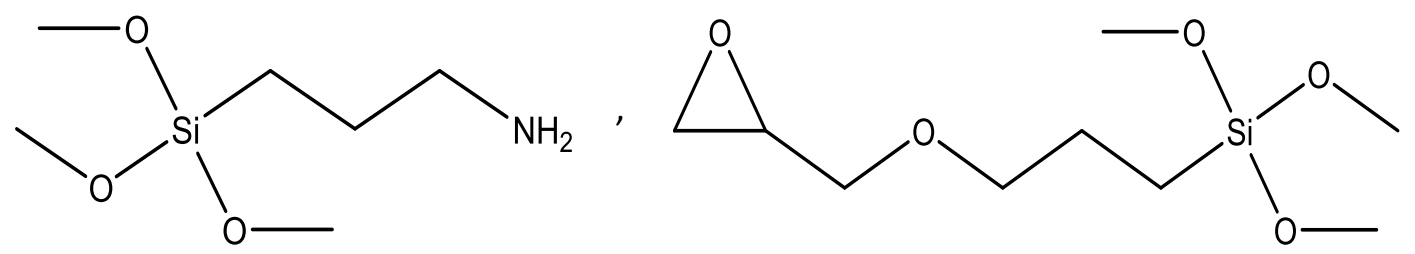

Figure 2.15: Epoxy Compatible and Reactive Silanes

In the case of styrenated unsaturated polyesters, the organic group would contain a reactive double bond such as the methacrylate functionality, as seen in Figure 2.16. The organic group may also be designed to impart features such as hydrophobicity as with the silane presented in Figure 2.17.

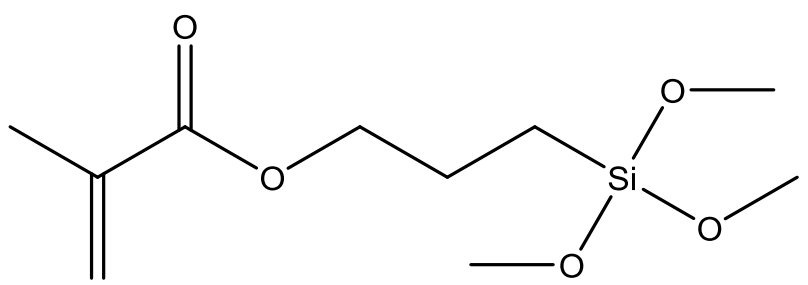

Figure 2.16: Vinyl Compatible and Reactive Silane 


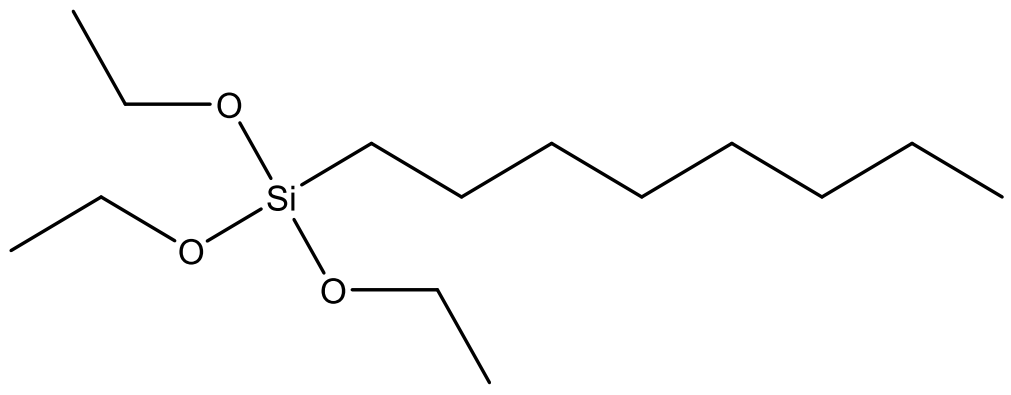

Figure 2.17: Hydrophobic Silane

Silane treatments of natural fibers have been studied by numerous researchers. ${ }^{33-}$

${ }^{37,50-53}$ In some cases, the treatment was applied after an alkaline pretreatment to increase reactive sites thus enhancing the coupling capacity.

Rong et al. treated sisal fiber with a $2 \%$ 3-aminopropyltrimethoxysilane in $95 \%$ alcohol at $\mathrm{pH}$ of 4.5-5.5 for $5 \mathrm{~min} .^{34}$ The fiber was then exposed to air for $30 \mathrm{~min}$ to hydrolyze the coupling agent before an oven dry for $2 \mathrm{~h}$ at $100{ }^{\circ} \mathrm{C}$. With this treatment, epoxy composites had increased elongation at break but no enhancement of tensile strength or modulus resulted.

Van der Weyenberg et al. soaked flax fibers for $2 \mathrm{~h}$ in $1 \%$ 3-aminopropyl trimethoxysilane in a 50//50 acetone/water solution followed by drying for $8 \mathrm{~h}$ at $80{ }^{\circ} \mathrm{C} .{ }^{35}$ Both strength and modulus for epoxy composites were enhanced.

Valadex-Gonzoles et al. reports treatment of henequen fibers with a $0.033 \% \mathrm{w} / \mathrm{w}$ aqueous vinyl tri(2-methoxyethoxy)silane solution, with dicumyl peroxide initiator at a $\mathrm{pH}$ of 3.5, for $1 \mathrm{~h} .{ }^{36}$ The fibers were dried and the silane was polymerized at $60{ }^{\circ} \mathrm{C}$ for 24 h. This was applied to both as-received and alkali treated fibers. In both cases, tensile strength was enhanced for HDPE composites. 
Ju and Drzal studied microfibrillated cellulose (MFC) treated with a prehydrolyzed $2.5 \%$ solution of 3-aminopropyl trimethoxysilane in acetone and water. ${ }^{51}$ The solution was stirred for $3 \mathrm{~h}$, filtered and dried at room temperature for 1 day, followed by curing at $120^{\circ} \mathrm{C}$ for $2 \mathrm{~h}$ in air. An over three-fold increase in contact angle was reported with the treatment and modulus was increased. No significant enhancement in tensile strength was observed.

In addition to water absorption and mechanical performance studies of composites, the literature includes kinetic and mechanistic studies of the silane grafting process. Agrawal et al. used $1 \%$ ethyl triethoxysilane in a 40/60 water/ethanol solution maintained at 3.5-4 $\mathrm{pH}$, for $3 \mathrm{~h}$ to treat palm fibers. ${ }^{37}$ After the fibers were washed and dried, a decrease of $6 \%$ weight was reported, indicating expulsion of water due to the treatment and drying. Crystallization kinetics of the treated and untreated palm fiber in phenol formaldehyde composites were quantified and modeled.

Rangel-Vazquez et al. treated rice husk fiber with 2\% 3-propylmethacrylate trimethoxysilane in ethanol for $30 \mathrm{~min}$ at ambient temperature, followed by a $180{ }^{\circ} \mathrm{C}$ bake for 9 min. ${ }^{38}$ FTIR and NMR spectroscopy were used to study the grafted structures.

Belgacem and his colleagues used solution and solid-state NMR spectroscopy to study the mechanisms, kinetics, efficiencies, and structure of grafted and adsorbed silane on cellulose fibers. ${ }^{52,53,54}$ Their techniques provided insight into the methods to optimize the silane treatment for ideal monolayer coupling of substrate and matrix. 


\subsubsection{Acetylation}

There has been a vast amount of research on the acetylation of lumber for improved durability, of cellulose textiles for hydrophobicity, and of paper for various attributes. The reaction is presented in Figure 2.18. The focus of the following citations is on flours, fibers, or chips that can be used in composites.

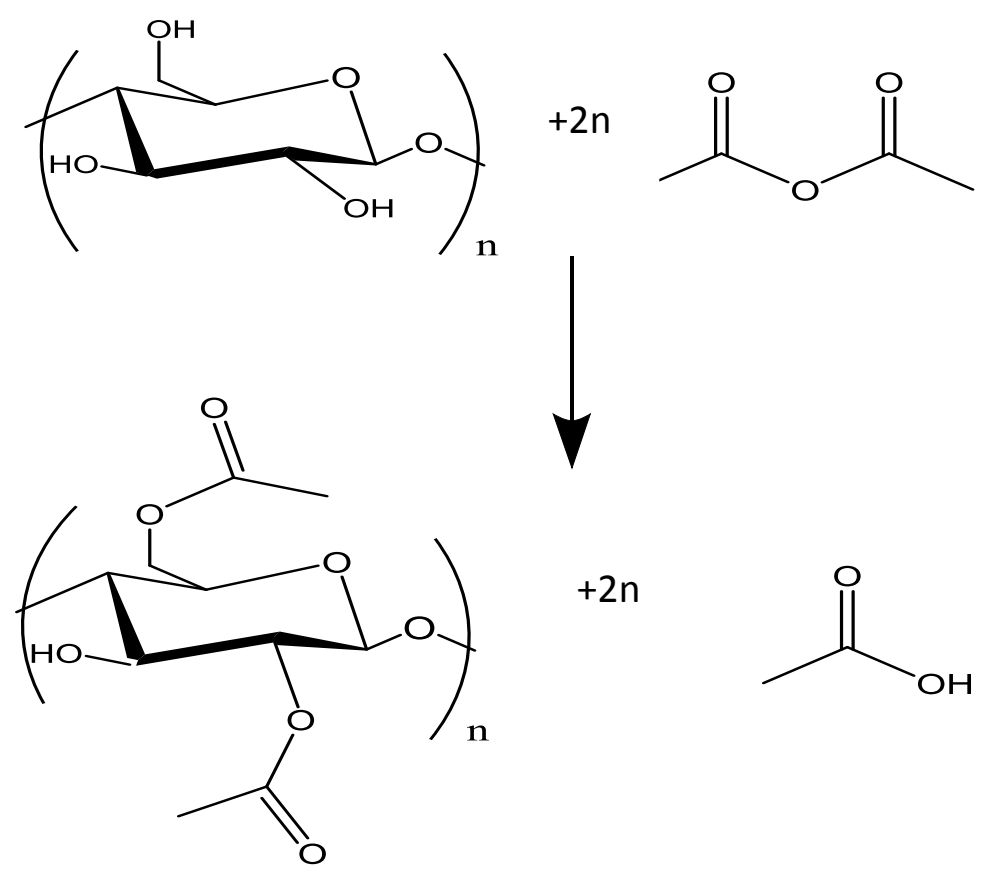

Figure 2.18Acetylation of Cellulose

Heitner and coworkers demonstrated full derivitization of hydroxy groups on milled wood lignin using either acetic anhydride in pyridine at $25{ }^{\circ} \mathrm{C}$ or acetic anhydride alone at $100{ }^{\circ} \mathrm{C} .{ }^{55}$ This resulted in decreased photo-degradation of the material. 
Hill et al. reported acetylation of coir fibers by refluxing of the fibers in acetic anhydride at $100{ }^{\circ} \mathrm{C}$ for $30 \mathrm{~min}$, followed by a reflux in acetone for $3 \mathrm{~h}$ to remove the reagents and byproducts. ${ }^{56}$ Improvements in strength and modulus resulted.

Chand and his colleagues acetylated $9 \mathrm{~g}$ of sisal fibers with a $1 \mathrm{~h}$ soak in glacial acetic acid at room temperature, followed by a wash in $50 \mathrm{ml}$ of acetic anhydride with 2 drops of concentrated sulfuric acid. ${ }^{57}$ The fibers were then washed with water to a neutral $\mathrm{pH}$. Their results indicated reduction in moisture weight regain, from $11.5 \%$ for the untreated fibers to $5.4 \%$ with the treatment.

Rowell et al. used refluxing $1 / 1 \mathrm{v} / \mathrm{v}$ acetic anhydride / xylene at $120{ }^{\circ} \mathrm{C}$ for acetylation of wood chips. ${ }^{58}$ Water swelling and weight gain experiments showed significant reductions in flakeboards constructed from the acetylated flakes relative to the untreated flakes. After a 1 day water soak, the control flakeboard gained over 30\% weight, while boards from the acetylated flakes had as little as 3\% weight gain.

Pyridine is not a chemical of choice in design of a green chemical process. It is known to negatively impact male reproductive health and is a suspected mutagen. It is also desirable for the process to use mild reaction conditions, including ambient temperature and short reactions times, if possible. A number of lower hazard catalysts have been reported that enable milder reaction conditions and do not require use of pyridine. Secen and Kalpar used graphite bisulphate as a catalyst for acetylation of alcohols in cyclohexane solvent. ${ }^{59} \mathrm{NMR}$ analysis demonstrated faster acetylation and higher yields than controls that were acetylated using pyridine. Ch et al. reported the use 
of diazabicyclo[2.2.2] octane (DABCO) for ambient temperature, solvent-free acetylation of various carbohydrates in less than an hour with high yields. ${ }^{60} \mathrm{Li}$ et al. used microwave assist to drive solvent-free acetylation of cellulose with acetic anhydride in the presence of iodine catalyst. $^{61}$

The use of solvent is not ideal, because mixed with the acetic acid by-product it can become a large waste stream. However, the slurry reactions carried out without solvent required a significant excess of acetic anhydride, to achieve good mixing. This, along with the acetic acid by-product, can become an equally large and problematic waste stream.

A couple of described processes stand out in terms of waste stream management. Simonson and Rowell described a continuous solvent-free acetylation process for wood flour using a screw feed mixer with recapture of the acetic anhydride and acetic acid byproduct during filler drying. ${ }^{62}$ In this closed loop system, the acid and acetic anhydride are separated and the acid was reacted with ketene to regenerate anhydride.

Petersen and Fleischmann used ketene gas as the acetate donor for a solventless, no-by-product process for acetylation of cellulose. ${ }^{63}$ In this case, no liquid was used or generated in the process.

\subsection{Characterization of Modified Soy Flours}

Regardless of the modification used to convert the soy flour to an effective polymer filler, characterization of the resulting filler will be the key to understanding the changes that are responsible for performance improvements. In the literature, methods to 
measure chemical composition and characteristics, as well as performance attributes, are abundant. In this section we will explore some of the methods that might provide insight into our filler development effort.

\subsubsection{Food Industry Methods}

Typical compositional attributes reported in the Food Industry for soy products include protein, carbohydrate, moisture, ash, crude fiber, and fat content. The American Oil Chemists' Society (OACS) has made an effort to standardize the test methods and reporting conventions of these attributes; however, multiple variations of the various methods are used.

For determination of protein content, various modified Kjeldahl methods are employed. ${ }^{64}$ For example, OACS Method Ba 4f-00 describes the Dumas combustion method for the determination of crude soy protein, where high temperature $\left(950{ }^{\circ} \mathrm{C}\right.$ or higher) combustion in pure oxygen liberates nitrogen as $\mathrm{NO}_{2} \cdot{ }^{65}$ The effluent is isolated and then measured by thermal conductivity. The quantity of nitrogen is then converted to equivalent protein by a numerical factor. General practice is to use a catch-all quantity for protein of 6.25 , but Jones proposed specific factors for different foods and determined the appropriate value for soybeans should be $5.71 .^{25}$ This discrepancy is a result of differences in the amino acid sequences of proteins and non-protein sources of nitrogen found in different food sources. In recent years, an effort to use amino acid residues to determine protein content has been championed. After hydrolysis of the peptide bonds, ion-exchange or HPLC is used to separate the amino acids, which are individually quantified. The summation is the "true protein". ${ }^{66}$ 
Total carbohydrates have historically been determined by difference. That is, other measurable components (protein, fat/oil, water/volatiles, ash/minerals) are quantified and subtracted out, leaving the remainder as "total carbohydrate". Due to constituents not detected by the other methods, the total carbohydrate reported is certainly overstated.

An alternative means to arrive at total carbohydrates is to use the sum of separately measured available carbohydrates digested by enzymes and dietary fiber. AOCS Method Bc 6-49 measures crude fiber as the loss of incineration of the dried residue after digesting the sample with dilute sulfuric acid and sodium hydroxide. ${ }^{65}$ The available carbohydrates are measured by extraction of soluble monosaccharides and oligosaccharides with alcohol and use of clarifying agents or ion-exchange to remove proteins, amino acids, minerals and other soluble compounds. ${ }^{67}$

AOCS Method Bc 2-49 describes the measurement of moisture and volatiles by weight loss determination after $2 \mathrm{~h}$ at $130{ }^{\circ} \mathrm{C}$. AOCS Method Bc 3-49 utilizes a Butt-type extraction apparatus for petroleum ether extraction of oils. AOCS Method Bc-49 determines the ash residue after $2 \mathrm{~h}$ at $600{ }^{\circ} \mathrm{C} . .^{65}$

\subsubsection{Methods to Study Chemical Modification of Treatments}

The key to advancing the effectiveness of the various treatments to the defatted soy flour is in understanding the effects of the treatment on the filler composition and characteristics. Various methods have been reported in the literature, which demonstrate use of analytical techniques to characterize changes in treated biomass. 
FTIR analysis is a useful tool in defining qualitative and semi-quantitative chemical composition and transformations of biomass after treatment. Dankovich and Hsieh reported the emergence of an absorption at $1746 \mathrm{~cm}^{-1}$, confirming some level of esterification of their cotton samples. ${ }^{46}$ Liu and Wang concluded, based on the disappearance of benzene absorptions near 1600 and $1500 \mathrm{~cm}^{-1}$, that lignin in their kapock fiber was dissolved in their alkali treatment. ${ }^{33}$ Likewise Rong et al reported reduction in lignin with merceration due to a diminishing absorption at $1650 \mathrm{~cm}^{-1} .34$

Valadez-Gonzalez and coworkers used FTIR diffuse reflective (DRIFT) mode to track the appearance of as absorptions around 765 and $700 \mathrm{~cm}^{-1}$. The former is due to the -Si-C- symmetric stretching vibrations and the latter is due to the -Si-O-Si- symmetric stretching vibrations indicating successful grafting of the silanes to their henequen fiber. ${ }^{36}$ Rangel-Vazquez and Leal-Garcia also verified successful silane grafting to rice husk fiber using the appearance of absorptions at 1162 and $1059 \mathrm{~cm}^{-1}$, indicating -Si-O-Sistretching vibrations, and at $1463 \mathrm{~cm}^{-1}$ from the methoxy C-H deformations. ${ }^{38} \mathrm{An}$ increase in intensity of the $1035 \mathrm{~cm}^{-1}$ absorption on microfibrillated cellulose (MFC) after silane treatment provided evidence to Ju and Drazl of successful grafting. ${ }^{51}$

Similarly, success of acetylation treatments has been monitored by FTIR spectroscopy. Clemons, Young and Rowell used the appearance of absorptions at 1720 and $1750 \mathrm{~cm}^{-1}$ to substantiate successful acetylation of aspen fiber. These absorptions are due to the $\mathrm{C}=\mathrm{O}$ from the ester group. ${ }^{68} \mathrm{Chand}$, Verma and Khazanchi observed an absorption in acetylated sisal at $3450 \mathrm{~cm}^{-1}$ and the disappearance of absorptions at 3370 
$\mathrm{cm}^{-1}$. This shift in $-\mathrm{OH}$ absorbance is consistent with conversion of hydroxyls to ester groups. $^{57}$

Infrared analysis also proved to be useful in characterizing torrefacted biomass. Rousset and colleagues reported reduction of the $-\mathrm{OH}$ absorption at $3350 \mathrm{~cm}^{-1}$, as well as multiple changes in the fingerprint regions, as evidence of selective decomposition of less stable constituents of their bamboo precursor. ${ }^{69} \mathrm{Lv}$, Almeida and Perre studied torrefaction of wood. ${ }^{70}$ They used FTIR total attenuated reflectance (ATR) spectra to determine a temperature-duration equivalence at a common weight loss up to $50 \%$.

In addition to IR analysis, elemental analysis provides evidence of functionalizations and changes due to constituent extraction. Another method is x-ray photoelectron spectroscopy (XPS), with which Bel -Hassen and coworkers confirmed the bonding of silane on cellulose fiber. ${ }^{54}$ Likewise, Lu and Drzal quantified silane functionalization of microfibrillated cellulose with XPS. ${ }^{51}$ Another elemental analysis option is Micro-Dumas Combustion, which was previously discussed in the Food Analysis section. In addition to nitrogen, oxygen, carbon and hydrogen can be quantified using this method.

\subsubsection{Methods to Study Structural Modification of Treatments}

Scanning Electron Microscopy (SEM) is a popular tool to analyze structural modifications. Chen and Zhang used SEM to study the morphological changes of plasticized soy protein in thermoplastics. ${ }^{47,48}$ Liu and Wang employed SEM to observe etching with alkali treatment of kapok cotton yarns. ${ }^{33}$ Barkakaty studied delignification 
of sisal with merceration. ${ }^{71}$ Chand and coworkers observed microfibril formation in sisal fibers after acetylation. ${ }^{57}$ Hill and Khalil monitored surface topography with SEM after acetylation and silane treatments. ${ }^{56}$ Rees and Robertson utilized SEM to study the unraveling of proteins with denaturing. ${ }^{72}$

In addition to the surface microstructure of treated biomass the particulate size and shape are important features to characterize. Methods that could be used to study this include laser light scattering analysis for particle size distribution and the BrunauerEmmett-Teller (BET) surface area measurements. Capouchova, Petr and Maresova used the former to study size distribution in wheat starch granules. ${ }^{73} \mathrm{Lu}$ and Drzal used the latter to characterize the effects of surface treatments on microfibrillated cellulose. ${ }^{51}$

Another modification imparted by treatments are changes in the crystal structure of the polymeric cellulose. X-ray diffraction (XRD) has been used to determine the degree of crystallinity and to study transitions between cellulose I and cellulose II arrangements. Sreenivasan and colleagues studied crystal structure changes in coir fibers with alkali treatments. ${ }^{74} \mathrm{Lu}$ and Wang presented a similar study with their kapok cotton yarns. ${ }^{33}$ Sisal modifications have also been studied with XRD by Barkakaty. ${ }^{71}$

\subsection{Modified Milled Biomass as a Composite Filler}

The motivation for this work is to create useful composite materials from the modified soy precursor. Attributes critical for this application include wetout, formation of an intimate interface with the matrix, ease and latitude of compounding, effects on 
polymerization and crystallization of the matrix, mechanical performance and environmental stability.

\subsubsection{Rheology Techniques}

The effect of the filler on the rheology of the composite molding compound is critical to wetout, adhesion, process ease and latitude in compounding and molding. For composites, this effect can be measured by a variety of methods. Oil absorption is used as a measure of the thermoset resin demand of fillers. Brookfield Viscosity Index (BVD) and Dynamic Mechanical Analysis (DMA) are used to study the rheology of filled thermoset pastes. Dynamic Mechanical Analysis (DMA), Melt Flow Index (MFI), squeeze flow rheometry and capillary rheometry are means to define the viscosity response of thermoplastic polymers and fully formulated molding compounds.

\subsubsection{Calorimetric Methods}

For thermosets, polymerization can be studied using differential scanning calorimetry (DSC). Thermoplastics melt and crystallization can be evaluated with the same tool. In addition, glass transition temperatures can be determined.

\subsubsection{Mechanical Properties}

Mechanical performance, including tensile and flexural strength and modulus, where measured using a universal tester at ambient conditions, as well as after environmental equilibration to increase moisture level or at elevated temperature. Izod 
impact is another useful property that provides an indication of material toughness. Failure mode analysis can be aided by use of microscopy of fracture surfaces.

\subsubsection{Thermal Stability}

Thermogravimetric analysis (TGA) provides information about the thermal stability of the fillers and composites materials. The onset of decomposition during a temperature ramp, as well as isothermal weight loss over time, can be monitored. Final ash can also be determined.

\subsection{Research Goals}

The intent of this research effort was to convert soy precursor powder into a useful polymer matrix composite filler. The studies included evaluation of different precursors and treatments to modify the hydrophobicity and compatibility to matrix resins. Treatments demonstrated to have significant promise were analyzed to study transformations. The fillers were incorporated into thermoset molding compounds, using both conventional and bio-based matrix resins and the performance of the composites were evaluated in comparison to mineral filled controls. 


\section{CHAPTER III}

\section{SOY PRECURSOR TREATMENTS}

\subsection{Converting Soy to a Useful Polymer Filler}

Refinement, thermal treatments and chemical modifications can alter both the chemical composition and morphological features of the soy filler and therefore its interaction with matrix resins. The hydrophillic character of the soy precursors is directly related to the abundant hydroxyl functionality and water soluble portions of the carbohydrates and proteins. Selective elimination or functionalization of these constituents is a means to convert the soy precursors to a useful filler. Throughout this dissertation, the fillers are identified by the section number that describes their preparation, and in some cases, a differentiating letter defining a variable in the treatment.

\subsection{Materials}

This chapter describes the various precursor materials and treatments applied by a number of methods. Enzymatic, chemical and thermal treatments were evaluated, including cellulose digestion, torrefaction, coating, alkali etching, silane grafting and esterification for treatment of soy meal and hull biomass. 


\subsubsection{Precursors}

The untreated soy flour (UTSF), Honeysoy® 90 PDI defatted soya flour, was provided by CHS Inc. This grade is a high solubility, enzyme active, 100\% soy flour with minimal heat treatment. The minimum protein specification for this grade is $48 \%$ and for total carbohydrates it is $44 \%$ with $19 \%$ dietary fiber. The flour is granulated to pass a minimum of $95 \%$ through a 200 mesh alpine sieve. This translates to less than 75 micron diameter particles.

The untreated soy meal (UTSM) was Bunge solvent extracted soy meal purchased from Rome Feed Inc. The minimum protein specification is $47 \%$, crude fiber is not more than $3.5 \%$ and crude fat is not less than $0.5 \%$.

The untreated soy hulls (UTSH) were Bunge soybean hulls with a minimum protein level of $9 \%$, crude fat not less than $0.5 \%$ and crude fiber not more than $38 \%$. This granular material has a bulk density of $0.37 \mathrm{~g} / \mathrm{cm}^{3}$.

\subsubsection{Enzymatic refinement}

Cellulase was produced by researchers in Dr. Lu-Kwang Ju's lab, using his patented foam fractionization process from Trichoderma reesei. The Trichoderma reesei Rut C-30 (NRRL 11460) strain was originally procured from the USDA and was cultivated in Dr. Ju's lab using methods described in Coffman et al. ${ }^{75}$ 


\subsubsection{Thermal Treatments}

Both thermally treated meal and hulls were evaluated. The $\mathrm{CO}_{2}$ used for some of the treatments was supplied from Air Products.

\subsubsection{Coatings}

Michem® Emulsion 66045 (ME66045), supplied by Michelman, Inc. is an 45\% solids anionic paraffin / polyethylene wax emulsion with a nominal pH of 10. Lab stock $\mathrm{MeOH}$ was used with the emulsion for the filler coating. RBD soy oil, supplied by $\mathrm{ADM}$, is pressed extracted triglycerides from soy bean processing. $\mathrm{NaOH}$ pellets, $(95 \%)$ and $\mathrm{MeOH}$ from Fisher were used with the oil for a refining and etching coating application, and acetone from lab stock was used with the oil for a neutral non-refining coating application.

\subsubsection{Alkali Etching}

$\mathrm{NaOH}(95 \%)$ from Fisher and lab stock $\mathrm{MeOH}$ was used in the alkali etching and wash of the fillers, respectively.

\subsubsection{Organosilanes}

ACS+ grade glacial acetic acid (> 99.7\%) from Fisher and labstock MeOH were used with most of the silanes for application to the fillers. Silquest ${ }^{\circledR A} \mathrm{~A}-147$, A-174NT, A-1110 and Y-15866 silanes were supplied by Momentive Performance Materials Inc. Dyansylan ${ }^{\circledR} 6598$ silane was provided by Evonik Industries. Table 3.1 details the chemical structures for the various silanes. 
Table 3.1. Silanes used for Treatments

\begin{tabular}{|c|c|}
\hline Silane & Formula \\
\hline $\begin{array}{l}\text { APTMS: } \\
\text { r-aminopropyltrimethoxysilane }\end{array}$ & $\mathrm{H}_{2} \mathrm{~N}\left(\mathrm{CH}_{2}\right)_{3} \mathrm{Si}\left(\mathrm{OCH}_{3}\right)_{3}$ \\
\hline $\begin{array}{c}\text { MOPTMS: } \\
\text { §-methacryloxypropyltrimethoxysilane }\end{array}$ & $\mathrm{CH}_{2}=\mathrm{C}\left(\mathrm{CH}_{3}\right) \mathrm{CO}_{2}\left(\mathrm{CH}_{2}\right)_{3} \mathrm{Si}\left(\mathrm{OCH}_{3}\right)_{3}$ \\
\hline OTES: octyltriethoxy silane & $\mathrm{CH}_{3}\left(\mathrm{CH}_{2}\right)_{7} \mathrm{Si}\left(\mathrm{OCH}_{2} \mathrm{CH}_{3}\right)_{3}$ \\
\hline $\begin{array}{l}\text { GOPTMS: } \\
\text { 3-glycidyloxypropytrimethoxysilane }\end{array}$ & \\
\hline $\begin{array}{c}\text { OVTES: } \\
\text { oligomeric vinyltriethoxysilane }\end{array}$ & $\mathrm{H}_{2}=\mathrm{CH}(\mathrm{CH} 2)_{\mathrm{n}} \mathrm{Si}\left(\mathrm{OCH}_{3}\right)_{3}$ \\
\hline VGS: vinylglycoxysilane & \\
\hline
\end{tabular}

\subsubsection{Esterifications}

EMD anhydrous acetic anhydride (97\%) was used for acetylation of the fillers.

Lab stock $\mathrm{MeOH}$ was used for slurry acetylations. Pyridine (99\%) from EMD and DABCO (98\%) from Alfa Aesar were used for catalyst in attempts to acetylate at ambient temperature. Dixie Chemical ASA(20-24), carbon 20-24 alkenyl succinic anhydride, was also evaluated for esterification of hydroxyls. 


\subsection{Refinement Methods}

Work reported by the National Composites Center (NCC) indicated significantly lower water absorption of polyester composite samples with soy protein isolate as a filler, relative to soy flour filled samples ${ }^{30}$. To evaluate this, soy protein concentrate and isolates were prepared using enzymatic refinement in Dr. Lu-Kwang Ju's lab.

\subsubsection{Soy Protein Concentrate}

Concentrate, comprised of a minimum of $70 \%$ protein, were produced using enzymatic refinement of soy flour in a buffered broth. A $1 \mathrm{~L}$ charge of cultivated Trichoderma reesei broth was charged into $4 \mathrm{~L}$ of deionized water and the $\mathrm{pH}$ was adjusted to 4.8 with $3 \mathrm{~N} \mathrm{HCl}$. The slurry was agitated in a $250 \mathrm{rpm}$ shaker for $48 \mathrm{~h}$ at 50 ${ }^{\circ} \mathrm{C}$. This process reduced a large portion of the carbohydrate content of the biomass to water-soluble species and the protein rich precipitate was collected.

\subsubsection{Soy Protein Isolates}

Isolates with $>90 \%$ soy protein were prepared by two methods; a) dilution of the supernatant from SPC production with ethanol, to $60 \%$, resulting in precipitation of protein or b) the supernatant was heated to $90{ }^{\circ} \mathrm{C}$ for $30 \mathrm{~min}$ to denature the protein, which then precipitated.

\subsection{Thermal Treatment}

Thermal degradation of the saccharides, cellulose, hemicellulose and protein vary depending on their thermal stabilities. Dehydration will occur, as will denaturing of any 
remaining protein. In the literature, Korte asserts that hemicellulose, in particular, decomposes preferentially during thermolysis. ${ }^{76}$ Thermal treatment offers a simple route to alteration of the precursor soy to a more organophilic material, to be used as a polymer filler, without use of synthetic chemicals.

A variety of thermal treatments were applied to the precursors. Bench scale samples were prepared in a convection oven with a foil cover to exclude $\mathrm{O}_{2}$ or in a muffle furnace purged with $\mathrm{N}_{2}$. Continuous pilot scale samples were processed with a conveythrough closed barrel machine at North Carolina State University (NCSU) by Agri-Tech Producers Inc. (ATP) or in a rotary kiln by EarthCare®. Batch pilot scale samples were also prepared in an NCSU/ATP proprietary batch thermal chamber.

\subsubsection{ATP/NCSU Bench Scale}

Samples 3.4.1 a, b,c: A convection oven was used to process a) and b) soy meal and c) soy hulls. Roughly $1500 \mathrm{~g}$ of the precursors were spread on a baking sheet and covered with aluminum foil. Holes were put into the foil to allow for volatile escape. Sample a) was baked at $250{ }^{\circ} \mathrm{C}$ for $35 \mathrm{~min}$. Samples b) and c) were baked at $288^{\circ} \mathrm{C}$ for $15 \mathrm{~min}$. Soon after loading into the preheated oven, copious amounts of gasses were noted before tailoring off, at which point the samples were unloaded from the oven and cooled, still covered, at ambient temperature. These samples were ground using a Holmes benchtop pulverizer with a 60 mesh screen. 


\subsubsection{Premix Muffle Furnace Bench Scale}

Figure 3.1 presents the setup for the nitrogen purged muffle furnace thermal treatment. The purge was fed through a funnel in the furnace exhaust hole, leaving room for gasses to exit around the funnel. After a $30 \mathrm{~min} \mathrm{~N}_{2}$ purge, the precursors, loaded in crucibles, were quickly loaded into the preheated furnace.

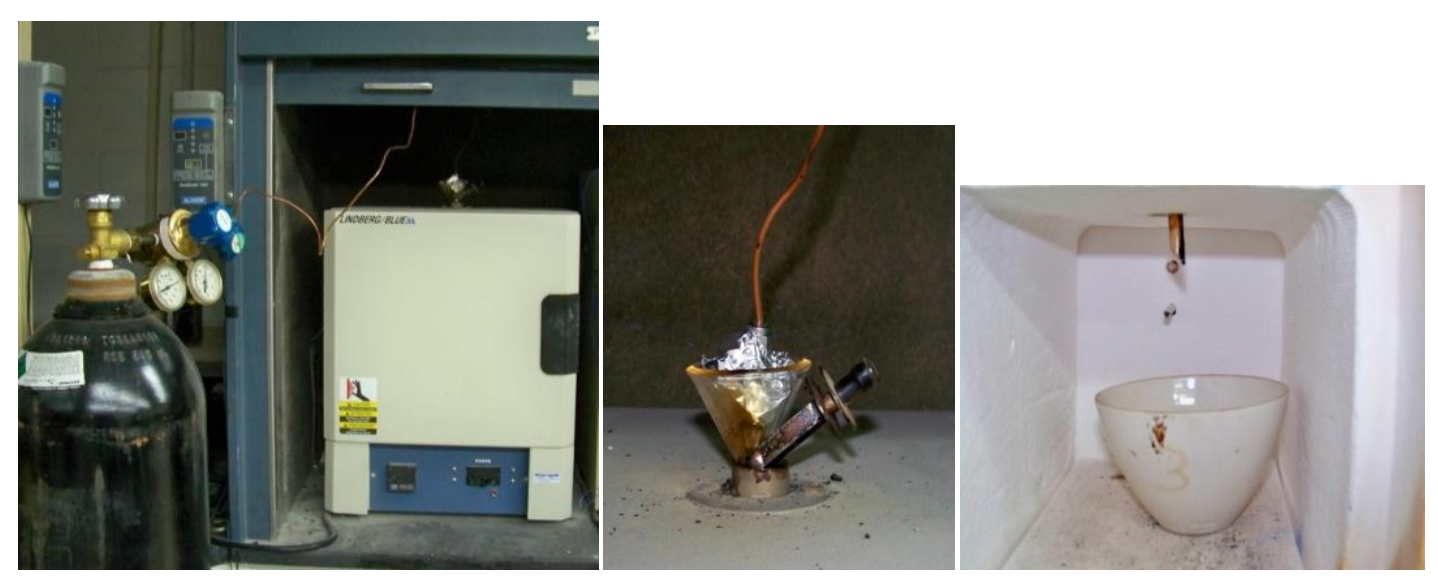

Figure 3.1 Muffle Furnace Bench Apparatus

Samples 3.4.2 a : A crucible with $100 \mathrm{~g}$ of the defatted soy flour was processed at $225^{\circ} \mathrm{C}$ for $80 \mathrm{~min}$. When the oven was opened to remove the sample, however, gassing was still excessive, therefore the sample was left in the oven, which was turned off, to cool. When the oven reached $120^{\circ} \mathrm{C}$, gassing was minor, and the sample could be removed and was placed in a dessicator to cool. Significant condensation on the oven walls and on the feed tube of the funnel had developed. The condensed material on the funnel had a resinous oily texture. Weight loss due to the treatment was roughly $40 \%$, resulting in a yield of $60 \mathrm{~g}$. The sample, now a dark brown, almost black, crusty solid, was ground with a mortar and pestle. 
Samples 3.4.2 b-e: The effects of post thermal treatment cooling and heating were evaluated. Roughly $10 \mathrm{~g}$ granular UTSH each were weighed in crucibles. The oven was equilibrated to $400{ }^{\circ} \mathrm{C}$ and purged with $\mathrm{N}_{2}$ for $30 \mathrm{~min}$. The samples were quickly loaded into the oven to avoid air incursion. After smoking dissipated at roughly 20 min, the samples were removed from the oven. The following post handling was applied to the samples: b) cooled in dessicator / no post oven exposure, c) cooled in dessicator / 50 ${ }^{\circ} \mathrm{C}$ overnight oven bake, d) cooled in desssicator / mixed with water / dried in $50{ }^{\circ} \mathrm{C}$ oven overnight, and e) quench cooled in water / dried in $50{ }^{\circ} \mathrm{C}$ oven overnight. All samples were ground with a mortar and pestle to similar consistency.

Samples 3.4.2 f, g: Roughly $200 \mathrm{~g}$ of hulls ground to 60 mesh were weighed in crucibles. The oven was equilibrated to f) $250{ }^{\circ} \mathrm{C}$ or g) $275^{\circ} \mathrm{C}$ and purged with $\mathrm{N}_{2}$ for 30 min. The samples were quickly loaded into the oven to avoid air incursion. After smoking dissipated at roughly 30 and $22 \mathrm{~min}$, respectively, the samples were removed from the oven.

Table 3.2: Muffle Furnace Experiments

\begin{tabular}{|c|c|c|c|c|c|c|c|c|}
\hline $\begin{array}{c}\text { treatment } \\
\text { ID }\end{array}$ & precursor-process unit & precursor & \begin{tabular}{|l|} 
torrefaction \\
temperature \\
\end{tabular} & $\begin{array}{l}\text { time } \\
\text { (min) }\end{array}$ & $\begin{array}{l}\text { initial weight } \\
\text { (g) }\end{array}$ & $\begin{array}{c}\text { final weight } \\
\text { (g) }\end{array}$ & yield & notes \\
\hline 3.4.2a & SF-MF1 & Flour & $225^{\circ} \mathrm{C}$ & 80 & 100 & 60 & $60.0 \%$ & \\
\hline $3.4 .2 \mathrm{~b}$ & SH-MF1 & Hulls & $400^{\circ} \mathrm{C}$ & 21 & 10.1 & 3.5 & $34.7 \%$ & $\begin{array}{c}\text { no water or } \\
\text { oven }\end{array}$ \\
\hline $3.4 .2 \mathrm{c}$ & SH-MF2 & Hulls & $400^{\circ} \mathrm{C}$ & 21 & 11.1 & 3.6 & $32.4 \%$ & no water \\
\hline $3.4 .2 \mathrm{~d}$ & SH-MF3 & Hulls & $400^{\circ} \mathrm{C}$ & 21 & 10.4 & 3.4 & $32.7 \%$ & water quench \\
\hline 3.4.2e & SH-MF4 & Hulls & $400^{\circ} \mathrm{C}$ & 21 & 10.3 & 3.2 & $31.1 \%$ & $\begin{array}{c}\text { water after } \\
\text { cool }\end{array}$ \\
\hline 3.4.2f & SH-MF5 & Hulls & $250^{\circ} \mathrm{C}$ & 30 & 171.6 & 70.6 & $41.1 \%$ & \\
\hline 3.4.2g & SH-MF6 & Hulls & $275^{\circ} \mathrm{C}$ & 22 & 131.3 & 52.8 & $40.2 \%$ & \\
\hline
\end{tabular}




\subsubsection{ATP/NCSU Pilot Scale Continuous}

Agri-Tech has licensed a patented NCSU process and equipment concept for a continuous screw feed torrefactor that utilizes the gasses generated after initial decomposition of the feedstock as fuel in a closed loop system depicted in Figure 3.2. ${ }^{77}$ The design results in a low-oxygen environment with typical temperatures reaching 225$400{ }^{\circ} \mathrm{C}$, which is a function of the fuel content of the precursor material. The combustion gasses generate as much as $80 \%$ of the torrefaction process heat.

\section{Torrefaction Machine Conceptual Schematic}

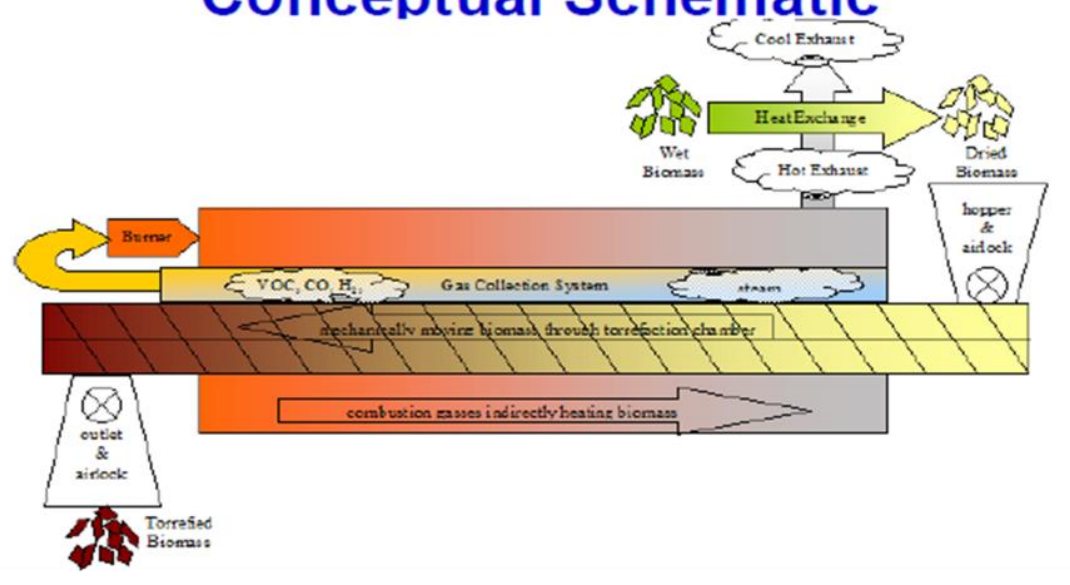

http://www.agri-techproducers.com/ retrieved 03/25/2012.

Figure 3. 2. ATP/NCSU Continuous Self-Fueling Torrefactor Design. ${ }^{77}$ Reproduced with permission from reference 77.

Sample 3.4.3 a: A $225 \mathrm{~kg}$ meal sample was processed through the unit. Typical residence time was 3-5 min and maximum temperature noted was $300{ }^{\circ} \mathrm{C}$. Upon machine exit the torrefacted material was misted with water to quench the decomposition. The 
material was dried to constant weight in batches, as needed for evaluations. Weight loss with drying indicated a water content of $60 \%$, on average. Visual inspection of the product, which ranged from charcoal like briquettes to powder, revealed a significant amount of what appeared to be wood fragments at different levels of decomposition. This apparent contamination was deemed to be due to dead spots in the continuous torrefaction unit. The material was then ground using the Holmes benchtop pulverizer with a 60 mesh screen.

Sample 3.4.3b: A hull sample was planned using $450 \mathrm{~kg}$ of precursor. Half of that was used to purge through the machine to minimize contamination prior to starting the thermal process. Once the heat was applied, the temperature quickly spiked to $>400{ }^{\circ} \mathrm{C}$, which is beyond the machine design. Therefore, the run was aborted after processing of only a limited amount of material. The material was misted with water to cool and sent to Union Process for a grinding.

\subsubsection{ATP/NCSU Pilot Scale Batch}

Sample 3.4.4 a: A proprietary batch scale torrefaction unit at NCSU was used to process a $90 \mathrm{~kg}$ sample of hulls at $500{ }^{\circ} \mathrm{C}$ for $10 \mathrm{~min}$. These were not misted with water for cooling. A portion of the material was ground using the Holmes benchtop pulverizer and the remainder was sent to Union Process for grinding evaluations to various particle size distributions. 


\subsubsection{EarthCare Batch Unit}

Hull batches, with a peak temperature targeted not to exceed $275^{\circ} \mathrm{C}$, were torrefacted. The rotary drum was preheated to a set point temperature (SPT) of $204{ }^{\circ} \mathrm{C}$, $227^{\circ} \mathrm{C}$ or $249{ }^{\circ} \mathrm{C}$. A $5 \mathrm{~kg}$ charge of hulls was loaded into the drum vessel causing a drop in drum temperature. The drum was closed and the test started with the drum rotation and the firing of the indirect gas burners, which brought the drum temperature back to the SPT. Once the internal drum temperature had reached the set point temperature, the burners shut off automatically. At that point, the biomass had reached its exothermic reaction point and the temperature inside the vessel continued to increase. When the temperature began to decrease, the drum rotation was stopped and the material was discharged. After cooling to ambient temperature, it was weighed to determine the batch yield. The equipment is seen in Figure 3.3 and a summary of the samples processed is reported in Table 3.3.

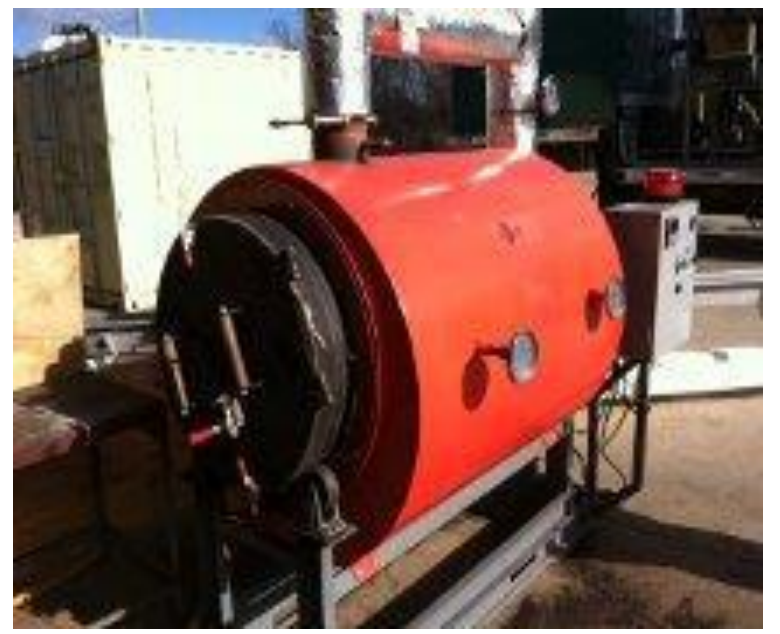

Figure 3.3 ECP Prototype Pilot Torrefactor. ${ }^{77}$

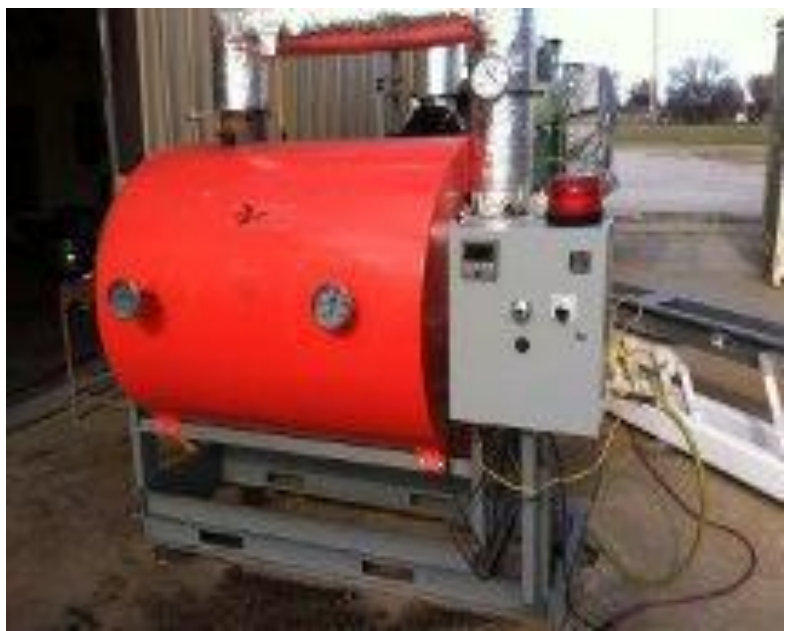

Reproduced with permission from reference 77. 
Table 3.3 : ECP Torrefaction Series

\begin{tabular}{|c|c|c|c|c|}
\hline Run \# & SPT $\left({ }^{\circ} \mathrm{C}\right)$ & $\begin{array}{c}\text { Time to Max } \\
\text { Temp }(\min )\end{array}$ & $\begin{array}{c}\text { Max } \\
\text { Temp }\left({ }^{\circ} \mathrm{C}\right)\end{array}$ & Yield (\%) \\
\hline 1 & 227 & 12 & 262 & 70 \\
\hline 2 & 249 & 12 & 282 & 63 \\
\hline 3 & 249 & 14 & 271 & 68 \\
\hline 4 & 204 & 12 & 237 & 78 \\
\hline 5 & 204 & 12 & 234 & 78 \\
\hline 6 & 227 & 12 & 253 & 73 \\
\hline 7 & 227 & 10 & 257 & 72 \\
\hline 8 & 249 & 10 & 274 & 67 \\
\hline 9 & 204 & 12 & 236 & 77 \\
\hline Avg & 204 & 12 & 236 & 78 \\
\hline Avg & 227 & 11.3 & 257 & 71.7 \\
\hline Avg & 249 & 12 & 276 & 66 \\
\hline
\end{tabular}

\subsection{Chemical Modifications}

Chemical treatments can alter both the composition and morphological features of the soy filler and therefore its interaction with matrix resins. Selective etching and washing with chemicals can result in increased surface roughness for mechanical interlocking and improved substrate integrity. The hydrophilic character of the soy flour is directly related to the hydroxyl functionality of the carbohydrates and the water soluble portions of the carbohydrates and proteins. Coating or chemical grafting of more hydrophobic functional groups can greatly alter the resin wetting and moisture resistance of the fillers.

\subsubsection{Wax Emulsion Coating}

Sample 3.5.1 a: A 3\% solution of Michem Emulsion 66035 in $\mathrm{MeOH}$ [3 g 66035 in $100 \mathrm{ml} \mathrm{MeOH}$ ] was added to $25 \mathrm{~g}$ HS90PD flour in a $600 \mathrm{ml}$ beaker. The slurry was 
hand mixed and then stirred with a magnetic stir plate. At $20 \mathrm{~min}$, the sample was filtered through a fritted glass funnel. The filtrate was a clear yellow liquid with $\mathrm{pH}=6$. The "wet" sludge was put into a preweighed pan and dried at $51{ }^{\circ} \mathrm{C}$ for 23 hours. The yield was $22.18 \mathrm{~g}$ ( $88.7 \%$ based on the initial flour weight). Of the $11.3 \%$ weight loss from as-received soy flour to dried crude product, $4.5 \%$ was water and $6.8 \%$ was solids dissolved in the filtrate and transfer losses. This calculation does not account for any weight gain due to coating of the filler.

Sample 3.5.1 b: The above procedure was also applied as a second step to a sample that had been alkali treated per section 3.5.3a. The coating was applied to the washed and filtered, but not yet dried, alkali treated product. The filtrate was a clear pale yellow liquid with $\mathrm{pH}=7.5$. The product yield was $21.21 \mathrm{~g}$ ( $84.8 \%$ based on initial flour).

\subsubsection{Triglyceride Coating}

Sample 3.5.2 a: A soy oil treatment was performed with a mix of $16.2 \mathrm{~g} \mathrm{RBD}$ soy oil in $15 \mathrm{ml}$ of acetone. Acetone does not swell the flour or extract a large amount of material from it. Although the filtrate did turn pale yellow, the solid residue after drying was negligible. A 5.03 g sample of the Honeysoy® 90 PDI was slurried, in the soy oil / acetone solution, in a $250 \mathrm{ml}$ flask and stirred at ambient temperature for $3.5 \mathrm{~h}$. The solids were concentrated by centrifuge and stored open to atmosphere at ambient temperature for 12 days. The material was then rinsed with $250 \mathrm{ml}$ of $\mathrm{MeOH}$ and filtered through a fritted glass funnnel. It was then dried at $70^{\circ} \mathrm{C}$ for 2 days. The resulting solid 
was a non-uniform tan to brown in color. Yield was $4.73 \mathrm{~g}$ (94\% based on the starting weight of the flour without accounting for any applied coating).

Sample 3.5.2 b: A soy oil treatment was performed with $18 \mathrm{~g}$ RBD soy oil in 15 $\mathrm{ml}$ of $0.45 \mathrm{M} \mathrm{NaOH} / \mathrm{MeOH}$ solution with a $\mathrm{pH}$ of 8.5. Alkali treatments solvate some constituents of the flour and swell the cellulose through a process known as merceration. A $5.05 \mathrm{~g}$ sample of the Honeysoy® 90 PDI was slurried, in the alkali soy oil $\mathrm{MeOH}$ solution, in a $250 \mathrm{ml}$ flask and stirred at ambient temperature for $4 \mathrm{~h}$. The solids were concentrated by centrifuge and stored open to atmosphere at ambient temperature for 12 days. The material was then rinsed with $250 \mathrm{ml}$ of $\mathrm{MeOH}$ and filtered through a fritted glass funnnel. It was then dried at $70{ }^{\circ} \mathrm{C}$ for 2 days. The resulting solid was a uniform tan color. Yield was $2.56 \mathrm{~g}(51 \%$ based on the starting weight of the flour without accounting for any applied coating). As expected, significant flour content was washed away in the filtrate.

\subsubsection{Alkali Etching}

Sample 3.5.3 a: A 3\% solution $\mathrm{NaOH}$ in $\mathrm{MeOH}(0.75 \mathrm{M})[6 \mathrm{~g} \mathrm{NaOH}$ in $200 \mathrm{ml}$ $\mathrm{MeOH}$ ] was added to $50 \mathrm{~g} \mathrm{HS} 90 \mathrm{PD}$ flour in a $600 \mathrm{ml}$ beaker. The slurry was hand mixed and then stirred on a magnetic stir plate. After $30 \mathrm{~min}$, the sample was collected in a fritted glass funnel. The filtrate was a clear yellow liquid with $\mathrm{pH}=9$. The tan filtered flour was washed with $100 \mathrm{ml} \mathrm{MeOH}$ twice, however the $\mathrm{pH}$ remained at 9. A third wash with $100 \mathrm{ml} \mathrm{MeOH}+1 / 2 \mathrm{ml}$ glacial acetic acid resulted in a cloudy filtrate. A final $100 \mathrm{ml} \mathrm{MeOH}$ only rinse yielded additional cloudy filtrate with a $\mathrm{pH}=5$. Over time, solid 
precipitated from the filtrate leaving a transparent yellow liquid. The "wet" sludge was put into a preweighed pan and dried at $51{ }^{\circ} \mathrm{C}$ for 23 hours. The yield was $22.20 \mathrm{~g}$ (88.8\%). Of the $11.2 \%$ weight loss from as-received soy flour to dried crude product, $4.5 \%$ was water loss and $6.7 \%$ was handling losses and solids removed with the filtrate.

\subsubsection{Organosilane Grafting}

Sample 3.5.4 a -f: For organosilane grafting using a slurry method, $6 \mathrm{ml}$ of the various silanes were added to $180 \mathrm{ml} \mathrm{MeOH}$. Roughly $3 \mathrm{ml}$ glacial acetic acid was added to adjust the $\mathrm{pH}$ to less than 5 for all the silanes, except for the basic A-1110 amine silane, for which no $\mathrm{pH}$ adjustment was made. The solution was added to $25 \mathrm{~g}$ HS90PD flour, then $20 \mathrm{ml}$ DI water was added to drive the silane hydrolysis. The slurry was mixed on a magnetic stir plate for 20 to $30 \mathrm{~min}$, and then collected in a fritted glass funnel. All of the filtrates were a clear yellow liquid, except for the A-1110 sample, which was a cloudy yellow. The "wet" sludge was put into a preweighed pan and dried at $52{ }^{\circ} \mathrm{C}$ overnight. Yields ranged from 20.12 to $22.69 \mathrm{~g}$ (81-91\% based on starting weight of as-received flour). The change in functional group was not accounted for in this calculation.

Several application processes were evaluated for the A137 octyltriethoxy silane:.

Sample 3.5.4 g A repeat of the 3.5.4c slurry treatment was used, except only $20 \mathrm{~min}$, instead of $30 \mathrm{~min}$, of mix time was employed.

Sample 3.5.4 h: Another slurry treatment per 3.5.4c except with $4 \mathrm{~h}$ of mix time. 
Sample 3.5.4 i: A slurry treatment per 3.5.4c exceptt with no $\mathrm{pH}$ adjustment.

Sample 3.5.4j: A “dry" filler treatment was applied. A $217.3 \mathrm{~g}$ sample of the Honeysoy® 90PD was loaded into a lab scale BMC mixer. In a $200 \mathrm{ml}$ beaker $51.3 \mathrm{~g} \mathrm{MeOH}$ was mixed with with $5.7 \mathrm{~g}$ deionized water and acidified with $1 / 2 \mathrm{ml} 50 / 50 \mathrm{HCl} / \mathrm{DI}$ water solution. The $\mathrm{pH}=3$. A $3 \mathrm{~g}$ aliquot of A137 was added and the solution was mixed several minutes until it was clear. A squirt bottle was used to distribute the silane solution over the flour as it was tumbled in the mixer. Mixing continued after application for 15 minutes. The treated flour was placed in a weigh pan at $80{ }^{\circ} \mathrm{C}$ for $1 \mathrm{~h}$ to dry. Yield was $204.2 \mathrm{~g}$ (94\% based on initial flour weight).

\subsubsection{MeOH Wash Blank}

A blank control was made with $100 \mathrm{ml} \mathrm{MeOH}$ added to $25 \mathrm{~g}$ HS90PD flour in a $600 \mathrm{ml}$ beaker. The slurry was hand mixed and allowed to sit $105 \mathrm{~min}$ at ambient temperature. It was then filtered with a fritted glass funnel. The filtrate was a cloudy yellow liquid with slight precipitation over time and had a $\mathrm{pH}=6.5$. The roughly $100 \mathrm{ml}$ $\mathrm{MeOH}$ contained $1.75 \mathrm{~g}$ solid residue. The "wet" sludge was put into a preweighed pan and dried at $51{ }^{\circ} \mathrm{C}$ for $23 \mathrm{~h}$. Yield was $21.65 \mathrm{~g}$ (86.6\% based on the starting weight of the flour). Of the $13.4 \%$ weight loss, $4.5 \%$ was known water content of the starting flour, $7 \%$ was filtrate solids and $1.9 \%$ was due to transfer losses.

\subsection{Esterifications}

Reaction of the carbohydrate hydroxyls with anhydrides creates an ester linkage. This resulting ester is less hydrophilic than the hydroxyl. 


\subsubsection{Acetylation with Catalyst}

Sample 3.6.1 a: A $327.5 \mathrm{mg}$ sample of Honeysoy® 90PD was weighed into a 100 $\mathrm{ml}$ Schlenk flask and $3 \mathrm{ml}$ pyridine $(37.2 \mathrm{mmol})$ was added. A stir bar and addition funnel with acetic anhydride were assembled. While stirring at ambient temperature, under a $\mathrm{N}_{2}$ atmosphere, $0.7 \mathrm{ml}$ acetic anhydride $(7.4 \mathrm{mmol})$ was added dropwise over 27 min. The sample, which started as a cloudy yellowish brown slurry, became darker and turned reddish. After stirring for $43 \mathrm{~h}$, the slurry became a purplish brown. To this, $50 \mathrm{ml}$ of $\mathrm{MeOH}$ was added and it became pink/peach in color and cloudy. The sample was collected on a fritted glass funnel and was washed 3 times with $20 \mathrm{ml}$ each $\mathrm{MeOH}$. The $110 \mathrm{ml} \mathrm{MeOH}$ filtrate was light orange/yellow. The light tan wet sludge was dried at 52 ${ }^{\circ} \mathrm{C}$ for $21.5 \mathrm{~h}$. The yield was $228 \mathrm{mg}$ (55\% based on flour + functionalization). The 110 $\mathrm{ml}$ filtrate was air dried in a hood. The residue weight was $79 \mathrm{mg}$.

Sample 3.6.1 b: A $354.9 \mathrm{mg}$ sample of Honeysoy® 90PD was weighed into a $100 \mathrm{ml}$ round bottom flask with a stir bar and placed in an ice bath. The vessel was purged with $\mathrm{N}_{2}$ and $4 \mathrm{ml}(42.4 \mathrm{mmol})$ of acetic anhydride was added through an addition funnel to form a light tan slurry. To this, $319.1 \mathrm{mg}(2.84 \mathrm{mmol})$ of DABCO was added through an addition port, which resulted in a slight darkening of the slurry. After stirring under a $\mathrm{N}_{2}$ atmosphere for $19 \mathrm{~h}$, while allowing the ice bath to reach ambient temperature, the slurry was a dark tan color. $\mathrm{MeOH}(50 \mathrm{ml})$ was added and it became a lighter brown and some warming of the solution was noted. The sample was collected on a fritted glass funnel and was washed 3 times with $20 \mathrm{ml}$ each $\mathrm{MeOH}$. The $110 \mathrm{ml} \mathrm{MeOH}$ 
filtrate was transparent yellow. The wet sludge, which was light tan, was dried at $52{ }^{\circ} \mathrm{C}$ for $5 \mathrm{~h}$. The yield was $227 \mathrm{mg}$ ( $64 \%$ based on flour + functionalization).

\subsubsection{Temperature Assisted Slurry Acetylation}

Sample 3.6.2 a: Acetylation of the soy flour with temperature assist and no catalyst was attempted in a $100 \mathrm{ml} 2$ neck round bottom flask with stir bar and condenser. $\mathrm{N}_{2}$ atmosphere was routed through the condenser. A $341.6 \mathrm{mg}$ sample of flour and $10 \mathrm{ml}$ (106 mmol) acetic anhydride were mixed in the flask creating a cloudy yellowish brown slurry. The flask was positioned in an oil bath equilibrated at $120{ }^{\circ} \mathrm{C}$ and the sample was stirred at reflux for $3.75 \mathrm{~h}$. The sample was dark brown. After $15 \mathrm{~min}$ of cooling, the sample was poured into $50 \mathrm{ml} \mathrm{MeOH}$ and then collected on a fritted glass funnel. Three washes with $20 \mathrm{ml}$ each $\mathrm{MeOH}$ resulted in a $110 \mathrm{ml}$ filtrate that was a clear light brown. The dark brown solids were dried at $51{ }^{\circ} \mathrm{C}$ for $3 \mathrm{~h}$. The yield was $202 \mathrm{mg}(56 \%$ based on flour + functionalization). The $110 \mathrm{ml}$ filtrate was dried in a hood and the residue weight was $162 \mathrm{mg}$, corresponding to an additional $27.8 \%$ yield.

Sample 3.6.2 : A scaled up reaction based on 3.5.5c with temperature assist and no catalyst was performed. In a $1 \mathrm{~L}$ single neck round bottom flask with stir bar and condenser, with $\mathrm{N}_{2}$ atmosphere routed through the condenser, $10.2337 \mathrm{~g}$ Honeysoy ${ }^{\circledR}$ 90PD was mixed with $250 \mathrm{ml}$ (2.65 mol) acetic anhydride to form a cloudy yellowish brown slurry. The flask was suspended in an oil bath equilibrated at $120^{\circ} \mathrm{C}$ and the sample was refluxed for $2 \mathrm{~h} 50 \mathrm{~min}$. The slurry was a dark brown. After $15 \mathrm{~min}$ of cooling, it was poured into $250 \mathrm{ml} \mathrm{MeOH}$ and the precipitate was collected on a fritted 
glass funnel. The roughly $500 \mathrm{ml}$ filtrate was a clear light brown. The dark brown wet sludge was dried at $70{ }^{\circ} \mathrm{C}$ for $3 \mathrm{~h} 20 \mathrm{~min}$. The yield was $8.06 \mathrm{~g}(62 \%$ based on flour + functionalization). The filtrate residue after drying was an additional $1.95 \mathrm{~g}$ (15\% yield), increasing the yield to $87 \%$.

\subsubsection{Temperature Assisted Sludge Acetylation}

Sample 3.6.3 a: The use of $\mathrm{MeOH}$ to wash the sample results in solids loss and reduced yields. Without solvent, to achieve a slurry consistency, a large excess of acetic anhydride is required. An experiment, to evaluate acetylation using only a small excess of anhydride and to strip the residual anhydride and acetic acid by-product without use of solvent, was attempted. In a $1 \mathrm{~L}$ round bottom flask with a condenser and gas adaptor on the Schlenk line, with the $\mathrm{N}_{2}$ feed into the gas adaptor, $25.02 \mathrm{~g}$ Honeysoy® 90PD and 50 $\mathrm{ml}(530 \mathrm{mmol})$ acetic anhydride were mixed and the flask was positioned in a $120{ }^{\circ} \mathrm{C}$ equilibrated oil bath. At first the material was a thick slurry that could be agitated, however it quickly became a sludge and stirring was ineffective. The mixture was left refluxing 3 h 20 min. The outer layer was a dark crust but the bulk was lighter brown. The sludge was air dried in the hood for 34 days unintentionally because the parafilm on the flask failed, opening it to atmosphere. A faint vinegar odor persisted, indicating that acetic anhydride and acetic acid were not cleanly stripped from the sample.

Sample 3.6.3 b: Using the lower amount of anhydride, the sample was not agitated. Still, significant esterification was indicated in the infrared spectra. This implies that a simpler sludge acetylation method is possible. Roughly $5.5 \mathrm{~g}$ of soy flour was 
mixed with roughly $11 \mathrm{ml}(117 \mathrm{mmol})$ of acetic anhydride at ambient temperature to a consistent sludge. Four replicas were mixed. The samples were covered with a $\mathrm{N}_{2}$ blanket, capped with a balloon and placed in an oven preheated to $120^{\circ} \mathrm{C}$. After $2 \mathrm{~h}$ the balloon caps had failed, leaving the samples open to ambient air. After an additional $2 \mathrm{~h}$, samples were removed and placed in a dessicator to cool.

Sample 3.6.3 c: Roughly $15 \mathrm{~g}$ of Honeysoy® 90PD and $30 \mathrm{ml}$ of acetic anhydride (318 mmol) were mixed in each of six $125 \mathrm{ml}$ Parr Digester Bombs that were then blanketed with $\mathrm{N}_{2}$, sealed and placed in an oven at $120^{\circ} \mathrm{C}$. The samples were held at 120 ${ }^{\circ} \mathrm{C}$ for 50 - $52 \mathrm{~h}$. The oven was shut off and cooled before removing the bombs. After an additional 18 days sealed in the bombs, the samples were transferred to a single $1 \mathrm{~L}$ flask and dried by rotary evaporation.Because very little liquid evolved at ambient temperature, the water bath was gradually ramped to $98^{\circ} \mathrm{C}$. After a total time of $4.5 \mathrm{~h}$, and little additional evolution, the rotary evaporation was stopped. The sample was tenaciously adhered to the walls of the flask and could not be removed. Liquid was still visible at the flask / sample interface. Therefore, the open flask was placed in a vacuum oven equilibrated to $80{ }^{\circ} \mathrm{C}$ overnight, after which the sample still could not be broken free from the walls. Acetone was used to soften the sample and it was transferred to a sample bottle. The open bottle was further dried in an oven at $70{ }^{\circ} \mathrm{C}$ for $6 \mathrm{~h}$, but a faint vinegar odor still persisted. The dark brown chunks weighed $86 \mathrm{~g}$ ( $84 \%$ yield based on starting flour + functionalization). 


\subsubsection{ASA Esterification of Soy hulls}

Sample 3.6.4 a,b,c: Soy hull samples weighing 13-15 g were ground with a 60 mesh screen and mixed with $30 \mathrm{ml}$ of either a) acetic anhydride (318 mmol), b) 50/50 mixture of acetic anhydride and $\mathrm{C}_{20}-\mathrm{C}_{24}$ ASA or c) $\mathrm{C}_{20}-\mathrm{C}_{24}$. ASA (70.8 mmol) in $125 \mathrm{ml}$ Parr digestion bombs. These bombs were placed in an oven maintained at $140{ }^{\circ} \mathrm{C}$ for 48 $\mathrm{h}$, then removed and cooled. After 3 days, $30 \mathrm{ml} \mathrm{MeOH}$ was added and then the samples were poured into $150 \mathrm{ml} \mathrm{MeOH}$. THe slurries were collected in a fritted glass funnel, washed three times with $60 \mathrm{ml} \mathrm{MeOH}$ and oven dried at $50{ }^{\circ} \mathrm{C}$ for $45 \mathrm{~h}$.

\subsection{Combined Treatments}

In Chapter IV, water absorption testing indicated some of the evaluated treatments were effective at reducing hydrophillicity of the fillers. A number of these promising treatments were combined in an attempt to leverage additive benefit.

\subsubsection{Acetylation of SPI with Acetic Anhydride and Pyridine}

Both refinement to SPI and acetylation reduced water absorption by $40 \%$.

Combining the treatments had the potential for additive benefit. It is desirable to have light colored filler, but to date, only temperature assisted acetylation was successful in significant acetylation of the solids. This approach darkens the filler. In earlier work, soluble species were successfully acetylated at ambient temperature in the presence of pyridine. The solids, from that process, were not acetylated. Since SPI has different solubility than soy flour, perhaps the room temperature base-catalyzed acetylation may work with the SPI. 
Sample 3.7.1 a: A $4.98 \mathrm{~g}$ sample of EtOH precipitated SPI [3.3.2a] and $40 \mathrm{ml}$ (500 mmol) pyridine were loaded into a $100 \mathrm{ml}$ two neck round bottom flask equipped with a stir bar, addition funnel and gas adaptor on a Schlenk line and supported in an ice bath with $\mathrm{N}_{2}$ atmosphere. To this cloudy yellowish brown slurry, $11 \mathrm{ml}$ acetic anhydride (117 mmol) was added dropwise over $25 \mathrm{~min}$. The sample was stirred aggressively for 30 $\min$ at $<14{ }^{\circ} \mathrm{C}$, then the stirring was slowed and it warmed to ambient temperature. The sample was stirred an additional $24 \mathrm{~h}$ and then filtered and washed three times with $30 \mathrm{ml}$ each $\mathrm{MeOH}$. After drying at $50{ }^{\circ} \mathrm{C}$ for $8 \mathrm{~h} 5$ min the yield was $4.02 \mathrm{~g}(80.7 \%$ based on starting isolate).

\subsubsection{Temperature Assist Sludge Acetylation of Torrefacted Hulls}

Torrefaction provided a 50\% reduction in water absorption and acetylation provided $>40 \%$ reduction. Therefore, it follows that acetylation of the torrefacted soy might provide an additive affect. Since the torrefacted filler is already dark brown to black in color, the acetylation can be performed at elevated temperature without concern for discoloration.

Sample 3.7.2 a,b: For this study, the acetylation was performed on untreated soy hulls (60 mesh grind) and torrefaceted soy hulls (60 mesh grind). a) A $15.30 \mathrm{~g}$ sample of untreated soy hulls (60 mesh grind) and $30 \mathrm{ml}(318 \mathrm{mmol})$ acetic anhydride were loaded into a $125 \mathrm{ml}$ Parr digestion bomb and sealed. b) In another $125 \mathrm{ml}$ Parr digestion bomb $16.39 \mathrm{~g}$ torrefacted soy hulls (60 mesh grind) and $30 \mathrm{ml}(318 \mathrm{mmol})$ acetic anhydride were loaded and sealed. The bombs were placed in an oven maintained at roughly 120- 
$140{ }^{\circ} \mathrm{C}$ for $14 \mathrm{~h}$. Then the oven was cooled and the samples were removed. Roughly 50 $\mathrm{ml} \mathrm{MeOH}$ was added to each bomb and the slurries were poured into $300 \mathrm{ml} \mathrm{MeOH}$. The slurry solids were collected on fritted glass funnels and washed two times with $200 \mathrm{ml}$ $\mathrm{MeOH}$. After oven drying at $50{ }^{\circ} \mathrm{C}$ for $24 \mathrm{~h}$, yields were a) acetylated only- $13.5 \mathrm{~g}(88 \%)$ ; b) torrefacted \& acetylated- $13.7 \mathrm{~g}(83.5 \%)$.

\subsubsection{Silane Treatment with Octyltriethoxysilane (OTES)}

Refining the soy flour to soy protein concentrate (SPC), decreased the water absorption by roughly $35 \%$. OTES treatment of soy flour decreased the water absorption by $30 \%$. To test whether the treatment benefits would be additive, SPC was treated with OTES. OTES treatments of untreated soy hulls and torrefacated soy hulls were also evaluated.

Sample 3.7.3 a-c: A master solution was prepared : $135 \mathrm{ml} \mathrm{MeOH}+4.5 \mathrm{ml}$ OTES $+3 \mathrm{ml}$ acetic acid $+1 \mathrm{ml} \mathrm{DI} \mathrm{H}_{2} \mathrm{O}$. The following samples were treated in $100 \mathrm{ml} \mathrm{RBFs}$ with stir bars at ambient atmosphere and temperature.

Sample 3.7.3a: $6.083 \mathrm{~g}$ torrefacted hulls (60 mesh grind) $+50 \mathrm{ml}$ solution (Torr)

Sample 3.7.3b: $6.158 \mathrm{~g}$ untreated soy hulls (60 mesh grind) $+50 \mathrm{ml}$ solution(UT)

Sample 3.7.3c: $3.619 \mathrm{~g} \mathrm{SPC}+45 \mathrm{ml}$ solution (SPC)

Samples were stirred for 130 min and then filtered through a glass frit and rinsed with $\mathrm{MeOH}$. After drying at $50{ }^{\circ} \mathrm{C}$ for $42.25 \mathrm{~h}$, yields were: a) Torr $5.4 \mathrm{~g}(89.4 \%)$, b) UT $5.2 \mathrm{~g}$ $(83.5 \%)$, and c) SPC $2.8 \mathrm{~g}(76.8 \%)$. 
3.7.4 Silane treatment of SPC with $\gamma$-aminopropyltrimethoxysilane (APTMS)

APTMS treatment of soy flour did not provide a benefit. It was proposed, however, that because of the solubility of soy protein at basic $\mathrm{pH}$, that treatment of SPC might have a better outcome.

Sample 3.7.4 a: In $100 \mathrm{ml}$ round bottom flask with a stir bar, at ambient atmosphere and temperature, $5.04 \mathrm{~g} \mathrm{SPC}+45 \mathrm{ml} \mathrm{MeOH}+1.5 \mathrm{ml}$ silane was stirred for $24 \mathrm{~h}$. The material was then collected on a fritted glass funnel and rinsed with $15 \mathrm{ml}$ $\mathrm{MeOH}$. The filtrate was a light amber transparent liquid. After the solids were dried at 50 ${ }^{\circ} \mathrm{C}$ for $48 \mathrm{~h}$, the yield was $4.0 \mathrm{~g}(80 \%)$ of a medium brown filler. 


\section{CHAPTER IV}

\section{CAST RESIN WATER ABSORPTION STUDIES}

\subsection{Rationale for Study}

Water absorption studies were used to the assess effectiveness of the various treatments to reduce the hydrophilic nature of the precursor soy materials. This is critical for use of the fillers in composites because of the decline of mechanical performance with high levels of water absorption.

\subsection{Materials}

The peroxide used was Noury F-85 40\% MEKP and the accelerator was Shephard Co octoate (12\%) in mineral spirits. Ashland MR642 is a maleic anhydride propylene glycol unsaturated polyester resin in $30 \%$ weight $\%$ vinyl toluene. S905-40, provided by AOC Resins, is a dicyclopentadiene unsaturated polyester resin in solution with $30 \%$ weight $\%$ styrene. The two polyester structures are depicted in Figures 4.1 and 4.2, respectively.

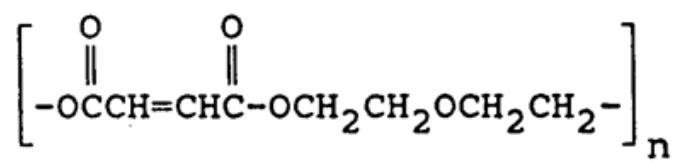

Figure 4.1: Structure for Ashland MR642 Polyester 


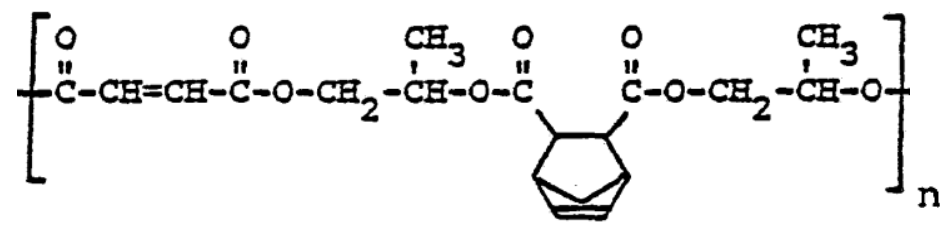

Figure 4.1: Structure for AOC S905 Polyester

Fillers used include the treated soy fillers described in Chapter III, untreated soy precursors and inorganic mineral fillers, as references. The $\mathrm{CaCO}_{3}$ used was Omya LV10 , which is a nominal 10 micron filler as characterized by light scattering particle size distribution area average diameter, $\mathrm{MA} . \mathrm{CaCO}_{3}$ is considered the ideal target material performance due to its low water absorption. Other mineral fillers widely used in composites, Alumina TriHydrate (ATH) and clay were also evaluated as reference materials. The ATH used was Huber SB432 and the clay was BASF ASP200.

\subsection{Method}

The general procedure for the specimen preparation was: using a tin weighing pan or medicine cup as molds, start with a resin that was accelerated with cobalt octoate, as a master batch. Methyl ethyl ketone peroxide was mixed in by hand and then the filler was added and also hand mixed for each specimen. The samples were cured under ambient conditions and then post baked stepwise up to $150{ }^{\circ} \mathrm{C}$, as reported in Table 4.1. Specimens were then submersed in deionized water in beakers for varying times. For measurements, they were pulled, dried with a paper towel and weighed immediately. $\mathrm{CaCO}_{3}$ was used as an internal reference. All data was normalized by dividing by its 
water weight gain. Table 4.1 summarizes the detail of compositions and thermal histories for castings used for water absorption evaluation. Data is presented for 15 different sets.

Table 4.1: Resin Casting Water Absorption Specimen

\begin{tabular}{|c|c|c|c|c|c|c|}
\hline Sample & Date (labbook page) & Resin & $\begin{array}{c}\text { Resin/Co } \\
(\mathrm{g})\end{array}$ & $\begin{array}{c}40 \% \text { MEKP } \\
(\mathrm{g})\end{array}$ & $\begin{array}{l}\text { Filler } \\
(\mathrm{g})\end{array}$ & Post bake Schedule \\
\hline & $9 / 14 / 2012(06)$ & & & & & \\
\hline $3.5 .5 \mathrm{a}$ & $\mathrm{SF}-\mathrm{MeOH}$ & MR642+styrene & 9.92 & 0.35 & 4.00 & RT/overnight, $80^{\circ} \mathrm{C} / 2 \mathrm{~h}, 120^{\circ} \mathrm{C} / 1 \mathrm{~h}, 150^{\circ} \mathrm{C} / 1 \mathrm{~h}$ \\
\hline 3.5.3a & SF-merc & MR642+styrene & 9.95 & 0.36 & 4.02 & RT/overnight, $80^{\circ} \mathrm{C} / 2 \mathrm{~h}, 120^{\circ} \mathrm{C} / 1 \mathrm{~h}, 150^{\circ} \mathrm{C} / 1 \mathrm{~h}$ \\
\hline 3.5.1a & SF-WC & MR642+styrene & 10.03 & 0.38 & 4.09 & RT/overnight, $80^{\circ} \mathrm{C} / 2 \mathrm{~h}, 120^{\circ} \mathrm{C} / 1 \mathrm{~h}, 150^{\circ} \mathrm{C} / 1 \mathrm{~h}$ \\
\hline $3.5 .1 \mathrm{~b}$ & SF-merctWC & MR642+styrene & 10.01 & 0.36 & 4.03 & RT/overnight, $80^{\circ} \mathrm{C} / 2 \mathrm{~h}, 120^{\circ} \mathrm{C} / 1 \mathrm{~h}, 150^{\circ} \mathrm{C} / 1 \mathrm{~h}$ \\
\hline $3.5 .4 \mathrm{a}$ & SF-APTMS & MR642tstyrene & 9.49 & 0.36 & 4.02 & RT/overnight, $80^{\circ} \mathrm{C} / 2 \mathrm{~h}, 120^{\circ} \mathrm{C} / 1 \mathrm{~h}, 150^{\circ} \mathrm{C} / 1 \mathrm{~h}$ \\
\hline $3.5 .4 b$ & SF-MOPTMS & MR642+styrene & 10.03 & 0.36 & 3.99 & RT/overnight, $80^{\circ} \mathrm{C} / 2 \mathrm{~h}, 120^{\circ} \mathrm{C} / 1 \mathrm{~h}, 150^{\circ} \mathrm{C} / 1 \mathrm{~h}$ \\
\hline $3.5 .4 c$ & SF-OTES-1 & MR642+styrene & 10.06 & 0.36 & 4.00 & RT/overnight, $80^{\circ} \mathrm{C} / 2 \mathrm{~h}, 120^{\circ} \mathrm{C} / 1 \mathrm{~h}, 150^{\circ} \mathrm{C} / 1 \mathrm{~h}$ \\
\hline $3.5 .4 \mathrm{~d}$ & SF-GOPTMS & MR642tstyrene & 10 & 0.42 & 4.06 & RT/overnight, $80^{\circ} \mathrm{C} / 2 \mathrm{~h}, 120^{\circ} \mathrm{C} / 1 \mathrm{~h}, 150^{\circ} \mathrm{C} / 1 \mathrm{~h}$ \\
\hline 3.5.4e & SF-OVTES & MR642tstyrene & 10.06 & 0.4 & 3.97 & RT/overnight, $80^{\circ} \mathrm{C} / 2 \mathrm{~h}, 120^{\circ} \mathrm{C} / 1 \mathrm{~h}, 150^{\circ} \mathrm{C} / 1 \mathrm{~h}$ \\
\hline \multirow[t]{4}{*}{$3.5 .4 f$} & SF-VGS & MR642+styrene & 10.04 & 0.37 & 4.05 & RT/overnight, $80^{\circ} \mathrm{C} / 2 \mathrm{~h}, 120^{\circ} \mathrm{C} / 1 \mathrm{~h}, 150^{\circ} \mathrm{C} / 1 \mathrm{~h}$ \\
\hline & $9 / 28 / 2012(13)$ & & & & & \\
\hline & $\mathrm{CaCO}$ & MR642+styrene & 5.08 & 0.16 & 3.97 & RT/overnight, $80^{\circ} \mathrm{C} / 2 \mathrm{~h}, 120^{\circ} \mathrm{C} / 2 \mathrm{~h}, 150^{\circ} \mathrm{C} / 2 \mathrm{~h}$ \\
\hline & UTSF & MR642+styrene & 5.08 & 0.15 & 2.01 & RT/overnight, $80^{\circ} \mathrm{C} / 2 \mathrm{~h}, 120^{\circ} \mathrm{C} / 2 \mathrm{~h}, 150^{\circ} \mathrm{C} / 2 \mathrm{~h}$ \\
\hline $3.5 .5 \mathrm{a}$ & SF-MeOH & MR642+styrene & 5.07 & 0.16 & 1.98 & RT/overnight, $80^{\circ} \mathrm{C} / 2 \mathrm{~h}, 120^{\circ} \mathrm{C} / 2 \mathrm{~h}, 150^{\circ} \mathrm{C} / 2 \mathrm{~h}$ \\
\hline $3.5 .4 c$ & SF-0TES-1 & MR642+styrene & 5.07 & 0.18 & 2.02 & RT/overnight, $80^{\circ} \mathrm{C} / 2 \mathrm{~h}, 120^{\circ} \mathrm{C} / 2 \mathrm{~h}, 150^{\circ} \mathrm{C} / 2 \mathrm{~h}$ \\
\hline $3.5 .4 \mathrm{~g}$ & SF-0TES-2 & MR642+styrene & 5.01 & 0.14 & 2.03 & RT/overnight, $80^{\circ} \mathrm{C} / 2 \mathrm{~h}, 120^{\circ} \mathrm{C} / 2 \mathrm{~h}, 150^{\circ} \mathrm{C} / 2 \mathrm{~h}$ \\
\hline 3.5.4h & SF-OTES-3 & MR642+styrene & 5.04 & 0.16 & 2.05 & RT/overnight, $80^{\circ} \mathrm{C} / 2 \mathrm{~h}, 120^{\circ} \mathrm{C} / 2 \mathrm{~h}, 150^{\circ} \mathrm{C} / 2 \mathrm{~h}$ \\
\hline 3.5 .41 & SF-0TES-4 & MR642tstyrene & 5.06 & 0.16 & 1.98 & RT/overnight, $80^{\circ} \mathrm{C} / 2 \mathrm{~h}, 120^{\circ} \mathrm{C} / 2 \mathrm{~h}, 150^{\circ} \mathrm{C} / 2 \mathrm{~h}$ \\
\hline \multirow[t]{7}{*}{$3.5 .4 j$} & SF-0TES -5 & MR642+styrene & 5.02 & 0.16 & 2.00 & RT/overnight, $80^{\circ} \mathrm{C} / 2 \mathrm{~h}, 120^{\circ} \mathrm{C} / 2 \mathrm{~h}, 150^{\circ} \mathrm{C} / 2 \mathrm{~h}$ \\
\hline & DDG-SE & MR642+styrene & 4.99 & 0.18 & 2.03 & RT/overnight, $80^{\circ} \mathrm{C} / 2 \mathrm{~h}, 120^{\circ} \mathrm{C} / 2 \mathrm{~h}, 150^{\circ} \mathrm{C} / 2 \mathrm{~h}$ \\
\hline & YP-Torr & MR642+styrene & 5.07 & 0.21 & 2.06 & RT/overnight, $80^{\circ} \mathrm{C} / 2 \mathrm{~h}, 120^{\circ} \mathrm{C} / 2 \mathrm{~h}, 150^{\circ} \mathrm{C} / 2 \mathrm{~h}$ \\
\hline & Resin only & MR642+styrene & 7.02 & 0.25 & 0 & RT/overnight, $80^{\circ} \mathrm{C} / 2 \mathrm{~h}, 120^{\circ} \mathrm{C} / 2 \mathrm{~h}, 150^{\circ} \mathrm{C} / 2 \mathrm{~h}$ \\
\hline & $10 / 5 / 12(16)$ & & & & & \\
\hline & UTSF & MR642 & 5.05 & 0.18 & 2.00 & RT/weekend, $50-70^{\circ} \mathrm{C} / 2.75 \mathrm{~h}$, to $180^{\circ} \mathrm{C} / 1.5 \mathrm{~h}$ \\
\hline & UTSF & MR642 & 5.09 & 0.18 & 2.01 & RT/weekend, $50-70^{\circ} \mathrm{C} / 2.75 \mathrm{~h}$, to $180^{\circ} \mathrm{C} / 1.5 \mathrm{~h}$ \\
\hline 3.5 .4 & SF-OTES - 5 & MR642 & 5.08 & 0.21 & 2.06 & RT/weekend, $50-70^{\circ} \mathrm{C} / 2.75 \mathrm{~h}$, to $180^{\circ} \mathrm{C} / 1.5 \mathrm{~h}$ \\
\hline $3.5 .4 \mathrm{k}$ & SF-0TES - 6 & MR642 & 5 & 0.18 & 2.00 & RT/weekend, $50-70^{\circ} \mathrm{C} / 2.75 \mathrm{~h}$, to $180^{\circ} \mathrm{C} / 1.5 \mathrm{~h}$ \\
\hline $3.5 .4 c$ & SF-0TES-1 & MR642 & 5.04 & 0.19 & 2.00 & RT/weekend, $50-70^{\circ} \mathrm{C} / 2.75 \mathrm{~h}$, to $180^{\circ} \mathrm{C} / 1.5 \mathrm{~h}$ \\
\hline \multirow[t]{2}{*}{$3.5 .5 \mathrm{a}$} & SF-MeOH & MR642 & 5.01 & 0.19 & 2.03 & RT/weekend, $50-70^{\circ} \mathrm{C} / 2.75 \mathrm{~h}$, to $180^{\circ} \mathrm{C} / 1.5 \mathrm{~h}$ \\
\hline & $\mathrm{CaCO3}$ & MR642 & 5.06 & 0.18 & 4.11 & RT/weekend, $50-70^{\circ} \mathrm{C} / 2.75 \mathrm{~h}$, to $180^{\circ} \mathrm{C} / 1.5 \mathrm{~h}$ \\
\hline
\end{tabular}


Table 4.1: Resin Casting Water Absorption Specimen, continued

\begin{tabular}{|c|c|c|c|c|c|c|}
\hline & $10 / 8 / 2012(17)$ & & & & & \\
\hline & $\mathrm{CaCO}$ & MR642 & 5.08 & 0.2 & 4.04 & RT/overnight, $50^{\circ} \mathrm{C} / 2.7 \mathrm{~h}, 80^{\circ} \mathrm{C} / 4.5 \mathrm{~h}, 120^{\circ} \mathrm{C} / 1 \mathrm{~h}, 150^{\circ} \mathrm{C} / 1.5 \mathrm{~h}$ \\
\hline $3.5 .5 a$ & SF-MeOH & MR642 & 5.04 & 0.18 & 2.02 & RT/overnight, $50^{\circ} \mathrm{C} / 2.7 \mathrm{~h}, 80^{\circ} \mathrm{C} / 4.5 \mathrm{~h}, 120^{\circ} \mathrm{C} / 1 \mathrm{~h}, 150^{\circ} \mathrm{C} / 1.5 \mathrm{~h}$ \\
\hline $3.5 .4 \mathrm{k}$ & SF-0TES-6 & MR642 & 5.07 & 0.18 & 2.02 & RT/overnight, $50^{\circ} \mathrm{C} / 2.7 \mathrm{~h}, 80^{\circ} \mathrm{C} / 4.5 \mathrm{~h}, 120^{\circ} \mathrm{C} / 1 \mathrm{~h}, 150^{\circ} \mathrm{C} / 1.5 \mathrm{~h}$ \\
\hline 3.5.4h & SF-OTES-3 & MR642 & 5.00 & 0.19 & 2.03 & RT/overnight, $50^{\circ} \mathrm{C} / 2.7 \mathrm{~h}, 80^{\circ} \mathrm{C} / 4.5 \mathrm{~h}, 120^{\circ} \mathrm{C} / 1 \mathrm{~h}, 150^{\circ} \mathrm{C} / 1.5 \mathrm{~h}$ \\
\hline $3.5 .4 c$ & SF-OTES-1 & MR642 & 5.03 & 0.19 & 2.00 & RT/overnight, $50^{\circ} \mathrm{C} / 2.7 \mathrm{~h}, 80^{\circ} \mathrm{C} / 4.5 \mathrm{~h}, 120^{\circ} \mathrm{C} / 1 \mathrm{~h}, 150^{\circ} \mathrm{C} / 1.5 \mathrm{~h}$ \\
\hline 3.5.4b & SF-MOPTMS & MR642 & 5.07 & 0.17 & 2.04 & RT/overnight, $50^{\circ} \mathrm{C} / 2.7 \mathrm{~h}, 80^{\circ} \mathrm{C} / 4.5 \mathrm{~h}, 120^{\circ} \mathrm{C} / 1 \mathrm{~h}, 150^{\circ} \mathrm{C} / 1.5 \mathrm{~h}$ \\
\hline 3.5.4e & SF-OVTES & MR642 & 5.01 & 0.19 & 2.00 & RT/overnight, $50^{\circ} \mathrm{C} / 2.7 \mathrm{~h}, 80^{\circ} \mathrm{C} / 4.5 \mathrm{~h}, 120^{\circ} \mathrm{C} / 1 \mathrm{~h}, 150^{\circ} \mathrm{C} / 1.5 \mathrm{~h}$ \\
\hline \multirow[t]{2}{*}{ 3.5.4f } & SF-VGS & MR642 & 5.01 & 0.18 & 2.02 & RT/overnight, $50^{\circ} \mathrm{C} / 2.7 \mathrm{~h}, 80^{\circ} \mathrm{C} / 4.5 \mathrm{~h}, 120^{\circ} \mathrm{C} / 1 \mathrm{~h}, 150^{\circ} \mathrm{C} / 1.5 \mathrm{~h}$ \\
\hline & $10 / 9 / 2012(18)$ & & & & & \\
\hline 3.5.4f & SF-VGS & MR642 & 5.00 & 0.19 & 2.03 & RT/overnight, $50^{\circ} \mathrm{C} / 1.7 \mathrm{~h}, 80^{\circ} \mathrm{C} / 1.5 \mathrm{~h}, 120^{\circ} \mathrm{C} / 1.4 \mathrm{~h}, 150^{\circ} \mathrm{C} / 1.4 \mathrm{~h}$ \\
\hline $3.5 .4 c$ & SF-0TES-1 & MR642 & 5.01 & 0.18 & 2.01 & RT/overnight, $50^{\circ} \mathrm{C} / 1.7 \mathrm{~h}, 80^{\circ} \mathrm{C} / 1.5 \mathrm{~h}, 120^{\circ} \mathrm{C} / 1.4 \mathrm{~h}, 150^{\circ} \mathrm{C} / 1.4 \mathrm{~h}$ \\
\hline $3.5 .5 \mathrm{a}$ & SF-MeOH & MR642 & 5.05 & 0.18 & 2.02 & RT/overnight, $50^{\circ} \mathrm{C} / 1.7 \mathrm{~h}, 80^{\circ} \mathrm{C} / 1.5 \mathrm{~h}, 120^{\circ} \mathrm{C} / 1.4 \mathrm{~h}, 150^{\circ} \mathrm{C} / 1.4 \mathrm{~h}$ \\
\hline \multirow[t]{2}{*}{$3.5 .4 b$} & SF-MOPTMS & MR642 & 5.00 & 0.19 & 2.02 & RT/overnight, $50^{\circ} \mathrm{C} / 1.7 \mathrm{~h}, 80^{\circ} \mathrm{C} / 1.5 \mathrm{~h}, 120^{\circ} \mathrm{C} / 1.4 \mathrm{~h}, 150^{\circ} \mathrm{C} / 1.4 \mathrm{~h}$ \\
\hline & $\mathrm{CaCO}$ & MR642 & 5.03 & 0.20 & 4.02 & RT/overnight, $50^{\circ} \mathrm{C} / 1.7 \mathrm{~h}, 80^{\circ} \mathrm{C} / 1.5 \mathrm{~h}, 120^{\circ} \mathrm{C} / 1.4 \mathrm{~h}, 150^{\circ} \mathrm{C} / 1.4 \mathrm{~h}$ \\
\hline $3.5 .4 \mathrm{k}$ & SF-0TES-6 & MR642 & 5.03 & 0.20 & 2.04 & RT/overnight, $50^{\circ} \mathrm{C} / 1.7 \mathrm{~h}, 80^{\circ} \mathrm{C} / 1.5 \mathrm{~h}, 120^{\circ} \mathrm{C} / 1.4 \mathrm{~h}, 150^{\circ} \mathrm{C} / 1.4 \mathrm{~h}$ \\
\hline 3.5.4e & SF-OVTES & MR642 & 5.05 & 0.20 & 2.03 & RT/overnight, $50^{\circ} \mathrm{C} / 1.7 \mathrm{~h}, 80^{\circ} \mathrm{C} / 1.5 \mathrm{~h}, 120^{\circ} \mathrm{C} / 1.4 \mathrm{~h}, 150^{\circ} \mathrm{C} / 1.4 \mathrm{~h}$ \\
\hline \multirow[t]{4}{*}{$3.5 .4 \mathrm{~h}$} & SF-OTES-3 & MR642 & 5.02 & 0.21 & 2.02 & RT/overnight, $50^{\circ} \mathrm{C} / 1.7 \mathrm{~h}, 80^{\circ} \mathrm{C} / 1.5 \mathrm{~h}, 120^{\circ} \mathrm{C} / 1.4 \mathrm{~h}, 150^{\circ} \mathrm{C} / 1.4 \mathrm{~h}$ \\
\hline & Neroplast & MR642 & 5.02 & 0.2 & 2.01 & did not Cure \\
\hline & DDG-SE & MR642 & 5.05 & 0.19 & 2.03 & RT/overnight, $50^{\circ} \mathrm{C} / 1.7 \mathrm{~h}, 80^{\circ} \mathrm{C} / 1.5 \mathrm{~h}, 120^{\circ} \mathrm{C} / 1.4 \mathrm{~h}, 150^{\circ} \mathrm{C} / 1.4 \mathrm{~h}$ \\
\hline & 10/15/2012 (21) & & & & & \\
\hline 3.5.5a & SF-MeOH & MR642 & 5.01 & 0.18 & 2.03 & RT/overnight, $50^{\circ} \mathrm{C} / 2 \mathrm{~h}, 80^{\circ} \mathrm{C} / 2 \mathrm{~h}, 120^{\circ} \mathrm{C} / 2 \mathrm{~h}, 150^{\circ} \mathrm{C} / 2 \mathrm{~h}$ \\
\hline \multirow[t]{2}{*}{$3.5 .4 b$} & SF-MOPTMS & MR642 & 5.01 & 0.19 & 2.00 & RT/overnight, $50^{\circ} \mathrm{C} / 2 \mathrm{~h}, 80^{\circ} \mathrm{C} / 2 \mathrm{~h}, 120^{\circ} \mathrm{C} / 2 \mathrm{~h}, 150^{\circ} \mathrm{C} / 2 \mathrm{~h}$ \\
\hline & UTSF & MR642 & 5.04 & 0.2 & 2.05 & RT/overnight, $50^{\circ} \mathrm{C} / 2 \mathrm{~h}, 80^{\circ} \mathrm{C} / 2 \mathrm{~h}, 120^{\circ} \mathrm{C} / 2 \mathrm{~h}, 150^{\circ} \mathrm{C} / 2 \mathrm{~h}$ \\
\hline \multirow[t]{10}{*}{ 3.6.1a } & SF-aCet1 & MR642 & 5.01 & 0.19 & 2.01 & RT/overnight, $50^{\circ} \mathrm{C} / 2 \mathrm{~h}, 80^{\circ} \mathrm{C} / 2 \mathrm{~h}, 120^{\circ} \mathrm{C} / 2 \mathrm{~h}, 150^{\circ} \mathrm{C} / 2 \mathrm{~h}$ \\
\hline & $\mathrm{CaCO}$ & MR642 & 5.03 & 0.18 & 4.02 & RT/overnight, $50^{\circ} \mathrm{C} / 2 \mathrm{~h}, 80^{\circ} \mathrm{C} / 2 \mathrm{~h}, 120^{\circ} \mathrm{C} / 2 \mathrm{~h}, 150^{\circ} \mathrm{C} / 2 \mathrm{~h}$ \\
\hline & $10 / 30 / 2012(27)$ & & & & & \\
\hline & SPC & MR642 & 5.04 & 0.21 & 2.02 & RT/overnight, $70^{\circ} \mathrm{C} / 1.25 \mathrm{~h}, 120^{\circ} \mathrm{C} / 1 \mathrm{~h}, 150^{\circ} \mathrm{C} / 1 \mathrm{~h}$ \\
\hline & EtOHSPI & MR642 & 5.05 & 0.18 & 2.00 & RT/overnight, $70^{\circ} \mathrm{C} / 1.25 \mathrm{~h}, 120^{\circ} \mathrm{C} / 1 \mathrm{~h}, 150^{\circ} \mathrm{C} / 1 \mathrm{~h}$ \\
\hline & Heat SPI & MR642 & 5.03 & 0.18 & 2.00 & RT/overnight, $70^{\circ} \mathrm{C} / 1.25 \mathrm{~h}, 120^{\circ} \mathrm{C} / 1 \mathrm{~h}, 150^{\circ} \mathrm{C} / 1 \mathrm{~h}$ \\
\hline & UTSF & MR642 & 5.05 & 0.18 & 2.01 & RT/overnight, $70^{\circ} \mathrm{C} / 1.25 \mathrm{~h}, 120^{\circ} \mathrm{C} / 1 \mathrm{~h}, 150^{\circ} \mathrm{C} / 1 \mathrm{~h}$ \\
\hline & $\mathrm{CaCO}$ & MR642 & 5.01 & 0.19 & 4.01 & RT/overnight, $70^{\circ} \mathrm{C} / 1.25 \mathrm{~h}, 120^{\circ} \mathrm{C} / 1 \mathrm{~h}, 150^{\circ} \mathrm{C} / 1 \mathrm{~h}$ \\
\hline & YP-Torr & MR642 & 5.02 & 0.61 & 2.01 & did not Cure \\
\hline & DDG-SE & MR642 & 5.03 & 0.44 & 2.00 & did not Cure \\
\hline $3.6 .3 b$ & SF-aCet6 & MR642 & 5.05 & 0.19 & 2.02 & RT/overnight, $70^{\circ} \mathrm{C} / 1.25 \mathrm{~h}, 120^{\circ} \mathrm{C} / 1 \mathrm{~h}, 150^{\circ} \mathrm{C} / 1 \mathrm{~h}$ \\
\hline $3.6 .3 b$ & SF-aCet6 & MR642 & 5 & 0.19 & 2.03 & RT/overnight, $70^{\circ} \mathrm{C} / 1.25 \mathrm{~h}, 120^{\circ} \mathrm{C} / 1 \mathrm{~h}, 150^{\circ} \mathrm{C} / 1 \mathrm{~h}$ \\
\hline $3.6 .3 b$ & SF-aCet6 & MR642 & 5.03 & 0.19 & 2.00 & RT/overnight, $70^{\circ} \mathrm{C} / 1.25 \mathrm{~h}, 120^{\circ} \mathrm{C} / 1 \mathrm{~h}, 150^{\circ} \mathrm{C} / 1 \mathrm{~h}$ \\
\hline
\end{tabular}


Table 4.1: Resin Casting Water Absorption Specimen, continued

\begin{tabular}{|c|c|c|c|c|c|c|}
\hline & $6 / 25 / 2013(38 a)$ & & & & & \\
\hline & UTSH & 5903 & 4.99 & 0.11 & 1.98 & $\mathrm{RT} / / 0.5 \mathrm{~h}, 70^{\circ} \mathrm{C} / 1 \mathrm{~h}, 88^{\circ} \mathrm{C} / 3 \mathrm{hs}, 150^{\circ} \mathrm{C} / 1 \mathrm{~h}$ \\
\hline 3.4.1b & SM-AGbench & 5903 & 5.01 & 0.12 & 1.98 & $\mathrm{RT} / / 0.5 \mathrm{~h}, 70^{\circ} \mathrm{C} / 1 \mathrm{~h}, 88^{\circ} \mathrm{C} / 3 \mathrm{hs}, 150^{\circ} \mathrm{C} / 1 \mathrm{~h}$ \\
\hline \multirow[t]{5}{*}{$3.4 .1 \mathrm{c}$} & SH-AGbenCh & 5903 & 5.05 & 0.10 & 1.97 & $\mathrm{RT} /<0,5 \mathrm{~h}, 70^{\circ} \mathrm{C} / 1 \mathrm{~h}, 88^{\circ} \mathrm{C} / 3 \mathrm{hs}, 150^{\circ} \mathrm{C} / 1 \mathrm{~h}$ \\
\hline & $\mathrm{CaCO}$ & 5903 & 4.99 & 0.11 & 4.00 & $\mathrm{RT} / / 0.5 \mathrm{~h}, 70^{\circ} \mathrm{C} / 1 \mathrm{~h}, 88^{\circ} \mathrm{C} / 3 \mathrm{hs}, 150^{\circ} \mathrm{C} / 1 \mathrm{~h}$ \\
\hline & $07 / 11 / 13(39)$ & & & & & \\
\hline & $\mathrm{CaCO}$ & 5903 & 5.10 & 0.10 & 4.00 & $\mathrm{RT} / 2 \mathrm{hs}, 50^{\circ} \mathrm{C} / 1 \mathrm{~h}, 100^{\circ} \mathrm{C} / 0.55 \mathrm{~h}, 150^{\circ} \mathrm{C} / 2 \mathrm{~h}$ \\
\hline & UTSH & 5903 & 5.00 & 0.10 & 2.00 & $\mathrm{RT} / \mathrm{R} 2 \mathrm{hs}, 50^{\circ} \mathrm{C} / 1 \mathrm{~h}, 100^{\circ} \mathrm{C} / 0.55 \mathrm{~h}, 150^{\circ} \mathrm{c} / 2 \mathrm{~h}$ \\
\hline 3.4 .36 & SH-AGpilotCG1 & 5903 & 5.00 & 0.10 & 2.00 & $\mathrm{RT} /<2 \mathrm{hs}, 50^{\circ} \mathrm{C} / 1 \mathrm{~h}, 100^{\circ} \mathrm{C} / 0.55 \mathrm{~h}, 150^{\circ} \mathrm{C} / 2 \mathrm{~h}$ \\
\hline \multirow[t]{6}{*}{3.4 .36} & SH-AGpilotCG2 & 5903 & 5.00 & 0.11 & 2.00 & 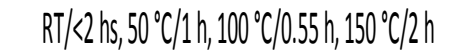 \\
\hline & ATH & 5903 & 5.00 & 0.11 & 4.10 & 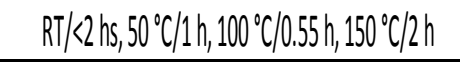 \\
\hline & $8 / 6 / 2013(44)$ & & & & & \\
\hline & $\mathrm{CaCO}$ & 5903 & 5.06 & 0.96 & 3.02 & $\mathrm{RT} /<0.7 \mathrm{~h}, 50^{\circ} \mathrm{C} / 1.75 \mathrm{~h}, 100^{\circ} \mathrm{C} / 1.5 \mathrm{~h}, 150^{\circ} \mathrm{C} / 0.5 \mathrm{~h}$ \\
\hline & Clay & 5903 & 4.98 & 0.10 & 2.95 & $\mathrm{RT} /<0.7 \mathrm{~h}, 50^{\circ} \mathrm{C} / 1.75 \mathrm{~h}, 100^{\circ} \mathrm{C} / 1.5 \mathrm{~h}, 150^{\circ} \mathrm{c} / 0.5 \mathrm{~h}$ \\
\hline & UTSH & 5903 & 5.05 & 0.12 & 1.97 & $\mathrm{RT} /<0.7 \mathrm{~h}, 50^{\circ} \mathrm{C} / 1.75 \mathrm{~h}, 100^{\circ} \mathrm{C} / 1.5 \mathrm{~h}, 150^{\circ} \mathrm{C} / 0.5 \mathrm{~h}$ \\
\hline $3.4 .1 \mathrm{C}$ & SH-AGbench & 5903 & 5.02 & 0.11 & 2.01 & $\mathrm{RT} /<0.7 \mathrm{Th}, 50^{\circ} \mathrm{C} / 1.75 \mathrm{~h}, 100^{\circ} \mathrm{C} / 1.5 \mathrm{~h}, 150^{\circ} \mathrm{c} / 0.5 \mathrm{~h}$ \\
\hline 3.7.2a & SH-aCet2 & 5903 & 5.02 & 0.11 & 2.00 & $\mathrm{RT} /<0.7 \mathrm{~h}, 50^{\circ} \mathrm{C} / 1.75 \mathrm{~h}, 100^{\circ} \mathrm{C} / 1.5 \mathrm{~h}, 150^{\circ} \mathrm{c} / 0.5 \mathrm{~h}$ \\
\hline $3.7 .2 b$ & SH-AgbenCh-aCet & 5903 & 5.02 & 0.09 & 1.99 & $\mathrm{RT} /<0.7 \mathrm{~h}, 50^{\circ} \mathrm{C} / 1.75 \mathrm{~h}, 100^{\circ} \mathrm{C} / 1.5 \mathrm{~h}, 150^{\circ} \mathrm{C} / 0.5 \mathrm{~h}$ \\
\hline $3.7 .3 \mathrm{a}$ & SH-AgbenCh-OTES & 5903 & 5.02 & 0.10 & 2.01 & $\mathrm{RT} /<0.7 \mathrm{~h}, 50^{\circ} \mathrm{C} / 1.75 \mathrm{~h}, 100^{\circ} \mathrm{C} / 1.5 \mathrm{~h}, 150^{\circ} \mathrm{C} / 0.5 \mathrm{~h}$ \\
\hline $3.7,3 b$ & SH-OTES & 5903 & 5.07 & 0.10 & 2.04 & $\mathrm{RT} /<0.7 \mathrm{~h}, 50^{\circ} \mathrm{C} / 1.75 \mathrm{~h}, 100^{\circ} \mathrm{C} / 1.5 \mathrm{~h}, 150^{\circ} \mathrm{C} / 0.5 \mathrm{~h}$ \\
\hline \multirow[t]{2}{*}{$3.7,3 \mathrm{C}$} & SPC-OTES & 5903 & 5.03 & 0.10 & 1.99 & $\mathrm{RT} /<0.7 \mathrm{~h}, 50^{\circ} \mathrm{C} / 1.75 \mathrm{~h}, 100^{\circ} \mathrm{C} / 1.5 \mathrm{sh}, 150^{\circ} \mathrm{C} / 0.5 \mathrm{~h}$ \\
\hline & SPC & 5903 & 5.00 & 0.12 & 2.02 & $\mathrm{RT} /<0.7 \mathrm{~h}, 50^{\circ} \mathrm{C} / 1.75 \mathrm{~h}, 100^{\circ} \mathrm{c} / 1.5 \mathrm{~h}, 150^{\circ} \mathrm{C} / 0.5 \mathrm{~h}$ \\
\hline $3.7 .4 a$ & SPC-APTMS & 5903 & 5.04 & 0.10 & 2.04 & $\mathrm{RT} /<0.7 \mathrm{~h}, 50^{\circ} \mathrm{C} / 1.75 \mathrm{~h}, 100^{\circ} \mathrm{C} / 1.5 \mathrm{~h}, 150^{\circ} \mathrm{C} / 0.5 \mathrm{~h}$ \\
\hline 3.3 .26 & Heat precipitated SPI & 5903 & 4.98 & 0.10 & 2.05 & $\mathrm{RT} /<0.7 \mathrm{~h}, 50^{\circ} \mathrm{C} / 1.75 \mathrm{~h}, 100^{\circ} \mathrm{C} / 1.5 \mathrm{~h}, 150^{\circ} \mathrm{C} / 0.5 \mathrm{~h}$ \\
\hline \multirow[t]{2}{*}{ 3.7.12 } & SPl-aCet1 & 5903 & 5.01 & 0.097 & 2.01 & $\mathrm{RT} /<0.7 \mathrm{~h}, 50^{\circ} \mathrm{C} / 1.75 \mathrm{~h}, 100^{\circ} \mathrm{C} / 1.5 \mathrm{~h}, 150^{\circ} \mathrm{C} / 0.5 \mathrm{~h}$ \\
\hline & $8 / 22 / 2013(44 a)$ & & & & & \\
\hline $3.4 .2 b$ & SH-MF1 & 5903 & 5.03 & 0.10 & 1.00 & $\mathrm{RT} /<1.5 \mathrm{hh}, 50 \mathrm{C} / 1.05 \mathrm{hr}, 100 \mathrm{C} / 1.05 \mathrm{hr}, 150 \mathrm{C} / \mathrm{hhr}$ \\
\hline $3.4 .2 c$ & SH-MF2 & 5903 & 5.06 & 0.10 & 1.02 & RT/<1.5hr, 50C/1.05hr, 100C/1.05hr, 150C/1hr \\
\hline 3.4.2e & SH-MF3 & 5903 & 5.01 & 0.12 & 1.03 & $\mathrm{RT} /<1.5 \mathrm{hr}, 50 \mathrm{C} / 1.05 \mathrm{hr}, 100 \mathrm{c} / 1.05 \mathrm{hr}, 150 \mathrm{c} / \mathrm{hr}$ \\
\hline 3.4.2. & SH-MF34 & 5903 & 5.03 & 0.09 & 1.03 & RT/<1.5hr, 50C/1.05hr, 100C/1.05hr, 150C/1hr \\
\hline 3.4 .36 & SH-AGpilotCG7.6u & 5903 & 5.01 & 0.11 & 1.02 & RT/<1.5hr, 50C/1.05hr, 100c/1.05hr, 150C/1hr \\
\hline
\end{tabular}


Table 4.1: Resin Casting Water Absorption Specimen, continued

\begin{tabular}{|c|c|c|c|c|c|c|}
\hline & $8 / 22 / 2013(44 a)$ & & & & & \\
\hline 3.4 .26 & SH-MF1 & 5903 & 5.03 & 0.10 & 1.00 & $\mathrm{RT} /<1.5 \mathrm{~h}, 50^{\circ} \mathrm{C} / 1.05 \mathrm{~h}, 100^{\circ} \mathrm{c} / 1.05 \mathrm{~h}, 150^{\circ} \mathrm{C} / 1 \mathrm{~h}$ \\
\hline 3.4 .26 & SH-MF2 & 5903 & 5.06 & 0.10 & 1.02 & $\mathrm{RT} /<1.5 \mathrm{~h}, 50^{\circ} \mathrm{c} / 1.05 \mathrm{~h}, 100^{\circ} \mathrm{c} / 1.05 \mathrm{~h}, 150^{\circ} \mathrm{c} / 1 \mathrm{~h}$ \\
\hline 3.4.2e & SH-MF3 & 5903 & 5.01 & 0.12 & 1.03 & $\mathrm{RT} /<1.5 \mathrm{sh}, 50^{\circ} \mathrm{C} / 1.05 \mathrm{~h}, 100^{\circ} \mathrm{c} / 1.05 \mathrm{~h}, 150^{\circ} \mathrm{c} / 1 \mathrm{~h}$ \\
\hline $3.4 .2 d$ & SHMMF34 & 5903 & 5.03 & 0.09 & 1.03 & $\mathrm{RT} /<1.5 \mathrm{~h}, 50^{\circ} \mathrm{c} / 1.05 \mathrm{~h}, 100^{\circ} \mathrm{c} / 1.05 \mathrm{~h}, 150^{\circ} \mathrm{c} / 1 \mathrm{~h}$ \\
\hline \multirow[t]{3}{*}{3.4 .36} & SH-AGpilotCG7.6u & 5903 & 5.01 & 0.11 & 1.02 & RT $/<1.5 h, 50^{\circ} / 1.05 h, 100^{\circ} / 11.05 h, 150^{\circ} / 1 / h$ \\
\hline & $\mathrm{CaCO3}$ & 5903 & 5.02 & 0.10 & 2.01 & $\mathrm{RT} /<1.5 \mathrm{sh}, 50^{\circ} \mathrm{C} / 1.05 \mathrm{~h}, 100^{\circ} \mathrm{c} / 1.05 \mathrm{~h}, 150^{\circ} \mathrm{c} / 1 \mathrm{~h}$ \\
\hline & Clay & 5903 & 5.08 & 0.10 & 0.70 & $\mathrm{RT} /<1.5 \mathrm{~h}, 50^{\circ} / 11.05 \mathrm{~h}, 100^{\circ} \mathrm{C} / 1.05 \mathrm{~h}, 150^{\circ} \mathrm{C} / 1 \mathrm{~h}$ \\
\hline \multirow[t]{3}{*}{$3.4 .1 c$} & SH-AGbenCh & 5903 & 5.02 & 0.11 & 1.02 & $\mathrm{RT} /<1.5 \mathrm{~h}, 50^{\circ} \mathrm{c} / 1.05 \mathrm{~h}, 100^{\circ} \mathrm{c} / 1.05 \mathrm{~h}, 150^{\circ} \mathrm{c} / 1 \mathrm{~h}$ \\
\hline & UTSH & 5903 & 5.02 & 0.11 & 1.04 & $\operatorname{RT} /<1.5 h, 50^{\circ} / 1.05 h, 100^{\circ} \mathrm{c} / 1.05 h, 150^{\circ} \mathrm{c} / 1 \mathrm{~h}$ \\
\hline & $8 / 30 / 2013(46)$ & & & & & \\
\hline 3.4.4a & SH-AGpilotB(200)/660M & 5903 & 4.99 & 0.11 & 1.02 & $\mathrm{RT} /<1 \mathrm{~h}, 50^{\circ} \mathrm{C} / 1,1 \mathrm{~h}, 100^{\circ} \mathrm{c} / 1.04 \mathrm{~h}, 150^{\circ} \mathrm{C} 1.1 \mathrm{~h}$ \\
\hline \multirow[t]{3}{*}{$3.4 .4 a$} & SH-AGpilotB(200)/G6OM & 5903 & 5.02 & 0.10 & 0.99 & $\operatorname{RT} /<1 \mathrm{~h}, 50^{\circ} \mathrm{C} / 1.1 \mathrm{~h}, 100^{\circ} \mathrm{C} / 1.04 \mathrm{.1}, 150^{\circ} \mathrm{C} 1.1 \mathrm{~h}$ \\
\hline & $\mathrm{CaCO}$ & 5903 & 5.00 & 0.10 & 2.05 & 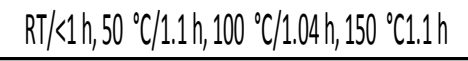 \\
\hline & Clay & 5903 & 4.99 & 0.10 & 0.70 & $\operatorname{RT} /<1$ h, $50^{\circ} \mathrm{C} / 1.1 \mathrm{~h}, 100^{\circ} \mathrm{C} / 1.04 \mathrm{Qh}, 150^{\circ} \mathrm{C} 1.1 \mathrm{~h}$ \\
\hline \multirow[t]{3}{*}{3.4 .16} & SH-AGbench & 5903 & 5.01 & 0.11 & 1.01 & $\operatorname{RT} /<1 \mathrm{~h}, 50^{\circ} \mathrm{c} / 1,1,1,100^{\circ} \mathrm{C} / 1.04 h, 150^{\circ} \mathrm{Cl1.1 \textrm {h }}$ \\
\hline & UTSH & 5903 & 5.03 & 0.10 & 1.00 & $\mathrm{RT} /<1 \mathrm{~h}, 50^{\circ} \mathrm{C} / 1,1 \mathrm{~h}, 100^{\circ} \mathrm{C} / 1.04 \mathrm{~h}, 150^{\circ} \mathrm{C} 1.1 \mathrm{~h}$ \\
\hline & $9 / 25 / 2013(46)$ & & & & & \\
\hline $3.57 \mathrm{a}$ & SH-a Cet1 & 5903 & 5.01 & 0.1 & 1.00 & $R T /<0.5 h / 50^{\circ} \mathrm{c} / 1 \mathrm{~h}, 100^{\circ} \mathrm{c} / 1 \mathrm{~h}, 150^{\circ} \mathrm{c} / 1 \mathrm{~h}$ \\
\hline 3.576 & SH-a Cet/asa & 5903 & 5.09 & 0.11 & 1.01 & $\mathrm{RT} / 0.5 \mathrm{sh} / 50^{\circ} \mathrm{C} / 1 \mathrm{~h}, 100^{\circ} \mathrm{c} / 1 \mathrm{~h}, 150^{\circ} \mathrm{c} / 1 \mathrm{~h}$ \\
\hline \multirow[t]{3}{*}{$3.57 c$} & SH-asa & 5903 & 5.01 & 0.11 & 0.99 & $\mathrm{RT} / 0.5 \mathrm{sh} / 50^{\circ} \mathrm{C} / 1 \mathrm{~h}, 100^{\circ} \mathrm{c} / 1 \mathrm{~h}, 150^{\circ} \mathrm{c} / 1 \mathrm{~h}$ \\
\hline & $\mathrm{CaCO}$ & 5903 & 4.98 & 0.1 & 1.99 & $\mathrm{RT} / / 0.5 \mathrm{~h} / 50^{\circ} \mathrm{c} / 1 \mathrm{~h}, 100^{\circ} \mathrm{c} / 1 \mathrm{~h}, 150^{\circ} \mathrm{c} / 1 \mathrm{~h}$ \\
\hline & UTSH & 5903 & 5.06 & 0.11 & 1.00 & $\mathrm{RT} / 0.5 \mathrm{sh} / 50^{\circ} \mathrm{C} / 1 \mathrm{~h}, 100^{\circ} \mathrm{C} / 1 \mathrm{~h}, 150^{\circ} \mathrm{C} / 1 \mathrm{~h}$ \\
\hline \multirow[t]{2}{*}{ 3.4.4a } & SH-AGälotB(200|G60M & 5903 & 4.99 & 0.11 & 1.00 & $\mathrm{RT} / 0.5 \mathrm{sh} / 50^{\circ} \mathrm{C} / 1 \mathrm{~h}, 100^{\circ} \mathrm{c} / 1 \mathrm{~h}, 150^{\circ} \mathrm{c} / 1 \mathrm{~h}$ \\
\hline & 10/7/2013(47a) & & & & & \\
\hline $3.4 .4 a$ & SH-AGpilotB(200)/G6OM & 5903 & 4.99 & 0.11 & 1.01 & $\mathrm{RT} / 11 \mathrm{~h}, 50^{\circ} \mathrm{c} / 1.05 \mathrm{sh}, 100^{\circ} \mathrm{C} \mathrm{ch}, 150^{\circ} \mathrm{C} / 1 \mathrm{~h}$ \\
\hline 3.4.4a & SH-AgajlobB(200) G6OM & 5903 & 5 & 0.10 & 1.02 & $\mathrm{RT} / 1 \mathrm{Lh}, 50^{\circ} \mathrm{c} / 1.05 \mathrm{~h}, 100^{\circ} \mathrm{Clh}, 150^{\circ} \mathrm{C} / 1 \mathrm{~h}$ \\
\hline 3.4.4a & SH-AGpilotB(200/G4U & 5903 & 5.03 & 0.10 & 1.04 & $\mathrm{RT} / 1 \mathrm{1h}, 50^{\circ} \mathrm{c} / 1.05 \mathrm{sh}, 100^{\circ} \mathrm{Clh}, 150^{\circ} \mathrm{c} / 1 \mathrm{~h}$ \\
\hline \multirow[t]{4}{*}{ 3.4.4a } & SH-AGpilotB(200)G4u & 5903 & 5.05 & 0.10 & 0.99 & $\mathrm{RT} / 11 \mathrm{~h}, 50^{\circ} \mathrm{c} / 1.05 \mathrm{sh}, 100^{\circ} \mathrm{C} \mathrm{ch}, 150^{\circ} \mathrm{C} / 1 \mathrm{~h}$ \\
\hline & $\mathrm{CaCO}$ & 5903 & 5.04 & 0.12 & 2.05 & $\mathrm{RT} / / 1 \mathrm{~h}, 50^{\circ} \mathrm{C} / 1.05 \mathrm{~h}, 100^{\circ} \mathrm{Clh}, 150^{\circ} \mathrm{c} / 1 \mathrm{~h}$ \\
\hline & Clay & 5903 & 5.03 & 0.10 & 1.00 & $\mathrm{RT} / 1 \mathrm{Lh}, 50^{\circ} \mathrm{c} / 1.05 \mathrm{sh}, 100^{\circ} \mathrm{Clh}, 150^{\circ} \mathrm{c} / 1 \mathrm{~h}$ \\
\hline & UTSH & 5903 & 5.04 & 0.10 & 1.00 & 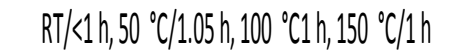 \\
\hline
\end{tabular}




\subsection{Method Uncertainty Assessment}

The validity and value of data obtained by any technique is only as good as the method repeatability, discernibility and its inherent limitations. Significant effort in refinement of this technique was expended to minimize the effects of filler settling, air entrapment and styrene loss, which all introduce some level of systemic error and uncertainty. It was found that gentle mixing to minimize air entrapment, higher viscosity and faster gelation of the material were beneficial to the method.

To demonstrate the utility of the method, an assessment of the internal reference specimen $\mathrm{CaCO}_{3}$ data for a total of 14 experimental sets were compared. One set was excluded because the weight change in the specimen was a loss which is known to be inaccurate. A weighing error or damage to the specimen likely occurred.

Figure 4.3 is the histogram for the $\mathrm{CaCO}_{3}$ filled casting weight gain at "1 day", which was actually 15 to 24 hours. Three sets had no 1 day measurements.

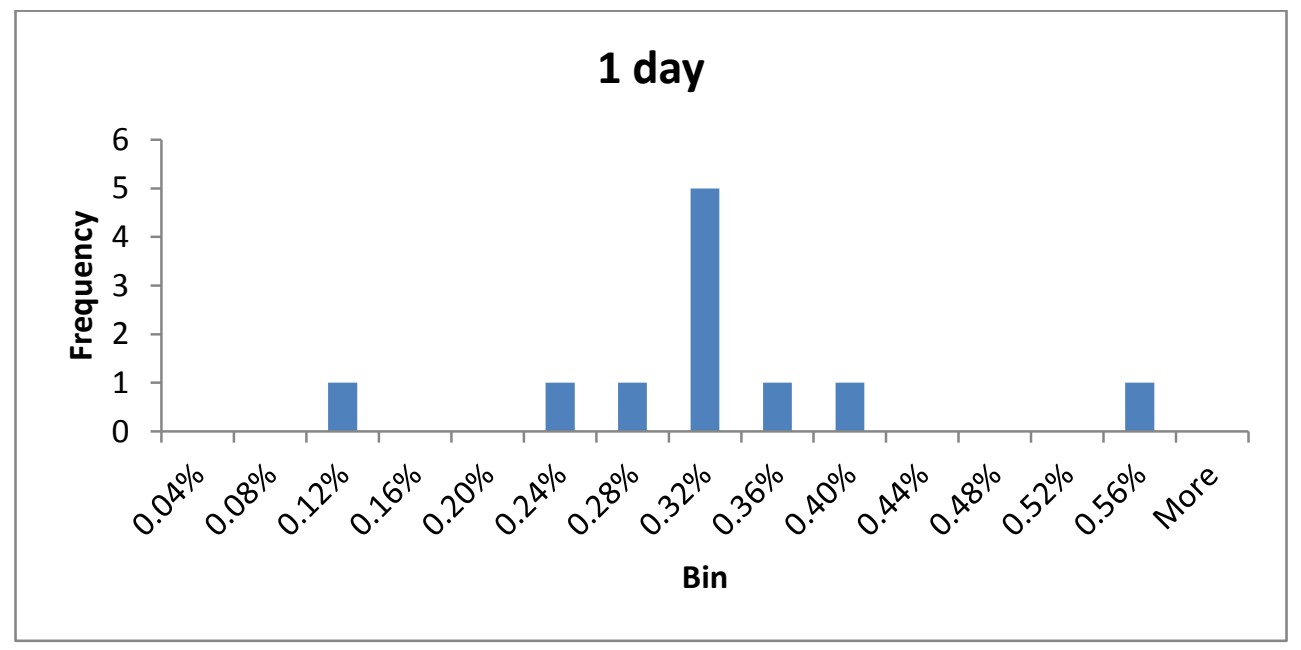

Figure 4.3: Control Data Repeatability 
For 1 day data, a normal distribution is seen with a fairly tight collection between 0.24 and $0.4 \%$ with 2 outliers. The average was $0.31 \%+/-0.11 \%$ standard deviation. Water absorption was also measured at longer times between 2 and 6 days. Since the weight gain continues to increase rather than reach a steady state, the data was converted to avg gain/ day (\%), as shown in Figure 4.4.

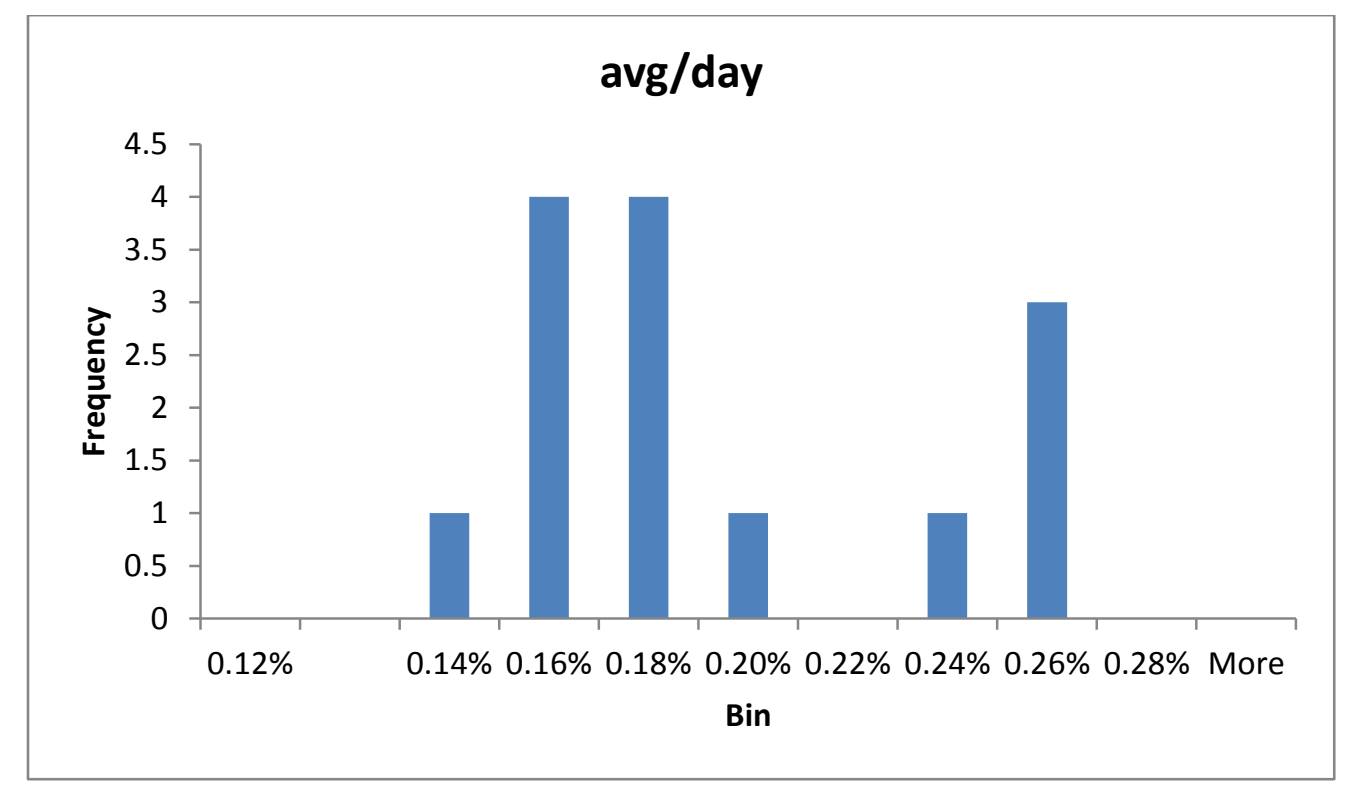

Figure 4.4: Average Weight Gain per Day

The distribution for the multiday average daily absorption is bimodal. In the analysis of this data, the 4 data points in the higher weight gain distribution were all from either 2 or 3 day readings. This is explained by observing the development of weight gain with time. As seen in Figure 4.5, the initial rate of absorption is greater than the rise after a slope reduction at roughly 3 days. This trend was true for all of the samples. 


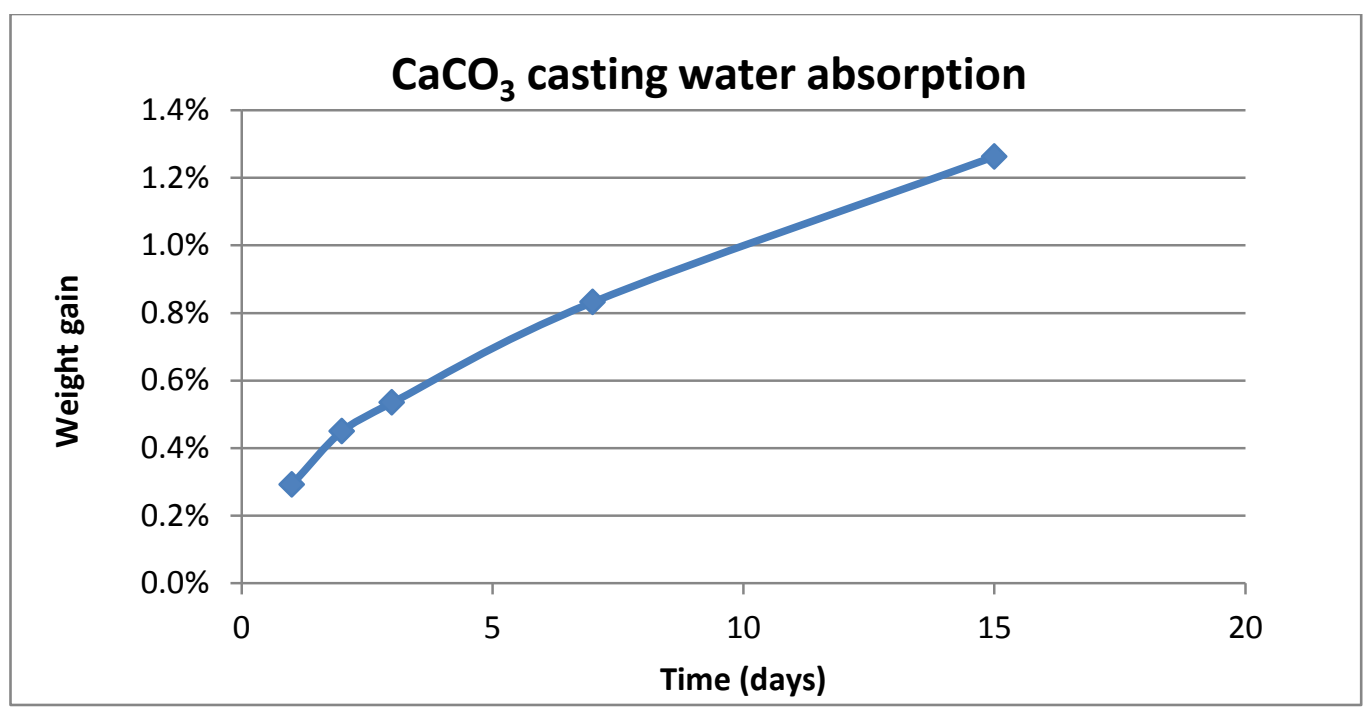

Figure 4.5: Water Weight Gain with Time

The resin only castings had longer term water absorptions, which were slightly lower than the internal $\mathrm{CaCO}_{3}$ specimens, as evidenced by the normalized multiday values $<1$. The SF-MeOH blanks are filled with soy flour that were rinsed with $\mathrm{MeOH}$ and filtered for comparison to treatments that were either applied in solution in $\mathrm{MeOH}$ or rinsed with $\mathrm{MeOH}$. The UTSF and UTSH are the untreated soy flour and hulls, respectively. All of these samples had significantly higher water absorption than the $\mathrm{CaCO}_{3}$ references with normalized multiday values between 4.5 and 7.4. The three precursor data sets, which overlap, are plotted together in figure 4.6, showing what appears to be a normal distribution.

- To minimize the error due to the slope change, the weight gains for the soy filler specimens were normalized $(\mathrm{N})$ by dividing them by the $\mathrm{CaCO}_{3}$ sample weight gain included in each set. Data, with normalized values, for resin only castings and several of the "untreated" precursor samples is seen in Table 4.2. 
Table 4.2: Resin Only and Precursor Weight Gain

\begin{tabular}{|c|c|c|c|c|c|}
\hline & \multicolumn{2}{|c|}{ wt gain } & & \multicolumn{2}{c|}{ normalized wt gain } \\
\hline Sample & 1 day & multiple days & avg/day & N1 day & N multiday \\
\hline Resin only & $0.27 \%$ & $0.39 \%$ & $0.13 \%$ & 1.05 & 0.86 \\
\hline Resin only & $0.34 \%$ & $0.56 \%$ & $0.14 \%$ & 0.61 & 0.73 \\
\hline SF-MeOH Blank & $2.00 \%$ & $3.18 \%$ & $1.59 \%$ & 6.29 & 6.61 \\
\hline SF-MeOH Blank & $1.35 \%$ & $5.05 \%$ & $0.84 \%$ & 4.31 & 6.43 \\
\hline SF-MeOH Blank & & $4.37 \%$ & $0.87 \%$ & & 5.46 \\
\hline SF-MeOH Blank & $1.27 \%$ & $3.16 \%$ & $1.05 \%$ & 4.36 & 5.91 \\
\hline UTSF & $1.72 \%$ & $3.95 \%$ & $1.32 \%$ & 5.89 & 7.39 \\
\hline UTSF & $1.57 \%$ & $3.10 \%$ & $1.03 \%$ & 6.54 & 6.60 \\
\hline UTSH & $2.05 \%$ & $4.11 \%$ & $1.37 \%$ & 6.20 & 5.88 \\
\hline UTSH & $1.72 \%$ & $4.24 \%$ & $1.06 \%$ & 5.71 & 6.52 \\
\hline UTSH & & $5.60 \%$ & $1.87 \%$ & & 7.31 \\
\hline UTSH & & $3.84 \%$ & $1.28 \%$ & & 4.95 \\
\hline UTSH & $2.42 \%$ & $4.98 \%$ & $1.00 \%$ & 6.20 & 6.02 \\
\hline
\end{tabular}

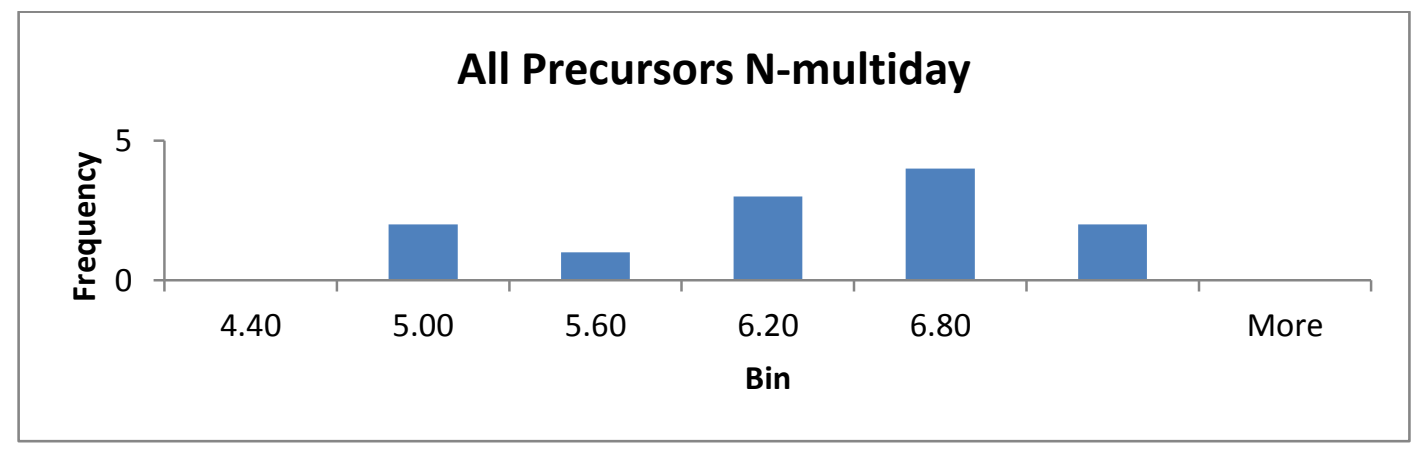

Figure 4.6: Distribution for all Precursor Samples

The method is capable of discerning intermediate performance between untreated soy and the $\mathrm{CaCO}_{3}$ references. The average for the precursor set is $6.1 \%+/-2.1 \%$ standard deviation. A significantly effective treatment, therefore, is defined as one that reduces the normalized multiday water absorption weight gain to less than $4 \%$. Table 4.3 
shows the results for each experimental data set. N\# indicates the number of days used in the multiday calculation.

Table 4.3: Weight Gain Data for Treated Fillers

\begin{tabular}{|c|c|c|c|c|c|c|}
\hline Sample & Date (labbook page) & wt gain & wt gain & wt gain & normalize & $\mathrm{CaCO}_{3}$ \\
\hline & $9 / 14 / 2012(06)$ & 1 day & 3 day & avg/day & N1 & N3 \\
\hline 3.5.5a & SF-MeOH & $1.50 \%$ & $5.75 \%$ & $1.92 \%$ & & \\
\hline 3.5.3a & SF-merc & $2.58 \%$ & $3.48 \%$ & $1.16 \%$ & & \\
\hline 3.5.1a & SF-merc+WC & $1.60 \%$ & $4.66 \%$ & $1.55 \%$ & & \\
\hline $3.5 .1 b$ & SF-WC & $3.13 \%$ & $6.66 \%$ & $2.22 \%$ & & \\
\hline 3.5.4a & SF-APTMS & $1.39 \%$ & $4.77 \%$ & $1.59 \%$ & & \\
\hline $3.5 .4 b$ & SF-MOPTMS & $0.89 \%$ & $3.50 \%$ & $1.17 \%$ & & \\
\hline $3.5 .4 \mathrm{c}$ & SF-OTES-1 & $0.67 \%$ & $1.49 \%$ & $0.50 \%$ & & \\
\hline $3.5 .4 \mathrm{~d}$ & SF-GOPTMS & $0.96 \%$ & $3.53 \%$ & $1.18 \%$ & & \\
\hline 3.5.4e & SF-OVTES & $1.08 \%$ & $2.46 \%$ & $0.82 \%$ & & \\
\hline \multirow[t]{3}{*}{$3.5 .4 \mathrm{f}$} & SF-VGS & $0.81 \%$ & $2.67 \%$ & $0.89 \%$ & & \\
\hline & $9 / 28 / 2012(13)$ & 1 day & 4 day & avg/day & N1 & N4 \\
\hline & $\mathrm{CaCO} 3$ & $0.56 \%$ & $0.77 \%$ & $0.19 \%$ & 1.00 & 1.00 \\
\hline $3.5 .5 \mathrm{a}$ & SF-MeOH & $1.24 \%$ & $2.38 \%$ & $0.60 \%$ & 2.22 & 3.08 \\
\hline $3.5 .4 \mathrm{c}$ & SF-OTES-1 & $2.61 \%$ & $4.46 \%$ & $1.12 \%$ & 4.68 & 5.77 \\
\hline $3.5 .4 \mathrm{~g}$ & SF-OTES-2 & $2.59 \%$ & $3.97 \%$ & $0.99 \%$ & 4.65 & 5.13 \\
\hline 3.5.4h & SF-OTES-3 & $0.92 \%$ & $2.18 \%$ & $0.55 \%$ & 1.65 & 2.82 \\
\hline $3.5 .4 \mathrm{i}$ & SF-OTES-4 & $3.00 \%$ & $3.97 \%$ & $0.99 \%$ & 5.39 & 5.13 \\
\hline \multirow[t]{4}{*}{ 3.5.4j } & SF-OTES-5 & $0.63 \%$ & $1.81 \%$ & $0.45 \%$ & 1.14 & 2.34 \\
\hline & resin only & $0.34 \%$ & $0.56 \%$ & $0.14 \%$ & 0.61 & 0.73 \\
\hline & $10 / 5 / 12(16)$ & 1 day & 2 day & avg/day & N1 & N2 \\
\hline & UTSF & $2.57 \%$ & $3.65 \%$ & $1.82 \%$ & 8.11 & 7.58 \\
\hline $3.5 .4 \mathrm{j}$ & SF-OTES-5 & $1.90 \%$ & $3.14 \%$ & $1.57 \%$ & 6.00 & 6.53 \\
\hline $3.5 .4 \mathrm{c}$ & SF-OTES-1 & $1.57 \%$ & $2.42 \%$ & $1.21 \%$ & 4.95 & 5.02 \\
\hline \multirow[t]{4}{*}{$3.5 .5 a$} & SF-MeOH & $2.00 \%$ & $3.18 \%$ & $1.59 \%$ & 6.29 & 6.61 \\
\hline & $\mathrm{CaCO} 3$ & $0.32 \%$ & $0.48 \%$ & $0.24 \%$ & 1.00 & 1.00 \\
\hline & $10 / 8 / 2012(17)$ & 1 day & 6 day & avg/day & N1 & N6 \\
\hline & $\mathrm{CaCO} 3$ & $0.31 \%$ & $0.78 \%$ & $0.13 \%$ & 1.00 & 1.00 \\
\hline $3.5 .5 \mathrm{a}$ & SF-MeOH & $1.35 \%$ & $5.05 \%$ & $0.84 \%$ & 4.31 & 6.43 \\
\hline 3.5.4j & SF-OTES-5 & $1.95 \%$ & $7.19 \%$ & $1.20 \%$ & 6.21 & 9.17 \\
\hline 3.5.4h & SF-OTES-3 & $1.32 \%$ & $5.13 \%$ & $0.86 \%$ & 4.20 & 6.55 \\
\hline $3.5 .4 \mathrm{c}$ & SF-OTES-1 & $1.26 \%$ & $5.03 \%$ & $0.84 \%$ & 4.01 & 6.41 \\
\hline $3.5 .4 b$ & SF-MOPTMS & $1.19 \%$ & $4.78 \%$ & $0.80 \%$ & 3.80 & 6.10 \\
\hline $3.5 .4 \mathrm{e}$ & SF-OVTES & $1.43 \%$ & $5.07 \%$ & $0.85 \%$ & 4.56 & 6.47 \\
\hline 3.5.4f & SF-VGS & $1.31 \%$ & $4.81 \%$ & $0.80 \%$ & 4.19 & 6.13 \\
\hline
\end{tabular}


Table 4.3: Weight Gain Data for Treated Fillers, continued

\begin{tabular}{|c|c|c|c|c|c|c|}
\hline & $10 / 9 / 2012(18)$ & & 5 day & avg/day & N1 & N5 \\
\hline $3.5 .4 f$ & SF-VGS & & $3.98 \%$ & $0.80 \%$ & & 4.97 \\
\hline $3.5 .4 \mathrm{c}$ & SF-OTES-1 & & $3.79 \%$ & $0.76 \%$ & & 4.73 \\
\hline $3.5 .5 a$ & SF-MeOH & & $4.37 \%$ & $0.87 \%$ & & 5.46 \\
\hline \multirow[t]{2}{*}{$3.5 .4 b$} & SF-MOPTMS & & $3.77 \%$ & $0.75 \%$ & & 4.71 \\
\hline & $\mathrm{CaCO} 3$ & & $0.80 \%$ & $0.16 \%$ & & 1.00 \\
\hline $3.5 .4 \mathrm{j}$ & SF-OTES-5 & & $5.98 \%$ & $1.20 \%$ & & 7.46 \\
\hline $3.5 .4 \mathrm{e}$ & SF-OVTES & & $3.96 \%$ & $0.79 \%$ & & 4.95 \\
\hline \multirow[t]{3}{*}{ 3.5.4h } & SF-OTES-3 & & $3.78 \%$ & $0.76 \%$ & & 4.72 \\
\hline & DDG-SE & & $5.82 \%$ & $1.16 \%$ & & 7.27 \\
\hline & $10 / 15 / 2012(21)$ & 1 day & 3 day & avg/day & N1 & N3 \\
\hline $3.5 .5 a$ & SF-MeOH & $1.27 \%$ & $3.16 \%$ & $1.05 \%$ & 4.36 & 5.91 \\
\hline \multirow[t]{2}{*}{$3.5 .4 b$} & SF-MOPTMS & $0.96 \%$ & $2.42 \%$ & $0.81 \%$ & 3.30 & 4.53 \\
\hline & UTSF & $1.72 \%$ & $3.95 \%$ & $1.32 \%$ & 5.89 & 7.39 \\
\hline \multirow[t]{8}{*}{ 3.6.1a } & SF- acet1 & $1.57 \%$ & $3.20 \%$ & $1.07 \%$ & 5.40 & 5.98 \\
\hline & $\mathrm{CaCO} 3$ & $0.29 \%$ & $0.53 \%$ & $0.18 \%$ & 1.00 & 1.00 \\
\hline & $10 / 30 / 2012(27)$ & 1 day & 4 day & avg/day & N1 & N4 \\
\hline & SPC & $1.24 \%$ & $2.83 \%$ & $0.71 \%$ & 4.27 & 4.60 \\
\hline & EtOH SPI & $0.95 \%$ & $2.21 \%$ & $0.55 \%$ & 3.29 & 3.60 \\
\hline & Heat SPI & $1.06 \%$ & $2.34 \%$ & $0.58 \%$ & 3.68 & 3.80 \\
\hline & UTSF & $1.99 \%$ & $4.62 \%$ & $1.15 \%$ & 6.89 & 7.51 \\
\hline & $\mathrm{CaCO} 3$ & $0.29 \%$ & $0.61 \%$ & $0.15 \%$ & 1.00 & 1.00 \\
\hline $3.6 .3 b$ & SF- acet6 & $0.76 \%$ & $2.05 \%$ & $0.51 \%$ & 2.62 & 3.33 \\
\hline $3.6 .3 b$ & SF- acet6 & $0.91 \%$ & $2.22 \%$ & $0.56 \%$ & 3.15 & 3.61 \\
\hline \multirow[t]{2}{*}{$3.6 .3 b$} & SF- acet6 & $0.88 \%$ & $1.88 \%$ & $0.47 \%$ & 3.04 & 3.06 \\
\hline & 05/17/2013 (37a) & 1 day & 3 day & avg/day & N1 & N3 \\
\hline \multirow[t]{2}{*}{ 3.4.3a } & SM-AGpilotC & $3.70 \%$ & $5.60 \%$ & $1.87 \%$ & 15.42 & 11.91 \\
\hline & $\mathrm{CaCO} 3$ & $0.24 \%$ & $0.47 \%$ & $0.16 \%$ & 1.00 & 1.00 \\
\hline \multirow[t]{2}{*}{$3.4 .1 \mathrm{~b}$} & SM-AGbench & $0.74 \%$ & $1.63 \%$ & $0.54 \%$ & 3.08 & 3.47 \\
\hline & UTSF & $1.57 \%$ & $3.10 \%$ & $1.03 \%$ & 6.54 & 6.60 \\
\hline \multirow[t]{3}{*}{ 3.4.1a } & SM-AGLbench & $1.33 \%$ & $3.10 \%$ & $1.03 \%$ & 5.54 & 6.60 \\
\hline & $6 / 25 / 2013$ (38a) & 1 day & 3 day & avg/day & N1 & N3 \\
\hline & UTSH & $2.05 \%$ & $4.11 \%$ & $1.37 \%$ & 6.20 & 5.88 \\
\hline $3.4 .1 b$ & SM-AGbench & $0.97 \%$ & $2.25 \%$ & $0.75 \%$ & 2.93 & 3.22 \\
\hline \multirow[t]{2}{*}{$3.4 .1 \mathrm{c}$} & SH-AGbench & $1.10 \%$ & $2.23 \%$ & $0.74 \%$ & 3.31 & 3.18 \\
\hline & $\mathrm{CaCO} 3$ & $0.33 \%$ & $0.70 \%$ & $0.23 \%$ & 1.00 & 1.00 \\
\hline
\end{tabular}


Table 4.3: Weight Gain Data for Treated Fillers, continued

\begin{tabular}{|c|c|c|c|c|c|c|}
\hline & $07 / 11 / 13$ (39) & 1 day & 4 day & avg/day & N1 & N4 \\
\hline & $\mathrm{CaCO} 3$ & $0.30 \%$ & $0.65 \%$ & $0.16 \%$ & 1.00 & 1.00 \\
\hline & UTSH & $1.72 \%$ & $4.24 \%$ & $1.06 \%$ & 5.71 & 6.52 \\
\hline $3.4 .3 b$ & SH-AGpilotCG1 & $15.12 \%$ & $25.05 \%$ & $6.26 \%$ & 50.28 & 38.53 \\
\hline \multirow[t]{6}{*}{$3.4 .3 \mathrm{~b}$} & SH-AGpilotCG2 & $13.06 \%$ & $13.31 \%$ & $3.33 \%$ & 43.41 & 20.48 \\
\hline & ATH & $0.49 \%$ & $1.38 \%$ & $0.35 \%$ & 1.63 & 2.12 \\
\hline & $8 / 6 / 2013$ (44) & 1 day & 4 day & avg/day & N1 & N4 \\
\hline & $\mathrm{CaCO} 3$ & $-0.02 \%$ & $0.25 \%$ & $0.06 \%$ & 1.00 & 1.00 \\
\hline & Clay & $1.99 \%$ & $3.61 \%$ & $0.90 \%$ & -99.71 & 14.68 \\
\hline & UTSH & $1.91 \%$ & $4.25 \%$ & $1.06 \%$ & -95.62 & 17.28 \\
\hline $3.4 .1 \mathrm{c}$ & SH-AGbench & $0.96 \%$ & $2.11 \%$ & $0.53 \%$ & -48.19 & 8.60 \\
\hline $3.7 .2 \mathrm{a}$ & SH-acet2 & $1.28 \%$ & $2.95 \%$ & $0.74 \%$ & -64.17 & 11.99 \\
\hline $3.7 .2 b$ & SH-Agbench-Torr & $0.97 \%$ & $2.25 \%$ & $0.56 \%$ & -48.63 & 9.16 \\
\hline $3.7 .3 a$ & SH-Agbench-OTES & $1.08 \%$ & $2.63 \%$ & $0.66 \%$ & -53.85 & 10.70 \\
\hline $3.7 .3 b$ & SH-OTES & $2.09 \%$ & $5.31 \%$ & $1.33 \%$ & -104.54 & 21.58 \\
\hline \multirow[t]{2}{*}{$3.7 .3 \mathrm{c}$} & SPC-OTES & $1.46 \%$ & $3.30 \%$ & $0.83 \%$ & -73.00 & 13.42 \\
\hline & SPC & $1.35 \%$ & $2.78 \%$ & $0.70 \%$ & -67.25 & 11.31 \\
\hline \multirow[t]{2}{*}{ 3.7.4a } & SPC-APTMS & $1.88 \%$ & $4.45 \%$ & $1.11 \%$ & -93.82 & 18.12 \\
\hline & SPI & $1.32 \%$ & $2.74 \%$ & $0.68 \%$ & -65.82 & 11.14 \\
\hline \multirow[t]{2}{*}{ 3.7.1a } & SPI-acet1 & $1.42 \%$ & $3.29 \%$ & $0.82 \%$ & -70.89 & 13.37 \\
\hline & $8 / 22 / 2013$ (44a) & 1 day & 3 day & avg/day & N1 & N3 \\
\hline $3.4 .2 b$ & SH-MF1 & & $3.63 \%$ & $1.21 \%$ & & 4.73 \\
\hline $3.4 .2 \mathrm{c}$ & SH-MF2 & & $4.02 \%$ & $1.34 \%$ & & 5.24 \\
\hline $3.4 .2 \mathrm{e}$ & SH-MF3 & & $3.88 \%$ & $1.29 \%$ & & 5.07 \\
\hline $3.4 .2 \mathrm{~d}$ & SH-MF34 & & $5.31 \%$ & $1.77 \%$ & & 6.93 \\
\hline \multirow[t]{3}{*}{$3.4 .3 \mathrm{~b}$} & SH-AGpilotCG7.6u & & $5.47 \%$ & $1.82 \%$ & & 7.13 \\
\hline & $\mathrm{CaCO} 3$ & & $0.77 \%$ & $0.26 \%$ & & 1.00 \\
\hline & Clay & & $1.95 \%$ & $0.65 \%$ & & 2.55 \\
\hline \multirow[t]{3}{*}{$3.4 .1 \mathrm{c}$} & SH-AGbench & & $2.54 \%$ & $0.85 \%$ & & 3.31 \\
\hline & UTSH & & $5.60 \%$ & $1.87 \%$ & & 7.31 \\
\hline & $8 / 30 / 2013(45)$ & 1 day & 3 day & avg/day & N1 & N5 \\
\hline 3.4.4a & SH-AGpilotB(200)G60M & & $1.51 \%$ & $0.50 \%$ & & 1.95 \\
\hline \multirow[t]{3}{*}{ 3.4.4a } & SH-AGpilotB(200)G60M & & $2.13 \%$ & $0.71 \%$ & & 2.75 \\
\hline & $\mathrm{CaCO} 3$ & & $0.77 \%$ & $0.26 \%$ & & 1.00 \\
\hline & Clay & & $1.00 \%$ & $0.33 \%$ & & 1.29 \\
\hline \multirow[t]{2}{*}{ 3.4.1c } & SH-AGbench & & $1.61 \%$ & $0.54 \%$ & & 2.08 \\
\hline & UTSH & & $3.84 \%$ & $1.28 \%$ & & 4.95 \\
\hline
\end{tabular}


Table 4.3: Weight Gain Data for Treated Fillers, continued

\begin{tabular}{|c|c|c|c|c|c|c|}
\hline & $9 / 25 / 2013$ (46) & 1 day & 5 day & avg/day & N1 & N5 \\
\hline $3.5 .7 a$ & SH-acet1 & $1.01 \%$ & $2.12 \%$ & $0.42 \%$ & 2.58 & 2.56 \\
\hline $3.5 .7 b$ & SH-acet/asa & $0.81 \%$ & $1.93 \%$ & $0.39 \%$ & 2.08 & 2.33 \\
\hline $3.5 .7 \mathrm{c}$ & SH-asa & $0.94 \%$ & $2.34 \%$ & $0.47 \%$ & 2.42 & 2.84 \\
\hline & CaCO3 & $0.39 \%$ & $0.83 \%$ & $0.17 \%$ & 1.00 & 1.00 \\
\hline & UTSH & $2.42 \%$ & $4.98 \%$ & $1.00 \%$ & 6.20 & 6.02 \\
\hline $3.4 .4 a$ & SH-AGpilotB(200)G60M & $1.53 \%$ & $1.82 \%$ & $0.36 \%$ & 3.93 & 2.20 \\
\hline & $10 / 7 / 2013(47 a)$ & 1 day & 5 day & avg/day & N1 & N5 \\
\hline $3.4 .4 a$ & SH-AGpilotB(200)G60M & $0.80 \%$ & $2.10 \%$ & $0.42 \%$ & 9.04 & 2.52 \\
\hline $3.4 .4 a$ & SH-AGpilotB(200)G60M & $0.78 \%$ & $2.10 \%$ & $0.42 \%$ & 8.89 & 2.51 \\
\hline $3.4 .4 a$ & SH-AGpilotB(200)G4u & $2.27 \%$ & $8.27 \%$ & $1.65 \%$ & 25.77 & 9.90 \\
\hline $3.4 .4 a$ & SH-AGpilotB(200)G4u & $2.41 \%$ & $8.03 \%$ & $1.61 \%$ & 27.35 & 9.61 \\
\hline & CaCO3 & $0.09 \%$ & $0.84 \%$ & $0.17 \%$ & 1.00 & 1.00 \\
\hline & Clay & $0.53 \%$ & $1.73 \%$ & $0.35 \%$ & 6.07 & 2.07 \\
\hline & UTSH & $1.27 \%$ & $3.76 \%$ & $0.75 \%$ & 14.44 & 4.50 \\
\hline
\end{tabular}

\subsection{Discussion}

The water absorption data was analyzed to determine which treatments provided promising fillers. Other attributes for filler performance were explored in Chapter V.

\subsubsection{Refined Soy Flour}

Table 4.4 reports data for the refined soy flour samples. Note that all of the values were normalized by the $\mathrm{CaCO}_{3}$ results for the first 3.3.1 set, because the $\mathrm{CaCO}_{3}$ sample from the second 3.3.2 set had a weight loss. 
Table 4.4 Refined Sample Normalized Weight Gain

\begin{tabular}{|c|c|c|c|}
\hline Treatment ID & Sample name & $\begin{array}{c}\text { normalized } \mathrm{H}_{2} \mathrm{O} \\
\text { Absorption } \mathrm{N} \\
\left(\mathrm{xCaCO}_{3}\right)\end{array}$ & $\begin{array}{c}\text { normalized } \mathrm{H}_{2} \mathrm{O} \\
\text { Absorption } \mathrm{N} \\
\left(\mathrm{xCaCO}_{3}\right) \\
\end{array}$ \\
\hline & & N1 & N4 \\
\hline 3.3 .1 & SPC & 4.27 & 4.60 \\
\hline 3.3.1 & SPC & 4.47 & 4.28 \\
\hline 3.3.2a & EtOH SPI & 3.29 & 3.60 \\
\hline $3.3 .2 b$ & Heat SPI & 3.68 & 3.80 \\
\hline \multirow[t]{5}{*}{$3.3 .2 b$} & Heat SPI & 4.38 & 4.22 \\
\hline & UTSF & 6.89 & 7.51 \\
\hline & UTSH & 6.36 & 6.54 \\
\hline & $\mathrm{CaCO} 3$ & 1.00 & 1.00 \\
\hline & Clay & 6.63 & 5.55 \\
\hline
\end{tabular}

Normalized results are seen in Figure 4.7. All of the soy fillers had significantly higher water absorption than the $\mathrm{CaCO}_{3}$ control. The refined fillers had significantly lower absorption than the untreated samples and a clay filled sample. The ethanol precipitated SPI had the lowest absorption of the soy fillers but was still over $3 \mathrm{x}$ that of the $\mathrm{CaCO}_{3}$ filled samples.

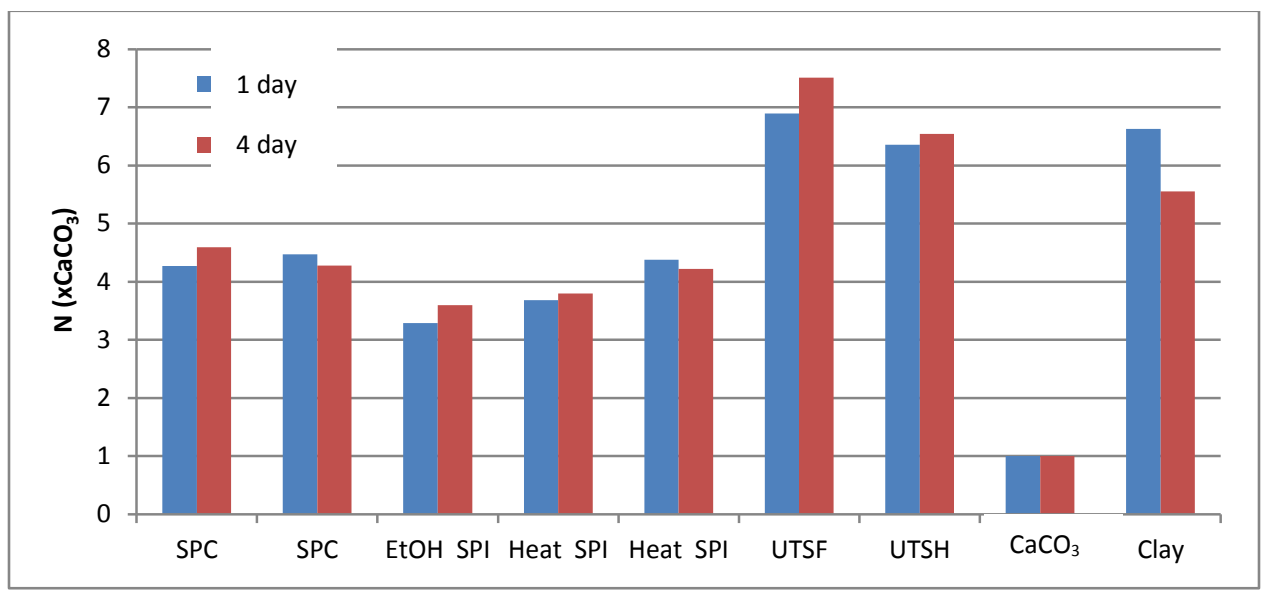

Figure 4.7: Refined Soy Filler Water Absorption 


\subsubsection{Torrefacted Soy Meal and Hulls}

Table 4.5 summarizes the sample description and results for water absorption tests for resin castings with the heat treated fillers. MV and MA are the volume average and area average diameter for the fillers.

Table 4.5: Summary of Heat Treated Soy Fillers

\begin{tabular}{|c|c|c|c|c|c|c|c|c|c|c|c|}
\hline $\begin{array}{c}\text { treatment } \\
\text { ID }\end{array}$ & precursor-process unit & sample & $\begin{array}{c}\text { normalized } \mathrm{H}_{2} \mathrm{O} \\
\text { Absorption } \mathrm{N} \\
\left(\mathrm{xCaCO}_{3}\right)\end{array}$ & $\begin{array}{c}\text { torrefaction } \\
\text { method }\end{array}$ & $\begin{array}{l}\text { torrefaction } \\
\text { temperature }\end{array}$ & time & notes & color & $\begin{array}{l}\text { grind } \\
\text { method }\end{array}$ & $\begin{array}{c}\mathrm{Mv} \\
\text { (micron) }\end{array}$ & $\begin{array}{c}\text { MA } \\
\text { (micron) }\end{array}$ \\
\hline & UTSF & $\begin{array}{l}\text { untreated } \\
\text { soy flour }\end{array}$ & 6.5 & none & na & na & & $\tan$ & $\begin{array}{c}\text { as } \\
\text { received }\end{array}$ & 50 & 13 \\
\hline 3.4.1a & SM-AGLbench & $\begin{array}{c}\text { light bench } \\
\text { meal }\end{array}$ & 6.5 & pan w foil & $250^{\circ} \mathrm{C}$ & $35 \mathrm{~min}$ & & brown & 60 mesh & $<325$ & \\
\hline $3.4 .1 b$ & SM-AGbench & bench meal & 3.5 & pan w foil & $288^{\circ} \mathrm{C}$ & $15 \mathrm{~min}$ & & black & 60 mesh & $<325$ & \\
\hline 3.4.3a & SM-AGpilotC & pilot meal & 12 & pilot unit & $\begin{array}{l}\max \\
300^{\circ} \mathrm{C}\end{array}$ & $3 \mathrm{~min}$ & contaminated & black & 60 mesh & $<325$ & \\
\hline & UTSH & $\begin{array}{l}\text { untreated } \\
\text { soy hulls }\end{array}$ & 4.9 & none & & & & $\tan$ & 60 mesh & $<325$ & \\
\hline $3.4 .1 \mathrm{c}$ & SH-AGbench & bench hulls & 2.3 & pan w foil & $288^{\circ} \mathrm{C}$ & $15 \mathrm{~min}$ & & black & 60 mesh & $<325$ & \\
\hline $3.4 .2 b$ & SH-MF1 & $\begin{array}{c}\text { muffle oven } \\
\text { hulls }\end{array}$ & 4.7 & $\begin{array}{c}\text { muffle oven } \\
\text { N2 }\end{array}$ & $400^{\circ} \mathrm{C}$ & $21 \mathrm{~min}$ & $\begin{array}{c}\text { no water or } \\
\text { oven }\end{array}$ & black & $M \& P$ & $?$ & \\
\hline $3.4 .2 \mathrm{C}$ & SH-MF2 & $\begin{array}{c}\text { muffle oven } \\
\text { hulls }\end{array}$ & 5.2 & $\begin{array}{c}\text { muffle oven } \\
\text { N2 }\end{array}$ & $400^{\circ} \mathrm{C}$ & $21 \mathrm{~min}$ & no water & black & M\&P & $?$ & \\
\hline $3.4 .2 \mathrm{~d}$ & SH-MF3 & $\begin{array}{c}\text { muffle oven } \\
\text { hulls }\end{array}$ & 5.1 & $\begin{array}{c}\text { muffle oven } \\
\text { N2 }\end{array}$ & $400^{\circ} \mathrm{C}$ & $21 \mathrm{~min}$ & water quench & black & M\&P & $?$ & \\
\hline 3.4.2e & SH-MF4 & $\begin{array}{c}\text { muffle oven } \\
\text { hulls }\end{array}$ & 6.9 & $\begin{array}{c}\text { muffle oven } \\
\text { N2 }\end{array}$ & $400^{\circ} \mathrm{C}$ & $21 \mathrm{~min}$ & $\begin{array}{c}\text { water after } \\
\text { cool }\end{array}$ & black & M\&P & $?$ & \\
\hline $3.4 .3 b$ & SH-AGpilotC & pilot hulls & 4.9 & pilot unit & $\begin{array}{c}\max \\
{ }^{\circ} \mathrm{C}\end{array}$ & $3 \mathrm{~min}$ & & black & clumpy & 25 & 8 \\
\hline $3.4 .4 a$ & SH-AGpilotB(200) & $\begin{array}{c}\text { pilot batch } \\
\text { hulls }\end{array}$ & 2.8 & $\begin{array}{c}\text { large batch } \\
\text { unit }\end{array}$ & $500^{\circ} \mathrm{C}$ & $10 \mathrm{~min}$ & & black & 60 mesh & $<325$ & \\
\hline
\end{tabular}


Figure 4.8 plots the normalized weight gain vs. the time duration of the treatment (in minutes) multiplied by the treatment temperature. With the exception of the wood contaminated meal sample 3.4.3a, the data indicates optimum intermediate treatment intensity (as defined as the time $\mathrm{x}$ temperature product) for minimum water absorption. This optimal range had treatment intensity characterized by 4000 to $5000{ }^{\circ} \mathrm{C}$-min. Results were similar at $\sim 50 \%$ reduction of water absorption with treatments at $288{ }^{\circ} \mathrm{C}$ for $15 \mathrm{~min}$ and $500{ }^{\circ} \mathrm{C}$ for $10 \mathrm{~min}$.

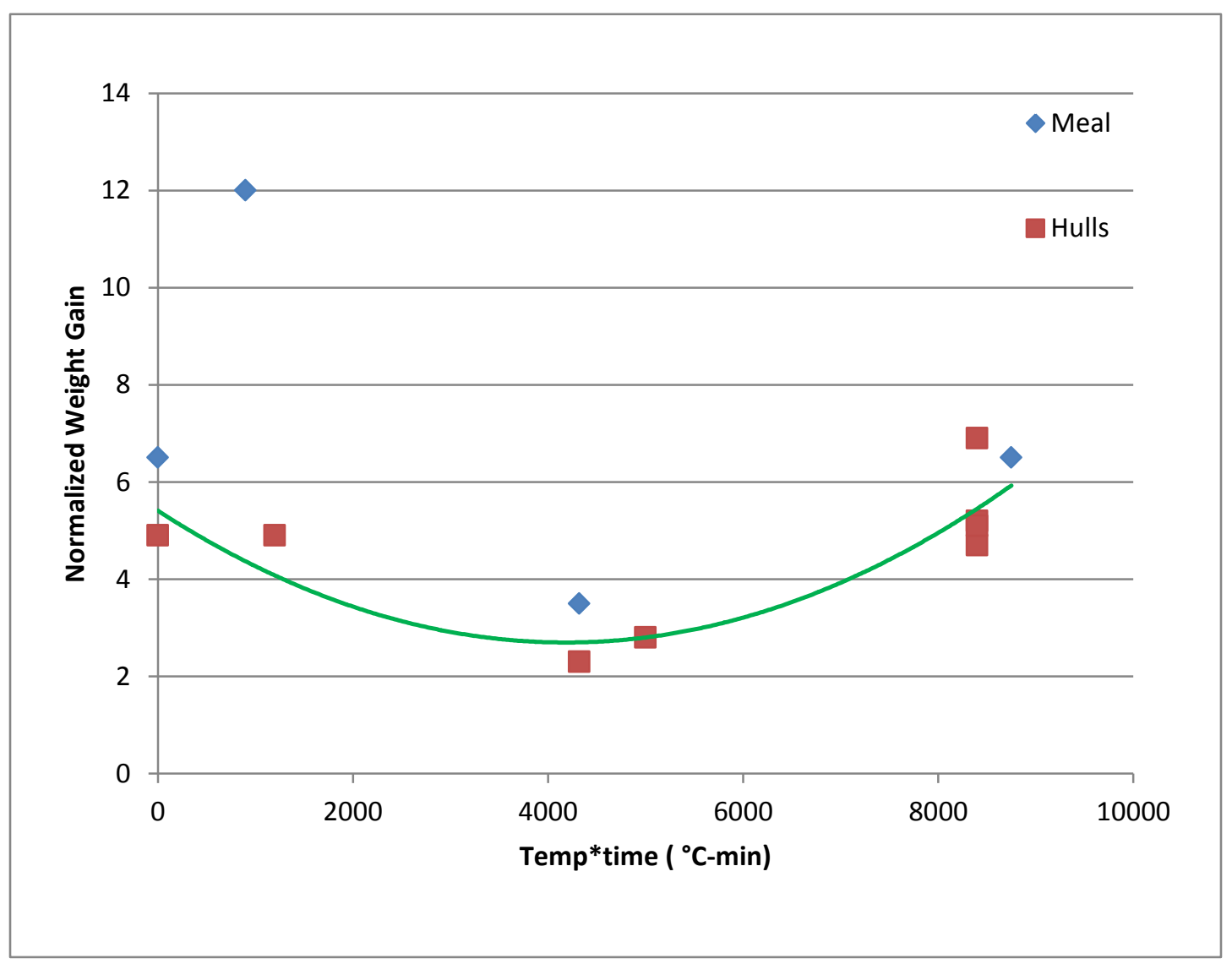

Figure 4.8: Normalized Weight Gain v. Time -Temperature for Heat Treated Fillers 


\subsubsection{Chemical Treatments}

Table 4.6 summarizes the sample description and results for water absorption tests for the resin castings with chemically treated fillers. Figure 4.7 displays the data graphically where the dotted lines are the untreated precursor absorption for each set.

Table 4.6: Summary of Chemically Treated Soy Fillers

\begin{tabular}{|c|c|c|c|c|c|c|}
\hline $\begin{array}{l}\text { treatment } \\
\text { ID }\end{array}$ & $\begin{array}{l}\text { precusor - } \\
\text { treatment }\end{array}$ & treatment & yield \% & $\begin{array}{l}\text { normalized } \mathrm{H} 2 \mathrm{O} \\
\text { Absorption } \\
\left(\mathrm{xCaCO}_{3}\right)\end{array}$ & process & time \\
\hline & UTSF & untreated soy flour & & 6.5 & none & \\
\hline 3.5.1a & SF-WC & wax coated flour & 89 & 7.8 & slurry & $20 \mathrm{~min}$ \\
\hline $3.5 .1 \mathrm{~b}$ & SF-merc+WC & mercerated + wax coated flour & 85 & 11.1 & slurry & $30 / 20 \mathrm{~min}$ \\
\hline 3.5.3a & SF-merc & mercerated flour & 89 & 6.3 & slurry & $30 \min$ \\
\hline 3.5.4a & SF-APTMS & $\begin{array}{l}\text { y aminopropyltrimethoxy } \\
\text { silanated flour }\end{array}$ & 81 & 8.0 & slurry & $25 \min$ \\
\hline $3.5 .4 \mathrm{~b}$ & SF-MOPTMS & $\begin{array}{l}\text { rmethacryloxypropyltrimethoxy } \\
\text { silanated flour }\end{array}$ & 87 & 5.8 & slurry & $30 \mathrm{~min}$ \\
\hline 3.5.4c & SF-OTES & octyltriethoxy silanated flour & 81 & 2.5 & slurry & $30 \mathrm{~min}$ \\
\hline 3.5.4d & SF-GOPTMS & $\begin{array}{l}\text { 3-glycidyloxypropytrimethoxy } \\
\text { silanated flour }\end{array}$ & 85 & 5.9 & slurry & $30 \min$ \\
\hline $3.5 .4 \mathrm{e}$ & SF-OVTES & $\begin{array}{l}\text { oligomeric vinyltriethoxy } \\
\text { silanated flour }\end{array}$ & 83 & 4.1 & slurry & $30 \mathrm{~min}$ \\
\hline 3.5.4f & SF-VGS & vinylglycoxy silanated flour & 91 & 4.5 & slurry & $30 \mathrm{~min}$ \\
\hline $3.5 .4 \mathrm{j}$ & SF-OTES-5 & $\begin{array}{l}\text { octyltriethoxy silanated flour } \\
\text { dry blend }\end{array}$ & 100 & 2.3 & dry blend & $15 \mathrm{~min}$ \\
\hline 3.5.5a & SF-MeOH & MeOH blank & 87 & 9.6 & slurry & $30 \mathrm{~min}$ \\
\hline 3.7.3a & TSH-OTES & $\begin{array}{l}\text { octyltriethoxy silanated } \\
\text { torrefacted hulls }\end{array}$ & 89 & 10.7 & slurry & $2.1 \mathrm{~h}$ \\
\hline 3.7.3b & SH-OTES & octyltriethoxy silanated hulls & 84 & 21.6 & slurry & $2.1 \mathrm{~h}$ \\
\hline 3.7.3c & SPC-OTES & octyltriethoxy silanated SPC & 77 & 13.4 & slurry & $2.1 \mathrm{~h}$ \\
\hline 3.7.4a & SPC-APTMS & $\begin{array}{l}\text { Y aminopropyltrimethoxy } \\
\text { silanated SPC }\end{array}$ & 80 & 18.1 & slurry & $24 \mathrm{~h}$ \\
\hline
\end{tabular}




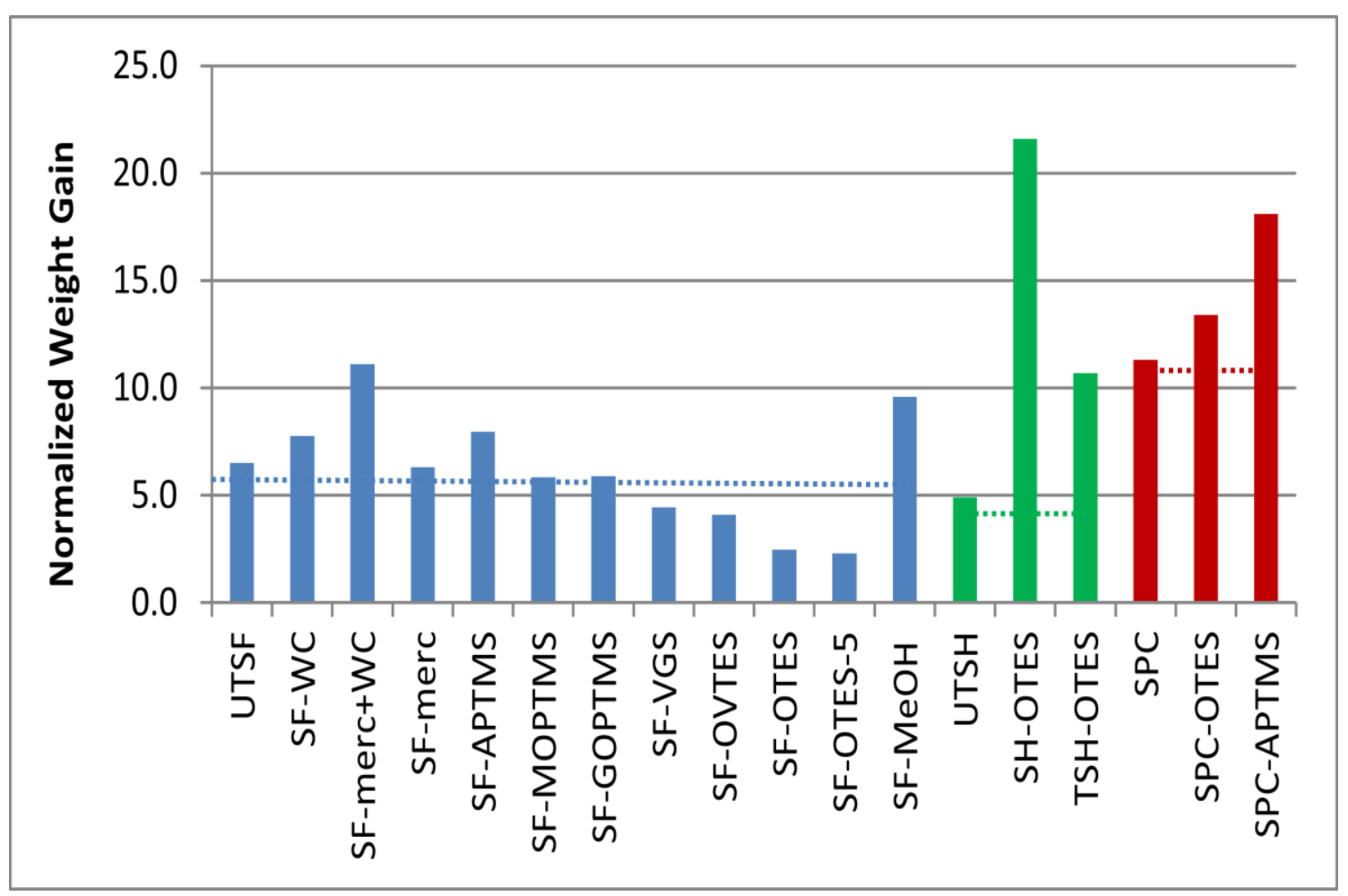

Figure 4.9: Normalized Water Absorption for Chemically Treated Fillers

As seen in Figure 4.9, the only chemical treatments that had a beneficial effect were four of the seven silane treatments on the soy flour. The untreated soy flour and hull samples had weight gains of roughly 5 times that of $\mathrm{CaCO}_{3}$ filled samples. The most effective treatments were the octyltriethoxysilane (OTES) treatments, which yielded a roughly $50 \%$ reduction in water absorption relative to the untreated soy flour. Results were similar for slurry and dry blend applied processes. The other silanes that reduced the water absorption were the oligomeric vinyltriethoxysilane (OVTES) and the vinylglycoxysilane (VGS), both yielding approximately $33 \%$ reductions. It is not clear why the OTES treatment on the hulls and the SPC did not produce a benefit. One process difference was that the treatment time for these samples was over four times longer. It is 
possible that the longer treatment was less effective, possibly due to reversal of the intended grafting.

\subsubsection{Esterifications}

Table 4.7 summarizes the sample description and results for water absorption tests for resin castings with the acetylated fillers. Figure 4.8 graphically depicts the results. The only acetylation that reduced the water absorption was the $4 \mathrm{~h} 120{ }^{\circ} \mathrm{C}$ vial treatment on the flour. This filler absorbed roughly $50 \%$ less water than the untreated flour.

Table 4.7 Summary of Acetylated Soy Fillers

\begin{tabular}{|c|c|c|c|c|c|c|c|}
\hline $\begin{array}{l}\text { treatment } \\
\text { ID }\end{array}$ & $\begin{array}{l}\text { precursor - } \\
\text { treatment }\end{array}$ & treatment & yield \% & $\begin{array}{c}\text { normalized } \mathrm{H} 2 \mathrm{O} \\
\text { Absorption } \\
\left(\mathrm{xCaCO}_{3}\right)\end{array}$ & $\begin{array}{l}\text { precursor } \\
\text { wt process }\end{array}$ & temperature & time \\
\hline & UTSF & untreated soy flour & & 6.5 & & & \\
\hline 3.6.1a & SF-acet1 & $\begin{array}{l}\text { pyridine catalyzed } \\
\text { acetylated flour }\end{array}$ & 55 & 6.0 & $\begin{array}{l}328 \mathrm{mg} \\
\text { slurry }\end{array}$ & ambient & $43 \mathrm{~h}$ \\
\hline 3.6.3b & SF-acet6 & $\begin{array}{l}\text { heat assist acetylated } \\
\text { flour in vials }\end{array}$ & & 3.3 & $\begin{array}{l}5.5 \mathrm{~g} \\
\text { sludge }\end{array}$ & $120^{\circ} \mathrm{C}$ & $4 \mathrm{~h}$ \\
\hline 3.7.1a & SPI-acet1 & $\begin{array}{l}\text { pyridine catalyzed } \\
\text { acetylated SPI }\end{array}$ & 81 & 13.4 & $\begin{array}{l}5 \mathrm{~g} \\
\text { slurry }\end{array}$ & ambient & $24.5 \mathrm{~h}$ \\
\hline 3.7.2a & SH-acet2 & $\begin{array}{l}\text { heat assist acetylated } \\
\text { hulls in Parr reactor }\end{array}$ & 88 & 12.0 & $\begin{array}{l}15 \mathrm{~g} \\
\text { sludge }\end{array}$ & $120{ }^{\circ} \mathrm{C}$ & $14 \mathrm{~h}$ \\
\hline $3.7 .2 b$ & $\begin{array}{c}\text { SH- } \\
\text { AGbench- } \\
\text { acet }\end{array}$ & $\begin{array}{c}\text { heat assist acetylated } \\
\text { torrefacted hulls in } \\
\text { Parr reactor }\end{array}$ & 84 & 9.2 & $\begin{array}{l}15 \mathrm{~g} \\
\text { sludge }\end{array}$ & $120{ }^{\circ} \mathrm{C}$ & $50 \mathrm{~h}$ \\
\hline
\end{tabular}


Figure 4.10 is the normalized weight gain data for the acetylated filler samples. Only the samples made from soy flour precursor showed any reduction in water absorption. With the soy hulls, SPI and torrefacted precursor, the attempted acetylation was detrimental.

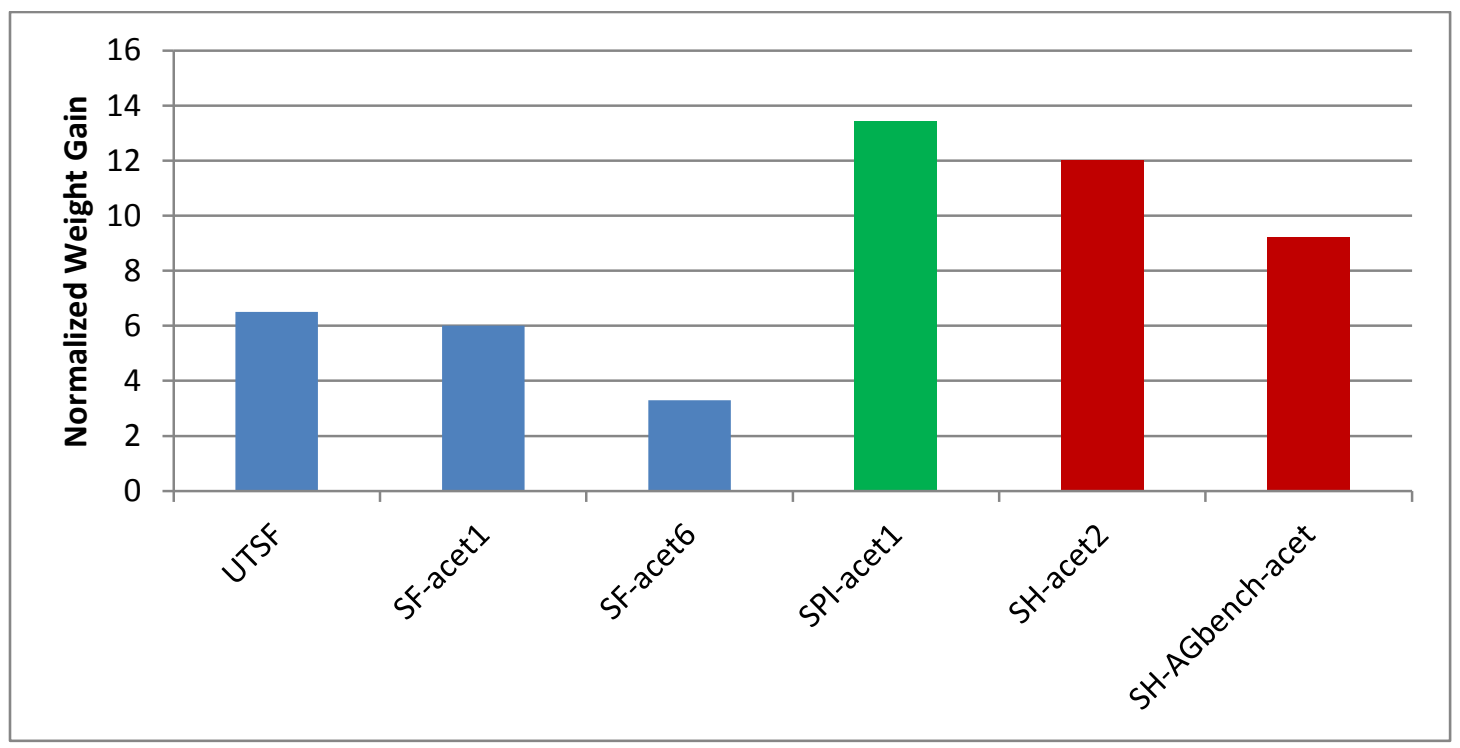

Figure 4.10 : Normalized Water Absorption for Acetylated Fillers

\subsection{Conclusions}

The following treatments resulted in a roughly $50 \%$ reduction in water absorption:

- Enzymatic refinement of soy flour to soy isolate

- Torrefaction with a "temperature x time" factor of 4000 to $5000{ }^{\circ} \mathrm{C}$-min

- Either $4 \mathrm{hr}$ slurry or $15 \mathrm{~min}$ dry blend silane treatment with octyltriethoxysilane

- A $4 \mathrm{~h} 120^{\circ} \mathrm{C}$ sludge acetylation of soy flour 


\section{CHAPTER V}

\section{COMPOSITE EVALUATIONS}

\subsection{Requirements for a Composite Filler}

In Chapter IV, reductions in hydrophilicity of the fillers, relative to the precursor biomass, were studied. While reduced water absorption is vital for use as a composite filler, it is not the only attribute that affects its functionality. Adhesion to the matrix resin is critical and the filler must not become the weak link in the composite, therefore it must be well distributed and well wetted. The absorption of the matrix by the filler will have an impact on the ability to affectively wet the reinforcing glass fibers and can be a limiting factor on the amount of filler that can be incorporated. Further, the filler cannot interfere with the thickening and polymerization reactions of the matrix system, or create incompatibilities with additives in the formulation. Finally, the process behaviors of the filled systems must be amenable to established manufacturing practices. In particular, cycle times and rheological considerations, such as molding pressure requirements and glass carry, are of concern. 


\subsection{Discontinuous Glass Molding Compounds}

One class of composites is formed by molding of compound containing matrix resin, curatives, additives, filler and discontinuous glass fibers. These materials, known commercially as bulk molding compound (BMC) and sheet molding compound (SMC), are used in a wide range of markets including, but not limited to, electrical, automotive consumer goods, appliance, construction, aerospace and military. The most common chemistry for these molding compounds is free radically cured unsaturated polyester resins, crosslinked with styrene. The material is weighed and charged into matched metal die tools to form three dimensional components. The material flows to fill the mold and is held, under pressure with application of heat, to drive the crosslinking reaction between the unsaturated polyester and styrene monomer. Glass fibers are used as reinforcement and fillers are used to reduce the cost of the overall formula, because they typically are priced an order of magnitude less than the resin or reinforcements.

\subsubsection{Materials}

Resins used in the composites studies were Reichhold 31615-20, AOC S903 and Dixie Chemical's MAESO. AOC S903 is a dicyclopentadiene propylene glycol maleic anhydride based polyester, dissolved in $30 \%$ styrene. Reichhold $31615-20$ is a maleic anhydride propylene glycol polyester, dissolved in 30\% styrene. Dixie MAESO is maleated acrylated epoxidized soy oil, dissolved in $30 \%$ styrene monomer. The low profile additive (LPA), used in the compound for shrinkage control, was R-158 from Premix, which is a proprietary thermoplastic dissolved in $30 \%$ styrene. For some 
formulas additional styrene, from Total Petrochemical, was included for viscosity reduction.

Trigonox BPIC-C75 from Akzo-Nobel, tert-butyl peroxy isopropyl carbonate peroxide or Trigonox C, tert-butyl perbenzoate (TBPB), were used as the free radical initiators for the systems. Inhibitors used included Chromoflo's IN-91029, a solution of 2,6-di-tertbutyl-p-cresol in vinyl toluene, and Chempac's POWER BLOC 12.5PC, a $12.5 \%$ solution of parabenzoquinone.

Mineral fillers, used as references, included Omya 10LV Calcium Carbonate $\left(\mathrm{CaCO}_{3}\right)$ and BASF ASP200 clay. Other fillers used include the soy modified materials as described and referenced in Chapter Three [identified by section and, in some cases, a letter differentiator]. Norac Coad 27P zinc stearate (ZnSt) and Norac Coad 10C calcium stearate (CaSt) were used for mold release. Chromoflo's black CF-20737 pigment concentrate was used, as well as their AM 9033 magnesium oxide thickener slurry. For SMC, $2.5 \mathrm{~cm}$ chopped OCF P-973C-AB-113 glass roving was used and for BMC, 0.32 cm chopped PPG 3075 was used.

\subsubsection{Bulk Molding Compound (BMC) Process}

In the BMC process, raw materials can be charged individually or as a resin/additive master batch into a mixer. The latter is depicted in Figure 5.1 A-E. The resins, monomers, pigment, cure package and mold release were first mixed under a Cowles, or other high shear spindle mixer, and then loaded into the BMC mixer. A popular mixer configuration is the sigma blade mixer, as seen in Figure 5.1. The filler 
was then weighed and added to the mixer and the blades were rotated until there was a uniform consistency, at which time the preweighed glass was added and final mixing was completed. The resulting bulk material varied from wet to fluffy consistencies, depending on the formula.

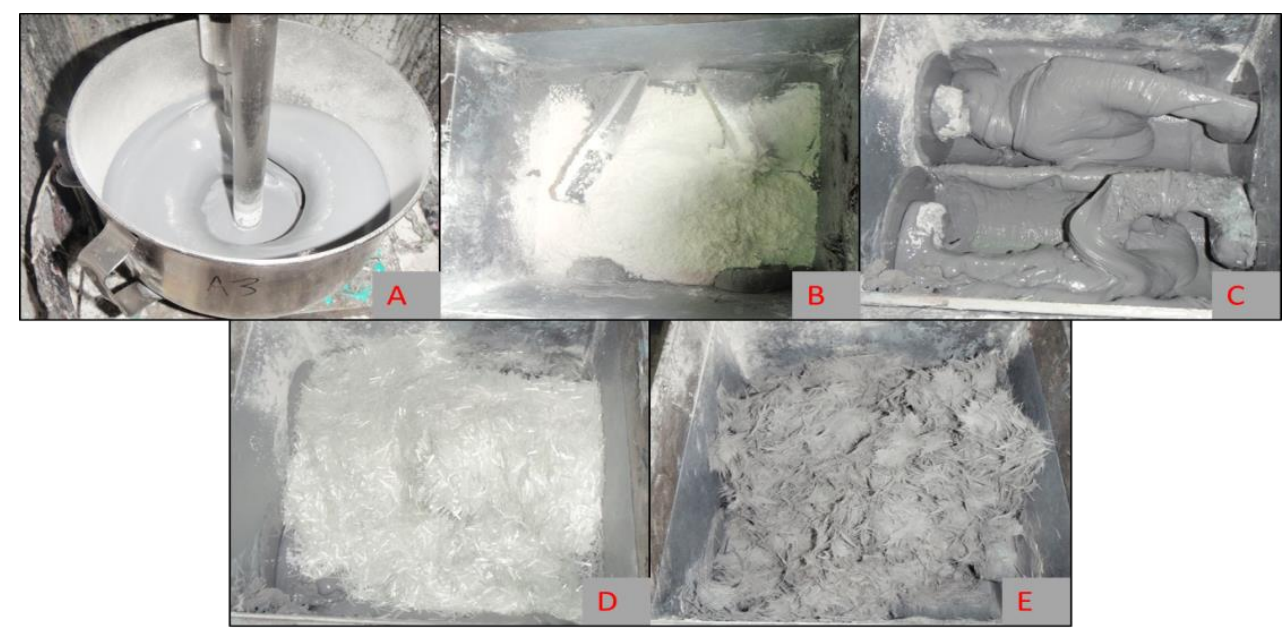

Figure 5.1: $\mathrm{BMC}$ Process, $\mathrm{A}=$ high shear mixing of paste, $\mathrm{B}=$ addition of filler, $\mathrm{C}=$ kneading to a uniform consistency, $\mathrm{D}=$ glass fiber addition, $\mathrm{E}=$ fully mixed BMC

\subsubsection{Sheet Molding Compound (SMC) Process}

In the SMC process, the filler was added to the resin master under the high speed mixer. The final addition to the mix was a chemical thickener that advances the system over time, to transform it from a flowable liquid to a non-tacky elastic solid. This reaction was separate and independent from the free radical cure reaction. As the thickening progresses, the viscosity increase slowed and plateaued to a target range, providing a minimum of 60 days of working life. In some operations, the thickener can be added as a separate stream to allow for longer pot life. 
A typical SMC machine is seen in Figure 5.2. The preblended mix was metered from doctor boxes onto carrier film at two locations. Glass was chopped, to typically 2.5 cm lengths, and sandwiched between the two paste layers. The material was transported through rollers or chains to assist glass wetting and then festooned or rolled. The thickening reaction occured over several days to the plateau target. After thickening, also referred to as maturation, the carrier film could be peeled away and the material could be charged for molding.

\section{SMC Manufacturing Process}

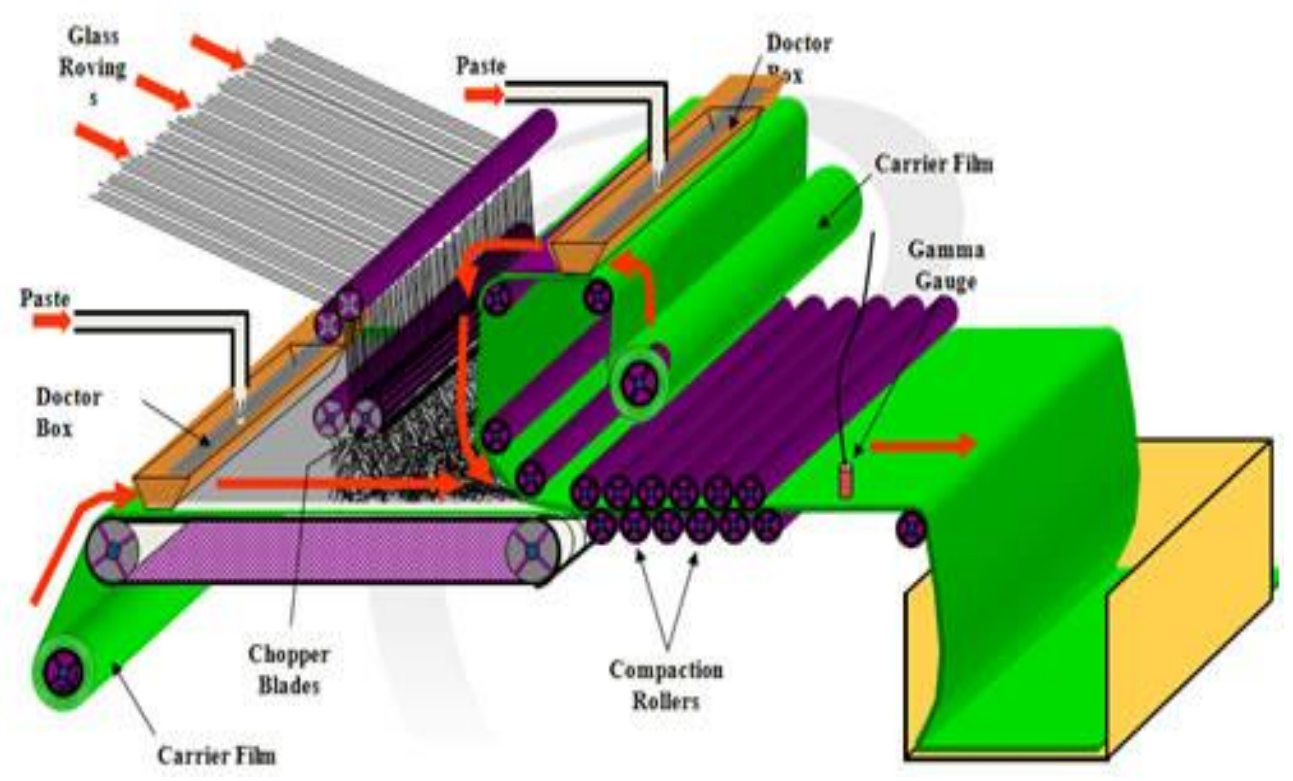

Figure 5.2: SMC Process

The SMC thickening, or viscosity build, is the key to use of the sheet form of molding compounds. As mixed, the raw materials form a low viscosity paste, which is capable of wetting out the glass reinforcement. In the mix, an alkaline earth oxide or hydroxide is included, which over time, forms a complex network, reacting covalently 
with the acid end groups of the polyester and via hydrogen and ionic affiliation of the carbonyls. After 24 to $48 \mathrm{~h}$ the viscosity build is sufficient to allow handling of the molding compound, without paste transfer. The material, at that point, has an elastic leather-like consistency.

\subsection{Materials Evaluations}

Characterizations of BMC and SMC made with the soy derived fillers and control samples, with mineral fillers, were compared to understand any process or performance differences that transitioning to the light weight soy filler would impart. Evaluations included thickening studies, cure evaluations, compound flow analysis and mechanical property testing.

\subsubsection{Thickening Studies}

The instrument used to track thickening was a Brookfield DV-III Ultra Programmable Rheometer calibrated with Brookfield Calibration Fluids 12500, 30000, 60000 and 100000. SMC paste samples, weighing between 400-450 g, were poured into $500 \mathrm{ml}$ cans after addition of the thickener. Viscosity index was measured periodically at $5 \mathrm{rpm}$ using a spindle TF for $36 \mathrm{~s}$. A heliopath was used to avoid cavitation during measurement.

\subsubsection{Squeeze Flow Rheometry (PPT)}

Parallel plate squeeze flow rheometry is a good approximation for the flow in the compression molding process. The instrument used for these studies was the Premix 
Processability Tester (PPT 1000), shown in Figure 5.3. It is a custom unit developed for Premix by Interlaken Technology Corp. The data treatment and methods are based on research by Meinecke, Collister, Allen and Yeh. ${ }^{78}$ The instrument is a hydraulic press with $7.62 \mathrm{~cm}$ diameter parallel plates equipped with a load cell to measure stress as a function of sample compression.

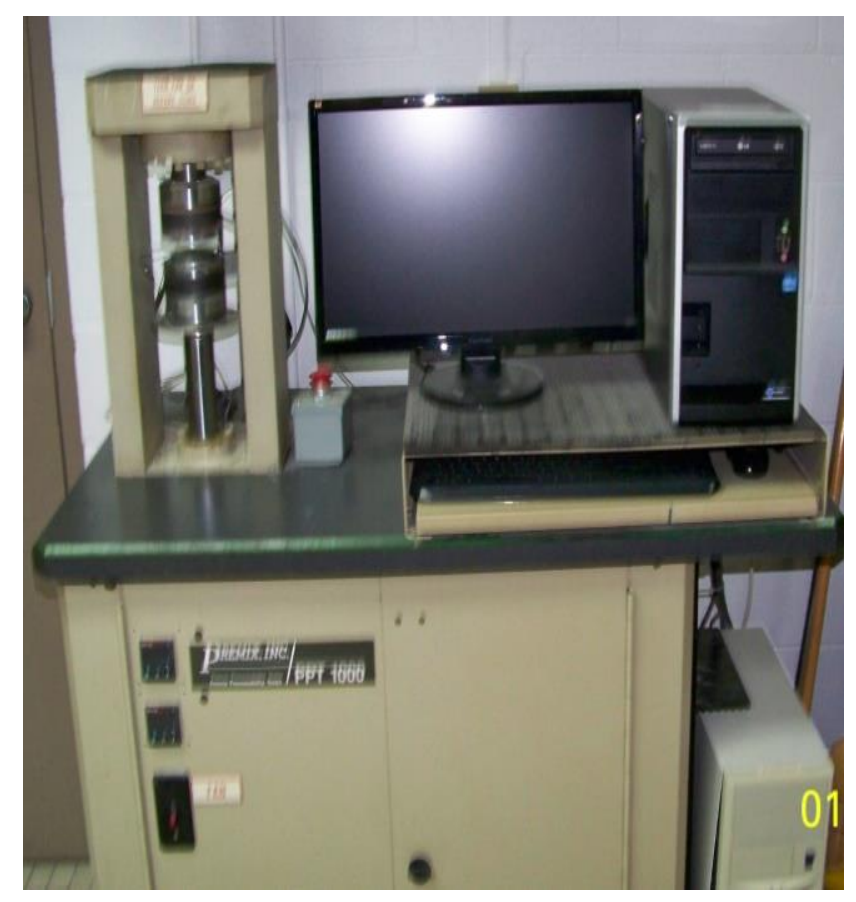

Figure 5.3: PPT 1000 Squeeze Flow Rheometer

Three plies of SMC were stacked and placed between the plates, which were initially separated by a $10 \mathrm{~mm}$ gap. A $10 \%$ precompaction to $9 \mathrm{~mm}$ was applied, prior to start of test data collection. The platens then closed at $2 \mathrm{~mm} / \mathrm{s}$ to $66 \%$ compaction, followed by up to a $5 \mathrm{~s}$ hold, to monitor stress relaxation. The platens then opened and the sample was removed. Stress was measured during compression and during the relaxation hold time. The squeeze flow geometry is presented in Figure 5.4, where 
$\mathrm{r}=$ radius, $\mathrm{h}(\mathrm{t})=$ plate separation as a function of time, $\mathrm{V}=$ compression velocity and $\mathrm{F}=$ measured force during compression. Typical data is shown in Figure 5.5.

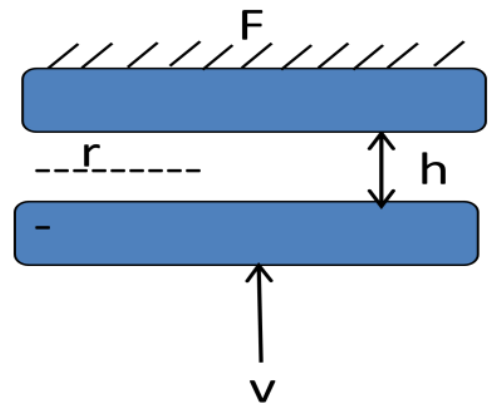

Figure 5.4: Geometry for Squeeze Flow Rheometer

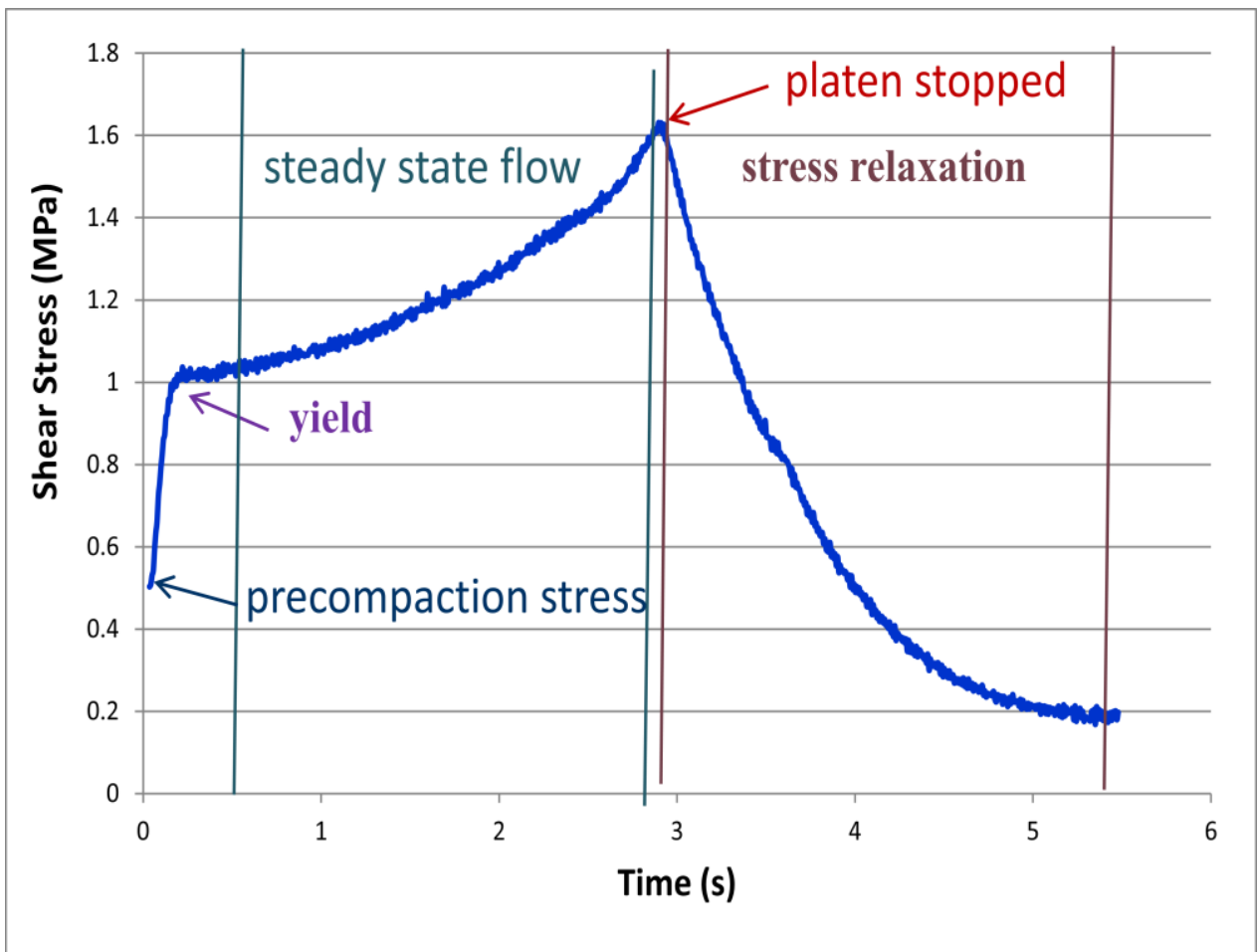

Figure 5.5: Typical Squeeze Flow Raw Data 
Because of the precompaction, the initial stress was not zero. The initial linear slope of the stress rise was used to calculate an effective compression modulus of the material, prior to yield. Yield stress was taken at the change in slope of the stress rise, and apparent viscosity was calculated from the steady state flow after yield. Equations used in data treatment are seen in Table 5.1.

Table 5.1: SMC Squeeze Flow Equations

$$
\begin{aligned}
& \tau_{A}=\frac{F}{\pi r^{2}} \\
& \dot{\gamma}=\frac{3}{2} \frac{v r}{\left(\frac{h}{2}\right)^{2}} \\
& \mu_{A}=\frac{\tau_{A}}{\dot{\gamma}}==\frac{2}{3} \frac{\left(\frac{h}{2}\right)^{2} F}{v \pi r^{3}} \\
& \tau_{A}=m \dot{\gamma}^{n}
\end{aligned}
$$

Apparent stress, $\tau_{A}$, was calculated from the measured force, $F$, and plate area, using Equation 1 and apparent shear rate, $\dot{\gamma}$,was calculated using Equation 2. Apparent viscosity, $\mu_{A}$, calculated as the stress divided by the strain rate, resulted in Equation 3. Note that this equation was based on the Stefan equation for parallel plate parabolic flow, but was modified because the SMC, with its glass fibers, exhibits plug flow as described by Allen and coworkers. ${ }^{79}$ From the slope of the $\log \log$ viscosity vs. shear rate curve, the power law index, $n$, for the material was determined using Equation 4. An apparent relaxation time, $\tau_{A}$, was assigned after compression during fixed displacement, where the stress diminishes to a plateau level. 


\subsubsection{Dielectric Analysis (DEA)}

A Signature Control System SmartTrac@ was used with a $2.54 \mathrm{~cm}$ diameter sensor embedded in a $15.24 \mathrm{~cm} \times 15.24 \mathrm{~cm}$ mold with $0.32 \mathrm{~cm}$ stops using a charge weight of $140 \mathrm{~g}$. The system is shown in Figure 5.6. Samples were molded at $150{ }^{\circ} \mathrm{C}$ for $2 \mathrm{~min}$ at roughly $7 \mathrm{MPa}$ pressure. Impedance was measured at $1 \mathrm{kHz}$ while curing at 150 ${ }^{\circ} \mathrm{C}$. Gel time was defined at the peak of the resulting impedance curve, and cure time was the point at which the curve plateaus to the baseline.

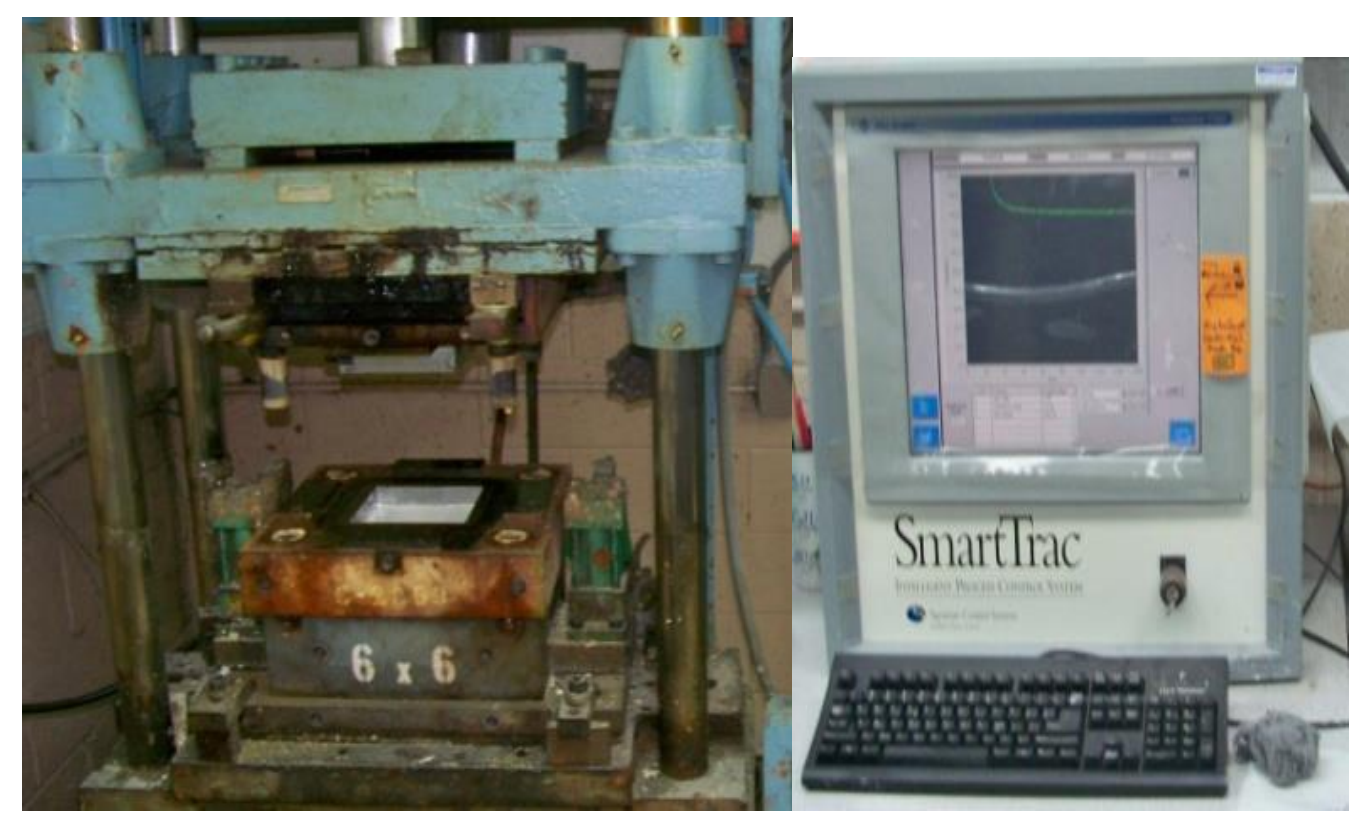

Figure 5.6. DEA Instrumented Mold and SmartTrac® Analyzer

\subsubsection{Reaktometer Study}

SMC Technologie's (Dr. Derek GmBH) Reaktometer was used as described in method EN ISO 12114. The molding compound was analyzed, after mold close, as it polymerized in a $12 \mathrm{~cm} \times 25 \mathrm{~cm}$ mold at thickness ranges from $.08 \mathrm{~cm}$ to $1.7 \mathrm{~cm}$. The 
upper mold core was equipped with a thermocouple, pressure transducer, displacement transducer and dielectric sensor. The instrument is seen in Figure 5.7.

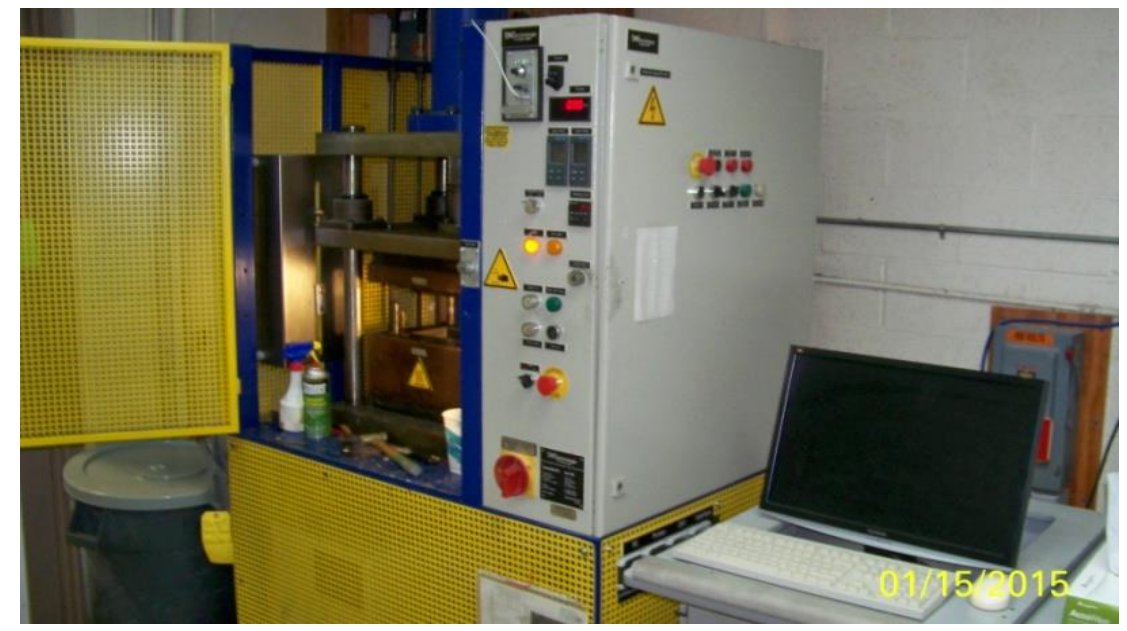

Figure 5.7: Reaktometer System

Testing was done at $0.32 \mathrm{~cm}$ and $0.64 \mathrm{~cm}$ thickness using hold times of $2 \mathrm{~min}$ and 5 min, respectively. Charge weights for the standard density material was $172 \mathrm{~g}$ and 344 $\mathrm{g}$, respectively Charge weights for the soy filler, low density, SMC was $133 \mathrm{~g}$ and $266 \mathrm{~g}$, respectively. Molding was done off stops with 15.5 MPa clamp pressure.

\subsubsection{Mechanical Testing}

The mechanical properties of BMC were tested on samples cut from the panels $(15.24 \mathrm{~cm} \times 15.24 \mathrm{~cm})$ molded during the dielectric analysis (DEA). Specimens for SMC were either net shape molded or cut from molded panels $(30.5 \mathrm{~cm}$ x $30.5 \mathrm{~cm})$. Flexural strength and modulus were tested according to ASTM D790; tensile strength and modulus according to ASTM D638; Izod impact according to D256; and water absorption was tested according to ASTM D570. 


\subsubsection{Particle Size Distribution (PSD)}

Union Process used a MicroTrac Particle Size Analyser laser diffraction system to determine the size distribution of the filler. Particle size was calculated as volume average (MV), number average (MN) and/or area average (MA) values.

\subsection{Bulk Molding Compound (BMC) Evaluations}

Two formulas were evaluated in BMC form. The first formula was used for screening tests to explore a range of treatments including refinement, heat treatment, chemical treatment, grafting and esterification. The second was used for a more thorough evaluation of process parameters for the heat treated torrefied fillers.

\subsubsection{MAESO Bio-resin Compounds with Various Treated Fillers}

The effect of water absorption on BMC formulations, with various fillers, was evaluated using the formula from Table 5.2. $\% \mathrm{BOW}$ and $\% \mathrm{BOV}$ indicate $\%$ based on weight and volume, respectively. Because of the limited amount of filler available, the BMCs in this set were only hand mixed. For each material, $3.2 \mathrm{~mm}$ thick plaques were molded at $150{ }^{\circ} \mathrm{C}$ for $2 \mathrm{~min}$ and flexural properties, with ambient air conditioning and after a $24 \mathrm{~h}$ water immersion, were tested on cut specimen. The $24 \mathrm{~h}$ water absorption weight gain was also measured. Due to the limited mixing, the glass in these samples were not debundled as well as samples made in the mixer, therefore property data cannot be directly compared to machine mixed samples. 
Table 5.2: BMC Composition

\begin{tabular}{|c|c|c|c|c|}
\hline BMC Formula & \% BOW & \% BOW & \% BOV & \% BOV \\
\hline & Bio-fillers & Control & Bio-fillers & Control \\
\hline MAESO & 22.3 & 16.0 & 28.1 & 28.1 \\
\hline LPA & 11.1 & 8.0 & 14.1 & 14.0 \\
\hline TBPB & & & & \\
\hline & 0.5 & 0.3 & 0.6 & 0.6 \\
\hline ZnSt & & & & \\
\hline CaCO3 & 3.2 & 2.3 & 4.1 & 4.1 \\
\hline Bio Filler & & 50.5 & 0.0 & 36.1 \\
\hline & 31.2 & & 36.1 & 0.0 \\
\hline 1/8 in. glass & & & & \\
\hline
\end{tabular}

Results for the hand mixed samples are seen in Figure 5.8. With standard conditioning, all of the BMC samples made with refined soy, prepared by Dr. Ju's lab, had lower strength and modulus than the untreated soy flour. However, after water immersion, the modulus of the BMCs with the SPC [3.3.1] concentrate and SPI-2 [3.3.2b], isolate precipitated using a denaturing heat treatment, were superior to the UTSF BMC and the gap on strength had narrowed.

The effect of water absorption on the BMCs made in the laboratory sigma blade BMC mixer with various fillers was evaluated, also using the formula from Table 5.2. A $\mathrm{CaCO}_{3}$-filled $\mathrm{BMC}$, with volume equivalent glass loading, was used as a control for comparison. For each material, $3.2 \mathrm{~mm}$ thick plaques were molded at $150{ }^{\circ} \mathrm{C}$ for $2 \mathrm{~min}$. Flexural properties with ambient air conditioning and after a $24 \mathrm{~h}$ water immersion, were tested on cut specimen. The $24 \mathrm{~h}$ water absorption was also measured. Results are seen in Figure 5.9. 


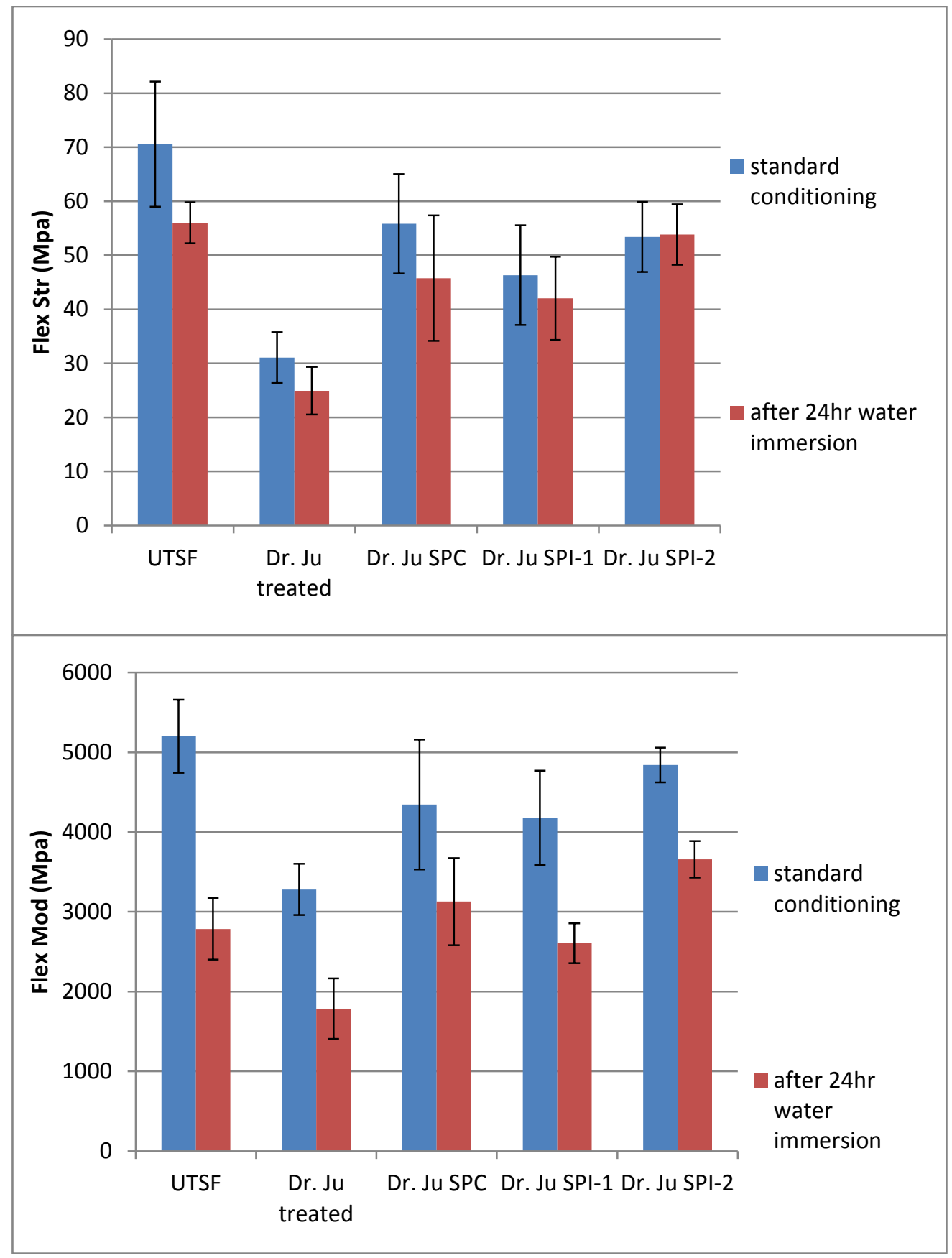

Figure 5.8: Flexural Properties for BMC with Refined Fillers. UTSF = untreated soy flour, Dr, Ju treated = undisclosed process (due to IP considerations), Dr. Ju SPC = soy protecin concentrate, Dr; Ju SPI-1 = ethanol precipitated soy protein isolate, Dr. Ju SPI-2 $=$ thermally precipitated soy protein isolate 


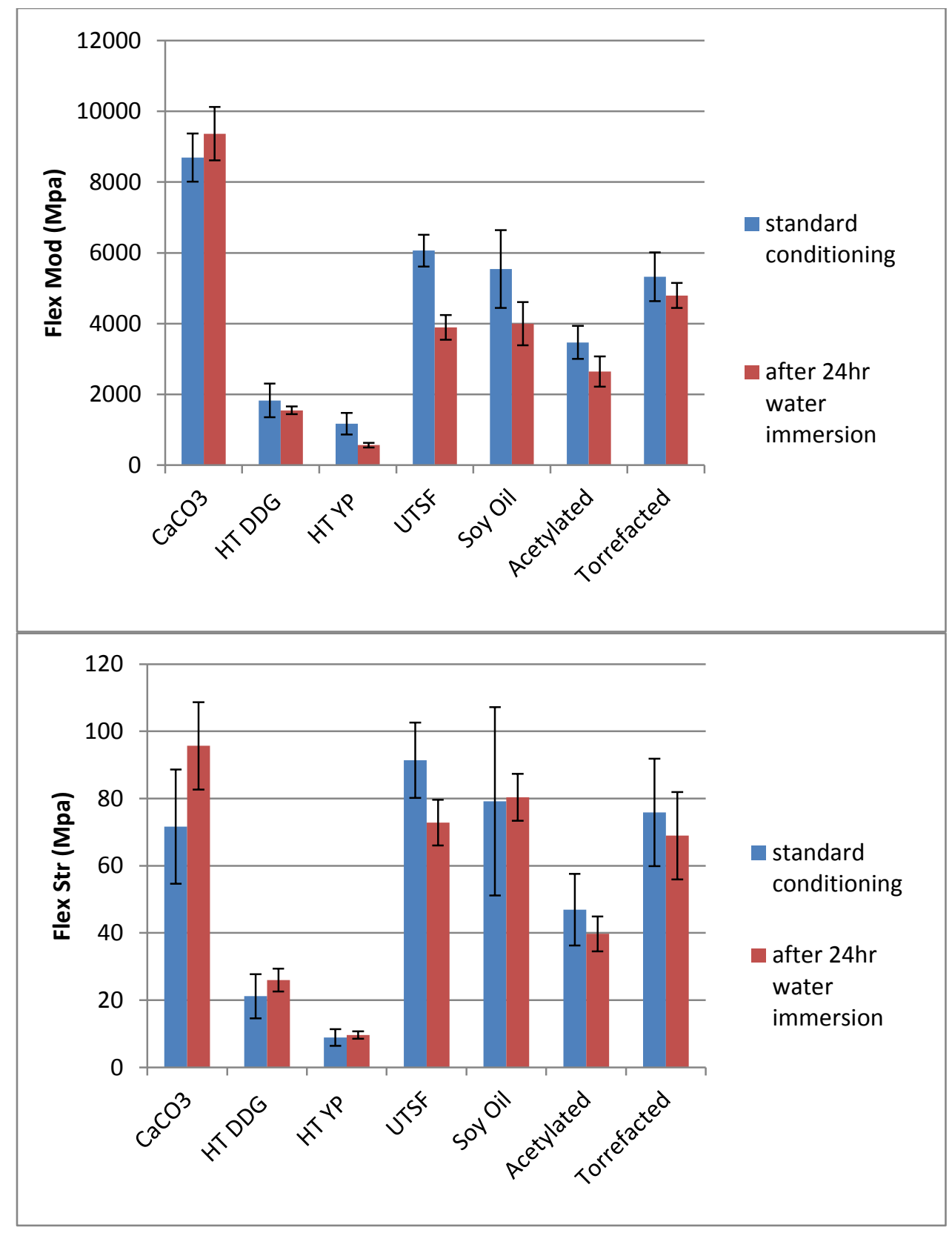

Figure 5.9: Flexural Properties of $\mathrm{BMC}$ with Treated Fillers. $\mathrm{CaCO}_{3}=$ calcium carbonate filled, HT DDG = heat treated dried distillery grains, HT YP = heat treated yellow pine, UTSF $=$ untreated soy flour, Soy oil $=[3.5 .2 \mathrm{a}]$ with acetone treated soy flour, acetylated $=[3.6 .3 \mathrm{c}]$ sludge acetylated hulls, torrefacted $=[3.4 .2 \mathrm{a}] 225^{\circ} \mathrm{C}$ treated soy meal 
Flexural strength for the untreated soy flour, with standard conditioning, was greater than the $\mathrm{CaCO}_{3}$ control sample. This advantage, however, was reversed after water immersion. All of the water soaked bio-filler BMC strengths were inferior to the $\mathrm{CaCO}_{3} \mathrm{BMC}$ strength. The standard conditioning modulus was lower for all of the biofillers relative to the $\mathrm{CaCO}_{3}$. The $\mathrm{CaCO}_{3}$ sample modulus and strength increased slightly with immersion, perhaps due to beneficial plasticization; however all the soy flour variations had decreased strength and modulus with water immersion. The acetylated sample [3.6.3 c] had inferior strength and modulus; however this filler was coarser than the others and it was probable that the acetic anhydride was not completely removed. The sample had pitting on the surface, probably due to outgassing, and the interior was more porous than the other samples. The soy oil treated [3.5.2 a] and torrefacted [3.4.2 a] samples had slightly lower strength and modulus than the untreated sample with standard conditioning, but were slightly superior after immersion. The HT DDG and HT YP filler samples are proprietary commercial heat treated bio-based fillers, based on dried distillery grains and yellow pine, respectively. These fillers have been demonstrated as effective in thermoplastic composites, but did very poorly in our thermoset system.

Although absolute mechanical properties cannot be compared for the data in Figures 5.3 and 5.4 due to the difference in mixing method, retention of properties and water absorption comparison should be valid. The water absorption of the BMC samples is seen in Figure 5.10 and the strength and moduli retention is seen in Figure 5.11. 


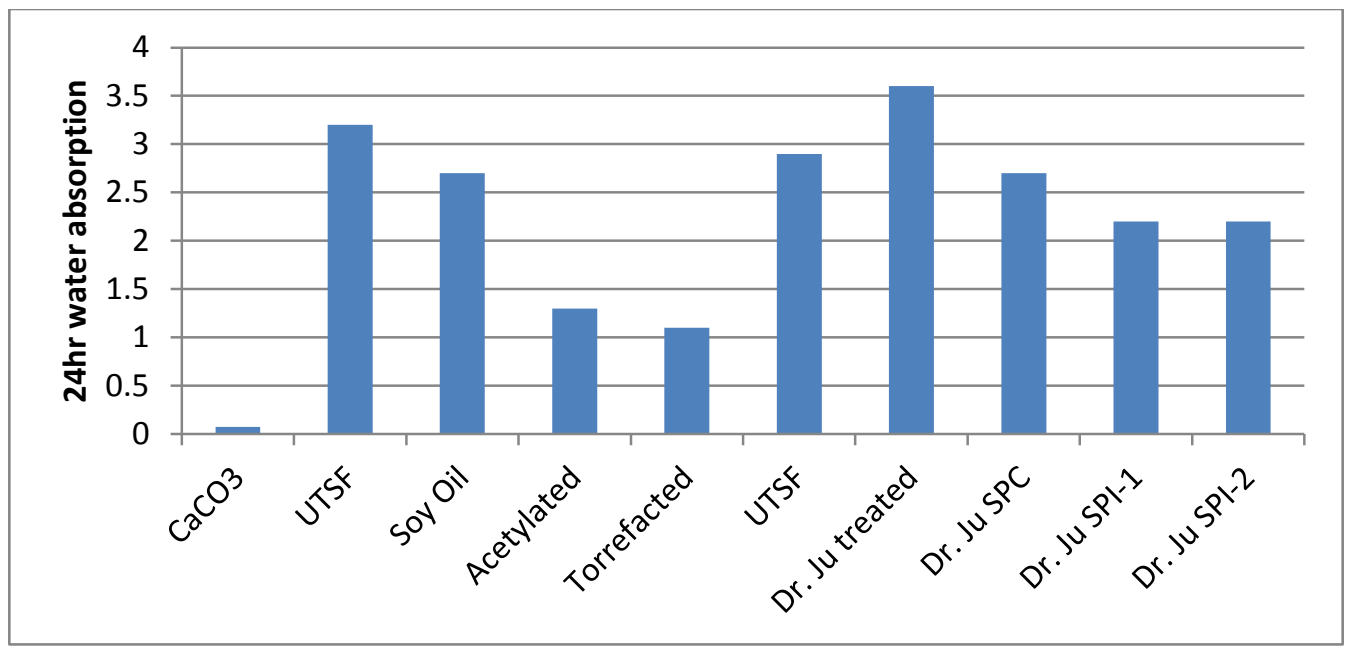

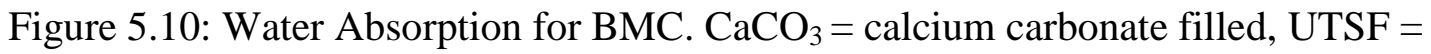
untreated soy flour, Soy oil $=[3.5 .2$ a $]$ with acetone treated soy flour, acetylated $=[3.6 .3$ c] sludge acetylated hulls, torrefacted $=[3.4 .2$ a $] 225^{\circ} \mathrm{C}$ treated soy meal, Dr. Ju SPC $=$ soy protecin concentrate, Dr; Ju SPI-1 = ethanol precipitated soy protein isolate, Dr. Ju SPI-2 = thermally precipitated soy protein isolate

Water absorption was reduced vs. the untreated soy flour for the soy oil, acaetylated, torrefacted, SPC and SPI samples. The torrefacted and acetylated samples had the lowest water absorption, which was roughly a third of the untreated absorption. All of the water absorptions were significantly higher than that of the $\mathrm{CaCO}_{3}$ control. Retention of properties was better for all of the treated samples, except Dr. Ju's treated sample in comparison to the UTSF, but none had "retentions" as high as that of the $\mathrm{CaCO}_{3}$, which were over $100 \%$. The flexural strength retention, of all of the soy samples, was in the 80 to $100 \%$ range; however the modulus for some samples fell to as low as $58 \%$. As seen in figure 5.12, the decrease in retention correlated very well to the \%water absorption, particularly for modulus. 


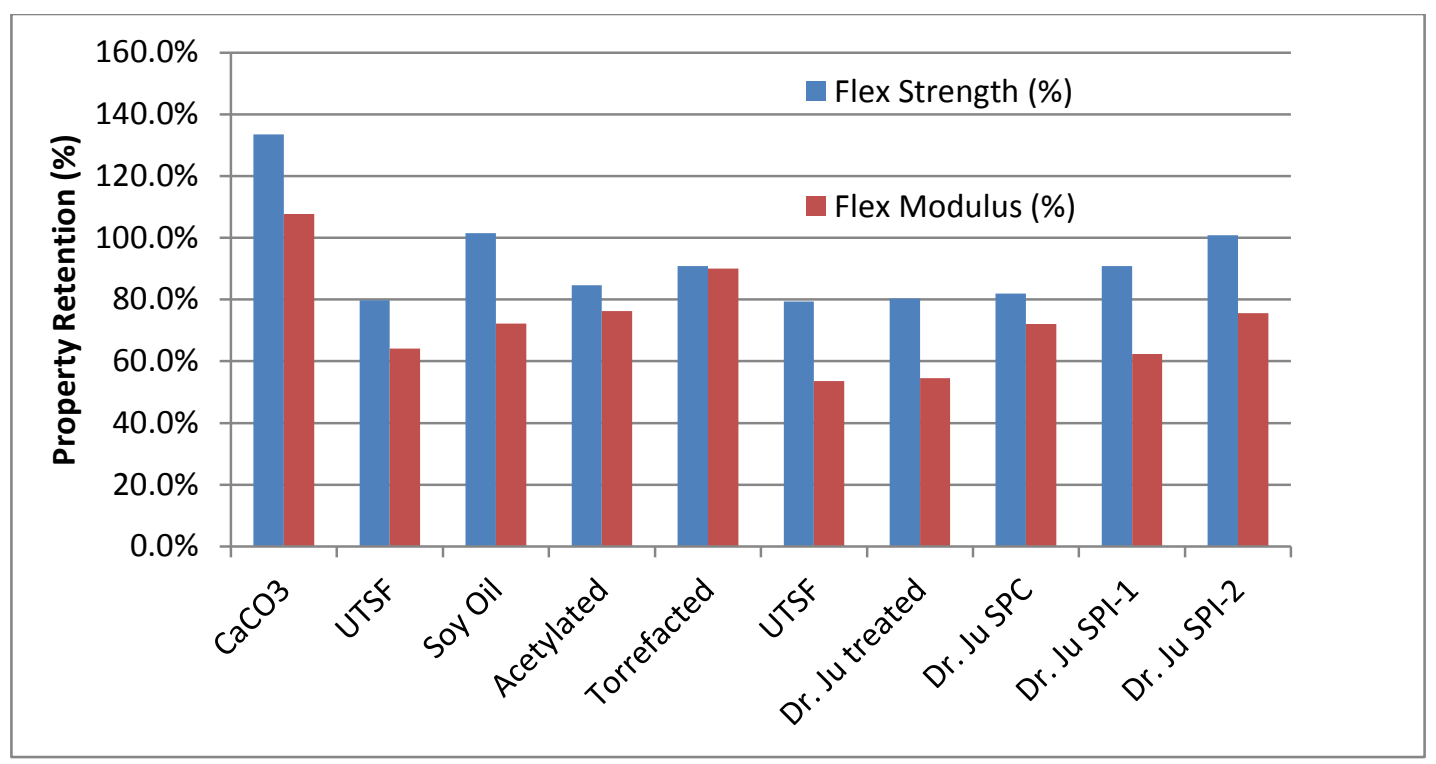

Figure 5.11: Property Retentions for BMC. UTSF $=$ untreated soy flour, Soy oil $=[3.5 .2$

a] with acetone treated soy flour, acetylated $=[3.6 .3 \mathrm{c}]$ sludge acetylated hulls, torrefacted $=[3.4 .2 \mathrm{a}] 225^{\circ} \mathrm{C}$ treated soy meal, Dr. Ju SPC $=$ soy protecin concentrate, Dr; Ju SPI-1 = ethanol precipitated soy protein isolate, Dr. Ju SPI-2 = thermally precipitated soy protein isolate

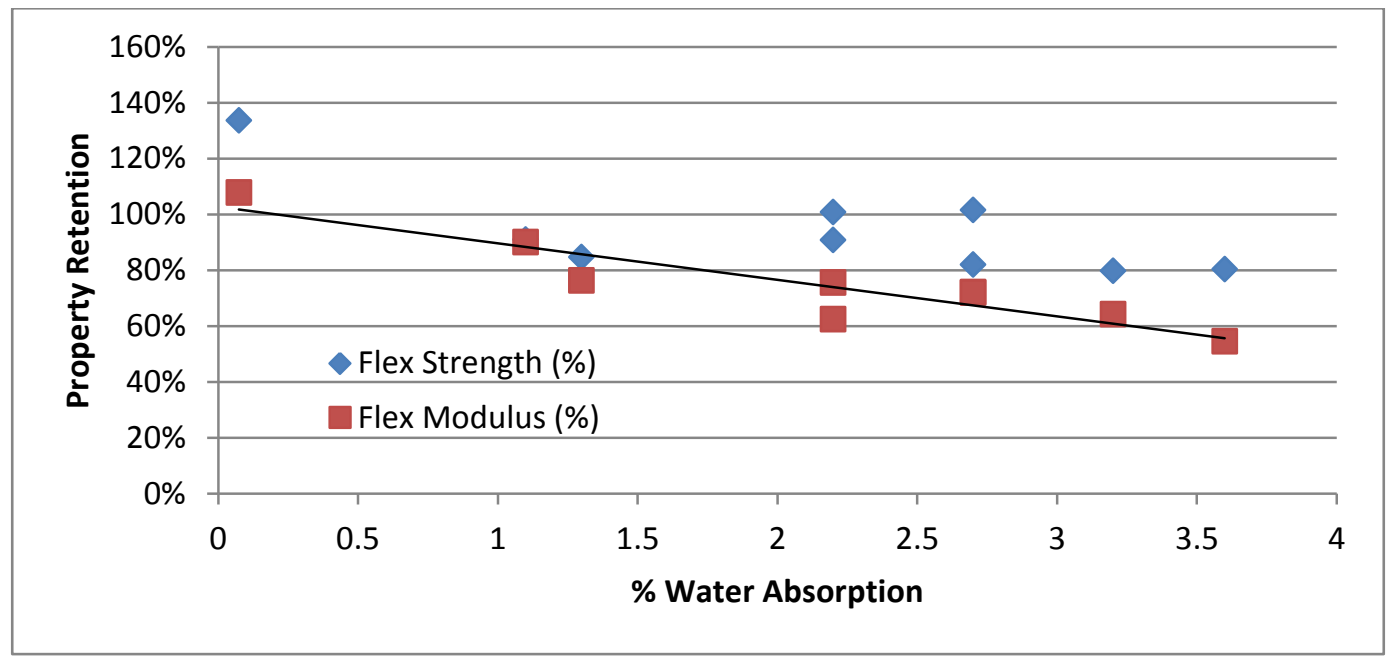

Figure 5.12: Effect of Water Absorption on Property Retentions 
Based on these results, the most effective treatments for reduced hydrophillicy are acetylation and torrefaction. The torrefacted sample properties were superior. Perhaps, if the acetylated samples had been completely free of residual acetic anhydride and ground to the same particle size, they may have performed better.

\subsubsection{UPE Resin Compounds of Heat Treated Fillers}

The formula in Table 5.3 was used for additional BMC evaluations, with varying levels of torrefaction. These soy filler BMCs were compared to clay filled compounds with equivalent density and glass volume loading.

Table 5.3: BMC Formula for Torrefaction Development

\begin{tabular}{|c|c|}
\hline SL1352-A6 & (\%BOW) \\
\hline DCPD Resin & 15.73 \\
\hline LPA & 10.46 \\
\hline Styrene & 8.14 \\
\hline Peroxide & 0.64 \\
\hline Inhibitor & 0.16 \\
\hline Pigment & 3.26 \\
\hline Mold release & 2.36 \\
\hline Thixotrope & 0.5 \\
\hline Filler & 18.58 \\
\hline Thickener & 2.5 \\
\hline Glass Fiber & 37.67 \\
\hline
\end{tabular}

Master batches of paste, inclusive of all ingredients except the filler and glass fiber, were mixed with the Cowles mixer. Approximately $57 \mathrm{~g}$ of bio-mass filler was hand mixed into $130 \mathrm{~g}$ of paste master and the mix was charged into the sigma blade mixer, followed by $113 \mathrm{~g}$ of $0.32 \mathrm{~cm}$ chopped glass fiber. Clay filled control batches were 
made with the common paste master, but with $30 \mathrm{~g}$ filler to $161 \mathrm{~g}$ of paste and $113 \mathrm{~g}$ glass. The resulting volume $\%$ filler and glass were similar to the biomass filled samples. BMCs were mixed for roughly 4 min, with a scrape down half way through the mixing cycle.

Evaluated fillers in this set included a clay control, untreated soy hulls, and torrefacted hull samples [3.4.3 b and 3.4.3 c], which were torrefacted at $400{ }^{\circ} \mathrm{C}$ and 500 ${ }^{\circ} \mathrm{C}$, respectively. All of the soy samples were ground to 60 mesh, except for $3.4 .3 \mathrm{c}$, which was fine ground to an area weighted mean diameter of 13,11 and $7 u \mathrm{~m}$ as measured by light scattering, seen in Figure 5.13.
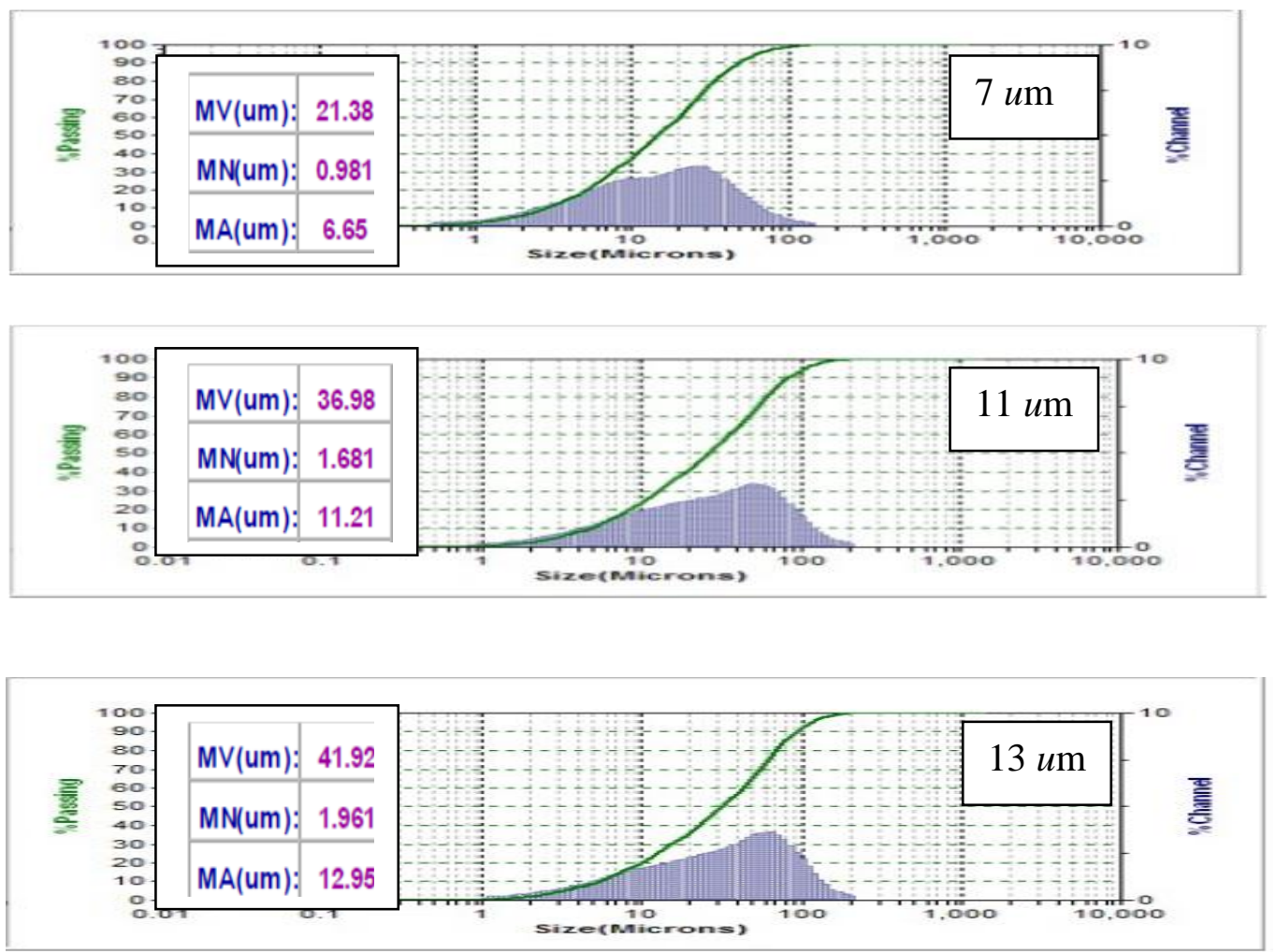

Figure 5.13: PSD for Various Grinds of Filler 3.4.3 c 
For each material, $3.2 \mathrm{~mm}$ thick plaques were molded at $150{ }^{\circ} \mathrm{C}$ for $2 \mathrm{~min}$. The first observation from this sample set is that the fine ground $500{ }^{\circ} \mathrm{C}$ torrefacted filler BMC did not have good mechanical integrity. Upon removal from the mold, it broke when handled, indicating a low level of cure. Dielectric cure analysis confirmed an issue with the cure, as seen in Figure 5.14, where the impedance fails to return to baseline indicating the incomplete solidification.

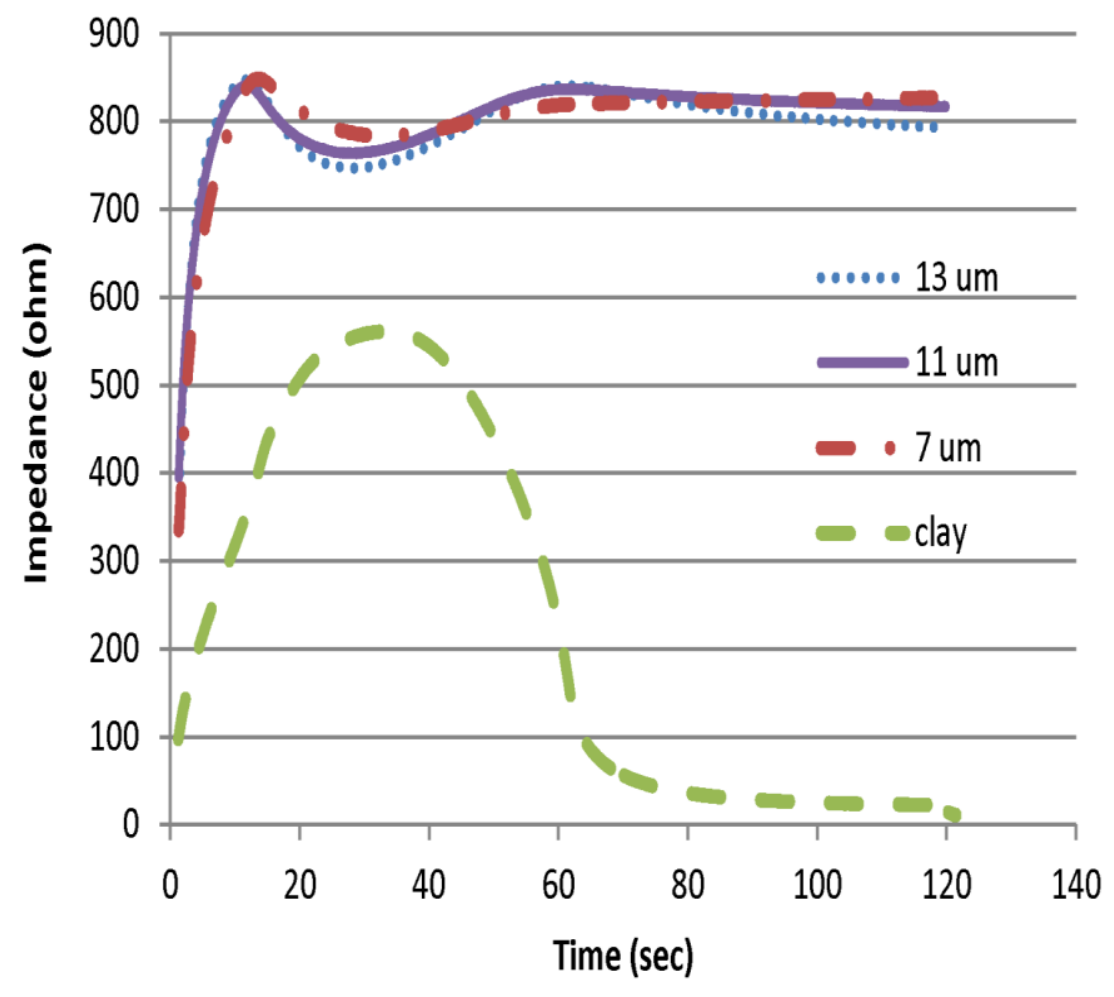

Figure 5.14: DEA Evidence of Cure Effects with Filler 3.4.3c

Flexural properties, for the BMC samples using soy hull fillers $\left[3.4 .3 \mathrm{~b}\left(400{ }^{\circ} \mathrm{C}\right)\right.$ and 3.4.4a $\left(500{ }^{\circ} \mathrm{C}\right)$ ], both as-molded and after a $24 \mathrm{hr}$ water immersion, are seen in Figure 5.15, along with the untreated soy hull and clay controls. While higher 
temperature torrefaction provides benefits in terms of cast resin water absorption, it is not good for a composite filler, at least at the $500{ }^{\circ} \mathrm{C}$ extreme, due to adverse effect on the polymerization reaction.

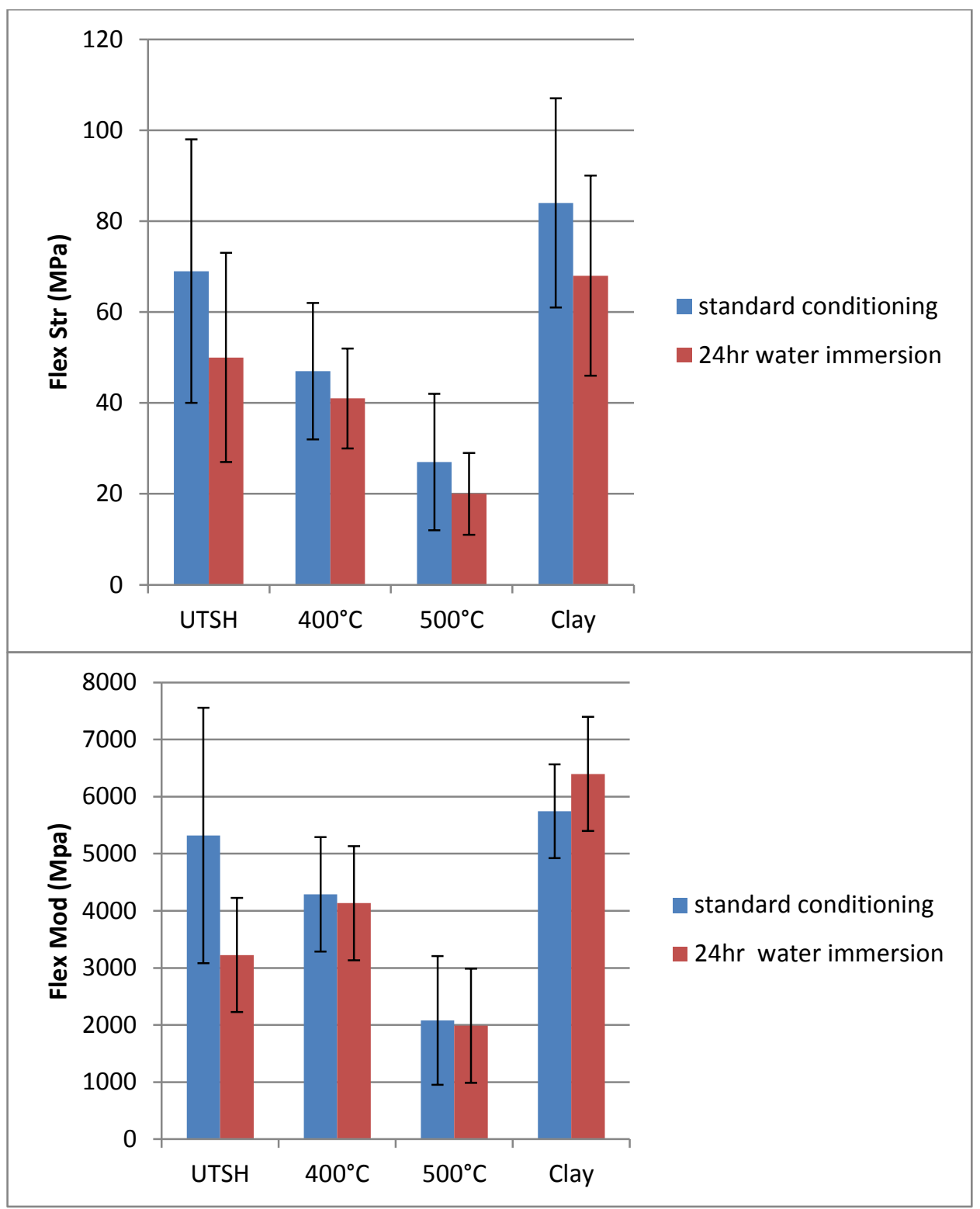

Figure 5.15: Flexural Properties of BMC with Torrefacted Filler 
In Figure 5.16, the density and $24 \mathrm{~h}$ water immersion weight gain are shown. The theoretical density for the compounds is $1.4 \mathrm{~g} / \mathrm{cm}^{3}$, howver the sample with the $500{ }^{\circ} \mathrm{C}$ treated filler had a density of only $1.34 \mathrm{~g} / \mathrm{cm} 3$, indicating porosity or internal delamination, which likely contributed to the very high water weight gains.

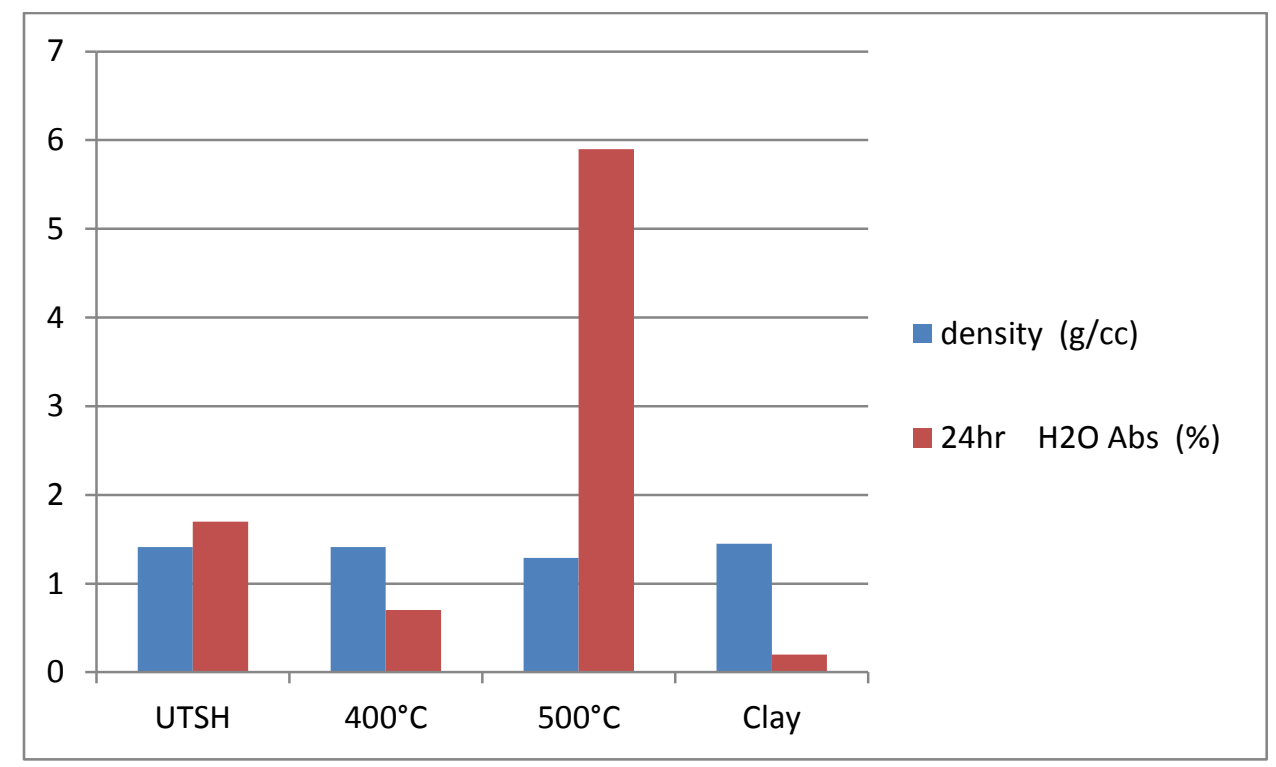

Figure 5.16:Density and Water Abs of BMC with Torrefacted Filler

In the next two sample sets, lower temperature torrefacted hull filler from EarthCare ${ }^{\circ}(\mathrm{KC})\left[3.4 .5\left(204^{\circ} \mathrm{C}, 227{ }^{\circ} \mathrm{C}, 249^{\circ} \mathrm{C}\right)\right]$ and from muffle oven (MO) experiments [3.4.2f $\left(250{ }^{\circ} \mathrm{C}\right)$ and 3.4.2g $\left.\left(275{ }^{\circ} \mathrm{C}\right)\right]$ were compared to untreated soy hulls and clay. For the first of these sample sets, the untreated soy hulls were used as ground, and for the second, the hulls were dried for 2 days at $50{ }^{\circ} \mathrm{C}$ prior to compounding into BMC. All of the soy fillers were ground to 60 mesh.

Figure 5.17 presents the dielectric cure analysis for the EarthCare set of BMCs. The timing for the impedance peak (gel time) and plateau to baseline (cure time) was 
very similar to the clay control for all of the soy filler samples. Gel times were roughly $35 \mathrm{~s}$ and cure times were approximately $80 \mathrm{~s}$.

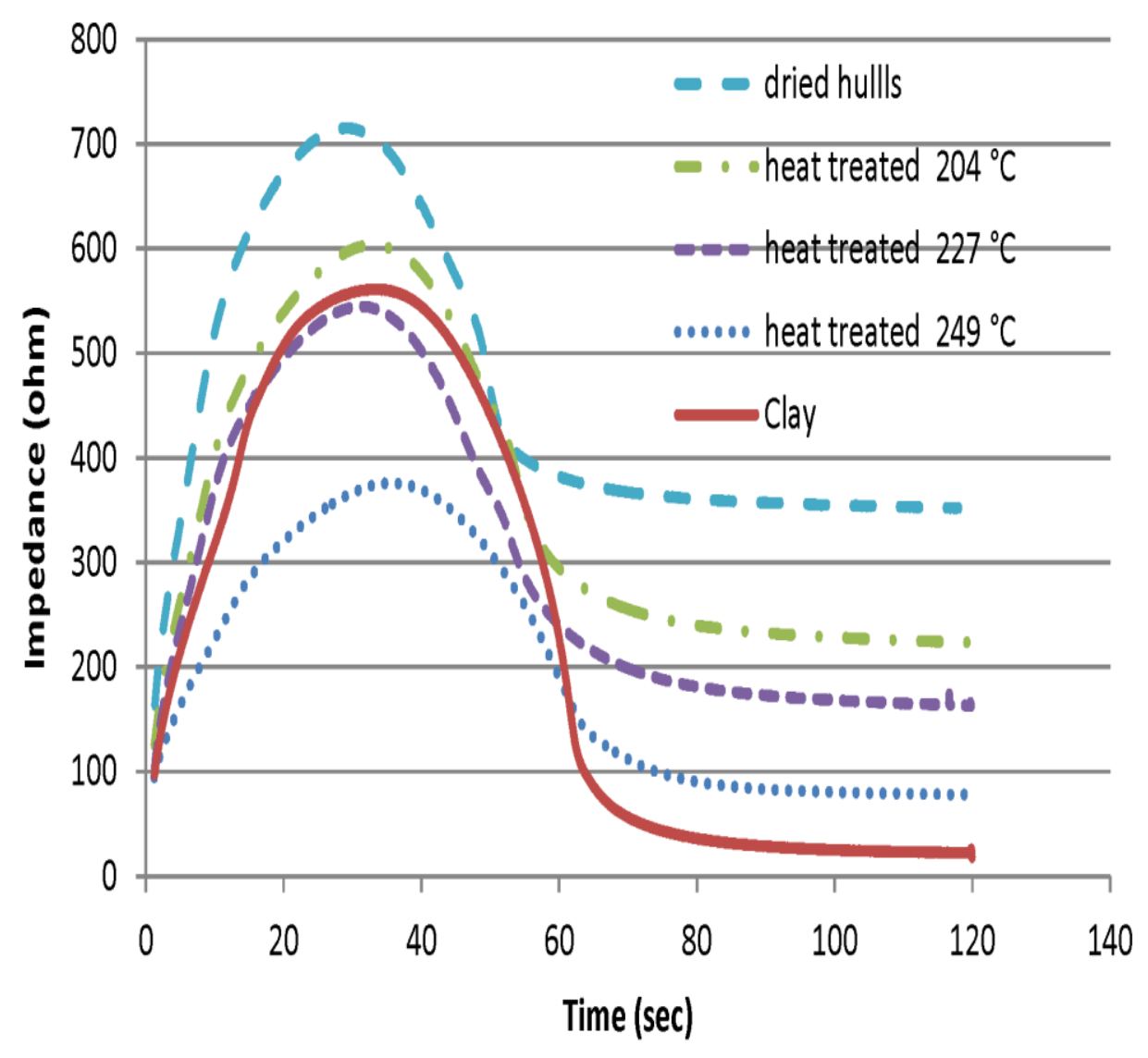

Figure 5.17: DEA Curves for Non-inhibiting Torrefacted Fillers

Flexural properties are seen in Figure 5.18 for samples as-molded and after $24 \mathrm{~h}$ water immersion. For both sets, the clay had better mechanical performance than the soy samples, as-molded and after immersion. Drying the untreated soy hulls prior to compounding, had a beneficial effect on strength and modulus after immersion. The mechanism of improvement is not clear, however, because the water absorption after $24 \mathrm{~h}$ immersion was not improved with the drying step, as seen in Figure 5.19. All of the 
samples had moduli of roughly $4500+/-500 \mathrm{MPa}$. The torrefacted soy filler samples had lower initial and wet strength than the clay sample by $\sim 20 \%$. When plotted as retention of properties, as seen in Figure 5.20, a benefit of higher temperature processing of the filler is indicated for these data sets.

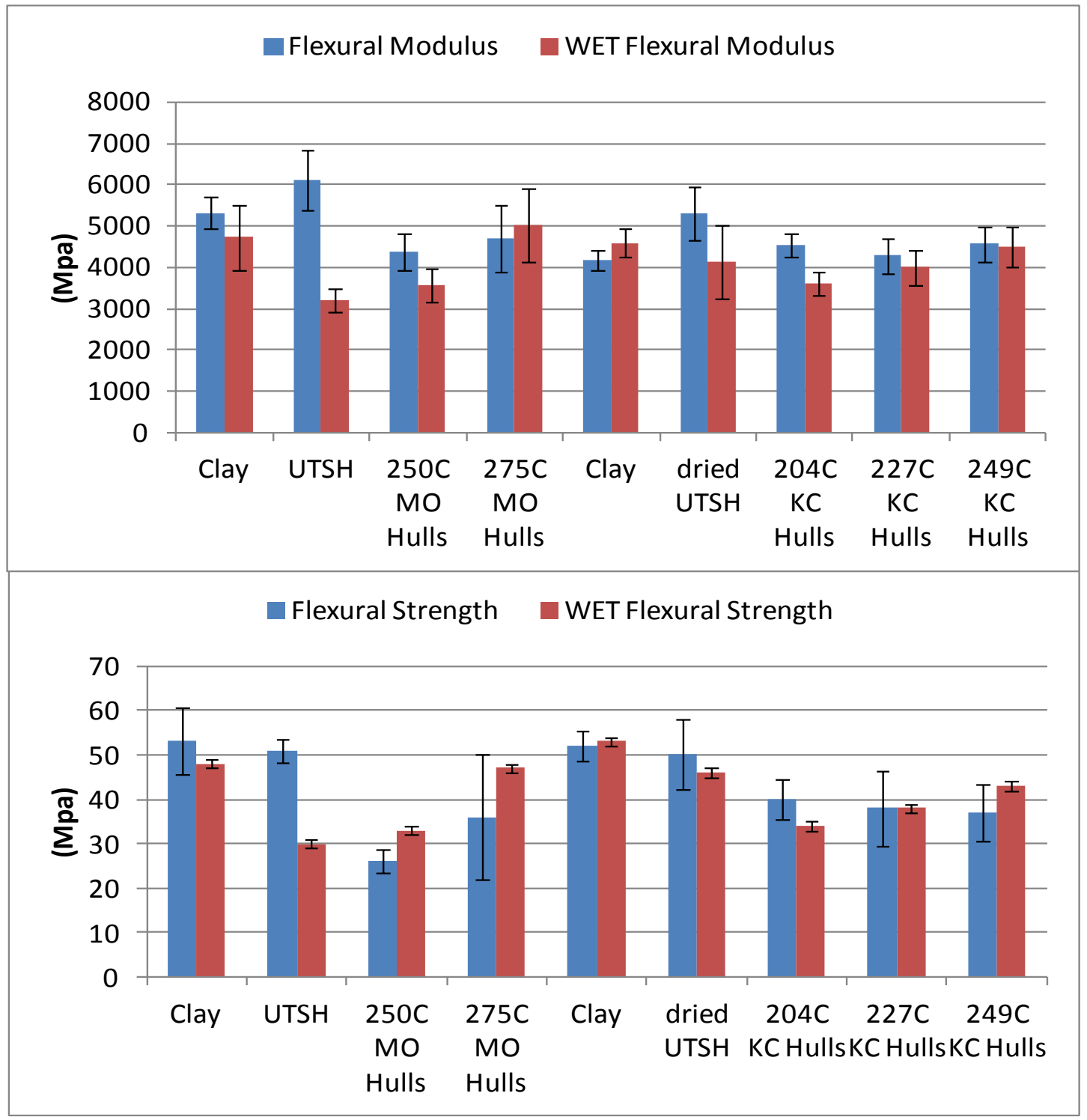

Figure 5.18: Flexural Properties of BMC with Torrefacted Fillers and Clay Control,

. KC indicates thermal treatment by EarthCare ${ }^{\circledR}, \mathrm{MO}$ indicates Muffle Oven treatment 


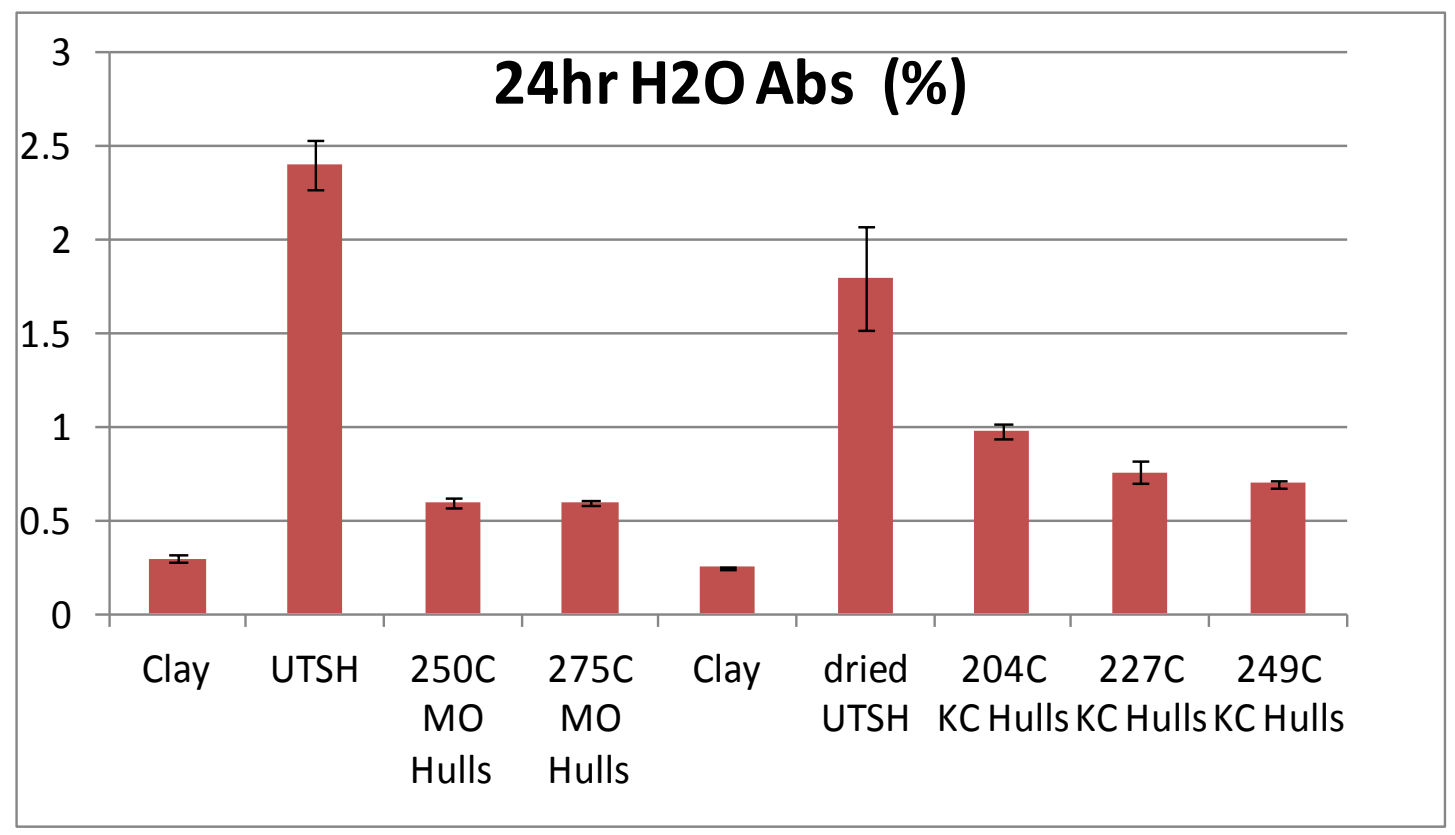

Figure 5.19: Water Absorption of BMC with Torrefacted Fillers and Clay Control, KC indicates thermal treatment by EarthCare ${ }^{\circledR}, \mathrm{MO}$ indicates Muffle Oven treatment

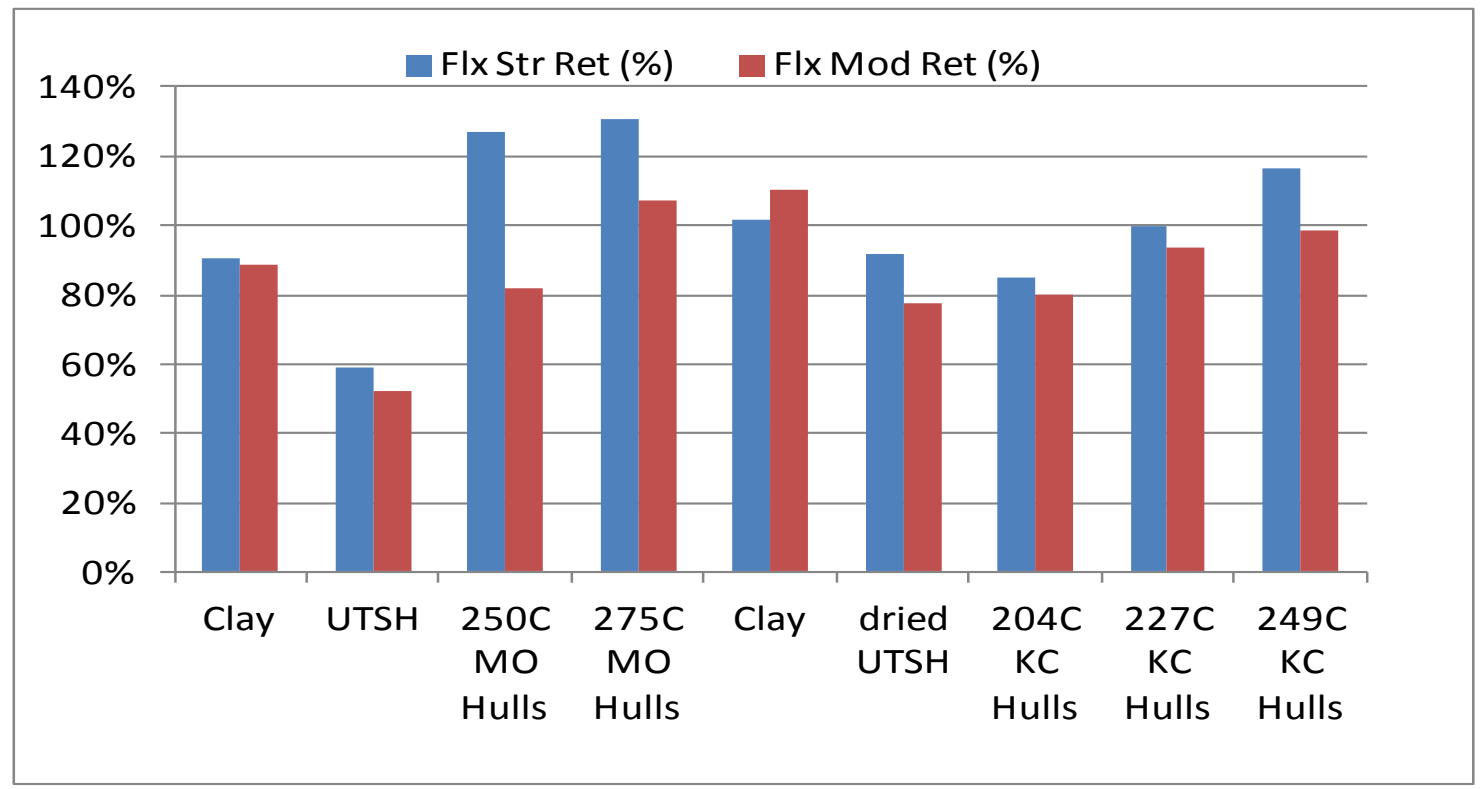

Figure 5.20: Water Absorption of BMC with Torrefacted Fillers and Clay Control. KC indicates thermal treatment by EarthCare ${ }^{\circledR}, \mathrm{MO}$ indicates Muffle Oven treatment 


\subsubsection{Comparison to UPE BMC Mechanicals to Glass Reinforced Nylon}

A potential application for the soy filled BMC could be an automotive alternator cover, which is currently molded from glass reinforced nylon. Engineers at the Ford Motor Company reported creep issues with the current material. A comparison of mechanical properties of the soy filled BMC and a Ford specification for glass reinforced nylon 6 is presented in Table 5.4. Although the BMC was slightly higher in density, strength and modulus were comparable to the incumbent material. The Impact was superior for the BMC and due to the thermoset chemistry, creep would not be an issue. Water absorption was similar for the two materials; however dimensional swelling and plasticization would not be an issue with the thermoset BMC, as it could be with the thermoplastic nylon.

Table 5.4: Comparison of BMC with Torrefacted Filler to Reinforced Nylon

\begin{tabular}{|c|c|c|c|c|c|c|}
\hline Material & Molding Process & $\begin{array}{c}\text { Density } \\
\left(\mathrm{g} / \mathrm{cm}^{3}\right)\end{array}$ & $\begin{array}{c}\text { Tensile } \\
\text { Modulus } \\
(\mathrm{Mpa})\end{array}$ & $\begin{array}{c}\text { Flexural } \\
\text { Modulus } \\
(\mathrm{Mpa})\end{array}$ & $\begin{array}{c}\text { Izod } \\
\text { Impact } \\
(\mathrm{J} / \mathrm{m})\end{array}$ & $\begin{array}{c}\mathbf{2 4} \mathrm{h} \\
\mathrm{H}_{2} \mathrm{O} \text { Abs } \\
(\%)\end{array}$ \\
\hline $1352-\mathrm{A8} \mathrm{BMC}$ & Compression & 1.45 & 8614 & 8033 & 308 & 1.2 \\
\hline std dev & & & 649 & 689 & 111 & 0.35 \\
\hline PA 6, 30\% glass? & Injection & 1.36 & 8300 & 8600 & 150 & 1.0 \\
\hline
\end{tabular}

\subsection{Sheet Molding Compound Evaluations}

In addition to BMCs, SMCs were also evaluated. For SMC, any effect the filler may have on the thickening reaction is important to understand. Flow and cure behavior, as well as mechanical property and aesthetics, were also evaluated. 


\subsubsection{SMC Paste Thickening}

Dr. Ju's SPI [3.3.2 b]: The first attempt to make SPI filled SMC, using a standard thickener level of $0.5 \%$, failed due to lack of thickening. A thickening study was initiated, using higher levels of thickener, to determine a suitable loading. A $1000 \mathrm{~g}$ master paste mix was made, using the formula in Table 5.5, without thickener or the glass fiber.

Table 5.5: SMC Formula used for SPI Thickening Study

\begin{tabular}{|c|c|}
\hline SL\# & SL1211-P1 \\
\hline \hline Color & Grey \\
\hline \hline Ingredients & \%BOT \\
\hline \hline DCPD Resin & 21.00 \\
\hline LPA & 20.00 \\
\hline Styrene & 6.00 \\
\hline Peroxide & 0.55 \\
\hline Inhibitor & 0.15 \\
\hline Pigment & 3.60 \\
\hline Mold release & 2.00 \\
\hline Thixotrope & 0.10 \\
\hline Soy Filler & 20.00 \\
\hline Thickener & 1.60 \\
\hline Glass Fiber & 25.00 \\
\hline
\end{tabular}

The paste was split into 2 aliquots, of $450 \mathrm{~g}$ each, and thickener was blended in at $1.5 \%$ and $2.5 \%$ total weight. Thickening curves, along with a typical $\mathrm{CaCO}_{3}$-filled control, are presented in Figure 5.21. The responses indicate that, at higher levels of thickener, the viscosity rise was significantly faster than the control; however plateau levels were similar. The need for higher thickener levels, with the SPI filler, may be due to moisture in the SPI. It is well known that higher water content in SMC has the effect of initially accelerating the viscosity increase, but then leveling at a lower plateau viscosity. 
Likewise, the hydroxyls and possibly the amines on the SPI, like water, can interfere with the thickening due to non-productive (non-thickening) interactions with the $\mathrm{MgO}$.

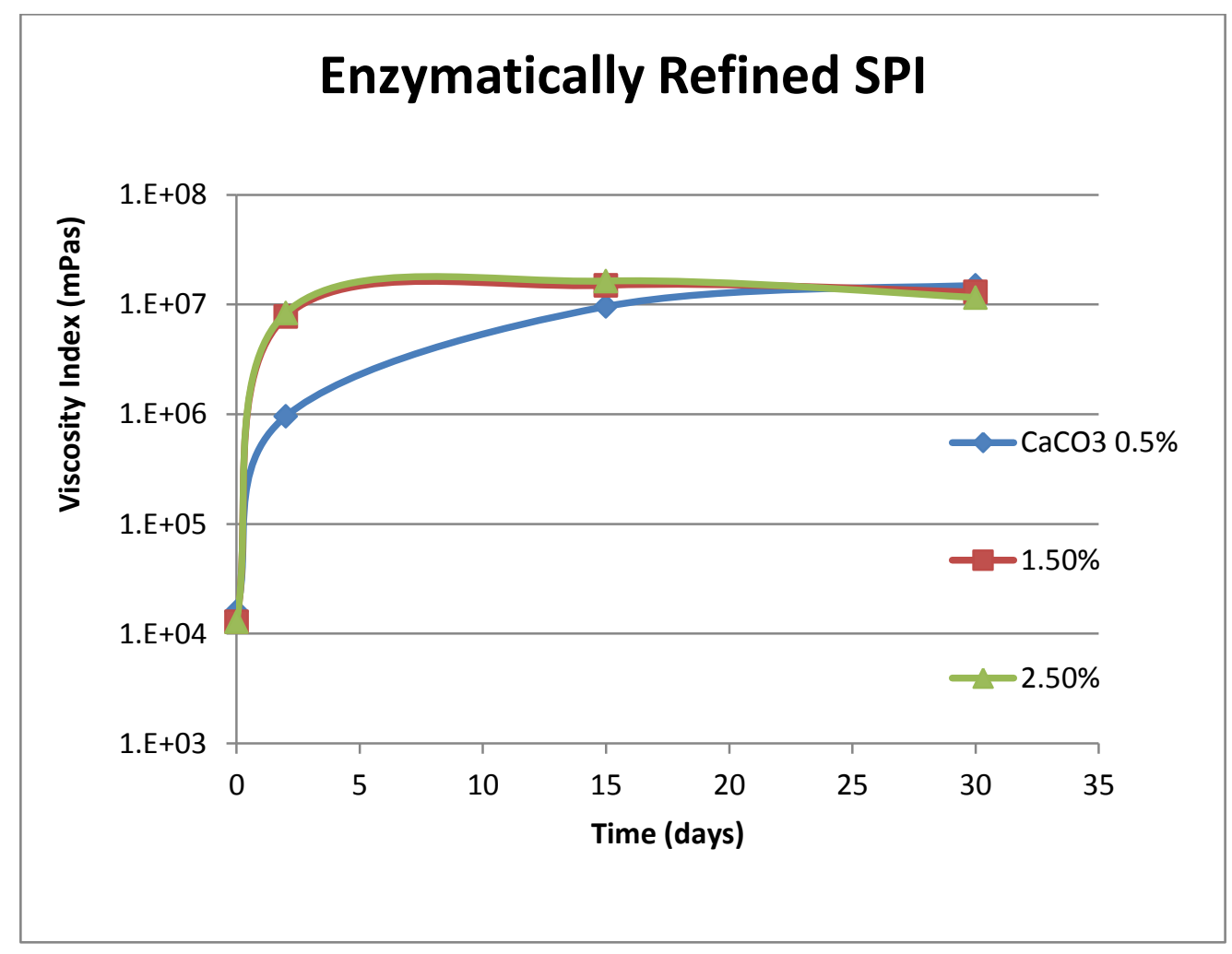

Figure 5.21: Thickening Profile with SPI Filled SMC Paste, \% indicates the thickener

EarthCare ${ }^{\circledR}\left[3.4 .5\left(204^{\circ} \mathrm{C}, 13 \mathrm{um}\right)\right]$ filler: A $2000 \mathrm{~g}$ master paste mix was made, using the formula in Table 5.3, without the thickener or glass fiber. This was split into four aliquots, of $450 \mathrm{~g}$ each, and thickener was blended in at $0.5 \%, 1 \%, 1.5 \%$ and $2.5 \%$ total weight. Thickening curves, along with a typical $\mathrm{CaCO}_{3}$-filled control curve, are seen in Figure 5.22. As with the SPI, use of this filler resulted in a requirement for increased thickener loading of $1.5 \%$, to match the $\mathrm{CaCO}_{3}$ filled paste thickening response. 


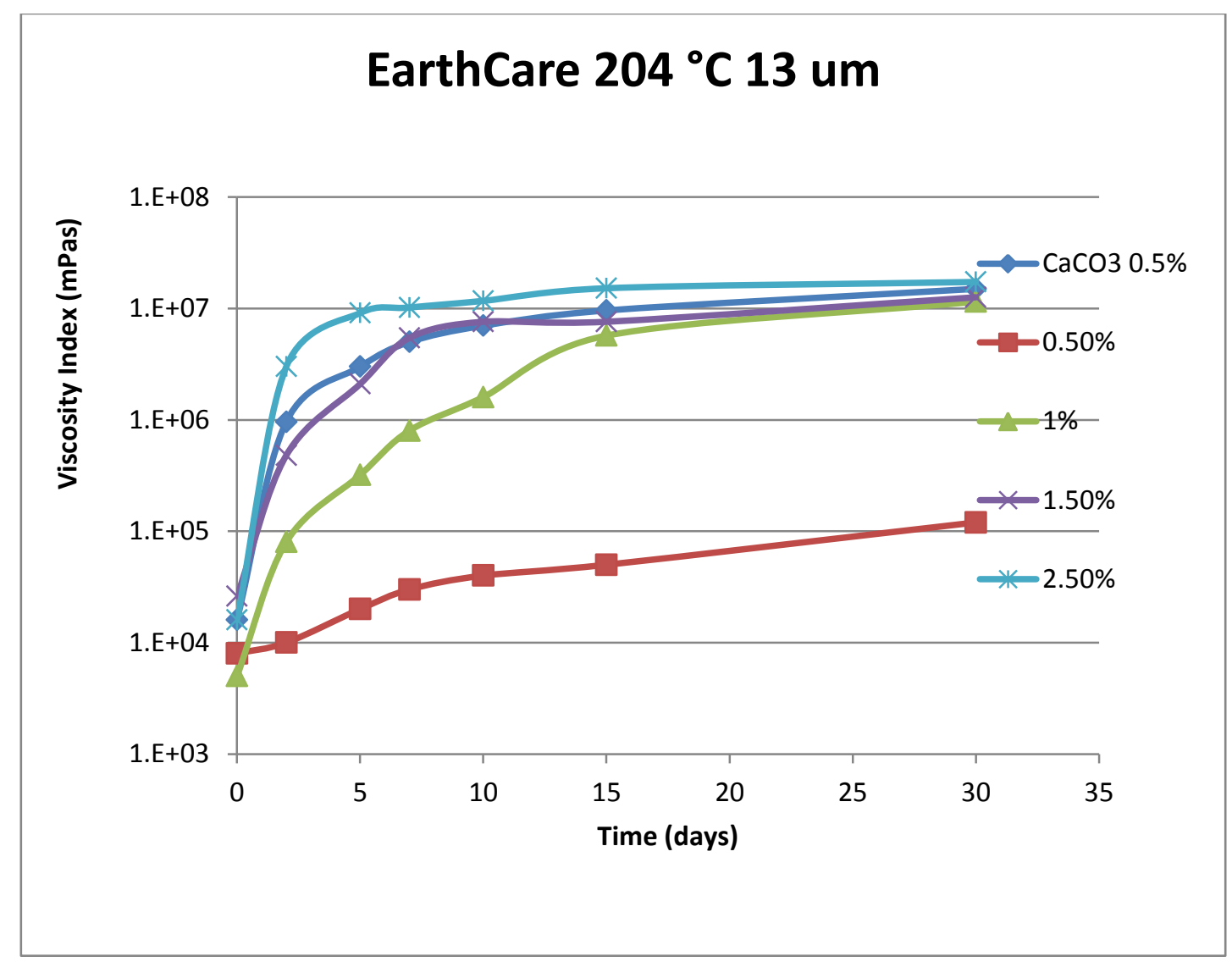

Figure 5.22: Thickening Profile with $204^{\circ} \mathrm{C}$ Torrefacted Filler, \% indicate thickener

EarthCare ${ }^{\circledR}\left[3.4 .5\left(249^{\circ} \mathrm{C} 13 \mathrm{um}\right)\right]$ filler: A $1500 \mathrm{~g}$ master paste mix was made using the formula in Table 5.3, without the thickener or glass fiber. This was split into three aliquots of $450 \mathrm{~g}$ each and thickener was blended in at $0.5 \%, 1 \%$ and $1.5 \%$ total weight. Thickening curves, including a typical $\mathrm{CaCO}_{3}$-filled control curve, are seen in Figure 5.23. The thickening response with this filler was much more abrupt, reaching a plateau within 2 days. The $\mathrm{CaCO}_{3}$ control and the previously evaluated soy filler mixes plateaued at roughly 10-15 days. The plateau level of $10 \mathrm{M} \mathrm{mPa}^{*}$, with this filler, was also insensitive to the thickener loading, with even the standard $0.5 \%$ loading reaching that level within 2 days. 


\section{EarthCare $249{ }^{\circ} \mathrm{C} 13$ um}

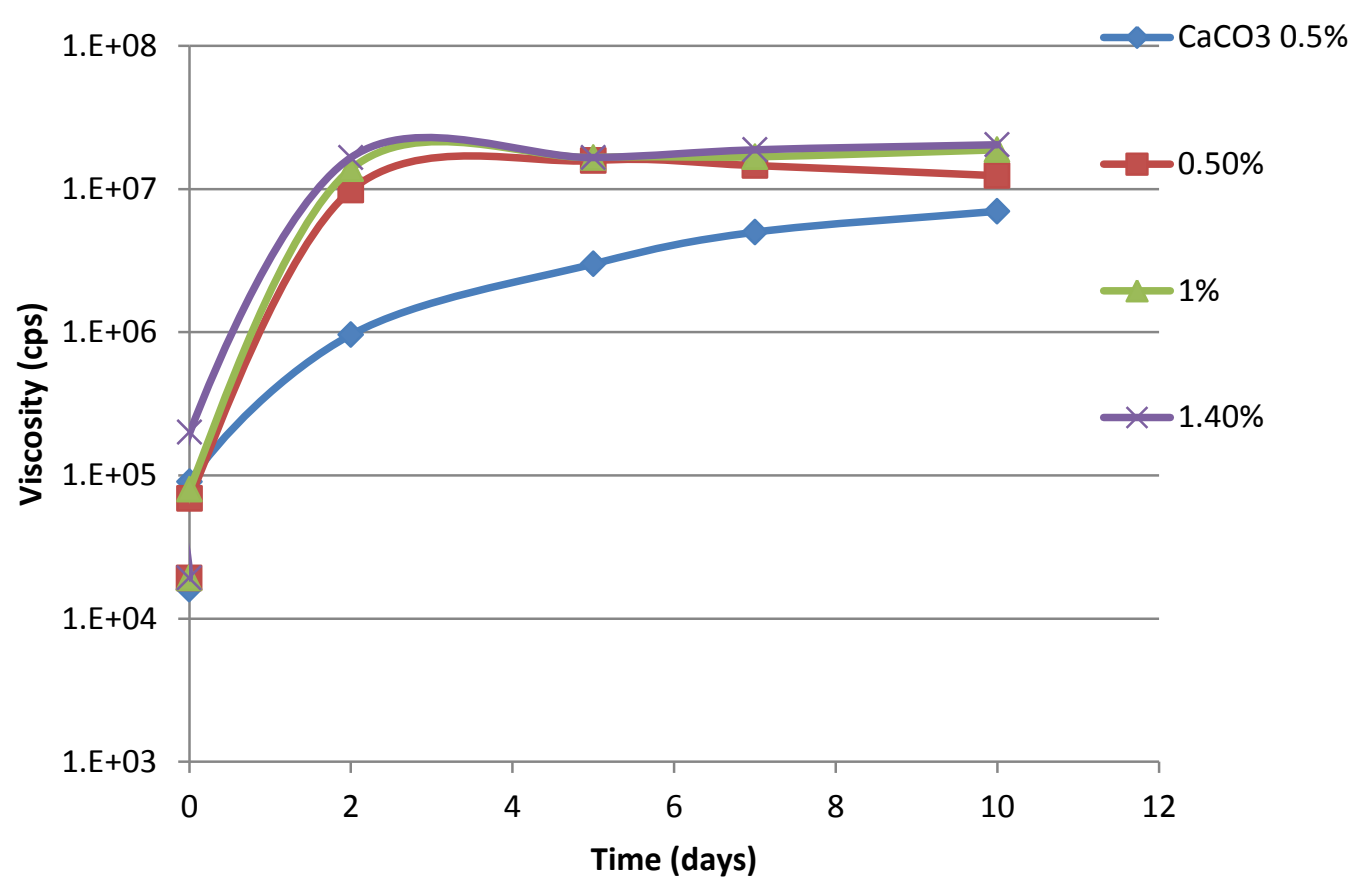

Figure 5.23: Thickening Profile with $249{ }^{\circ} \mathrm{C}$ Torrefacted Filler, \% indicates thickener

A possible explanation for why this filler did not have the thickening repression effect, which was observed with the other soy fillers tested, was that the high temperature treatment resulted in elimination of cellulose hydroxyls. It is not clear why the thickening was accelerated relative to $\mathrm{CaCO}_{3}$. Perhaps this is due to the alkalinity of $\mathrm{CaCO}_{3}$, which may impact the thickening response. 


\subsubsection{Squeeze Flow Rheometry}

SMC batches were made using the formula in Table 5.6. PPT stress profiles for five samples each, of a $\mathrm{CaCO}_{3}$-filled SMC and an analogous SMC filled with the EarthCare ${ }^{\circledR}\left[3.4 .5\left(249^{\circ} \mathrm{C}\right)\right]$ filler are presented in Figure 5.24. The initial rise is plotted in Figure 5.25. Averaged viscosity vs. shear rate and normalized relaxation curves are seen in Figure 5.26 and 5.27, respectively. Values derived from the PPT curves, along with the Brookfield viscosity index, are seen in Table 5.7.

Table 5.6: SMC Formula for PPT Samples

\begin{tabular}{|c||c|c|}
\hline Formula & CaCO3 & BioFiller \\
\hline Ingredients & \%BOW & \%BOW \\
\hline \hline UPE Resin solution & 10.8 & 14.7 \\
\hline LPA & 10.8 & 14.7 \\
\hline Styrene & 2.7 & 3.7 \\
\hline Peroxide & 0.3 & 0.4 \\
\hline Inhibitor & 0.2 & 0.3 \\
\hline Pigment & 3.0 & 4.1 \\
\hline Mold release & 1.3 & 1.8 \\
\hline Thixotrope & 0.2 & 0.3 \\
\hline Filler & 43.1 & 22.6 \\
\hline Thickener & 0.5 & 0.7 \\
\hline Glass Fiber & 27.0 & 36.8 \\
\hline
\end{tabular}

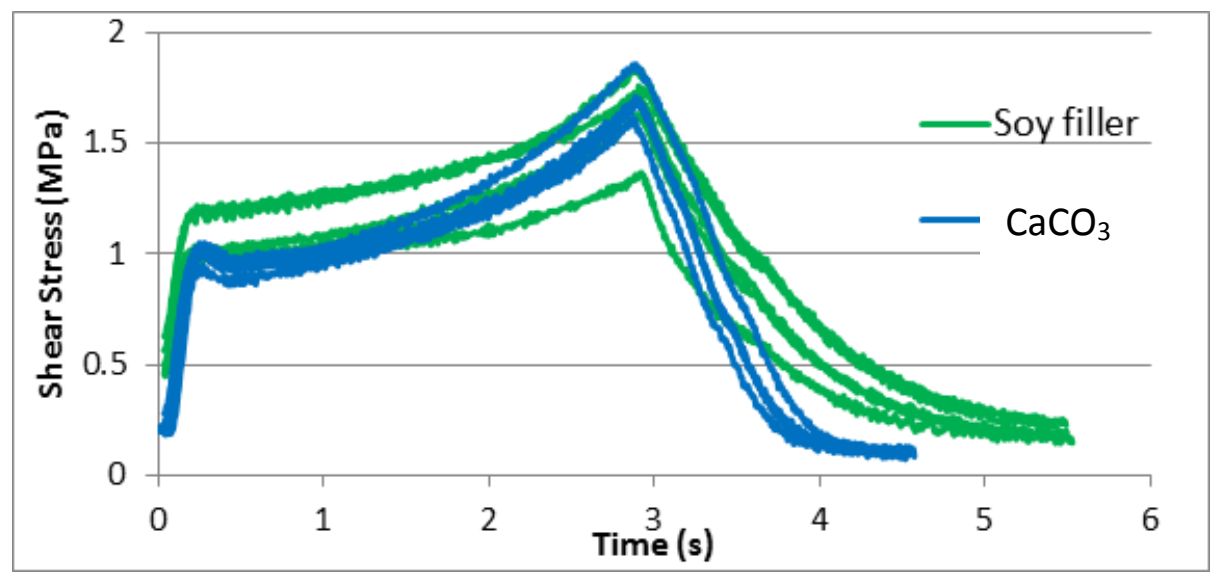

Figure 5.24: PPT Data for $\mathrm{CaCO}_{3}$ and Soy Filler SMCs 


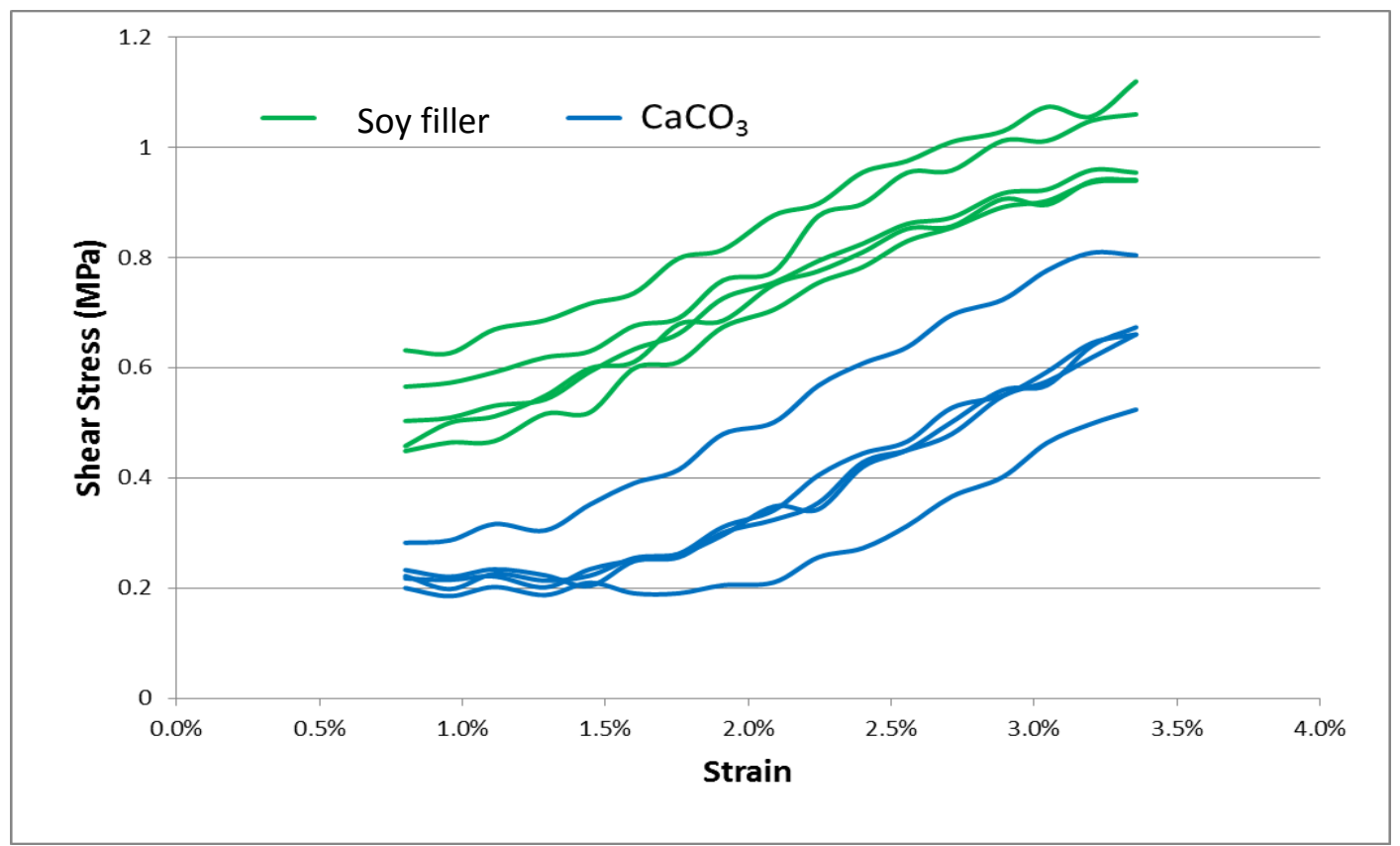

Figure 5.25: Initial Stress Increase

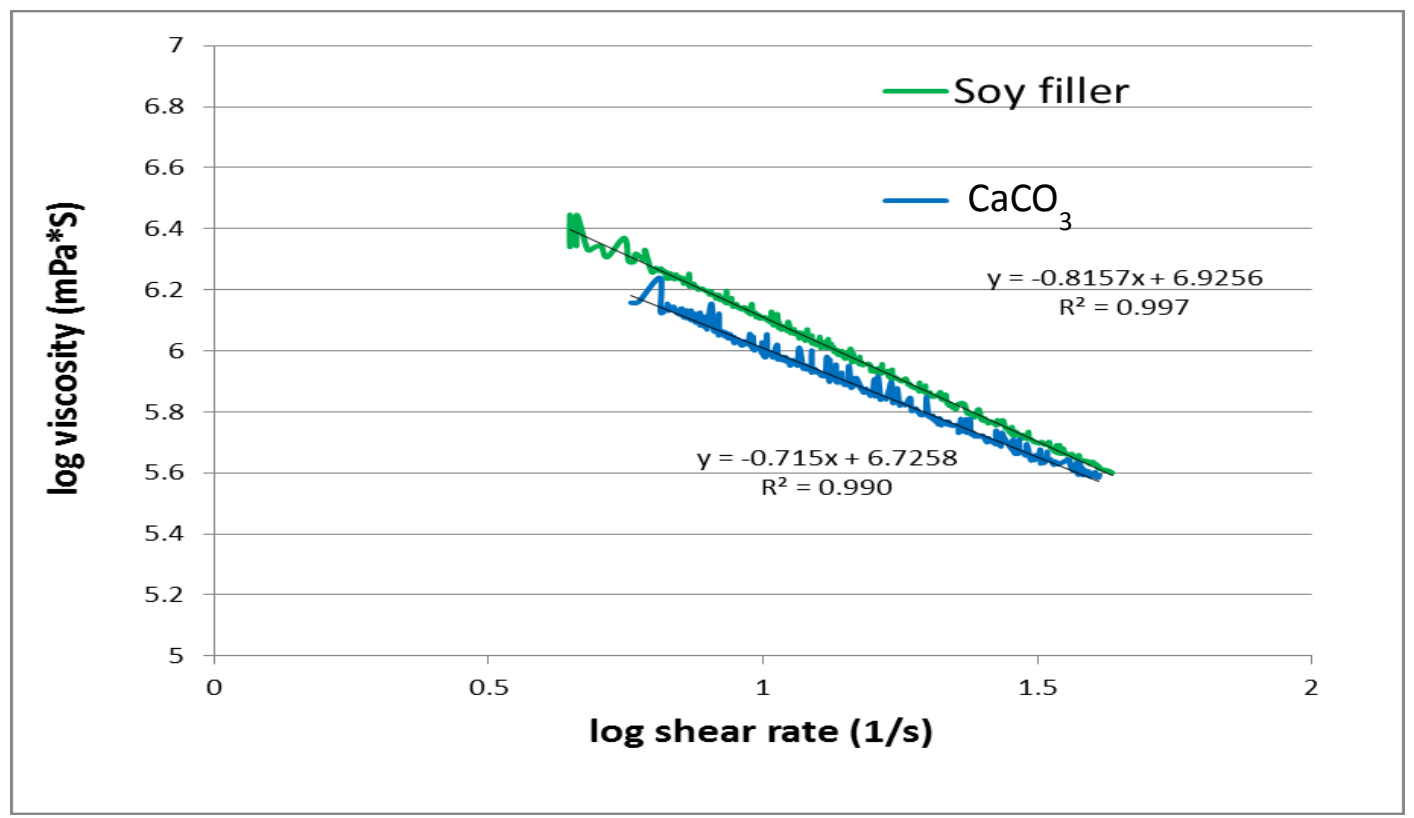

Figure 5.26: Viscosity vs. Shear Rate Curves 


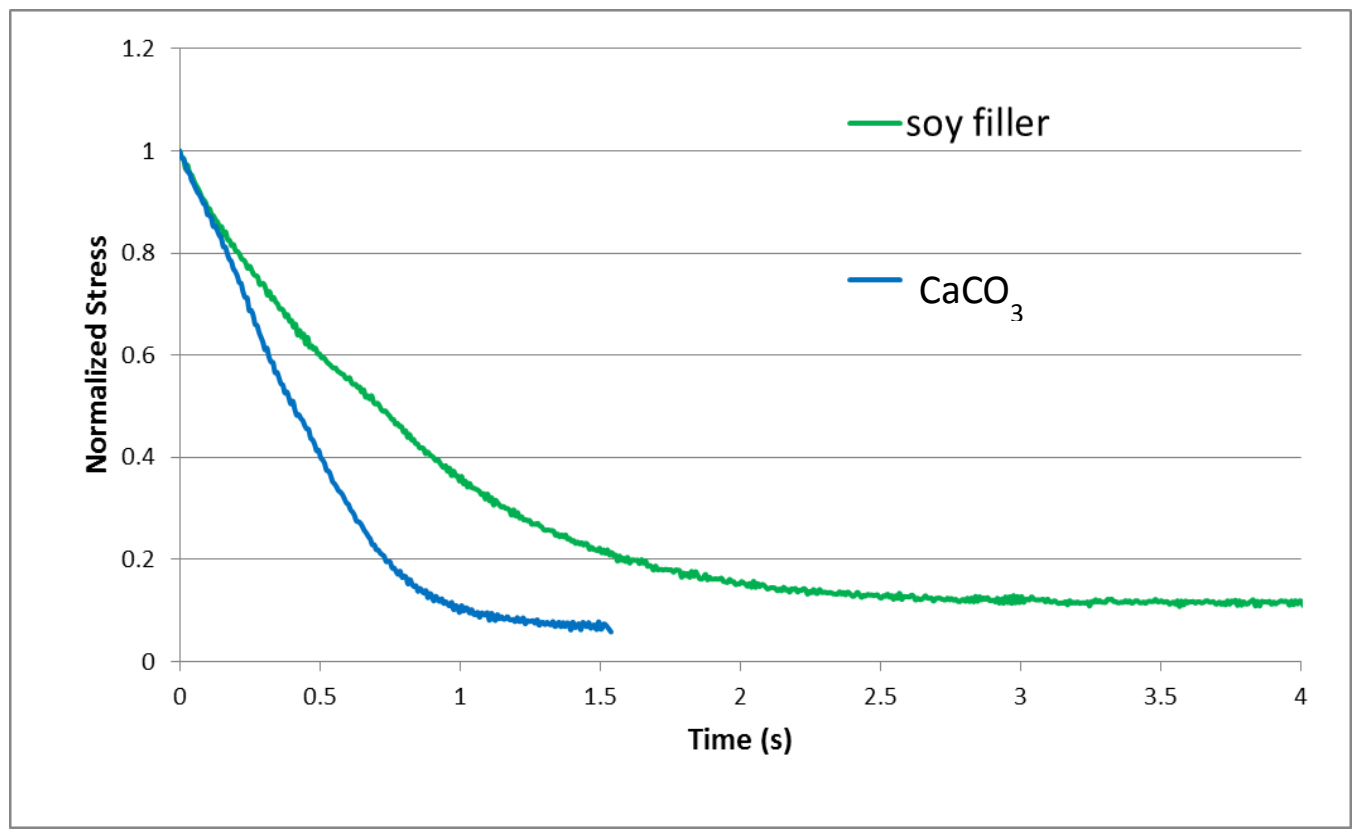

Figure 5.27: Normalized Stress Relaxation Curves

Table 5.7: Calculated Values from PPT Curves

\begin{tabular}{|c|c|c|c|c|c|c|c|c|c|}
\hline & $\begin{array}{l}\text { Brookitield } 2 \\
\text { day paste } \\
\text { viscosity }\end{array}$ & $\begin{array}{c}\text { Brookitield } 30 . \\
\text { day paste } \\
\text { viscosity }\end{array}$ & $\begin{array}{c}\text { PPT SMC } \\
\text { precompaction } \\
\text { stress }\end{array}$ & $\begin{array}{c}\text { PPT SMC } \\
\text { compression } \\
\text { modulus }\end{array}$ & $\begin{array}{l}\text { PPT SMC } \\
\text { yield stress }\end{array}$ & $\begin{array}{l}\text { PPT SMC } \\
\text { yield strain }\end{array}$ & $\begin{array}{c}\text { PPT SMC } \\
\text { viscosity at } \\
10 \sec ^{-1}\end{array}$ & $\begin{array}{l}\text { Power Law } \\
\text { Index }\end{array}$ & $\begin{array}{c}\text { Relaxation } \\
\text { time }\end{array}$ \\
\hline & (M mPa-s) & $(\mathrm{MmPa} \cdot \mathrm{s})$ & (MPa) & (MPa) & (MPa) & $(\%)$ & (M mPa-s) & & (s) \\
\hline Bio-Filler & 9.8 & 15 & 0.56 & 0.22 & 1.04 & 5.6 & 1.3 & 0.18 & 2.3 \\
\hline $\mathrm{CaCO}_{3}$ & 11 & 19.5 & 0.23 & 0.22 & 0.98 & 6.1 & 1.0 & 0.28 & 1.3 \\
\hline
\end{tabular}

In this formulation, the thickening response of the bio-filler SMC paste was similar to that of the $\mathrm{CaCO}_{3}$-filled $\mathrm{SMC}$, with a viscosity index of $11 \mathrm{vs} .10 \mathrm{mPa}$-s at 2 days and 20 vs $15 \mathrm{mPa}$-s at 30 days. The SMC apparent viscosity at $10 \sec ^{-1} 1$ was 1.3 vs. 
$1.0 \mathrm{mPa}$-s. With the $\mathrm{CaCO}_{3}$ filled SMC, the stress did not begin to increase at the $10 \%$ precompaction start point. This is an indication of incomplete compaction and trapped air. The bio-filler SMC was fully precompacted at $10 \%$, indicating better exclusion of air and improved fiber wetting. The initial stresses are higher for the soy filler SMC because of the more complete precompaction at the test start. Once the $\mathrm{CaCO}_{3}$-filled $\mathrm{SMC}$ stress rise began, the slope, or modulus, of the two were identical. Likewise, the yield stress was essentially the same for both materials, although the bio-filler SMC yielded at a lower strain due to the more complete precompaction at the start of the test. The most significant differences between the two materials were the power law index of 0.2 for the bio-filler SMC vs. 0.3 for the $\mathrm{CaCO}_{3}$-filled SMC, and the stress relaxation times of 2.3 and $1.3 \mathrm{sec}$, respectively.

\subsubsection{Dielectric Analysis (DEA) of System Cure}

The same SMC used in the squeeze flow rheometry study, whose formula is found in Table 5.6, was evaluated for cure behavior. The Signature ${ }^{\circledR}$ DEA impedance curves for $3.2 \mathrm{~cm}$ thick bio-filler and $\mathrm{CaCO}_{3}$-filled $\mathrm{SMC}$ molded plaques is shown in Figure 5.28. The $\mathrm{CaCO}_{3}$-filled $\mathrm{SMC}$ had a flat impedance plateau, rather than a peak, during gelation. This is a known anomaly of the technique at lower frequencies. The peak impedance for the bio-filler SMC corresponds to the center of the impedance plateau for the $\mathrm{CaCO}_{3}$-filled SMC, indicating similar gel times. The return to baseline timing, indicating completion of cure, was also similar. The higher impedance after cure for the soy filler SMC could be due to polar species that are present in the bio-filler or 
due to the lower stiffness of the bio-filled matrix relative to the $\mathrm{CaCO}_{3}$ filled matrix. In both cases, more dipole flipping would be facilitated.

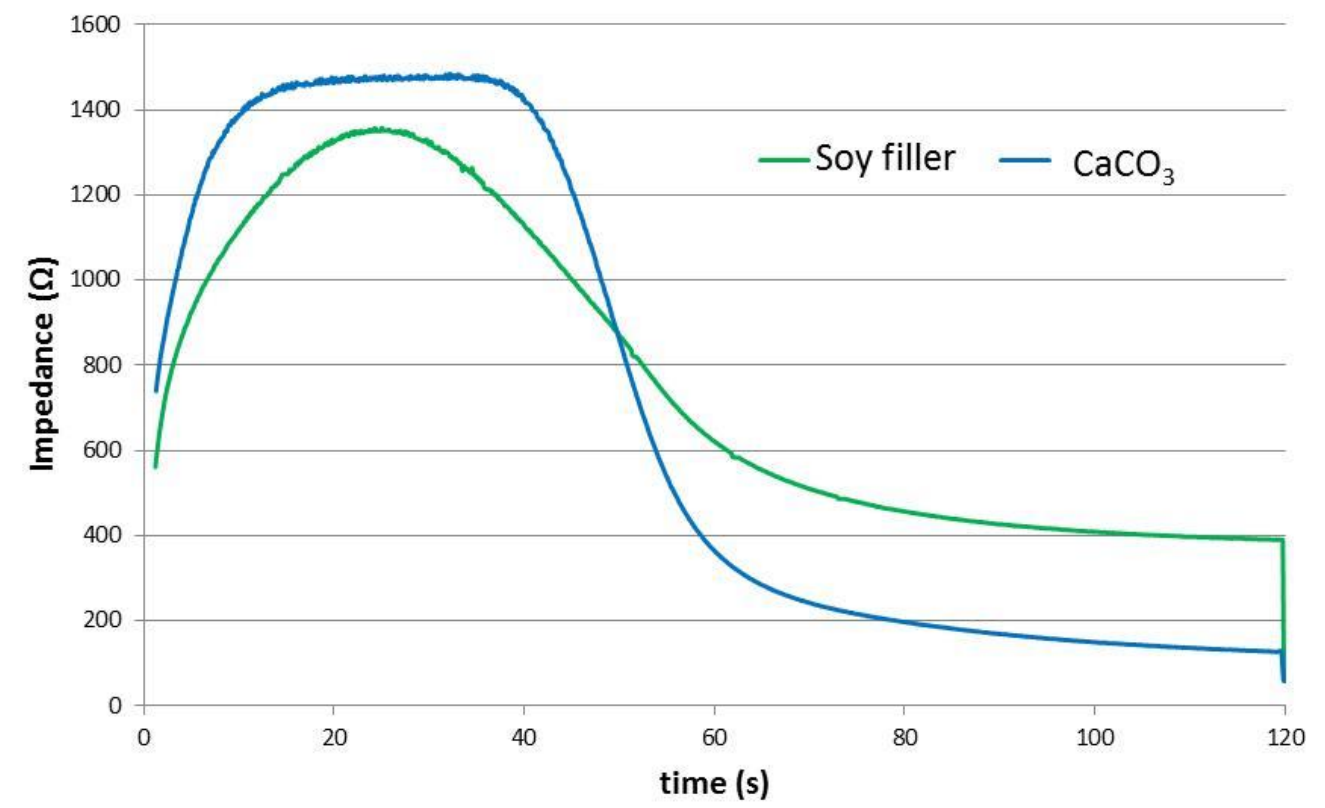

Figure 5.28: Signature ${ }^{\circledR}$ DEA Curves

\subsubsection{Reaktometer Molding Process Study}

In spite of the similar DEA curves at $3.2 \mathrm{~mm}$ thick, in molding of actual parts some hold time extension was necessary to avoid blow out blisters in thick sections. The cure response as a function of thickness was studied to provide insight into this issue. The same SMC that was used for the squeeze flow comparisons, with the formula in Table 5.6, was tested using the Reaktometer, which is equipped with dielectric, pressure, displacement and temperature sensors. Data for $3.2 \mathrm{~cm}$ and $6.4 \mathrm{~cm}$ thick panels are presented in Figures 5.29 through 5.32. Data is summarized in Tables 5.8 and 5.9. 


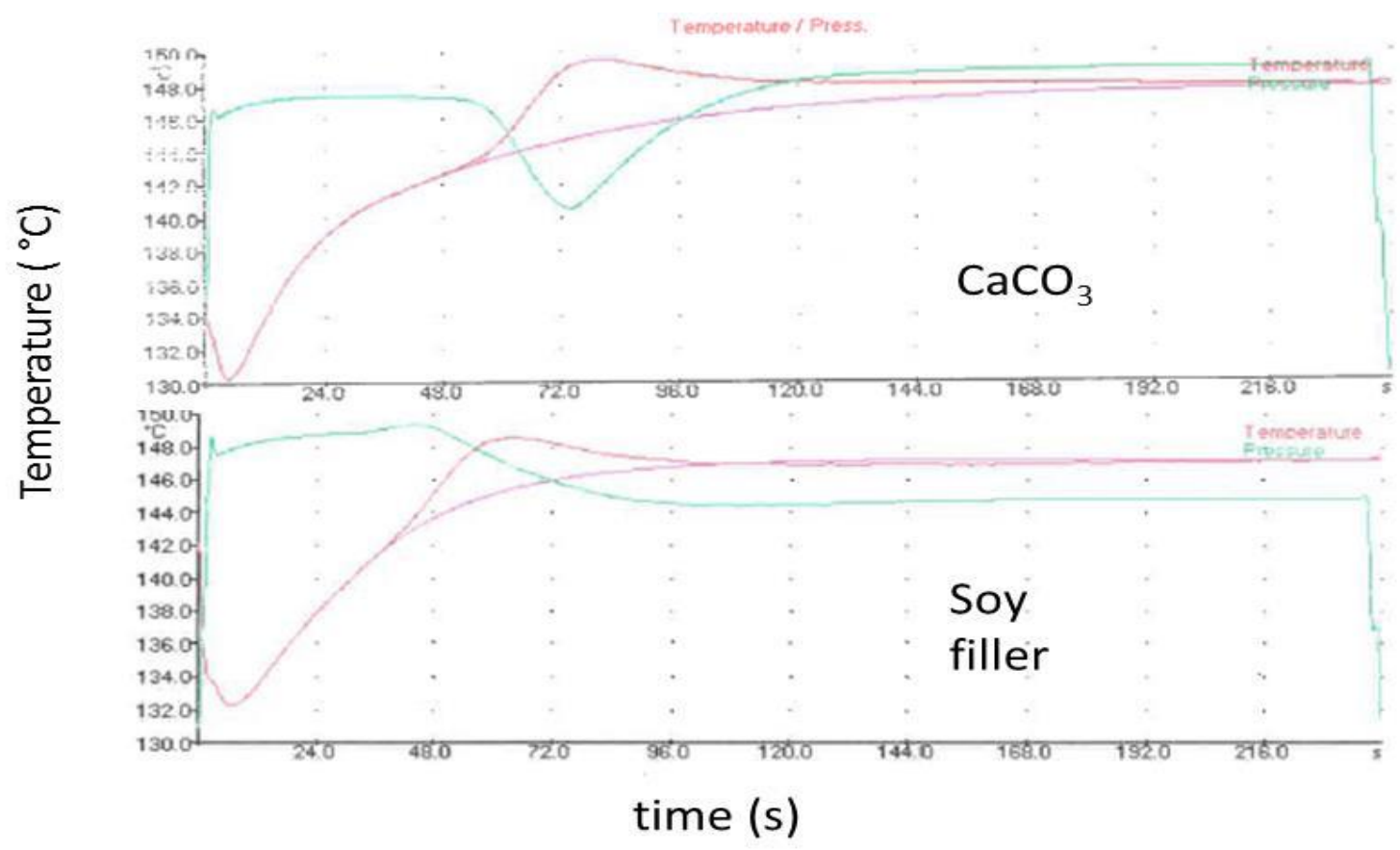

Figure 5.29: Reaktometer Temperature (pink) and Pressure (green) for $3.2 \mathrm{~mm}$ Panels

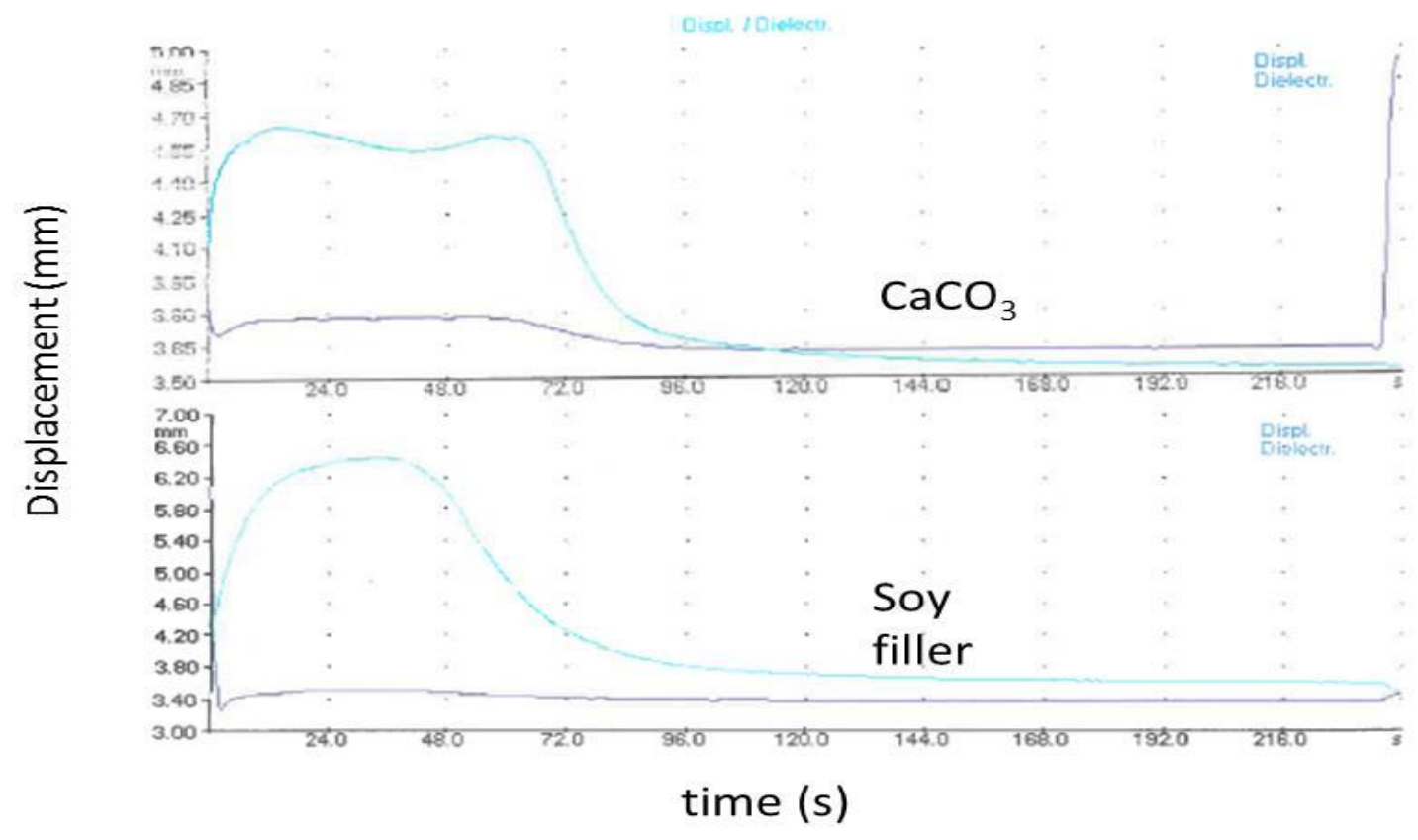

Figure 5.30: Reaktometer Impedance (blue) and Displacement (black) for $3.2 \mathrm{~mm}$ Panels 


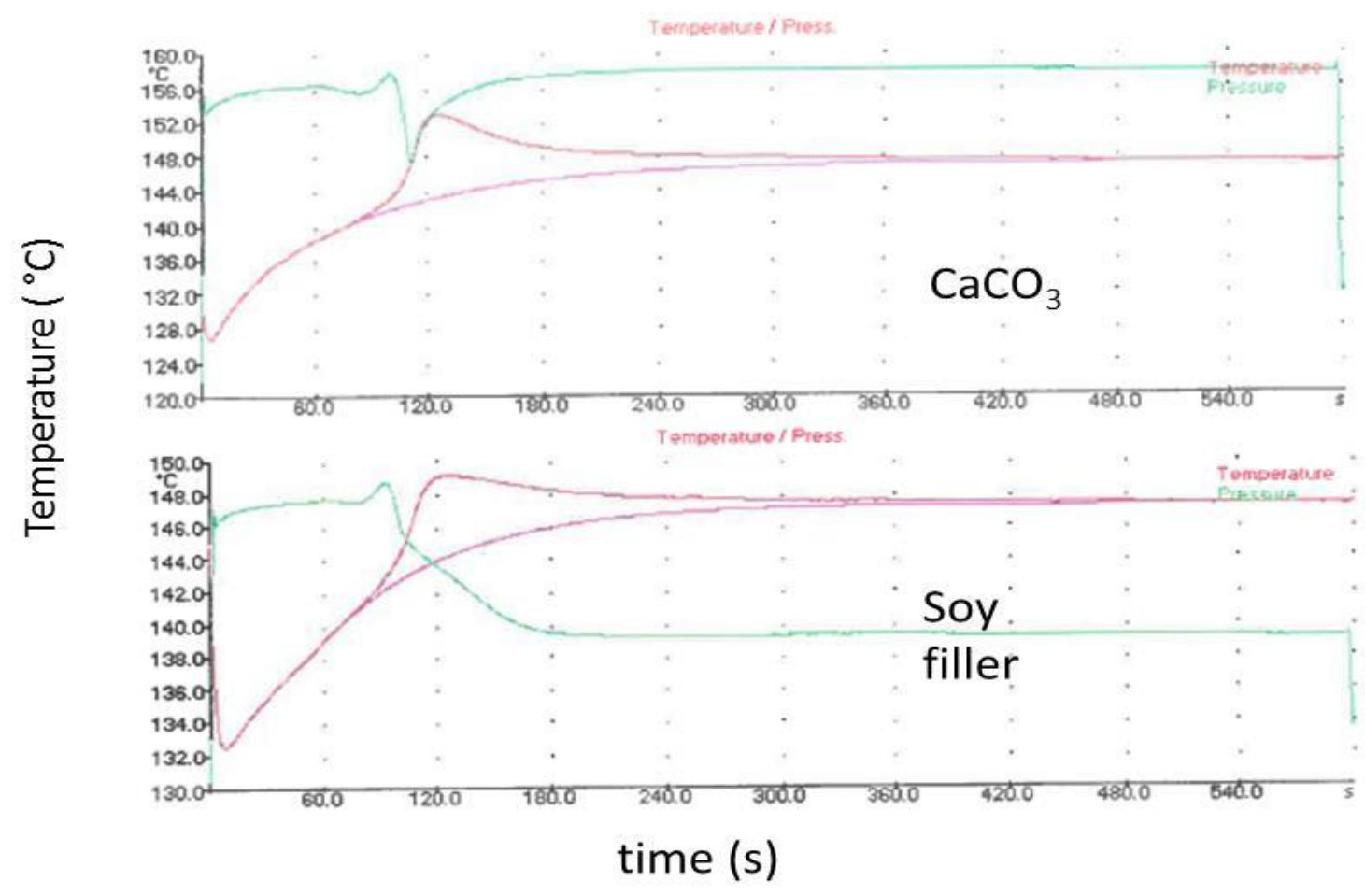

Figure 5.31: Reaktometer Temperature (pink) and Pressure (green) for $6.4 \mathrm{~mm}$ Panels

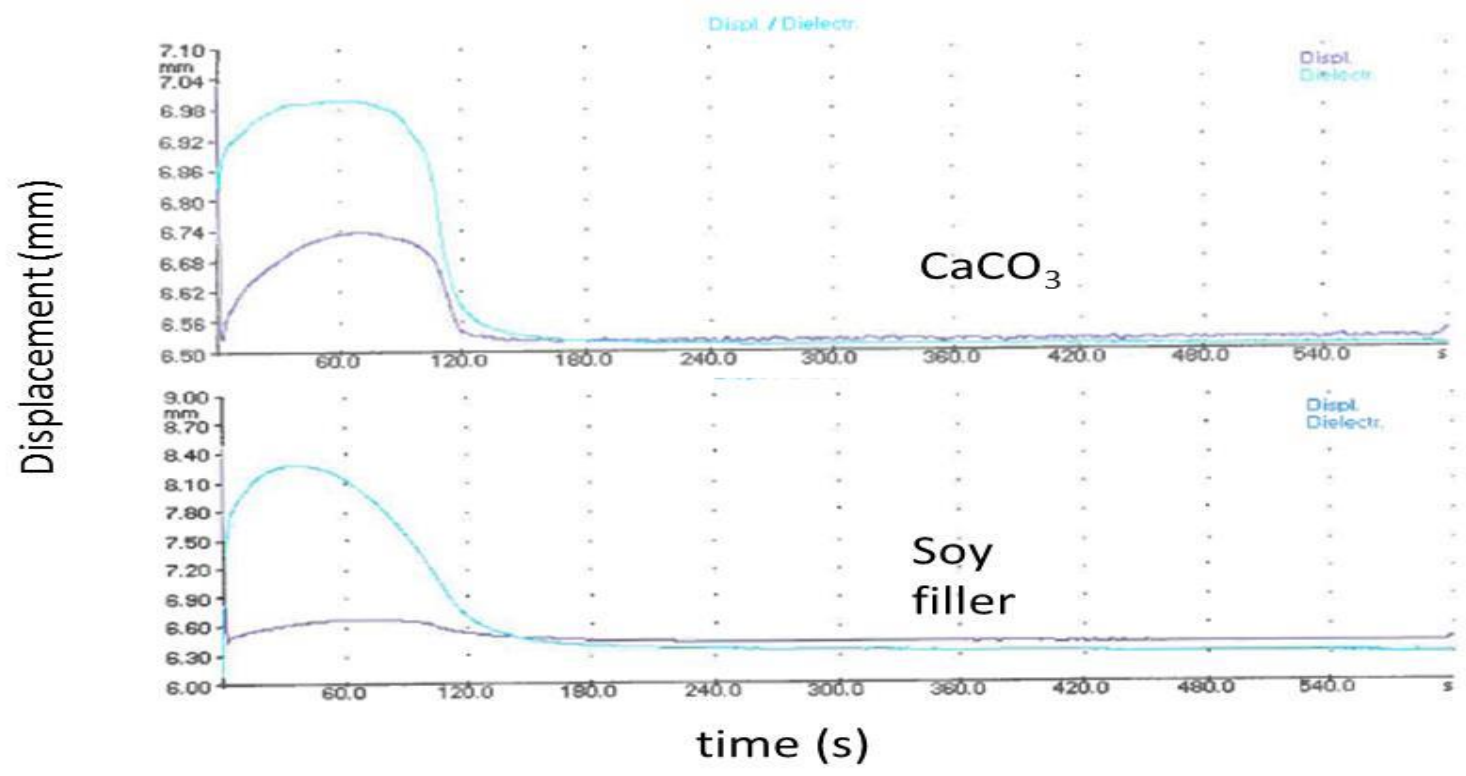

Figure 5.32: Reaktometer Impedance (blue) and Displacement (black) for $6.4 \mathrm{~mm}$ Panels 
Table 5.8: Values from Cure Studies at $3.2 \mathrm{~mm}$ Thick

\begin{tabular}{|c|c|c|c|c|c|c|c|c|c|c|}
\hline Filler & $\begin{array}{l}\text { Signature } \\
\text { Gel time }\end{array}$ & $\begin{array}{l}\text { Signature } \\
\text { Cure time }\end{array}$ & Peak Impedance & Final Impedance & $\begin{array}{l}\text { Reaktomete } \\
\text { Gel time }\end{array}$ & $\begin{array}{l}\text { Reaktometer } \\
\text { Cure time }\end{array}$ & $\begin{array}{l}\text { Reaktomete } \\
\text { Start of } \\
\text { exotherm }\end{array}$ & $\begin{array}{l}\text { Reaktomete } \\
\text { Time to peal } \\
\text { exotherm }\end{array}$ & $\begin{array}{l}\text { Reaktioneter } \\
z \text { zirection } \\
\text { shriknage }\end{array}$ & $\begin{array}{c}\text { QA } x-y \\
\text { expansion }\end{array}$ \\
\hline & (s) & (s) & 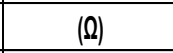 & 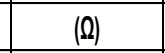 & (s) & (s) & (s) & (s) & (\%) & $(\%)$ \\
\hline Bio-Filler & 28 & 100 & 1353 & 390 & 34 & 72 & 38 & 64 & -3.7 & 0.5 \\
\hline $\mathrm{CaCO}_{3}$ & 38 & 80 & 1470 & 118 & 65 & 82 & 45 & 80 & 0 & 0.5 \\
\hline
\end{tabular}

Table 5.9: Values from Cure Studies at $6.4 \mathrm{~mm}$ Thick

\begin{tabular}{|c|c|c|c|c|c|}
\hline Filler & $\begin{array}{c}\text { Reaktometer } \\
\text { Gel time }\end{array}$ & $\begin{array}{c}\text { Reaktometer } \\
\text { Cure time }\end{array}$ & $\begin{array}{c}\text { Reaktometer } \\
\text { Start of } \\
\text { exotherm }\end{array}$ & $\begin{array}{c}\text { Reaktometer } \\
\text { Time to peak } \\
\text { exotherm }\end{array}$ & $\begin{array}{c}\text { Reaktometer } \\
\text { z direction } \\
\text { shrinkage }\end{array}$ \\
\hline Bio-Filler & $(\mathrm{s})$ & $(\mathrm{s})$ & $(\mathrm{s})$ & $(\mathrm{s})$ & $(\%)$ \\
\hline $\mathrm{CaCO}_{3}$ & 57 & 124 & 73 & 126 & 0.3 \\
\hline
\end{tabular}

In all cases, the impedance data indicated that the bio-filler SMC had lower gel time than the $\mathrm{CaCO}_{3} \mathrm{SMC}$. The cure time results between tests, however, were inconsistent, with the Signature ${ }^{\circledR}$ and $6.4 \mathrm{~mm}$ thick Reaktometer tests indicating faster cure for the $\mathrm{CaCO}_{3}$ filled SMC; and the $3.2 \mathrm{~mm}$ Reaktometer test indicating the bio-filler SMC was faster. Visual comparison of the curves indicates similar timing for cure completion, in all cases, but impedance levels varied. The cure time for both devices is automatically set at a trigger slope value for the impedance. Because the peak and final impedance for the two materials are different, this method of determining the cure time is not valid and the visual assessment has more merit. 
5.5.5 Mechanical Performance and Aesthetics

SMC was made with meal filler torrefied by ATP/NCSU [3.4.3 a] using the formula in Table 5.6. Mechanical properties and water absorption for the soy filler SMC are reported in Table 5.10, along with properties for a commercial $1.85 \mathrm{~g} / \mathrm{cm}^{3}$ density SMC, which has similar volume loading of glass fibers. The calculated bio-based on organic content, which is the projected bio-based on carbon (BBC) content of the material, is reported as well. \%BBC is the criteria used by the USDA to quantify the biocontent of products.

Table 5.10 Mechanical Properties of SMC

\begin{tabular}{|c|c|c|c|c|c|c|c|c|}
\hline $\begin{array}{c}\text { SMC from } \\
\text { Molded } \\
\text { specimen }\end{array}$ & BBC & density & $\begin{array}{c}\text { Flexural } \\
\text { Strength }\end{array}$ & $\begin{array}{c}\text { Flexural } \\
\text { Modulus }\end{array}$ & $\begin{array}{c}\text { Tensile } \\
\text { Strength }\end{array}$ & $\begin{array}{c}\text { Tensile } \\
\text { Modulus }\end{array}$ & $\begin{array}{c}\text { Notched } \\
\text { Izod }\end{array}$ & $\mathrm{H}_{2} \mathrm{O}$ Abs \\
\cline { 2 - 9 } & $(\%)$ & $(\mathrm{g} / \mathrm{cc})$ & $(\mathrm{MPa})$ & $(\mathrm{MPa})$ & $(\mathrm{MPa})$ & $(\mathrm{MPa})$ & $(\mathrm{J} / \mathrm{m})$ & $(\%)$ \\
\hline $\begin{array}{c}\text { Torr Soy Meal } \\
\text { SL 1352-A3 }\end{array}$ & 22 & 1.39 & 104 & 4668 & 46 & 5380 & 629 & 2.1 \\
\hline std dev & 0.01 & 11.8 & 384 & 5.4 & 521 & 135 & 0.3 \\
\hline $\begin{array}{c}\text { Typical } \\
\mathrm{CaCO}_{3} \text { filled }\end{array}$ & 0 & 1.85 & 125 & 10000 & 47 & 11000 & 560 & 0.1 \\
\hline
\end{tabular}

The tensile strength was not affected by the type of filler. The flexural strength, however, was $17 \%$ lower and the moduli were roughly half with the soy meal filler. The toughness was enhanced, as evidenced by the notched Izod impacts. Water absorption was very high, as expected, based on the resin casting water weight gain screening experiments. 
A valve cover was molded to evaluate moldability and appearance, as seen in Figure 5.33. Mold temperatures were $147 / 153{ }^{\circ} \mathrm{C}$. The material flowed and filled the part without issue; however, the appearance was not smooth and glossy like the production material moldings. Areas of glass bundles appeared resin starved, and between these were resin-rich areas. The soy filler SMC parts did not develop an encasing resin layer against the mold surface to cover and smooth the glass pattern.

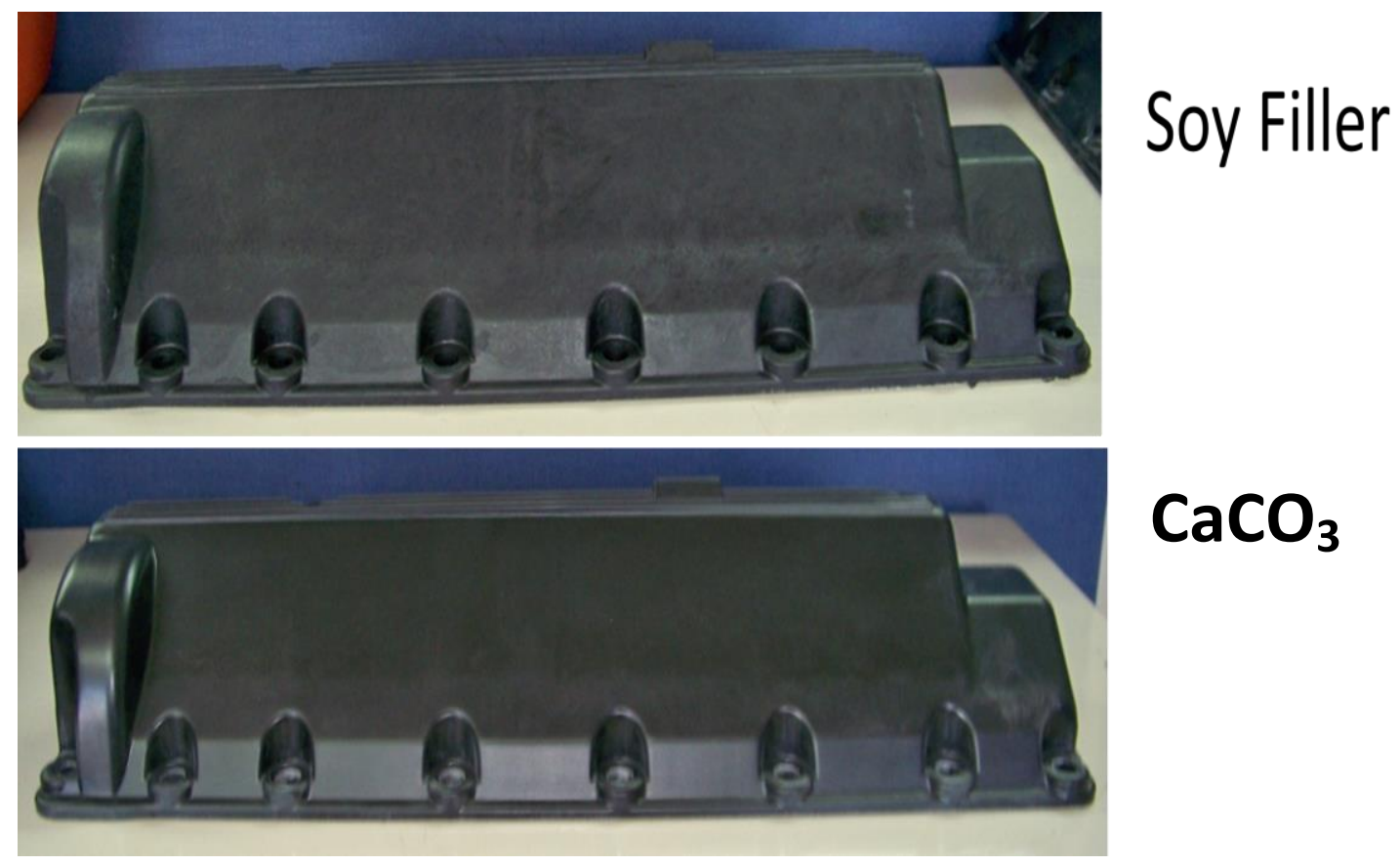

Figure 5.33: SMC Molded Valve Covers

SMC batches, targeting a glass loading of $38 \%$ BOW, were manufactured using torrefacted meal $\left[3.4 .3 \mathrm{a}\left(300{ }^{\circ} \mathrm{C}\right)\right]$ and hulls $\left[3.4 .3 \mathrm{~b}\left(400{ }^{\circ} \mathrm{C}\right)\right]$. Both torrefacted soy samples were processed using the ATP/NCSU pilot machine. The meal was rough ground with a 60 mesh screen, and the hull sample was ground to a nominal 8 micron diameter at Union Process. The finer grind hulls had higher resin demand than the rough 
ground meal. Additional styrene was added for that batch to adjust the viscosity to a usable range. The fine ground hulls agglomerated in the pail after grinding and drying. Chunks were easy to break up by hand, therefore this was done during addition with the expectation that the high shear Cowles mixing would complete the dispersion process. This was not the case and clumping in the mix persisted. When dispensed through the doctor box, the larger clumps blocked resin deposition, resulting in areas in the SMC that were starved of resin paste. After leveling and compaction, fiber wetting looked reasonable; however at $43 \%$, the resulting glass content was higher than the $38 \%$ based on weight target. The actual formulations with the process adjustments are reported in Table 5.11.

Table 5.11 Meal and Hull Filled SMC Formulas

\begin{tabular}{|c|c|}
\hline SL\# & SL1352-A4 \\
\hline \hline Premi-Glas & SF LD1 \\
\hline \hline Color & Black \\
\hline \hline & \\
\hline \hline Ingredients & \%BOT \\
\hline \hline UPE Resin solution & 16.00 \\
\hline PS solution & 10.66 \\
\hline Styrene & 5.00 \\
\hline Peroxide & 0.65 \\
\hline Inhibitor & 0.26 \\
\hline Pigment & 3.85 \\
\hline Mold release & 2.40 \\
\hline & \\
\hline Torr Soy Meal & 20.58 \\
\hline & \\
\hline Thickener & 2.50 \\
\hline & \\
\hline Glass Fiber & 38.10 \\
\hline \hline Total & \\
\hline \hline
\end{tabular}

\begin{tabular}{|c|c|}
\hline SL\# & SL1352-A5 \\
\hline \hline \multicolumn{1}{|c|}{ Premi-Glas } & SF LD1 \\
\hline \hline Color & Black \\
\hline \hline & \\
\hline \hline Ingredients & \%BOT \\
\hline \hline UPE Resin solution & 14.16 \\
\hline PS solution & 9.35 \\
\hline Styrene & 6.57 \\
\hline Peroxide & 0.57 \\
\hline Inhibitor & 0.22 \\
\hline Pigment & 3.38 \\
\hline Mold release & 2.10 \\
\hline & \\
\hline Torr Soy Hulls (8 u) & 18.43 \\
\hline & \\
\hline Thickener & 2.22 \\
\hline & \\
\hline Glass Fiber & 43.00 \\
\hline & \\
\hline \hline Total & 100.00 \\
\hline
\end{tabular}


The cosmetics of the meal SMC molded part was similar to the previous meal sample. There was obvious filler filtering resulting in resin rich areas around glass bundles, particularly in thin areas. This was not seen with the finer hulls; however, cosmetics were poor due to the clumps, which resulted in resin starved regions.

Properties were measured from specimen cut from molded panels. In Table 5.12, the bio-filler SMC properties are compared to those of two commercial low density SMC products: one that employs glass bubbles, to impart reduced density, and one that uses a low level of clay filler. Clay is used, instead of $\mathrm{CaCO}_{3}$, to increase the viscosity of the mix, for improved processing. BBC and water absorption were also included.

Table 5.12 SMC Mechanical Properties

\begin{tabular}{|c|c|c|c|c|c|c|c|c|}
\hline \multirow{2}{*}{$\begin{array}{l}\text { SMC from } \\
\text { Molded } \\
\text { specimen }\end{array}$} & $B B C$ & density & $\begin{array}{l}\text { Flexural } \\
\text { Strength }\end{array}$ & $\begin{array}{l}\text { Flexural } \\
\text { Modulus }\end{array}$ & $\begin{array}{l}\text { Tensile } \\
\text { Strength }\end{array}$ & $\begin{array}{c}\text { Notched } \\
\text { lzod }\end{array}$ & $\begin{array}{l}\text { Tensile } \\
\text { Modulus }\end{array}$ & $\begin{array}{l}\mathrm{H}_{2} \mathrm{O} \\
\mathrm{Abs}\end{array}$ \\
\hline & $(\%)$ & $(g / c c)$ & (MPa) & (MPa) & $(\mathrm{MPa})$ & $(\mathrm{J} / \mathrm{m})$ & (MPa) & $(\%)$ \\
\hline $\begin{array}{c}\text { Torr Soy Meal } \\
\text { SL1352-A4 }\end{array}$ & 35 & 1.45 & 132 & 5907 & 56 & 844 & 7176 & 1.7 \\
\hline std dev & & & 8.1 & 259 & 4.3 & 97 & 1323 & 0.3 \\
\hline $\begin{array}{c}\text { Torr Soy Hulls } \\
\text { SL1352-A5 }\end{array}$ & 35 & 1.4 & 89 & 5338 & 45 & 910 & 8327 & 0.65 \\
\hline std dev & & & 29.2 & 1924 & 18.5 & 154 & 2084 & 0.05 \\
\hline $\begin{array}{l}\text { Glass bubble } \\
\text { low density }\end{array}$ & 13 & 1.2 & 160 & 7000 & 65 & 700 & 8000 & 0.2 \\
\hline $\begin{array}{l}\text { Low filler } \\
\text { low density }\end{array}$ & 0 & 1.5 & 220 & 8000 & 100 & 1100 & 8500 & 0.6 \\
\hline
\end{tabular}


The density of the bio-filler SMCs was similar to the low level, clay filler, commercial product. The strength and modulus, of the meal SMC, was roughly $80-90 \%$ of the glass bubble commercial product. The hull SMC had poor strength, possibly due to the stress concentration of the clumps, or perhaps due to undercure as a result of cure inhibition, which was observed in the cast resin water weight gain screening test. Izod impact, an indication of toughness, was better for both soy filler SMCs than the glass bubble SMC. The water absorption of the meal SMC was $1.7 \%$. The hull-filled SMC had water absorption similar to the low filler, clay-filled, SMC. The projected cost of the soy fillers was roughly $33 \%$ lower than low level clay filler SMC on a volume basis and $25 \%$ lower than the glass bubble SMC on a volume basis. This would position the product favorably for applications requiring weight reduction, such as automotive or mass transit components. 


\section{CHAPTER VI}

\section{ANALYTICAL EVALUATIONS OF PREFERRED TREATMENTS}

\subsection{Purpose of Analytical Evaluations}

The purpose of the analytical studies in this chapter, is to understand the changes imparted in the material, when it was converted from the hydrophillic precursor to a less hydrophillic filler. The chemical and physical characteristics of the fillers can then be related to performance in terms of water resistance and other attributes important for composite performance.

\subsection{Instrumentation and Default Parameters}

Various methods were used to characterize the filler candidates that exhibited promising performance. The studies were intended to assist in understanding the filler transformations due to the different modification methods and to characterize the performance of the filler and compounds made with the fillers.

\subsubsection{Fourier Transform Infra-Red (FTIR) Spectroscopy}

A Nicolet Magna-IR 750 spectrometer with a nitrogen purge was used. An attenuated total reflection (ATR) sampler was employed for most of the fillers and 
extracted residue samples. For the heat treated soy hull fillers, transmission mode for filler pressed in $\mathrm{KBr}$ specimen was used due to the low intensity of the absorbances. Each spectrum was obtained using 64 scans and $4.0 \mathrm{~cm}^{-1}$ resolution.

\subsubsection{Elemental Analysis (EA)}

Prior to EA analysis, samples were dried for 2 days under vacuum at $25{ }^{\circ} \mathrm{C}$. A Perkin Elmer Series II CHNS/O Analyzer 2400, calibrated with acetanilide, was used to measure carbon, hydrogen and nitrogen contents of the filler combustibles. The remaining content was assigned to oxygen.

\subsubsection{Thermal Gravimetric Analysis (TGA)}

Prior to TGA testing, samples were dried under vacuum at $25^{\circ} \mathrm{C}$ for 2 days and then stored in a desiccator. A Perkin Elmer TGA-7 system was ramped from $40{ }^{\circ} \mathrm{C}$ to $250{ }^{\circ} \mathrm{C}$ at $40^{\circ} \mathrm{C} / \mathrm{min}$ for thermal weight loss curves, under a nitrogen purge. The instrument was calibrated with 5, 10, 50 and $100 \mathrm{mg}$ weights and with nickel and perkalloy wire for temperature.

\subsubsection{Differential Scanning Calorimetry (DSC)}

A Perkin Elmer DSC-7 calorimeter with nitrogen purge was used, in isothermal hold at $80{ }^{\circ} \mathrm{C}$ or $85{ }^{\circ} \mathrm{C}$ for the time required for the exotherm to return to baseline. Temperature ramp experiments from 30 to $250{ }^{\circ} \mathrm{C}$ at $20^{\circ} \mathrm{C} / \mathrm{min}$ were used to determine total exotherm. Samples were sealed in gasketed aluminum pans. Indium and zinc standards were used for temperature and enthalpy calibration. 


\subsubsection{Solid State Nuclear Magnetic Resonance (SS NMR)}

A BRUKER AVANCE III $300 \mathrm{MHz}$ NMR was used to obtain solid-state ${ }^{13} \mathrm{C}$ high speed magic-angle spinning (CPMAS) NMR spectra of filler samples at a resonance frequency of 75.6 MHz. A double resonance probe, at $13000 \mathrm{~Hz}$ spinning speed, with a $2 \mathrm{~ms}$ cross-polarization contact time and a pulse repetition rate of $2 \mathrm{~s}$ was employed.

\subsection{FTIR Analysis of Refined Soy Fillers}

Fourier transform infra-red (FTIR) spectroscopy using attenuated total reflectance (ATR) sampling was employed to evaluate the composition of the enzymatically refined soy proteins [3.3.2 b] in comparison to the soy flour precursor, as seen in Figure 6.1. The upper spectra was a refined sample with a protein content of greater than $90 \%$ (SPI) and the lower was the untreated soy flour (UTSF). The alkane C-H stretch absorbances at 2800 to $3000 \mathrm{~cm}^{-1}$ and $\mathrm{C}-\mathrm{H}$ bend absorbance at $1450 \mathrm{~cm}^{-1}$ intensified relative to the hydroxyl O-H stretch absorbances centered at $3300 \mathrm{~cm}^{-1}$. An absorption at $1790 \mathrm{~cm}^{-1}$ immerged. This region is where a $\mathrm{C}=\mathrm{O}$ stretch of strained ring is found. The amide $\mathrm{C}=\mathrm{O}$ stretch absorption at $1650 \mathrm{~cm}^{-1}$ intensified relative other local absorbances.

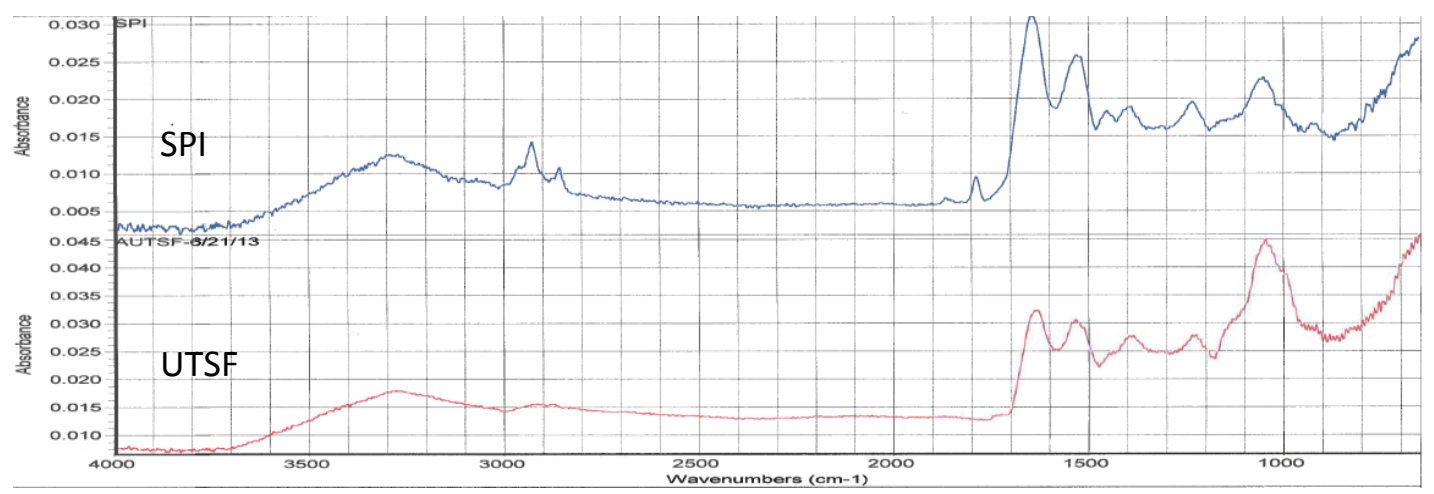

Figure 6.1: ATR FTIR of SPI and UTSF 
Figure 6.2 shows the SPI spectra with a soy-derived acetate. Many of the SPI absorbances were consistent with this soy compound, although the ester absorption at $1050 \mathrm{~cm}^{-1}$ and absorbances at wavenumbers less than $900 \mathrm{~cm}^{-1}$, which were also found in the UTSF structure, persisted indicating that the protein is not $100 \%$ pure.

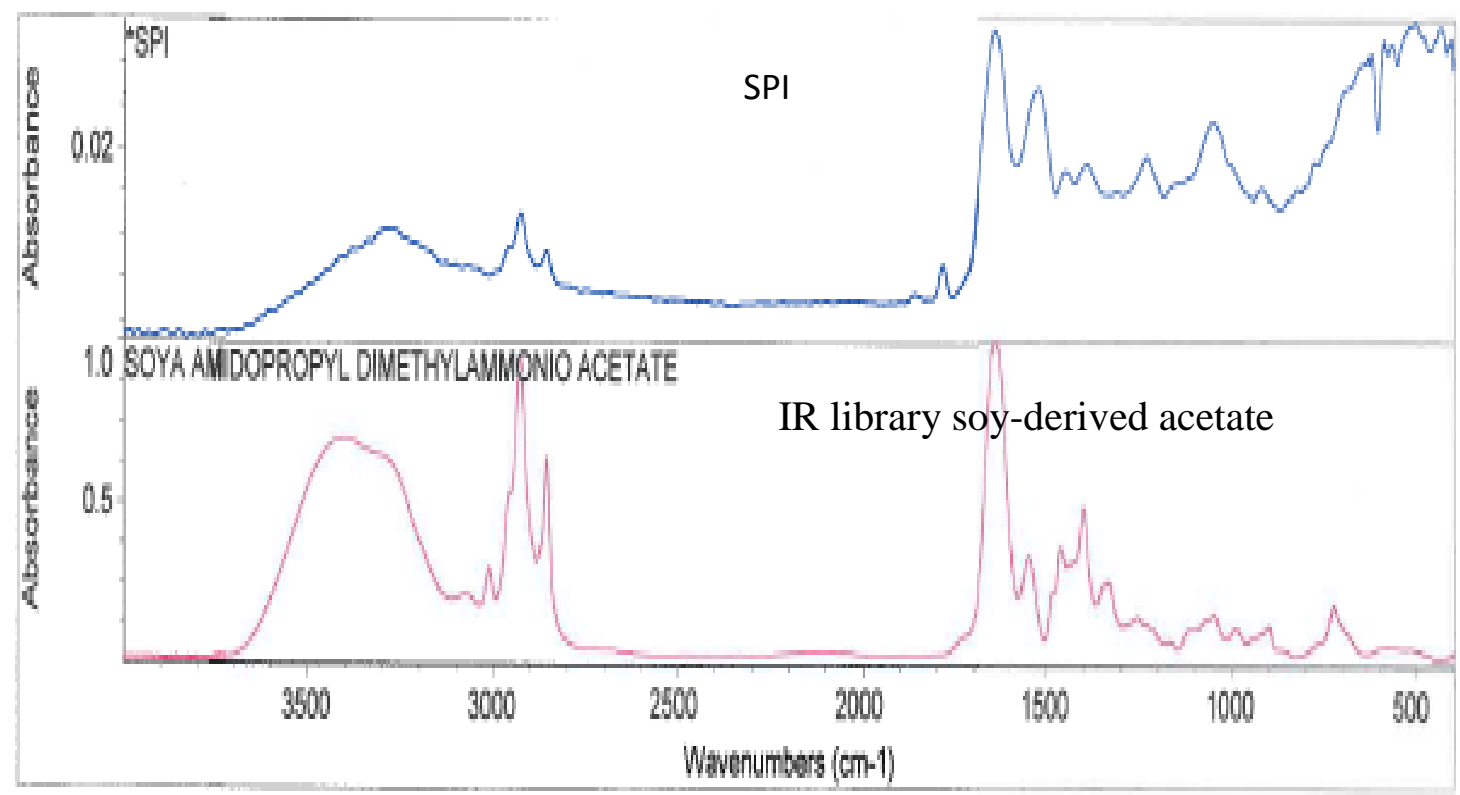

Figure 6.2: SPI spectra match to soy compound

\subsection{Analysis of Heat Treated Fillers}

Because the heat treated soy showed the greatest promise as a cost effective and scalable process, with effective results, multiple analysis methods were used to study these fillers. FTIR, TGA, EA, DSC and NMR were employed.

\subsubsection{Fourier Transform Infra-red Spectroscopy}

ATR FTIR was used to study the compositional changes of soy meal at different levels of torrefaction. In Figure 6.3, the top spectra is for untreated soy flour (UTSF), the 
middle spectra is sample [3.4.1 a] $\left(225^{\circ} \mathrm{C}\right.$ Torrefacted) and the bottom is sample [3.4.1 b] $\left(288{ }^{\circ} \mathrm{C}\right.$ Torrefacted). Within this sample set, the intensities of the absorptions diminished in a fairly uniform manner as the torrefaction level is increased.

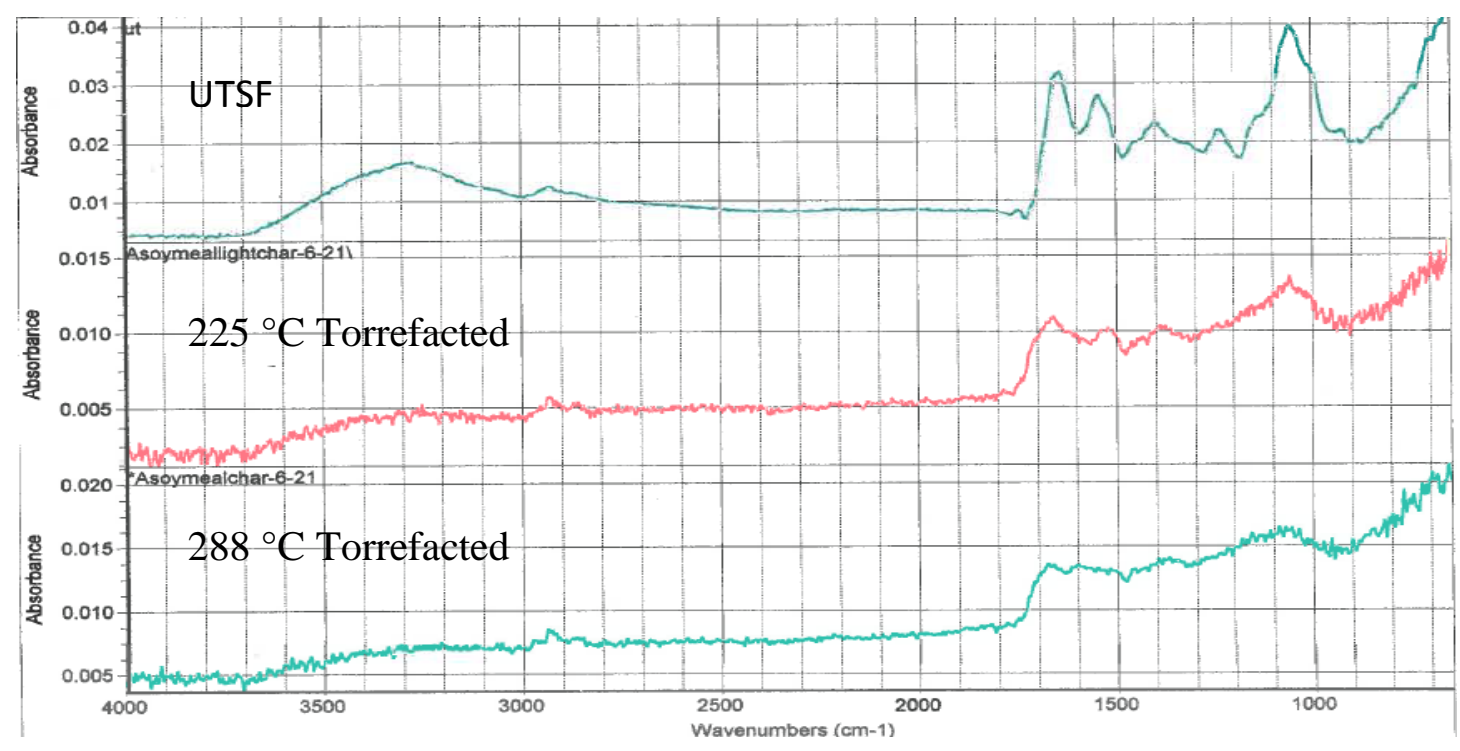

Figure 6.3: ATR FTIR of Untreated and Torrefacted Soy Meal

Figure 6.4 presents the fourier transform infrared transmission spectra of the dried untreated hulls (d-UTSH), sample [3.4.1 c] $288{ }^{\circ} \mathrm{C}$ ATP/NCSU bench torrefacted hulls $\left(288{ }^{\circ} \mathrm{C}\right.$ ATP Torrefacted), sample $[3.4 .2 \mathrm{f}] 250{ }^{\circ} \mathrm{C}$ muffle furnace hulls $\left(250{ }^{\circ} \mathrm{C}\right.$ MO Torrefacted), and [3.4.4 a] $500{ }^{\circ} \mathrm{C}$ ATP/NCSU pilot batch hulls $\left(500{ }^{\circ} \mathrm{C}\right.$ ATP Torrefacted). From top spectra to bottom spectra in the figure, the level of heat treatment increases. At lower levels of treatment, there was an increase in carbonyl absorbance at $1740 \mathrm{~cm}^{-1}$ relative to the other absorptions. These carbonyl absorptions diminished at higher levels of treatment, however. This indicates initial formation of carbonyl as hydroxyls are decomposed, followed by elimination of the oxygen, in a two-step 
mechanism. The aliphatic alkene absorbance at $1653 \mathrm{~cm}^{-1}$ diminished, as the aromatic absorbances at $1600 \mathrm{~cm}^{-1}$ and $1400 \mathrm{~cm}^{-1}$ intensified. With increasing treatment intensity, an aromatic absorption at $880 \mathrm{~cm}^{-1}$ formed as the aliphatic alkanes at $2925 \mathrm{~cm}^{-1}$ diminished. In spite of the higher process temperature of the $288^{\circ} \mathrm{C} \mathrm{ATP} / \mathrm{NCSU}$ bench hulls, the $250{ }^{\circ} \mathrm{C}$ muffle furnace hulls appear to be more highly torrefied, indicating that there are other critical factors that merit consideration.

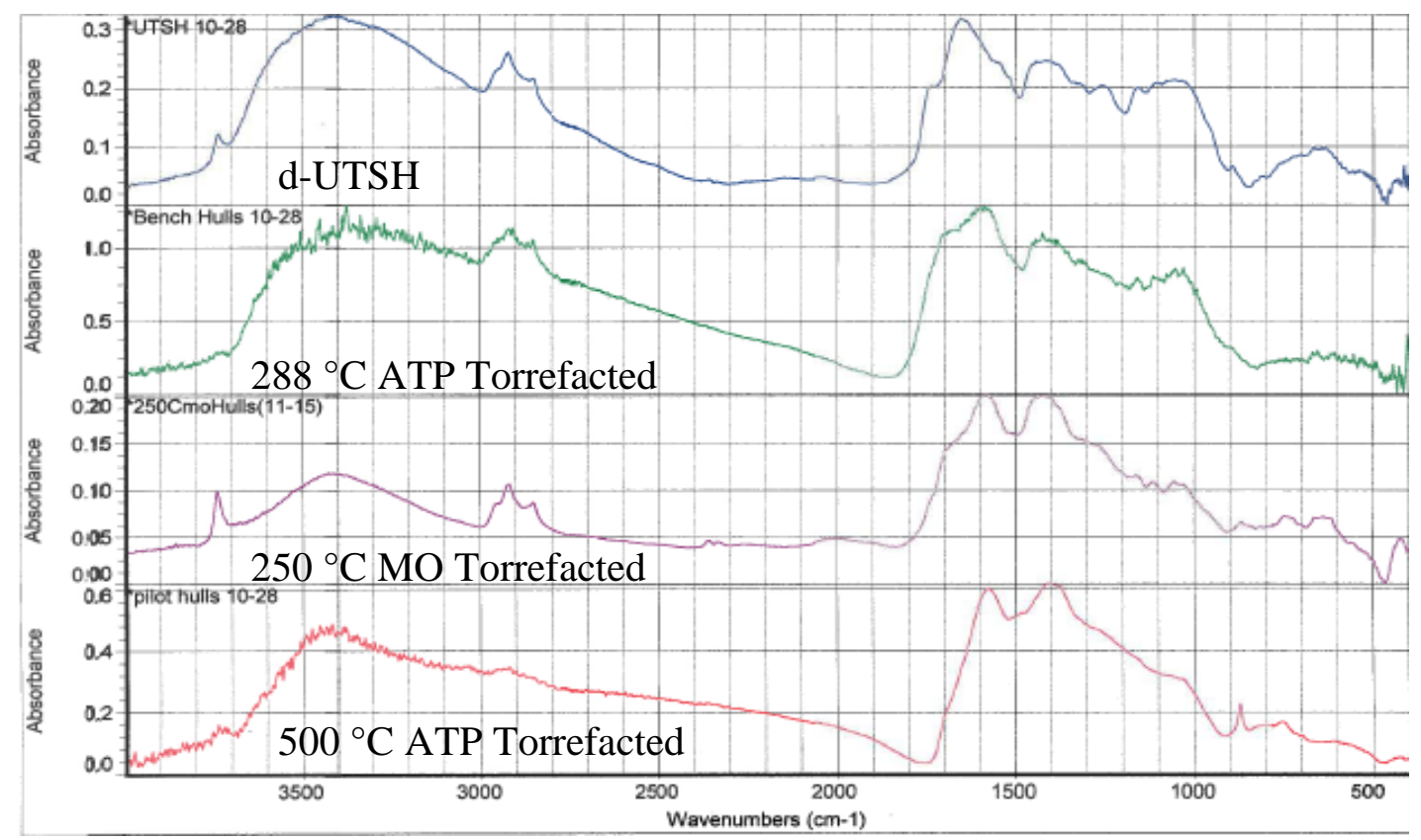

Figure 6.4: FTIR of Untreated and Torrefacted Soy Hulls

The fillers processed in the EarthCare ${ }^{\circledR}$ batch Unit [3.4.5] are presented, with the untreated soy hulls in Figure 6.5. Even with the highest level of treatment of $249{ }^{\circ} \mathrm{C}$, the aromatic absorption at $880 \mathrm{~cm}^{-1}$ had not begun to form. The aliphatic alkanes at 2925 $\mathrm{cm}^{-1}$ were not greatly diminished, although the carbonyls at $1740 \mathrm{~cm}^{-1}$ had lost definition with higher levels of torrefaction. The aliphatic alkene absorption at $1653 \mathrm{~cm}^{-1}$ shifted to 
the aromatic double bond absorption at $1600 \mathrm{~cm}^{-1}$. Based on this data, it appears that the EarthCare ${ }^{\circledR} 249{ }^{\circ} \mathrm{C}$ sample had not reached the same level of conversion as the $250{ }^{\circ} \mathrm{C}$ MO sample from Figure 6.4, even though the registered exotherm maximum was similar. This could be related to the larger sample sizes, the tumbling or the atmosphere in the torrefactor.

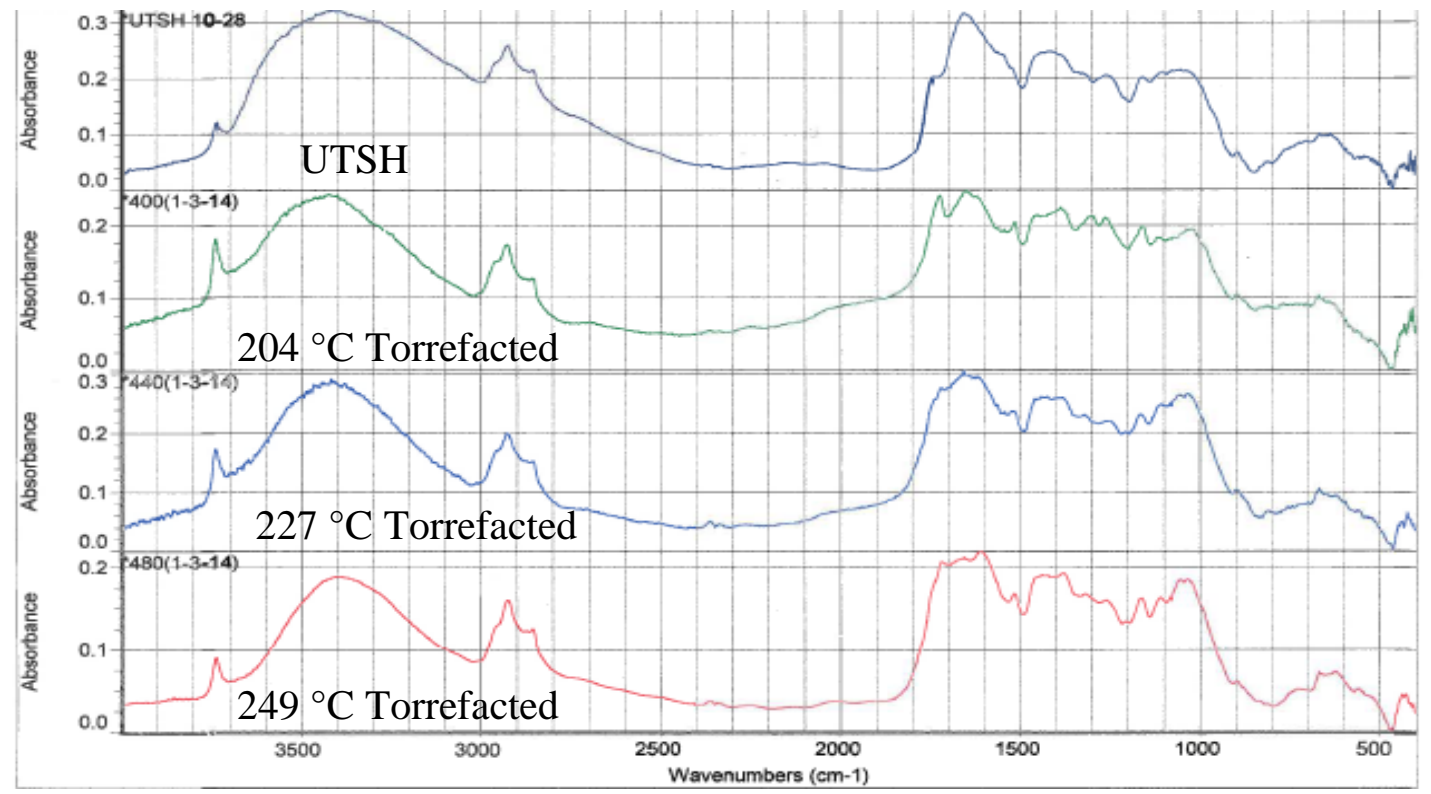

Figure 6.5: FTIR of UTSH and EarthCare ${ }^{\circledR}$ Torrefacted Fillers

\subsubsection{Extraction of Inhibiting Filler}

A hypothesis was posed that the inhibition effects observed with highly torrefacted samples may be due to extractable condensates in the filler, rather than the particulate filler. To test this, a $10 \mathrm{~g}$ sample of the highly inhibiting ATP/NCSU $500{ }^{\circ} \mathrm{C}$ batch filler[ 3.4.4a] was extracted with $100 \mathrm{ml}$ of toluene. Toluene was used because of its structural similarity to styrene. The slurry was stirred at ambient temperature for $6 \mathrm{~h}$, 
and then filtered. The filtrate was a yellow brown liquid. This was dried in a tared beaker under vacuum overnight. The yield was $26 \mathrm{mg}(0.26 \%$ based on filler). The residue was a brown oil with dark brown agglomerates. It was homogenized by stirring and analyzed by FTIR ATR spectroscopy. Figure 6.6 compares this spectrum and the results of a library search, which indicated a $75 \%$ match to petroleum hydrocarbons and aromatic oils. The solubility of this aromatic extract in toluene suggests that it would also be soluble in styrene.

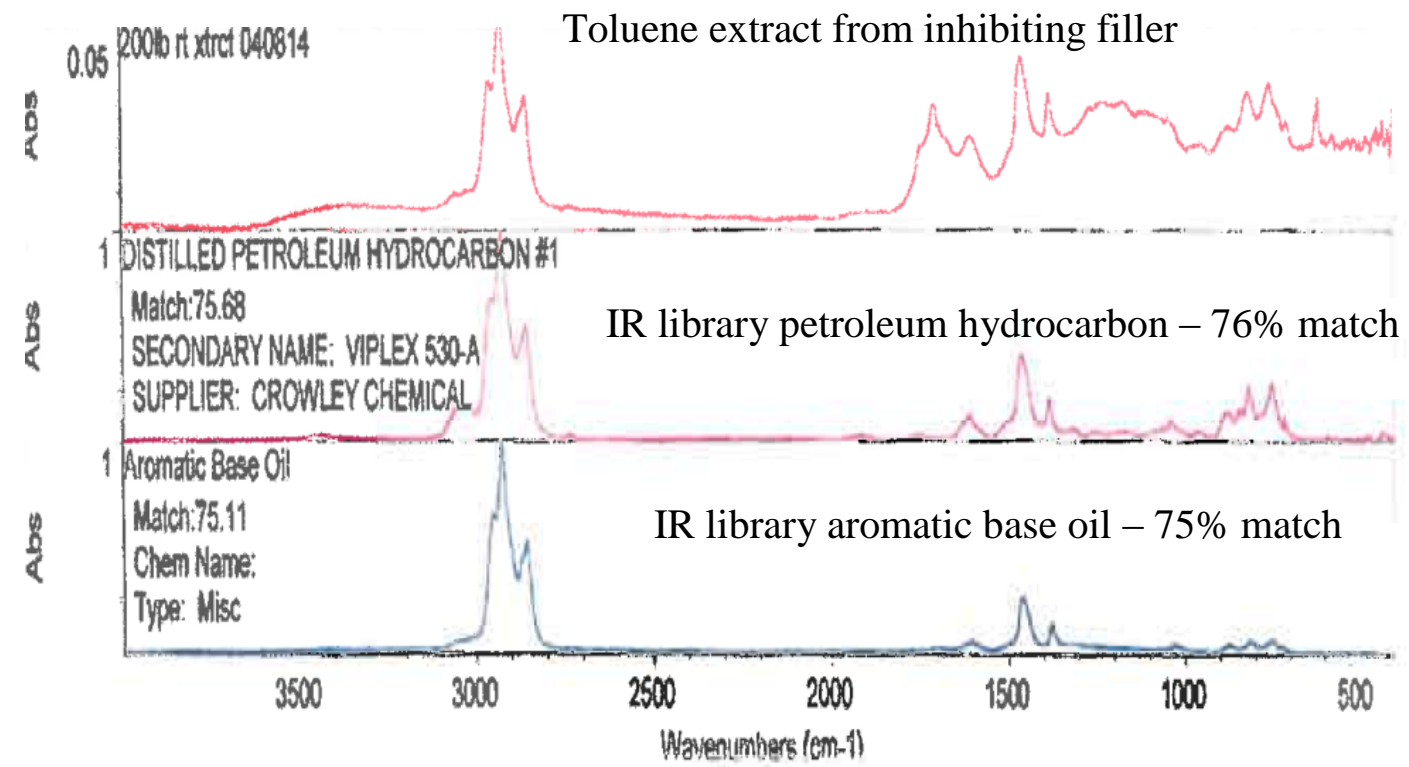

Figure 6.6: Spectra Match for Inhibiting Filler Extract

With time, the homogenized oil again separated, indicating a non-uniform composition. To try to resolve the different species in the oil, $4 \mathrm{ml}$ of methanol was added. Upon stirring, a reddish brown solution formed and a black tar-like material separated from the solution. The solution was decanted and the $\mathrm{MeOH}$ was driven off in a vacuum oven, yielding $6 \mathrm{mg}$ of oily brown residue. The tar was redissolved in $2 \mathrm{ml}$ of 
toluene, transferred to a weighing dish and dried to yield $9 \mathrm{mg}$ of tar. The total combined yield from the separation was 58\%. The FTIR spectra of the two residues in Figure 22 demonstrate that they are chemically similar, and provide a $64 \%$ match to a spectrum of aromatic hydrocarbon resin. Because the structures are similar, it may be a difference in molecular weight that resulted in different solubility in $\mathrm{MeOH}$.

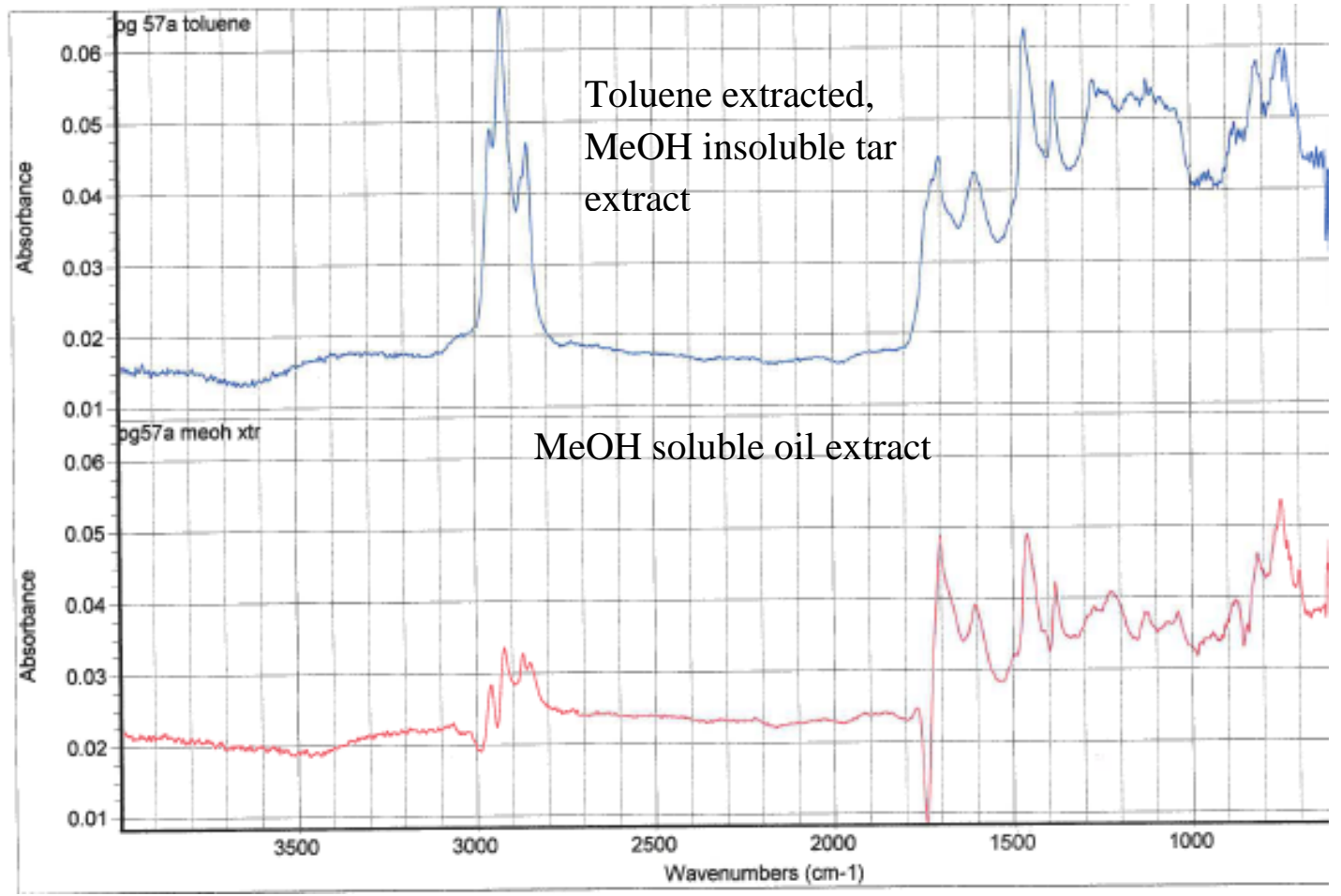

Figure 6.7: Spectra Comparison of Tar and Oil Extracted from Inhibiting Filler

\subsubsection{Elemental Analysis (EA) of Torrefacted Fillers}

EA was used to define the chemical composition of torrefacted fillers. The data is presented in Table 6.1 as the weight percent of each element divided by its atomic mass unit weight. The resulting molar ratios are presented in Figures 6.8 and 6.9. 
Table 6.1: Elemental Analysis (EA) Data

\begin{tabular}{|c|c|c|c|c|c|}
\hline \multirow[b]{2}{*}{ Sample } & \multirow[b]{2}{*}{ precursor } & \multicolumn{4}{|c|}{$\begin{array}{c}\text { Elemental analysis } \\
\text { (wt.\%/amu) }\end{array}$} \\
\hline & & $\mathbf{C}$ & $\mathbf{H}$ & $\mathbf{N}$ & $\mathbf{O}$ \\
\hline $\begin{array}{c}\text { Dried Untreated Soy Meal } \\
\text { (UTSM) }\end{array}$ & meal & 3.6 & 6.2 & 0.6 & 2.7 \\
\hline $\begin{array}{c}250{ }^{\circ} \mathrm{C} \text { ATP/NSU Bench Scale } \\
(3.4 .1 \mathrm{a})\end{array}$ & meal & 4.2 & 4.8 & 0.7 & 2.2 \\
\hline $\begin{array}{c}288^{\circ} \mathrm{C} \text { ATP/NSU Bench Scale } \\
(3.4 .1 \mathrm{~b})\end{array}$ & meal & 4.8 & 2.3 & 0.7 & 1.8 \\
\hline $\begin{array}{c}300{ }^{\circ} \mathrm{C} \text { ATP/NCSU Pilot Scale } \\
(3.4 .3 \mathrm{a})\end{array}$ & meal & 4.7 & 0.8 & 0.5 & 2.2 \\
\hline $\begin{array}{l}\text { Dried Untreated Soy Hulls } \\
\text { (UTSH) }\end{array}$ & hulls & 3.5 & 6.2 & 0.1 & 3.2 \\
\hline $\begin{array}{c}288^{\circ} \mathrm{C} \text { ATP/NSU Bench Scale } \\
(3.4 .1 \mathrm{c})\end{array}$ & hulls & 4.6 & 4.8 & 0.1 & 2.4 \\
\hline $400^{\circ} \mathrm{C}$ Muffle Furnace (3.4.2b) & hulls & 5.2 & 2.3 & 0.2 & 2.1 \\
\hline $\begin{array}{c}400{ }^{\circ} \mathrm{C} \mathrm{ATP} / \mathrm{NCSU} \text { Pilot Scale } \\
(3.4 .3 \mathrm{~b})\end{array}$ & hulls & 5.4 & 0.8 & 0.2 & 2.0 \\
\hline
\end{tabular}

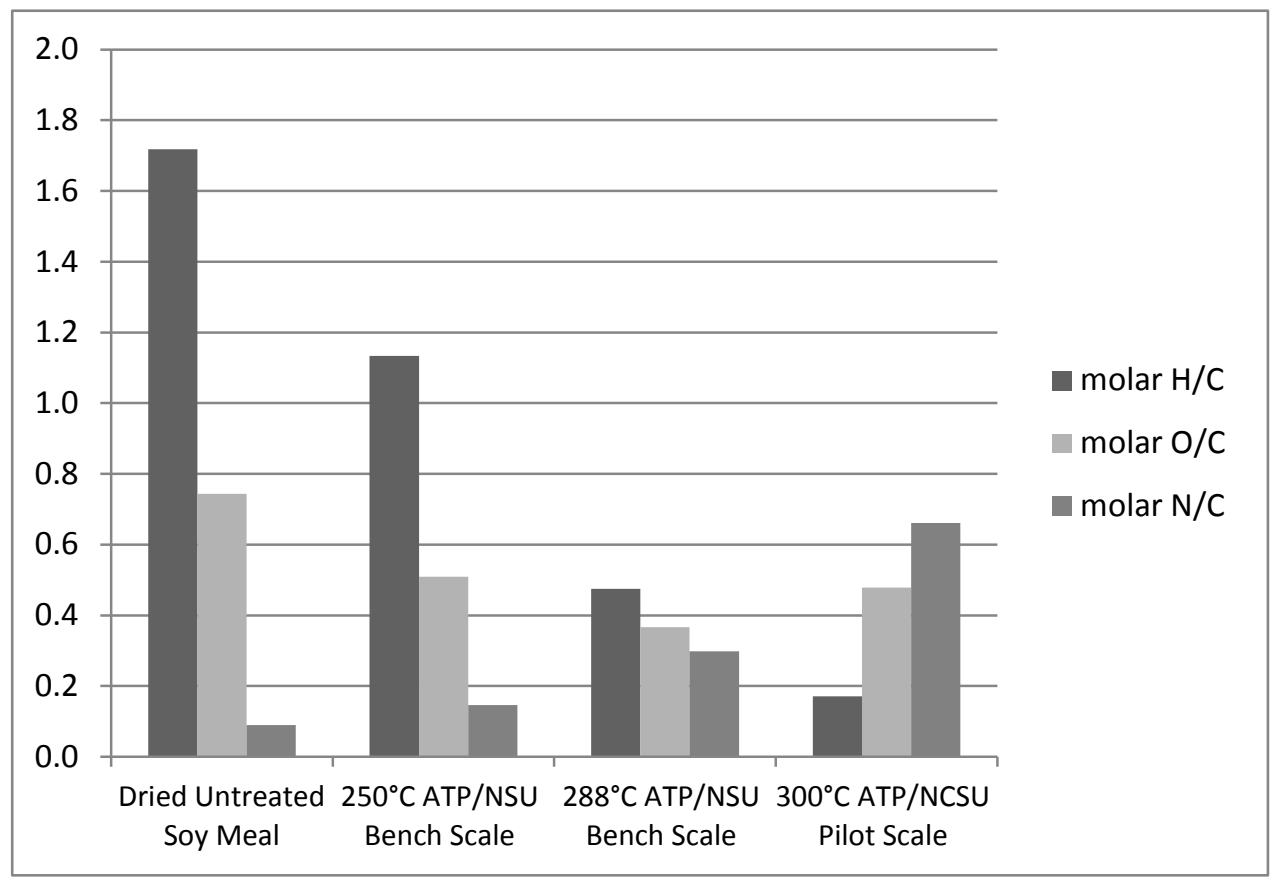

Figure 6.8: Molar Ratios of Elements in Meal Fillers 


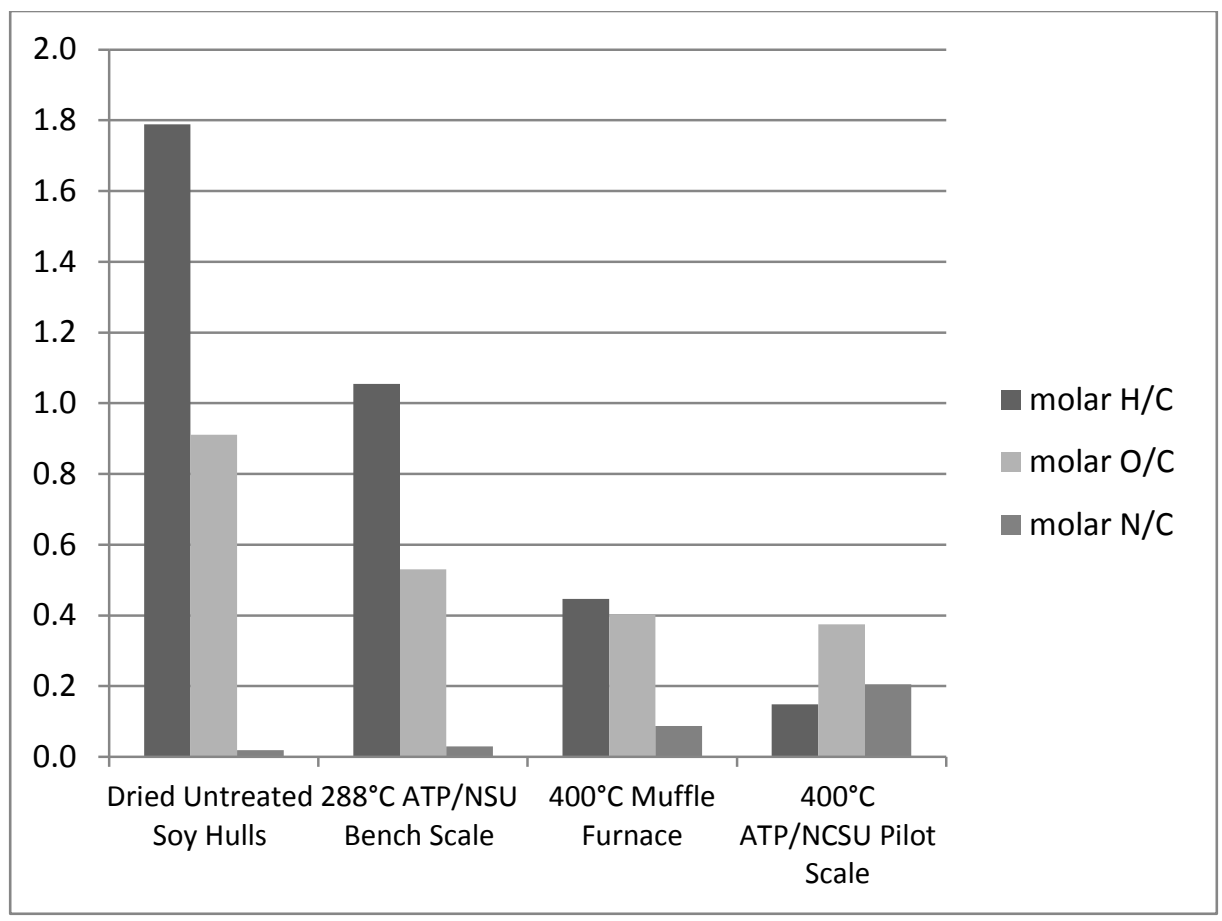

Figure 6.9: Molar Ratios of Elements in Hull Fillers

The heat treatments resulted in oxygen and hydrogen reduction, and increases in the carbon and nitrogen concentration. This supports the evolution of hydroxyl and carbonyl functionality from the system. Increasing the process temperature in the bench process with the meal precursor resulted in lower $\mathrm{O} / \mathrm{C}$ and $\mathrm{H} / \mathrm{C}$ ratios; however at $300{ }^{\circ} \mathrm{C}$ in the continuous pilot processor, the $\mathrm{O} / \mathrm{C}$ ratio was greater than at the lower temperature, while the $\mathrm{H} / \mathrm{C}$ continued to diminish, indicating cyclization. The hull precursor in different processors at $400{ }^{\circ} \mathrm{C}$ had a large difference in $\mathrm{H} / \mathrm{C}$. Lower $\mathrm{H} / \mathrm{C}$ values are consistent with higher levels of aromatic ring formation and fusing. Therefore, fillers treated in different processors had very different compositions. While the molar content of carbon, nitrogen and oxygen were similar, the hydrogen content was substantially lower for the AGT/NCSU pilot scale filler, suggesting that the AGT/NCSU pilot scale 
filler formed a higher level of aromatic structure in the char. Figure 6.10 is the elemental mapping of hydrogen versus carbon.

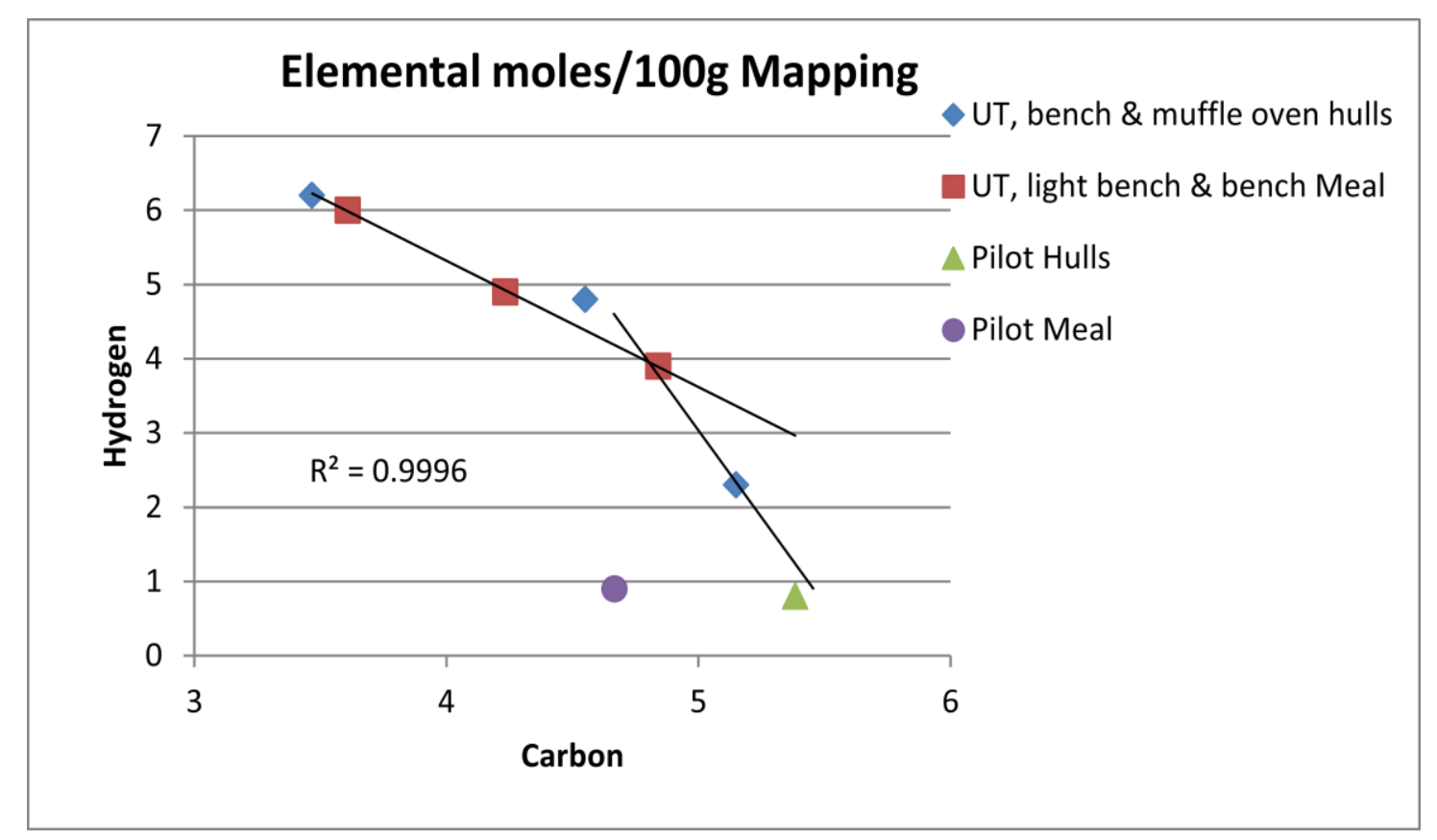

Figure 6.10 Elemental Mapping of Hydrogen vs. Carbon

A strong linear correlation coefficient $\left(R^{2}=0\right.$ 9996) was observed for the samples with a hydrogen molar $\%$ greater than four; however, below that, the slope changed. The change in slope indicates a significant change in mechanism of decomposition at higher levels of treatment. The pilot meal did not follow either trend, which may be due to contamination in the sample.

\subsubsection{TGA Analysis of Various Heat Treated Meal and Hull Fillers}

In Figures 6.11 and 6.12, respectively, heat treated soy meal and hull filler thermal decompositions are plotted. The meal samples were dried untreated meal [3.4.1 
a] $250{ }^{\circ} \mathrm{C} \mathrm{ATP} / \mathrm{NCSU}$ bench, [3.4.1b] $288^{\circ} \mathrm{C} \mathrm{ATP} / \mathrm{NCSU}$ bench and [3.4.3a] $300{ }^{\circ} \mathrm{C}$ ATP/NCSU pilot fillers. The hull samples were untreated hulls, [3.4.1c] $288{ }^{\circ} \mathrm{C}$ ATP/NCSU bench scale, [3.4.2b] $400{ }^{\circ} \mathrm{C}$ muffle furnace and [3.4.3b] $400{ }^{\circ} \mathrm{C}$ ATP/NCSU pilot scale. All samples were dried under vacuum at $25^{\circ} \mathrm{C}$ for two days prior to testing.

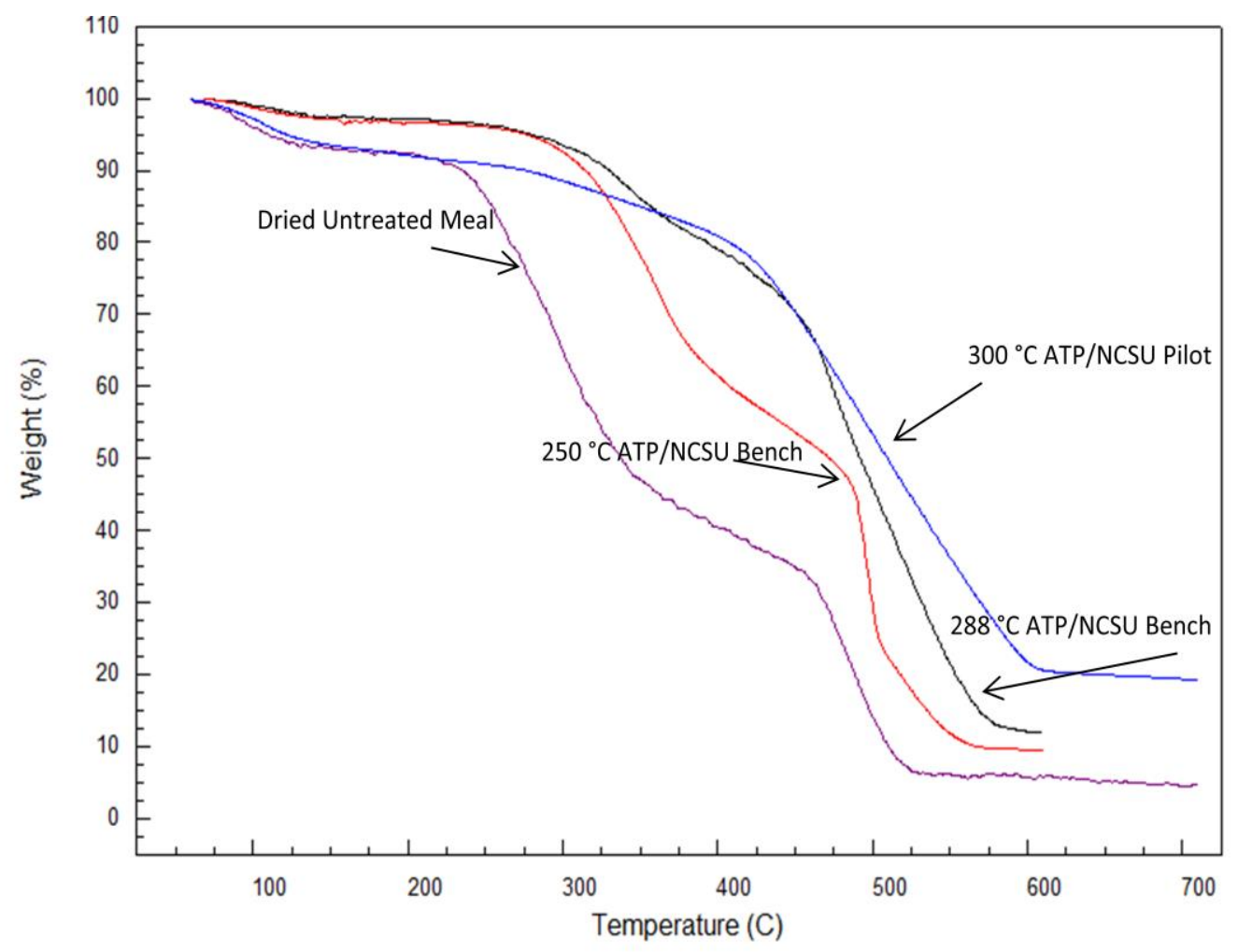

Figure 6.11: TGA for Meal Fillers

In the meal sample set, there is an increase in the final ash retention and final plateau temperature with increasing process temperature. The temperature stability up to $100{ }^{\circ} \mathrm{C}$, however, was lower for the highest process temperature sample produced in the ATP/NCSU pilot unit, relative to the other heat treated fillers. 


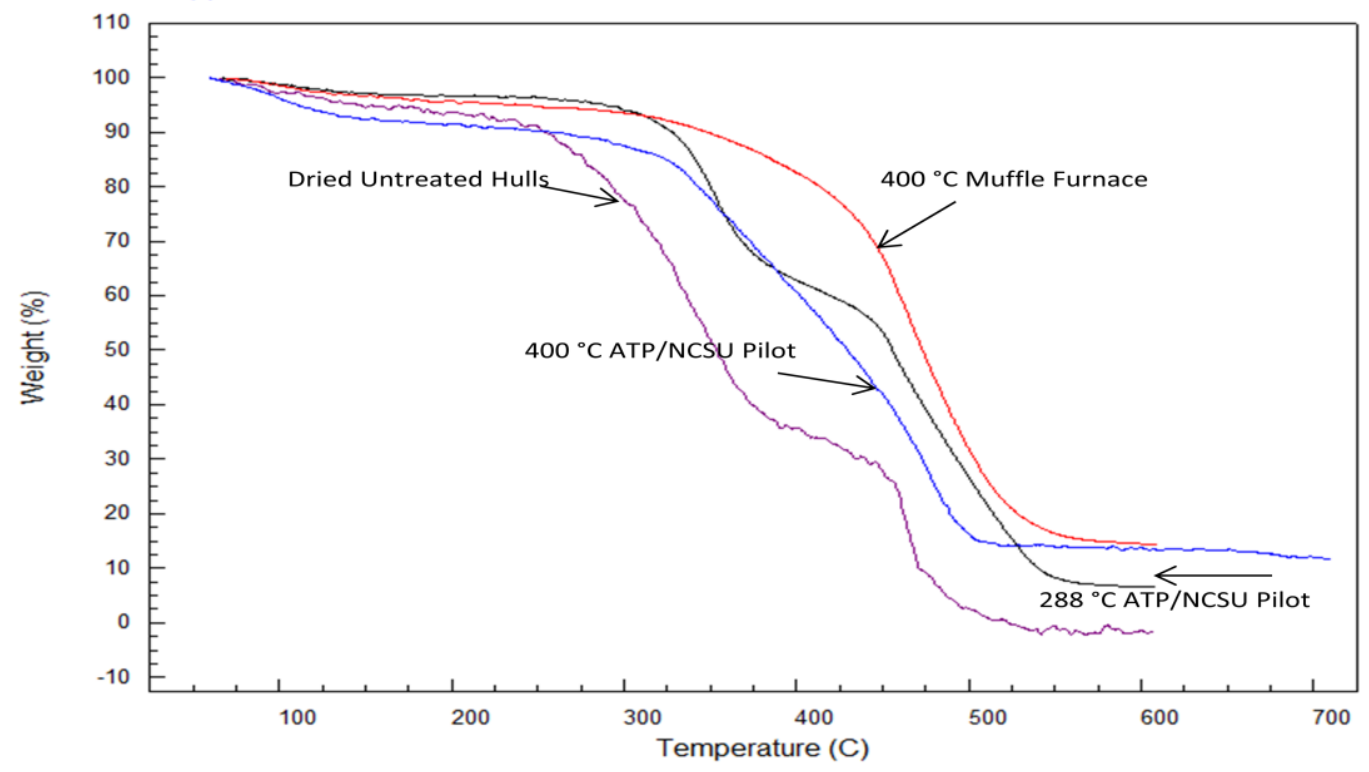

Figure 6.12: TGAs for Hull Fillers

In the hull sample set, increasing process temperatures also yielded higher ash retention, but not higher plateau temperature. The $400{ }^{\circ} \mathrm{C}$ ATP/NCSU pilot sample plateaued at a lower temperature than the other heat treated fillers. It also lost weight at a much lower temperature than the other heat treated fillers. The $400{ }^{\circ} \mathrm{C}$ muffle furnace torrefied sample was the most stable, but the $400{ }^{\circ} \mathrm{C}$ ATP/NCSU pilot sample was less stable than the $288^{\circ} \mathrm{C} \mathrm{ATP/NCSU}$ bench torrefacted hulls. The low temperature weight loss at less than $100{ }^{\circ} \mathrm{C}$ suggests that there are low molecular weight species in the 400 ${ }^{\circ} \mathrm{C}$ ATP/NCSU torrefacted filler. The differences in the $400{ }^{\circ} \mathrm{C}$ ATP/NCSU and $400{ }^{\circ} \mathrm{C}$ muffle furnace processed samples indicate that peak process temperature alone does not dictate the stability of the resulting filler, as previously observed with FTIR and EA results. While both environments were designed for oxygen exclusion, the continuous 
pilot process handling of off gasses is different from the nitrogen purge used in the muffle furnace. Other process differences were water quenching, wet grinding and smaller particle size of the pilot sample vs. the muffle furnace sample, which entailed rough dry grinding and oxygen excluded ambient cooling.

6.4.5 Differential scanning calorimetry (DSC) study on inhibition effects of filler

DSC was used to analyze the effect of the inhibiting [3.4.3 b] $400{ }^{\circ} \mathrm{C}$

ATP/NCSU pilot filler on the polymerization of peroxide-initiated free radical styrenated unsaturated polyester resins. A master resin was made using $1.3 \mathrm{~g}$ S903 resin with 20.2 mg Trig 122C80 peroxide and $63 \mathrm{mg}$ styrene. A 50:50 weight mixture of $64 \mathrm{mg}$ resin and $64 \mathrm{mg}$ of $\mathrm{CaCO}_{3}$ was prepared. A soy filler resin mix with $135 \mathrm{mg}$ master and $54 \mathrm{mg}$ of the inhibiting soy filler resulted in a 71.4:28.6 weight mixture, with an equivalent volume loading of filler to the 50:50 weight mixture with $\mathrm{CaCO}_{3}$.

The two mixes were compared using a DSC ramp for total exotherm and a hold at $80{ }^{\circ} \mathrm{C}$ for isothermal exotherm. The temperature ramp data is presented In Figure 6.13. The upper curve is for the torrefacted filler and the lower curve is for a $\mathrm{CaCO}_{3}$ filled sample. The total exotherms for the $\mathrm{CaCO}_{3}$ filled and soy filler samples, divided by the weight of the resin reactants, were $330 \mathrm{~J} / \mathrm{g}$ and $343 \mathrm{~J} / \mathrm{g}$, which is not a significant difference with expected uncertainty of the method. There was a slight time shift to longer times for the soy filled exotherm peak indicating some inhibition. In Figure 6.14, the isothermal cure affects were very apparent. The isotherms for the $\mathrm{CaCO}_{3}$ filled and soy filler samples, divided by the weight of the resin reactants, were $200 \mathrm{~J} / \mathrm{g}$ and $17 \mathrm{~J} / \mathrm{g}$, 
respectively, indicating severe retardation. The delay in cure with the soy filler was greater than $3 \mathrm{~h}$ in this comparison as well, indicating severe inhibition.

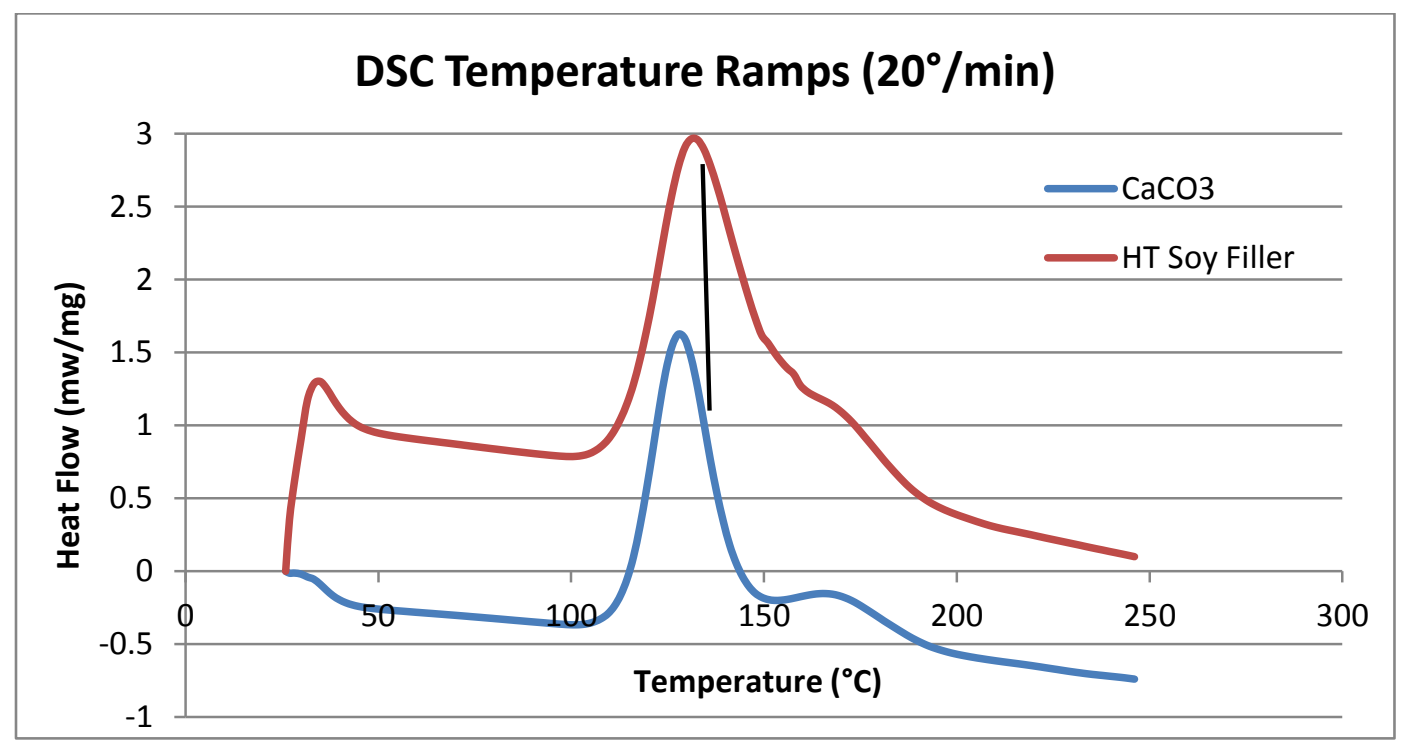

Figure 6.13: Total Polymerization Exotherm Comparisons of $\mathrm{CaCO}_{3}$ and Inhibiting Heat Treated Soy Filler in a Resin Master

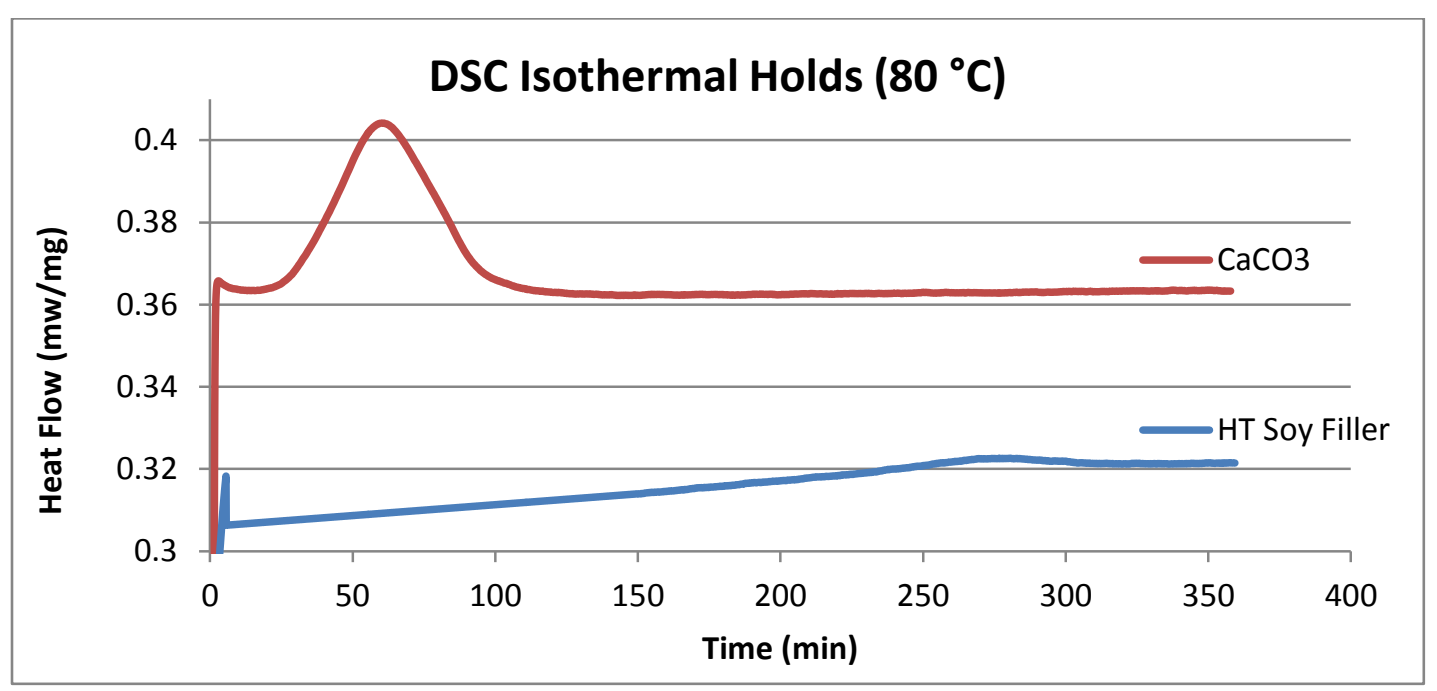

Figure 6.14: Isothermal Polymerization Comparisons of $\mathrm{CaCO}_{3}$ and Inhibiting Heat Treated Soy Filler in a Resin Master 


\subsubsection{Differential Scanning Calorimetry (DSC) Study on Inhibition Effects of Extracts}

DSC was also used to test the hypothesis that the extractables from section 6.4.2 were inhibiting agents, and to understand if both the oil and tar species had the same inhibiting effect. A master resin was made using $4 \mathrm{~g} \mathrm{~S} 903$ resin with $62 \mathrm{mg}$ Trig $122 \mathrm{C} 80$ peroxide. To $1.3 \mathrm{~g}$ aliquots, $55 \mathrm{mg}$ of either styrene alone (no res) or styrene with a $6 \mathrm{mg}$ residue / $1 \mathrm{~g}$ solution of the toluene-only soluble (toluene res) or $\mathrm{MeOH}$ soluble $(\mathrm{MeOH}$ res) residues were added. Isothermal DSC scans at $85^{\circ} \mathrm{C}$ were recorded to compare the timing of the curing exotherm.

As presented in Figure 6.14, both extracts induced similar shifts in the onset, peak and return to baseline relative to the styrene blank. The inhibition was roughly $9.5 \mathrm{~min}$, which is not nearly as severe as the $3 \mathrm{~h}$ inhibition observed with the filler itself. The integrated isotherms were $175+/-1 \mathrm{~J} / \mathrm{g}$ for all three samples, indicating no retardation.

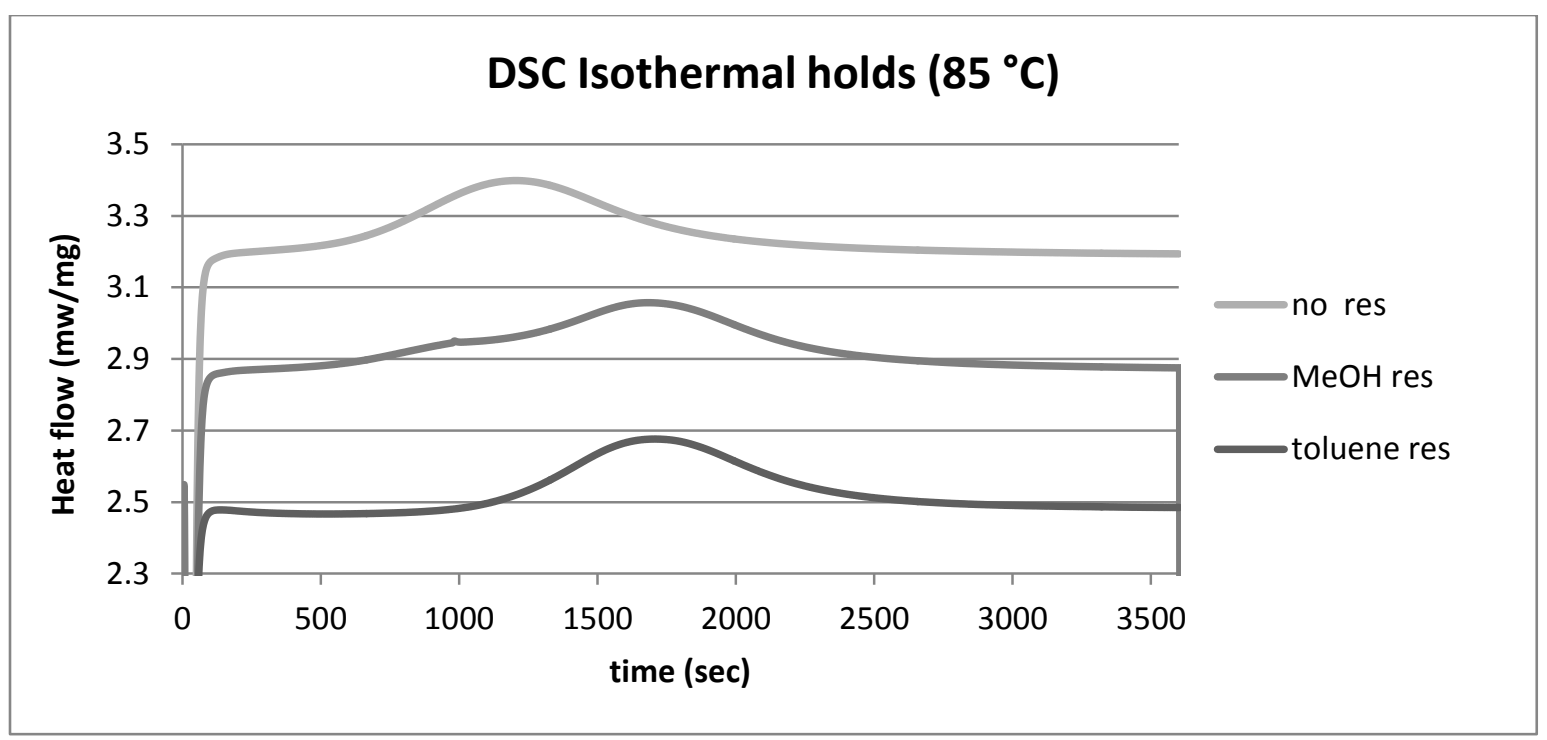

Figure 6.15: Isothermal Polymerization of a Resin Master with and without Extracts 


\subsubsection{Stevenson Kinetic Analysis of Extract Inhibition}

A study was performed to quantify the inhibition effect of the extracts on the resin polymerization. The treatment developed by Stevenson ${ }^{80}$ was applied. His KCI approximation equations, seen in Table 6.2, were used as a means to estimate characteristic kinetic parameters without the complexity of empirical curve fitting or mathematical algorithms. DSC data was coupled with initiator half-life data and concentration to provide real life inputs into the calculations. In contrast, earlier empirical treatments put forth by Kamal ${ }^{81}$ With and Putsatcioglu ${ }^{82}$ did not incorporate any actual system input parameters in analysis of the exotherm data. With this treatment, only the maximum heat flow rate, $\mathrm{r}_{\mathrm{m}}$, along with the isothermal and total exotherm integrations, are required to obtain rate constants, activation energy and pre-exponential factors.

Table 6.2: KCI Kinetic Equations

$$
\begin{gathered}
\left(\frac{[M]}{[M]_{0}}\right)_{m}=\left(1+\frac{k_{t}}{k_{p}}\right)^{-k_{p} / 2 k_{t}} \\
\frac{r_{m}}{H_{T}}=\left(2 k_{d} I_{z} k_{p}\right)^{0.5}\left[\left(1+k_{t} / k_{p}\right)^{0.5}\right]^{-\frac{k_{p}}{k_{t}}-1} \\
k=A \exp \left(-\frac{E_{a}}{R T}\right)
\end{gathered}
$$

A deviation from Stevenson was that the total exotherms used in the calculations were for the unreacted resin, rather than the summation of the isothermal and residual exotherms. This decision was made based on findings by Han and Lee ${ }^{83}$ that FTIR data was in better agreement with the DSC analysis when the ultimate exotherm from the 
uncured material is used, instead of the summation totals. This approach has the additional advantage that fewer experimental scans are needed.

The approximations on which the KCI treatment equations are derived include these standard assumptions:

1. The styrene-to-polyester and polyester-to-styrene cross-propagation rates are equal.

2. All of the rate constants involving inhibition of any type of radical are equal.

3. Consumption rates and concentration of the monomers ([M]) are proportional during polymerization.

4. An effective termination rate constant $(\mathrm{kt})$ is used for the combined termination reactions.

5. The monomer reactions rates with newly initiated monomer radicals and polymer radicals are combined.

6. Induced decomposition and chain transfer are neglected.

In addition, the following additional simplifying assumptions are applied:

$\mathrm{K}$ : The rate constants for propagation $\left(\mathrm{k}_{\mathrm{p}}\right)$ and termination $\left(\mathrm{k}_{\mathrm{t}}\right)$ are constant regardless of conversion.

C: The inhibition and polymerization reactions are consecutive, and polymerization does not start until the inhibitor is consumed. 
I: The rate of initiator decomposition is set to a constant value once the inhibitor is consumed; $\mathrm{k}_{\mathrm{d}}=$ rate constant of initiator decomposition.

Figure 6.16 shows the total exotherms for the samples. The curves for all three are very similar; however the tar residue spiked sample had a small shift to higher temperature from $127{ }^{\circ} \mathrm{C}$ to $131^{\circ} \mathrm{C}$.

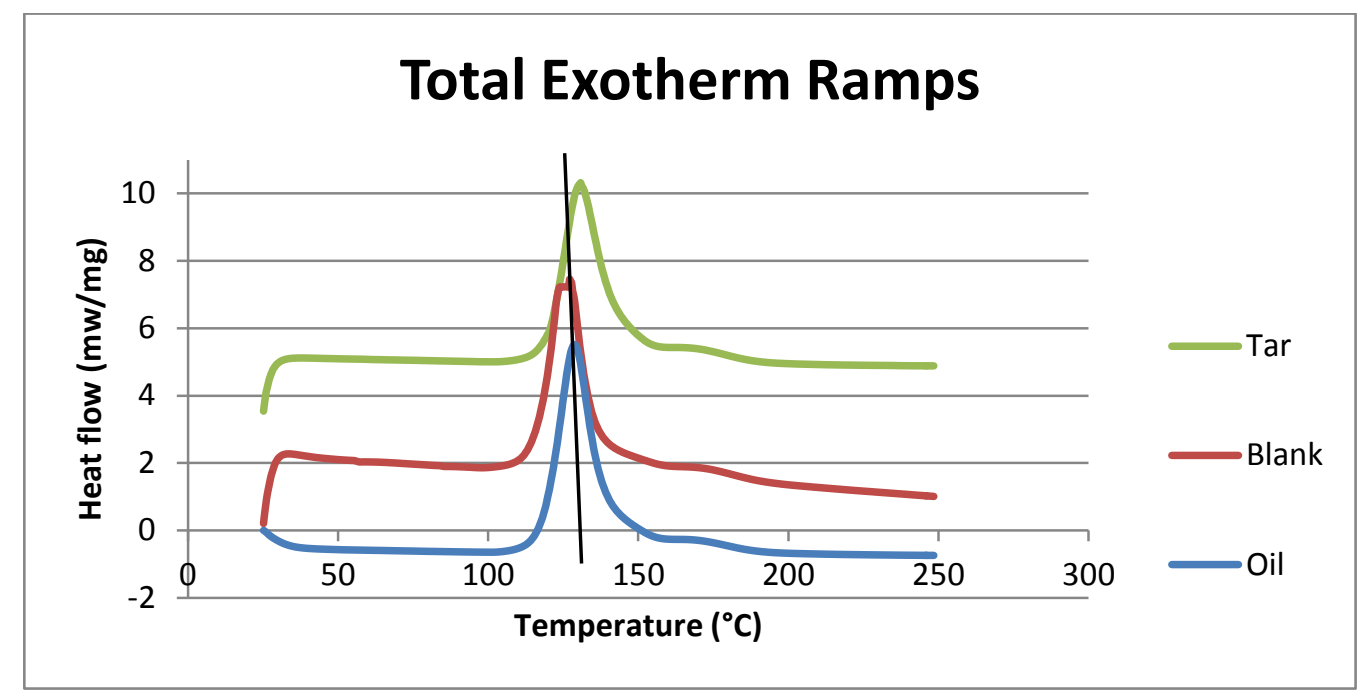

Figure 6.16: DSC Temperature Ramp Data of Unsaturated Polyester Master

Figures 6.17 through 6.19 present the baseline corrected isotherms at $75{ }^{\circ} \mathrm{C}, 80{ }^{\circ} \mathrm{C}$ and $85{ }^{\circ} \mathrm{C}$ for each of the three samples. Figure 6.17 shows the data for the resin/ initiator master with only styrene addition as a blank control. Figure 6.18 shows the master with the styrene solution spiked with the tar, and Figure 6.19 shows the data for the styrene spiked with the oil. In isothermal scans at all three temperatures with both residue-spiked styrene solutions, the initiation and peak of the exotherms shifted to longer times relative to the styrene blank. The shift was more significant for the $75^{\circ} \mathrm{C}$ 
tests, indicating that the inhibiting effect is reduced at higher temperatures, which is consistent with first order decomposition behavior of organic peroxides.

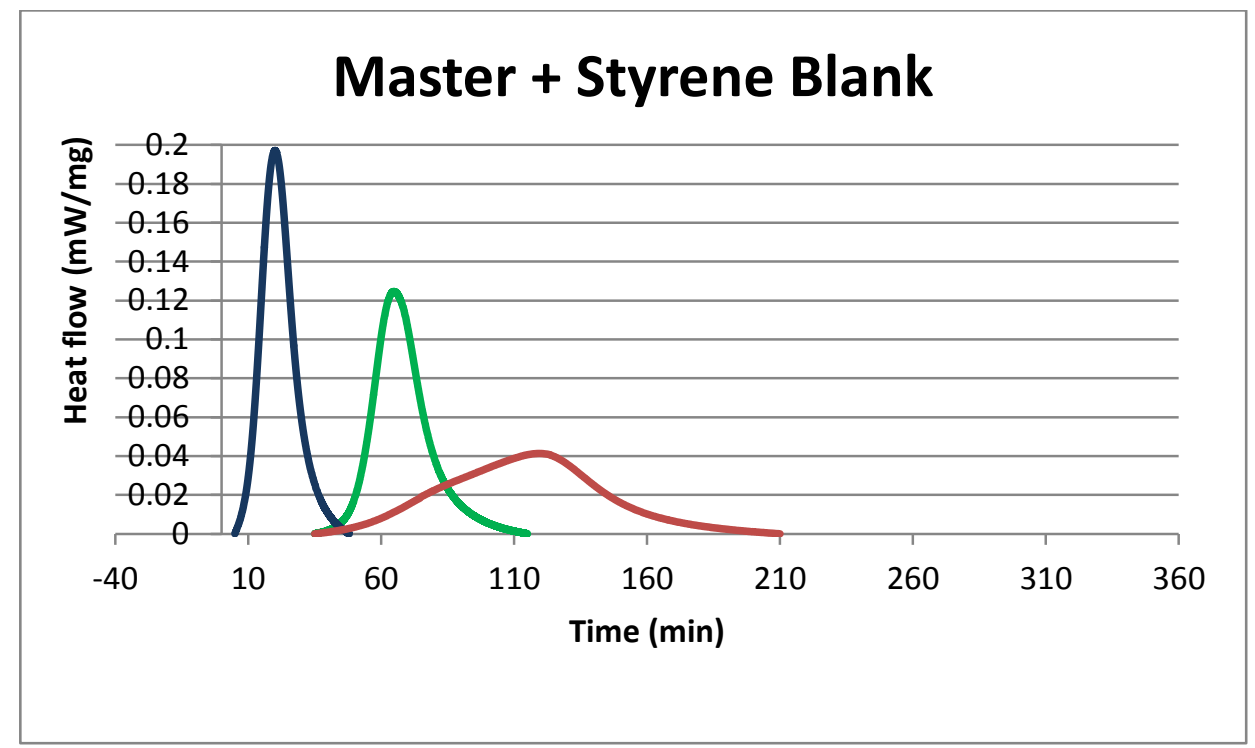

Figure 6.17: Isotherms for Unsaturated Polyester with Styrene Blank at $85^{\circ} \mathrm{C}$,

$80{ }^{\circ} \mathrm{C}$ and $75^{\circ} \mathrm{C}$, left to right, respectively

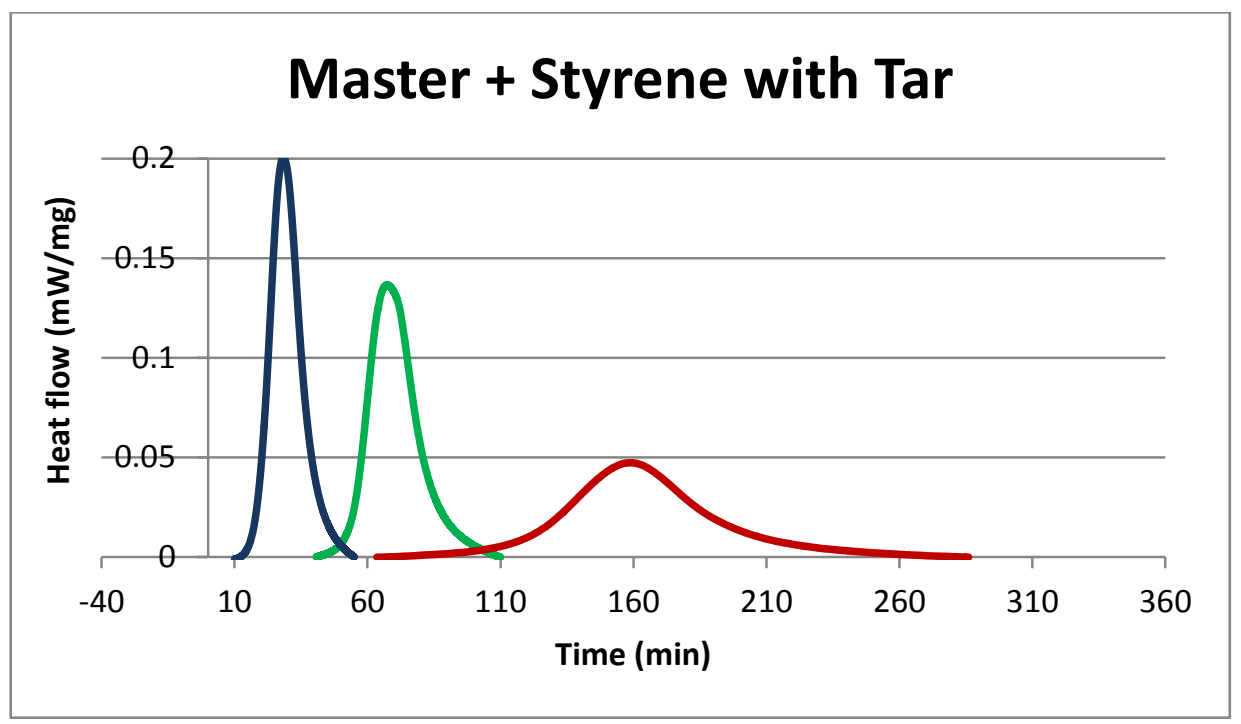

Figure 6.18: Isotherms for Unsaturated Polyester with Tar-spiked Styrene at 85 ${ }^{\circ} \mathrm{C}, 80{ }^{\circ} \mathrm{C}$ and $75{ }^{\circ} \mathrm{C}$, left to right, respectively 


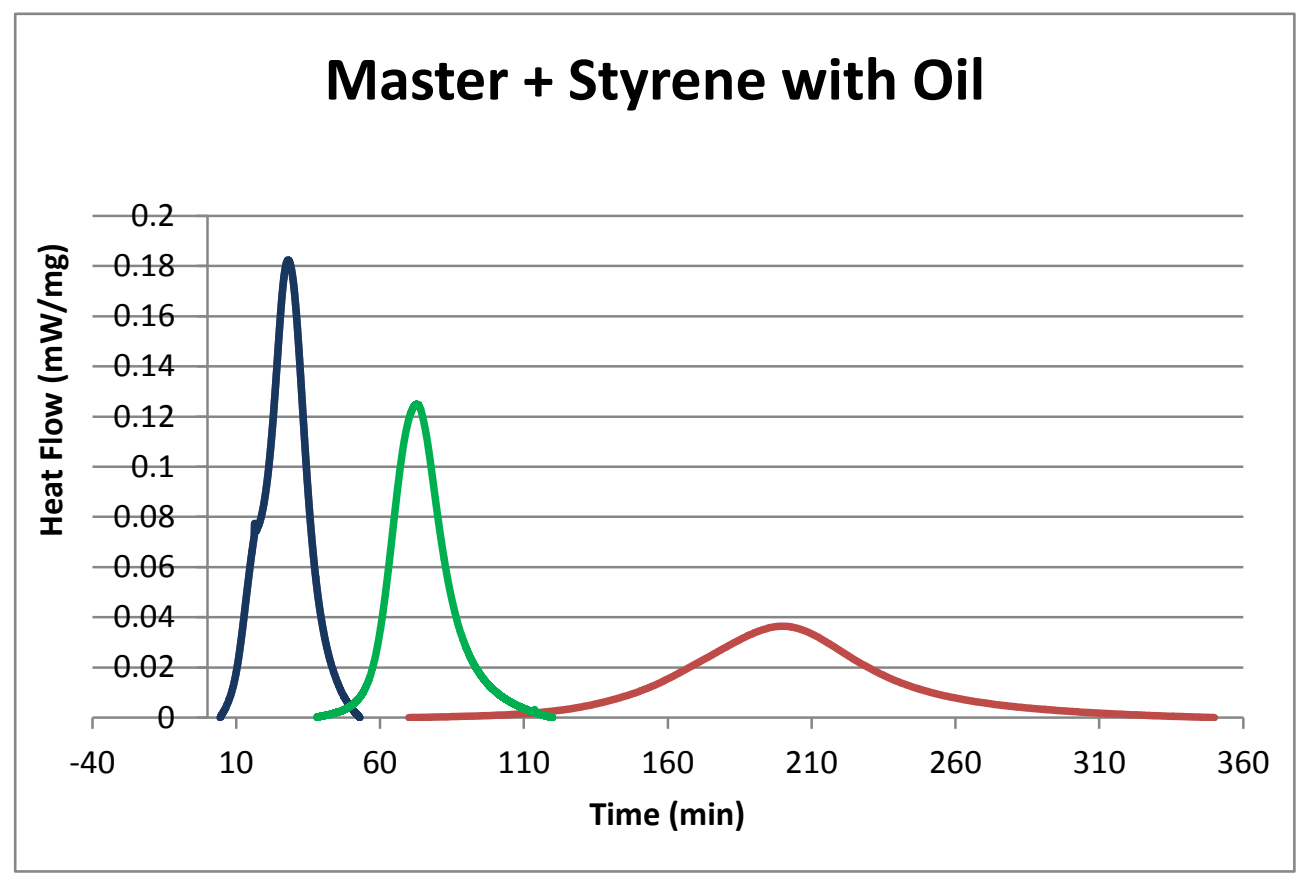

Figure 6.19: Isotherms for Unsaturated Polyester with Oil-spiked Styrene at 85 ${ }^{\circ} \mathrm{C}, 80{ }^{\circ} \mathrm{C}$ and $75^{\circ} \mathrm{C}$, left to right, respectively

The kinetic parameters extracted from the isotherm data are presented in Table 6.3. The initiator decomposition rate constant, $\mathrm{k}_{\mathrm{d}}$, was calculated from peroxide $1 \mathrm{~h}$ and $10 \mathrm{~h}$ half-life data using first order decomposition and the Arrhenius equations. The peak time, $t_{m}$, and peak rate, $r_{m}$, were taken directly from the isothermal curves. The total exotherms, $\mathrm{H}_{\mathrm{T}}$, and isothermal exotherms, $\mathrm{H}_{\mathrm{I}}$, were the integration of the baseline corrected experimental curves. The initiation time, $\mathrm{t}_{\mathrm{z}}$, was selected as the time when the exotherm started to deviate from the baseline and was used to calculate the initiator concentration at cure onset, $\mathrm{I}_{\mathrm{z}}$. B denotes the styrene blank, $\mathrm{T}$ is with the tar and $\mathrm{O}$ is with the oil. 
Table 6.3: Data from DSC Analysis

\begin{tabular}{|c|c|c|c|c|c|c|c|c|c|}
\hline & $k_{d}\left(s^{-1}\right)$ & $H_{T}(\mathrm{~J} / g)$ & $t_{m}$ & $r_{m}(\mathrm{~J} / g-5)$ & $r_{m} / H_{T}\left(s^{-1}\right)$ & $H_{I}(\mathrm{~J} / g)$ & $H_{I} / H_{T}$ & $t_{z}(\mathrm{sec})$ & $I_{z}(\mathrm{M} / \mathrm{L})$ \\
\hline B-75 & $4.0 \mathrm{E}-06$ & 320 & 120 & 0.041 & $1.28 \mathrm{E}-04$ & 176 & $55 \%$ & 2100 & $4.17 \mathrm{E}-02$ \\
\hline B-80 & $7.8 \mathrm{E}-06$ & 320 & 65 & 0.125 & $3.91 \mathrm{E}-04$ & 171 & $53 \%$ & 2100 & $4.17 \mathrm{E}-02$ \\
\hline B-85 & $1.5 \mathrm{E}-05$ & 320 & 21 & 0.200 & $6.25 \mathrm{E}-04$ & 175 & $55 \%$ & 300 & $4.29 \mathrm{E}-02$ \\
\hline & & & & & & & & & \\
\hline T-75 & $4.0 \mathrm{E}-06$ & 308 & 157 & 0.047 & $1.53 \mathrm{E}-04$ & 175 & $57 \%$ & 3780 & $4.06 \mathrm{E}-02$ \\
\hline T-80 & $7.8 \mathrm{E}-06$ & 308 & 66 & 0.134 & $4.35 \mathrm{E}-04$ & 180 & $58 \%$ & 2460 & $4.14 \mathrm{E}-02$ \\
\hline T-85 & $1.5 \mathrm{E}-05$ & 308 & 28 & 0.200 & $6.49 \mathrm{E}-04$ & 172 & $56 \%$ & 600 & $4.28 \mathrm{E}-02$ \\
\hline & & & & & & & & & \\
\hline 0-75 & $4.0 \mathrm{E}-06$ & 331 & 200 & 0.036 & $1.09 \mathrm{E}-04$ & 177 & $53 \%$ & 4560 & $4.01 \mathrm{E}-02$ \\
\hline $\mathbf{0}-80$ & $7.8 \mathrm{E}-06$ & 331 & 72 & 0.124 & $3.75 \mathrm{E}-04$ & 170 & $51 \%$ & 2400 & $4.15 \mathrm{E}-02$ \\
\hline $0-85$ & $1.5 \mathrm{E}-05$ & 331 & 27 & 0.180 & $5.44 \mathrm{E}-04$ & 172 & $52 \%$ & 336 & $4.28 \mathrm{E}-02$ \\
\hline
\end{tabular}

The range of 308 to $330 \mathrm{~J} / \mathrm{g}$ for the total isotherms of the three samples is not significantly different and is similar to values reported in the literature. For example, total isotherm reported by Han and Lee ${ }^{85}$ was $345 \mathrm{~J} / \mathrm{g}$. Based on experience, uncertainty in baseline construction and weighing errors are likely to account for the range observed. All of the isothermal scans, regardless of sample or temperature, indicate essentially the same level of cure at roughly $54 \%+/-3 \%$ of the total potential. This differs from that reported by Han and Lee ${ }^{85}$, in which increased polymerization temperatures resulted in increased isothermal enthalpy.

As shown in Figure 6.20, peak exotherm times, $\mathrm{t}_{\mathrm{m}}$, had strong exponential correlations, with $\mathrm{R}^{2}>0.97$, to temperature. Figure 6.21 shows that the maximum rate, $r_{m}$, had a strong linear correlation to temperature with $R^{2}>0.99$. 


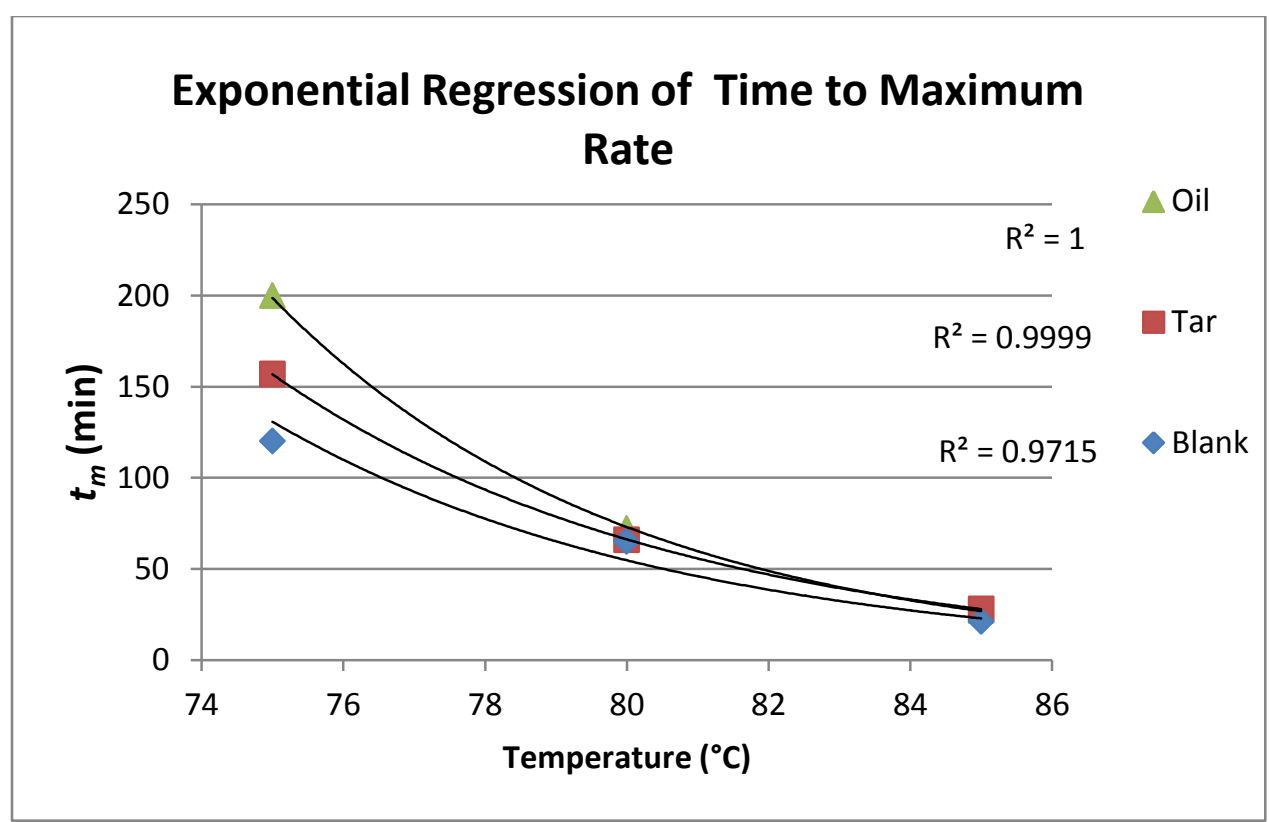

Figure 6.20: Regression Curves for Time to Isothermal Rate Maximum for Resin Master with and without Extracts

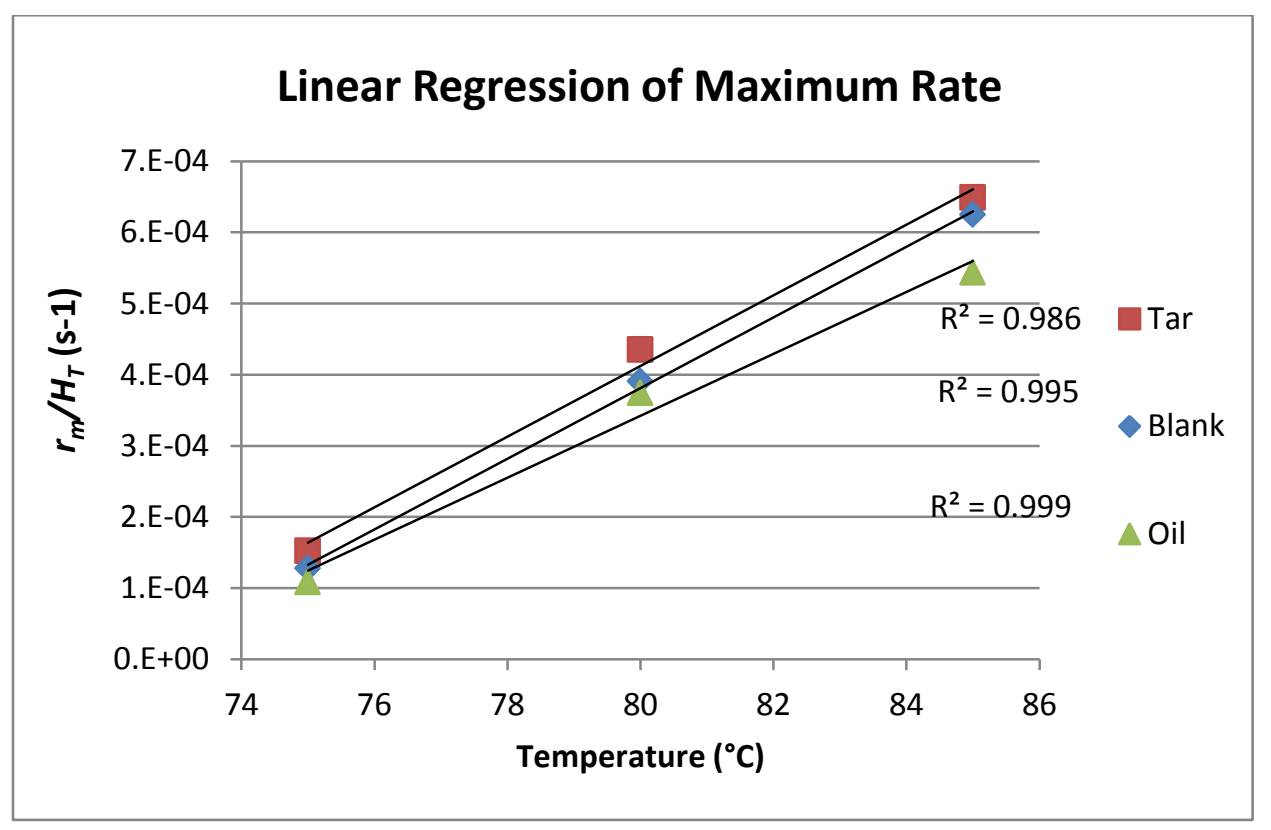

Figure 6.21: Regression Curves for the Isothermal Rate Maximum Maximum for Resin Master with and without Extracts 
The monomer conversion at the time of the maximum exotherm rate, (1$\left.[\mathrm{M}] /[\mathrm{M}]_{0}\right)_{\mathrm{m}}$, can be extracted from the $\mathrm{H}_{\mathrm{I}} / \mathrm{H}_{\mathrm{T}}$ integration at $\mathrm{t}_{\mathrm{m}}$. However, several of the curves were not symmetrical, which is a requirement of a good analysis; therefore, the conversion at half of the full conversion was assigned using an assumption of symmetry.

With Equation 1, the ratio of the propagation to termination rate constants, $\mathrm{k}_{\mathrm{p}} / \mathrm{k}_{\mathrm{t}}$, terms were isolated to one side and set to the numerical value of the other. Values were reiterated until a $\mathrm{k}_{\mathrm{p}} / \mathrm{k}_{\mathrm{t}}$ value was determined that successfully solved the equation. Equation 2 was used to decouple the rate constants using the maximum exotherm rate, $\mathrm{r}_{\mathrm{m}}$, the total exotherm $\mathrm{H}_{\mathrm{T}}$, and the peroxide decomposition rate, $\mathrm{k}_{\mathrm{d}} \mathrm{I}_{\mathrm{z}}$. These results are summarized in Table 6.4.

Table 6.4: Modified KCI Derived Kinetic Parameters

\begin{tabular}{|c|c|c|c|}
\hline & $\left(\mathbf{I}-[M] /[M]_{0}\right)_{m}$ & $k_{p}(L / M-s)$ & $k_{t}(\mathbf{L} / M-s)$ \\
\hline $\mathbf{B - 7 5}$ & 0.275 & 0.21 & 0.27 \\
\hline $\mathbf{B - 8 0}$ & 0.267 & 1.03 & 1.46 \\
\hline $\mathbf{B - 8 5}$ & 0.273 & 1.37 & 1.79 \\
\hline $\mathbf{T - 7 5}$ & 0.284 & 0.28 & 0.32 \\
\hline $\mathbf{T - 8 0}$ & 0.292 & 1.14 & 1.15 \\
\hline $\mathbf{T - 8 5}$ & 0.279 & 1.44 & 1.74 \\
\hline $\mathbf{O - 7 5}$ & 0.267 & 0.16 & 0.22 \\
\hline $\mathbf{O - 8 0}$ & 0.257 & 1.00 & 1.62 \\
\hline $\mathbf{O - 8 5}$ & 0.260 & 1.11 & 1.73 \\
\hline
\end{tabular}


The activation energy, $E_{p}$, and pre-exponential factor, $A_{p}$, were determined by Arrhenius regression of $\mathrm{k}_{\mathrm{p}}$ to 1/RT using Equation 3. Results are presented in Figure 6.22. Correlation $\mathrm{R}^{2}$ values were 0.8 to 0.87 , which with the limited data is reasonable.

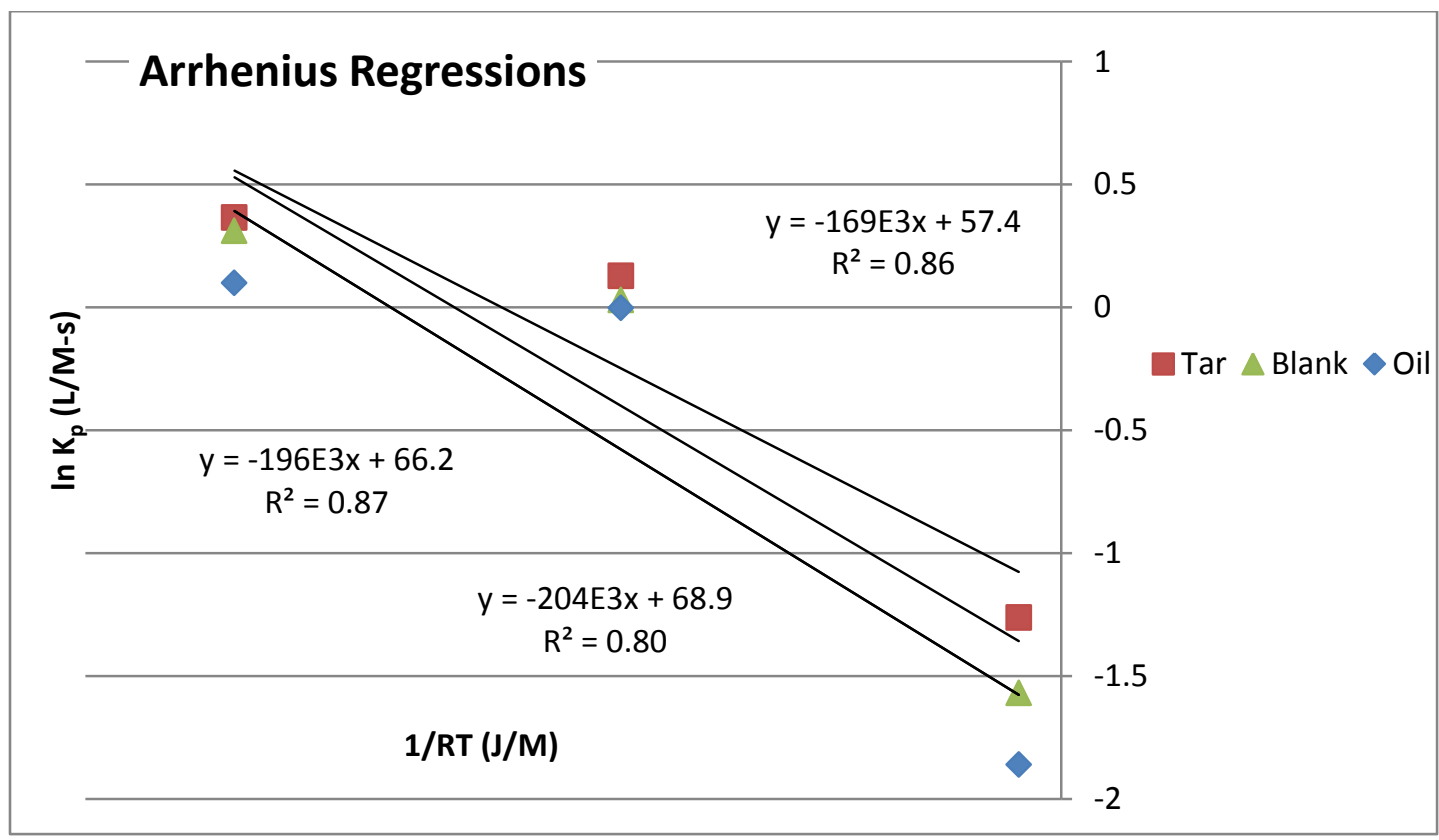

Figure 6.22: Arrhenius Regression for Propagation Kinetic

The activation energies, $\mathrm{E}_{\mathrm{p}}$, for the blank, the oil and the tar samples, respectively, are 196, 204 and $169 \mathrm{~kJ} / \mathrm{M}$ and the pre-exponential factors, $\mathrm{A}_{\mathrm{p}}$, are 8.4E29, 5.6E28 and 8.5E24 L/M-s. These values are higher than the $\mathrm{E}_{\mathrm{p}}=113 \mathrm{~kJ} / \mathrm{M}$ and $\mathrm{A}_{\mathrm{p}}=5.6 \mathrm{E} 17 \mathrm{~L} / \mathrm{M}-\mathrm{s}$ reported by Muzumdar and Lee ${ }^{84}$ for a system with similar isothermal cure timing. Their lower activation energy makes sense because the peroxide they employed was tert-butyl peroxy-2-ethylhexanoate, which has a $1 \mathrm{~h}$ half-life temperature of $91{ }^{\circ} \mathrm{C}$ versus $106^{\circ} \mathrm{C}$ for the peroxide used in this current study. Extrapolated $\mathrm{k}_{\mathrm{p}}\left(150^{\circ} \mathrm{C}\right)$ to a typical compound molding temperature, using the Arrhenius regressions, are seen in Table 6.5. 
Table 6.5: Comparison to Literature Results

\begin{tabular}{|c|c|c|c|c|}
\hline Sample & $1 h r T\left(t_{1 / 2}\right)$ & $E_{p}(k J / M)$ & $A_{p}(L / M-s)$ & $k_{p}\left(150^{\circ} \mathrm{C}\right)$ \\
\hline blank & $106^{\circ} \mathrm{C}$ & 196 & $8.4 E+29$ & $5.4 \mathrm{E}+05$ \\
\hline oil & $106^{\circ} \mathrm{C}$ & 204 & $5.6 E+28$ & $3.7 E+03$ \\
\hline $\operatorname{tar}$ & $106^{\circ} \mathrm{C}$ & 169 & $8.5 E+24$ & $1.2 E+04$ \\
\hline \multicolumn{5}{|l|}{ ref data } \\
\hline Muzumdar and Lee ${ }^{84}$ & $91^{\circ} \mathrm{C}$ & 113 & $5.6 \mathrm{E}+17$ & $6.3 E+03$ \\
\hline Han and Lee ${ }^{83}$ & mixed & 83 & $3.4 \mathrm{E}+14$ & $1.9 E+04$ \\
\hline
\end{tabular}

The oil and tar projected $\mathrm{k}_{\mathrm{p}}\left(150^{\circ} \mathrm{C}\right)$ values were in the same range as the literature results. The blank had a higher projected rate constant at the molding temperature than the literature reports; however, the resin / peroxide systems in the various studies differed, as did the kinetic treatments. Therefore, precise agreement was not expected.

\subsubsection{Solid State NMR Characterization of Torrefacted Fillers}

The DSC data indicated that, because the extracts were not shown to induce the level of inhibition seen with the filler, the solid filler was the major contributor. Untreated soy did not induce the inhibition therefore the cause was related to the changes that occured during torrefaction. FTIR analysis indicated the formation of aromatic species during torrefaction,, when hydroxyls were evolved and, due to the organized hydrogen bonding, ring structures were easily formed. The inhibiting effect was consistent with historical results with lignin, which has $50 \%$ aromatic content, in inducing cure inhibition. ${ }^{76}$ Lignin and aromatic rings have structures common to commercial free 
radical cure inhibitors. It is proposed that the mechanism of the inhibition is that the aromatic structures in the fillers function as free radical traps.

Quantification of the level of retarding or inhibiting species would be of use in development of specifications for the filler manufacture to insure no cure effects are induced with use of the filler. Solid state NMR spectroscopy is a semi-quantitative means to determine the relative ratio of aromatic content to other constituent species.

Figure 6.23 presents the ${ }^{13} \mathrm{C}$ solid state NMR spectra for the following samples are shown, with increasing torrefaction intensity from top to bottom: untreated soy hulls (UTSH), [3.4.4] ECP $204{ }^{\circ} \mathrm{C}$ and $249^{\circ} \mathrm{C}$, [3.4.1c] $288^{\circ} \mathrm{C}$ ATP/NCSU bench scale, [3.4.2] $400{ }^{\circ} \mathrm{C}$ muffle furnace and [3.4.4a] $400{ }^{\circ} \mathrm{C}$ ATP/NCSU pilot scale. All samples were dried under vacuum at $25^{\circ} \mathrm{C}$ for two days and sealed for storage, prior to testing.

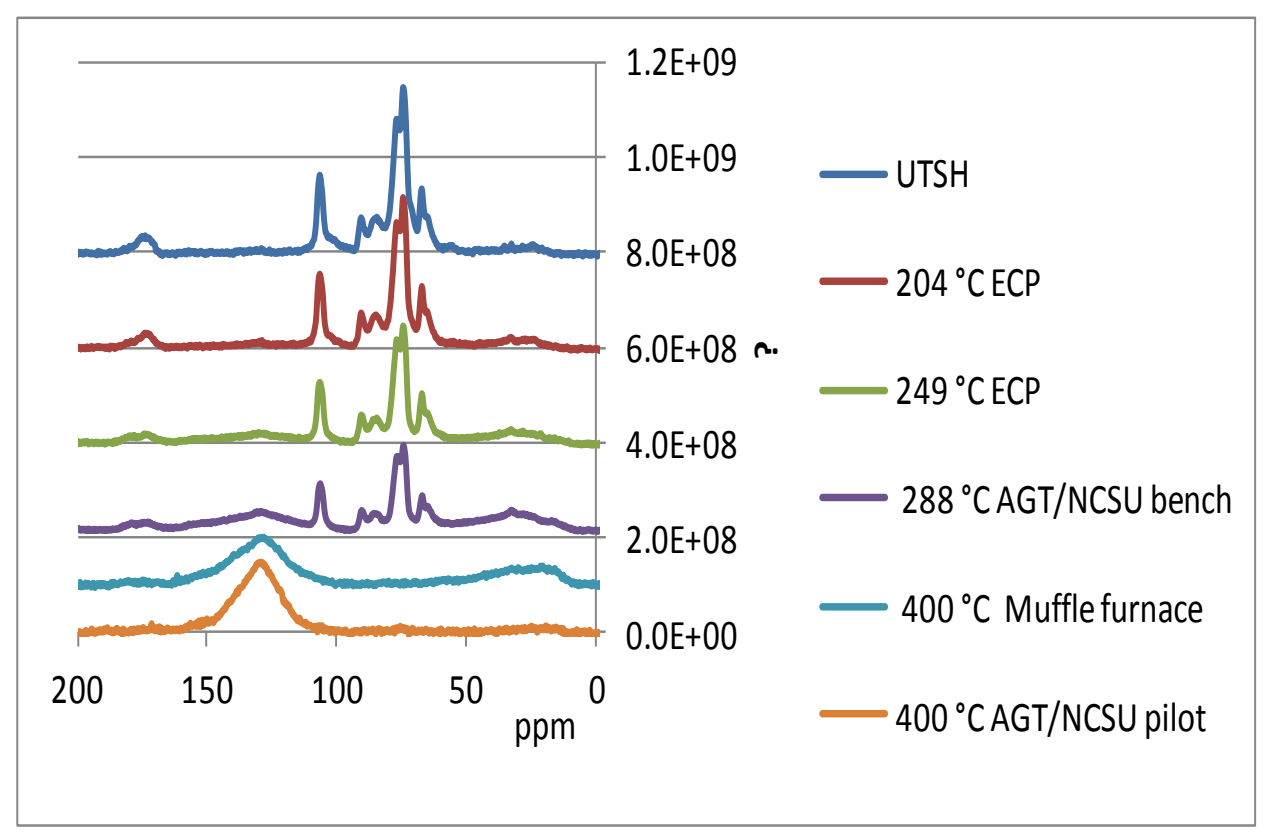

Figure 6.23: $\mathrm{SS}{ }^{13} \mathrm{C}$ NMR Spectra of Torrified Fillers 
The areas under the resonances were integrated to quantify the carboxyl, aromatic, cellulose and aliphatic content. Due to the signal to noise ratio of lower intensity resonances, smoothing using a 10 point running average was applied before the baseline correction and integration. The cellulose resonances were integrated without smoothing to avoid distortion because the random noise fluctuation had a minimal effect on the calculated values. The calculated values are depicted in Figure 6.24.

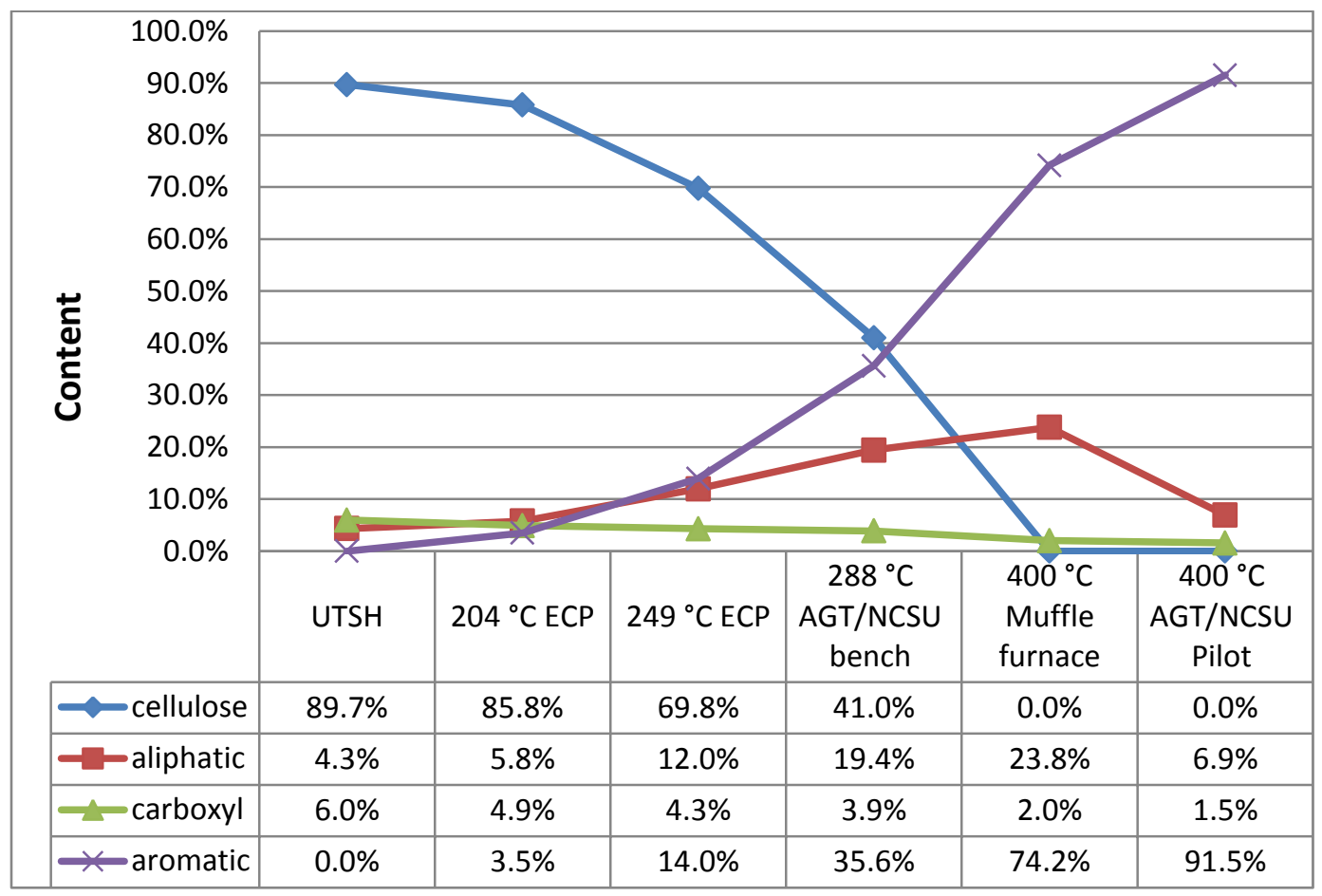

Figure 6.24: Composition of Various Torrefied Fillers by NMR Integrations

Figure 6.25 presents the baseline corrected region used for the cellulose integrations. As the intensity of the heat treatment increases the cellulose resonances diminished, and disappeared entirely in the two most aggressive treatments. 


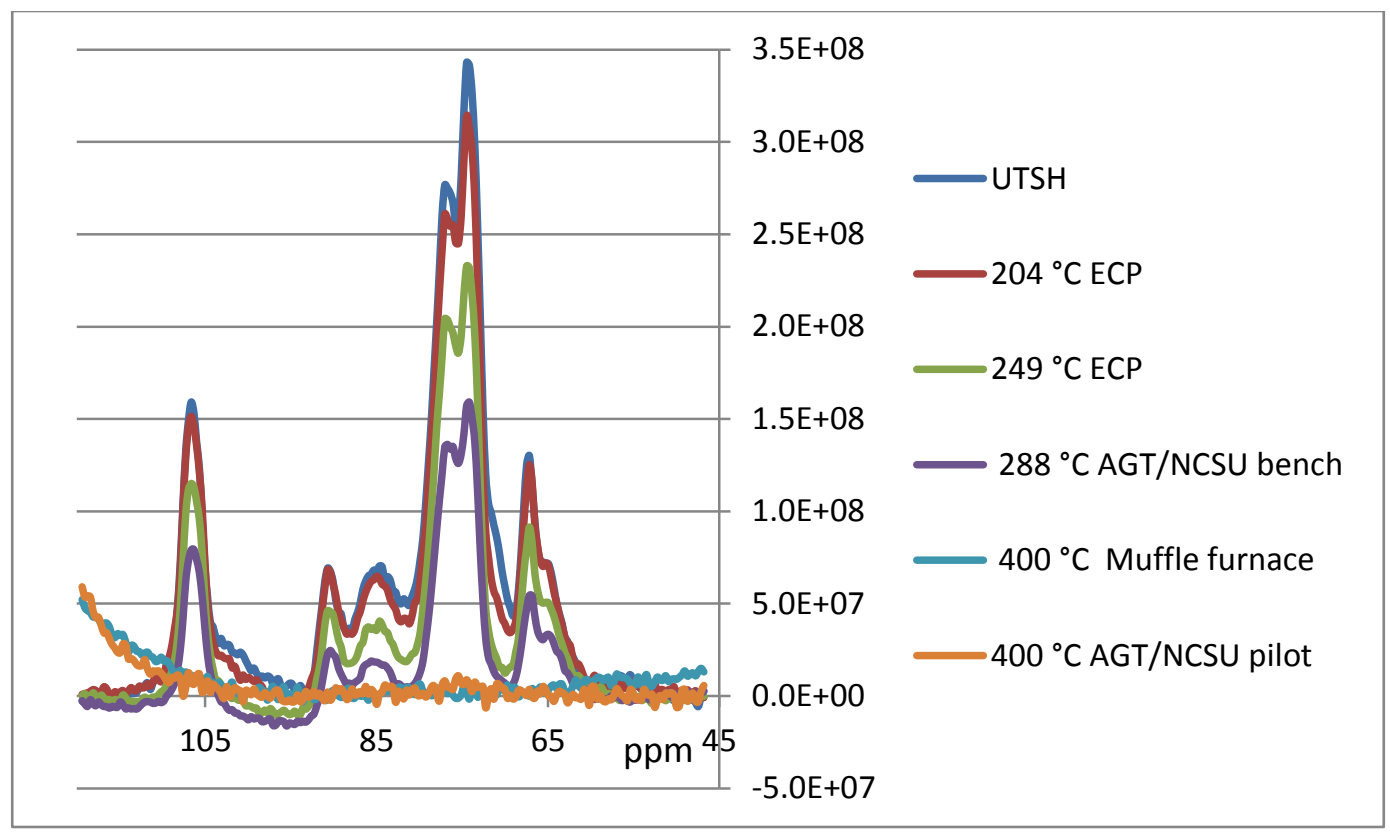

Figure 6.25: Baseline Adjusted Cellulose Region of SS ${ }^{13} \mathrm{C}$ NMR Spectra of Torrified Fillers

Figure 6.26 shows the changes in aliphatic content with the treatments. The aliphatic content increased as less stable oxygenated species were liberated. The profile shift seen in the $400{ }^{\circ} \mathrm{C}$ muffle furnace sample indicated an increase in $-\mathrm{CH}_{3}$ chain ends relative to $-\mathrm{CH}_{2}$ - groups as a result of thermally induced chain scission. In the most aggressively treated sample, the aliphatic content decreased significantly as ring formation of the aliphatic structures occured.

As shown in Figure 6.27, the carboxyl resonance decreases with increasing treatment, although even in the most aggressively treated sample, some carbonyl species persisted. The sharp decrease in resonance between the $204{ }^{\circ} \mathrm{C}$ and $249{ }^{\circ} \mathrm{C}$ treated ECP samples indicated an acceleration of carboxyl liberation in that range. 


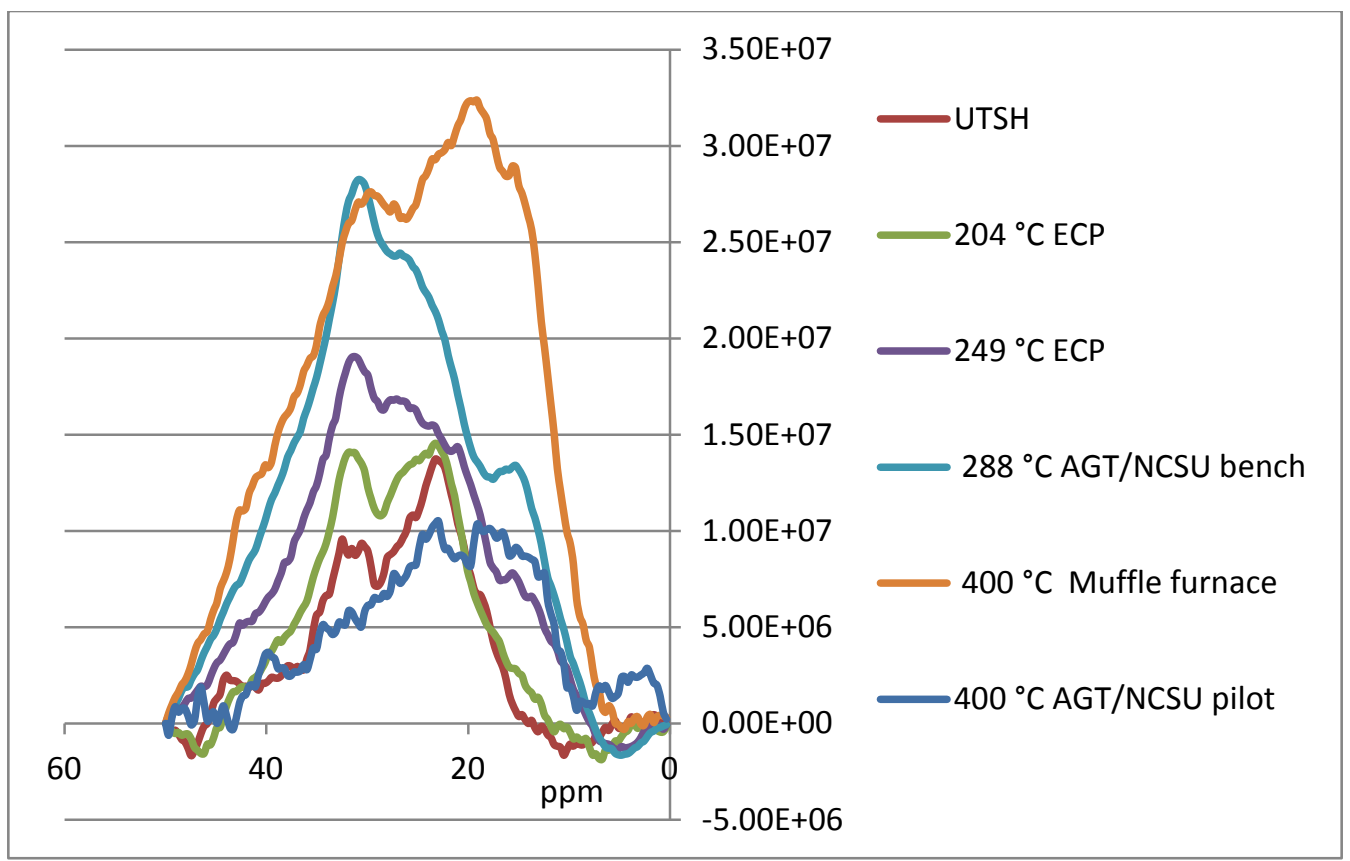

Figure 6.26: Baseline Adjusted Aliphatic Region Region of SS ${ }^{13} \mathrm{C}$ NMR Spectra of Torrified Fillers

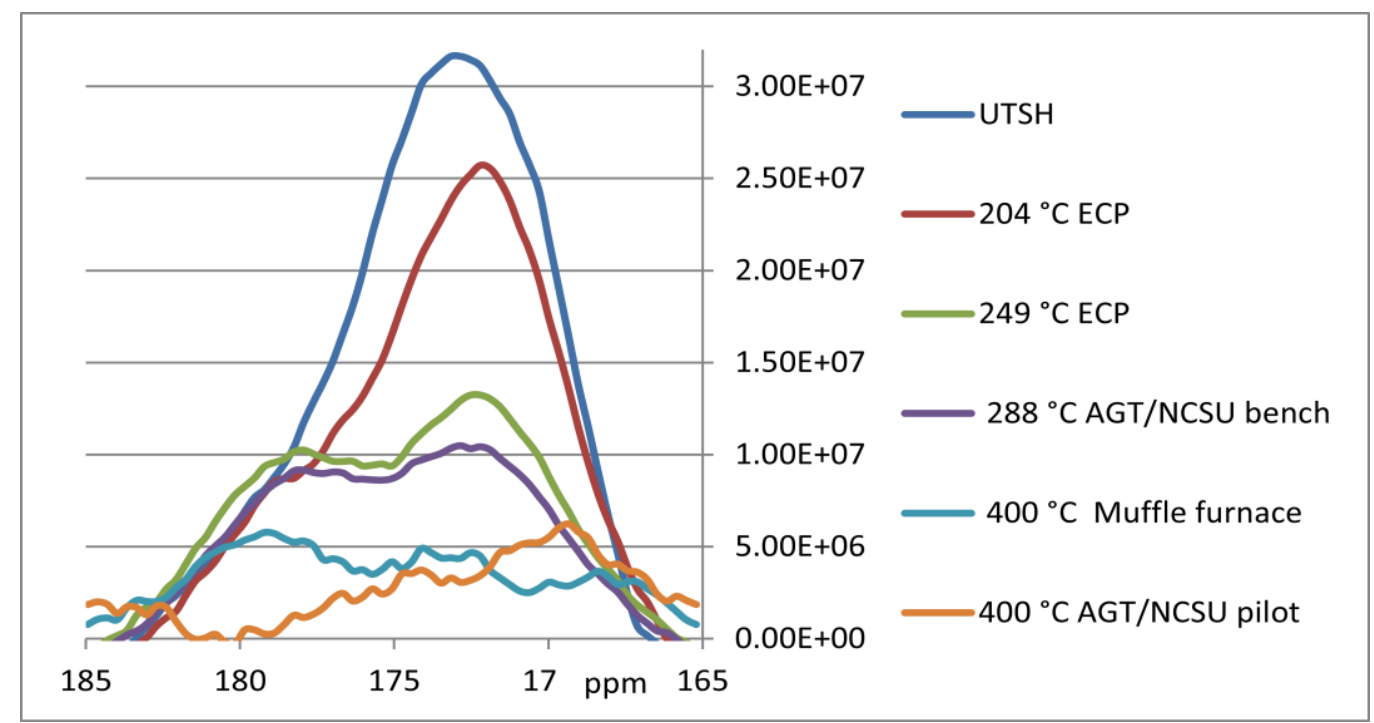

Figure 6.27: Baseline Adjusted Carboxyl Region Region of SS ${ }^{13} \mathrm{C}$ NMR Spectra of Torrified Fillers 
Finally, Figure 6.28 shows the increase in aromatic content as treatments intensify. The filler, did not inhibit cure up to the $288{ }^{\circ} \mathrm{C}$ treatment. The $400{ }^{\circ} \mathrm{C}$ filler, with much higher aromatic content, did induce significant inhibition resulting in reduction of properties.

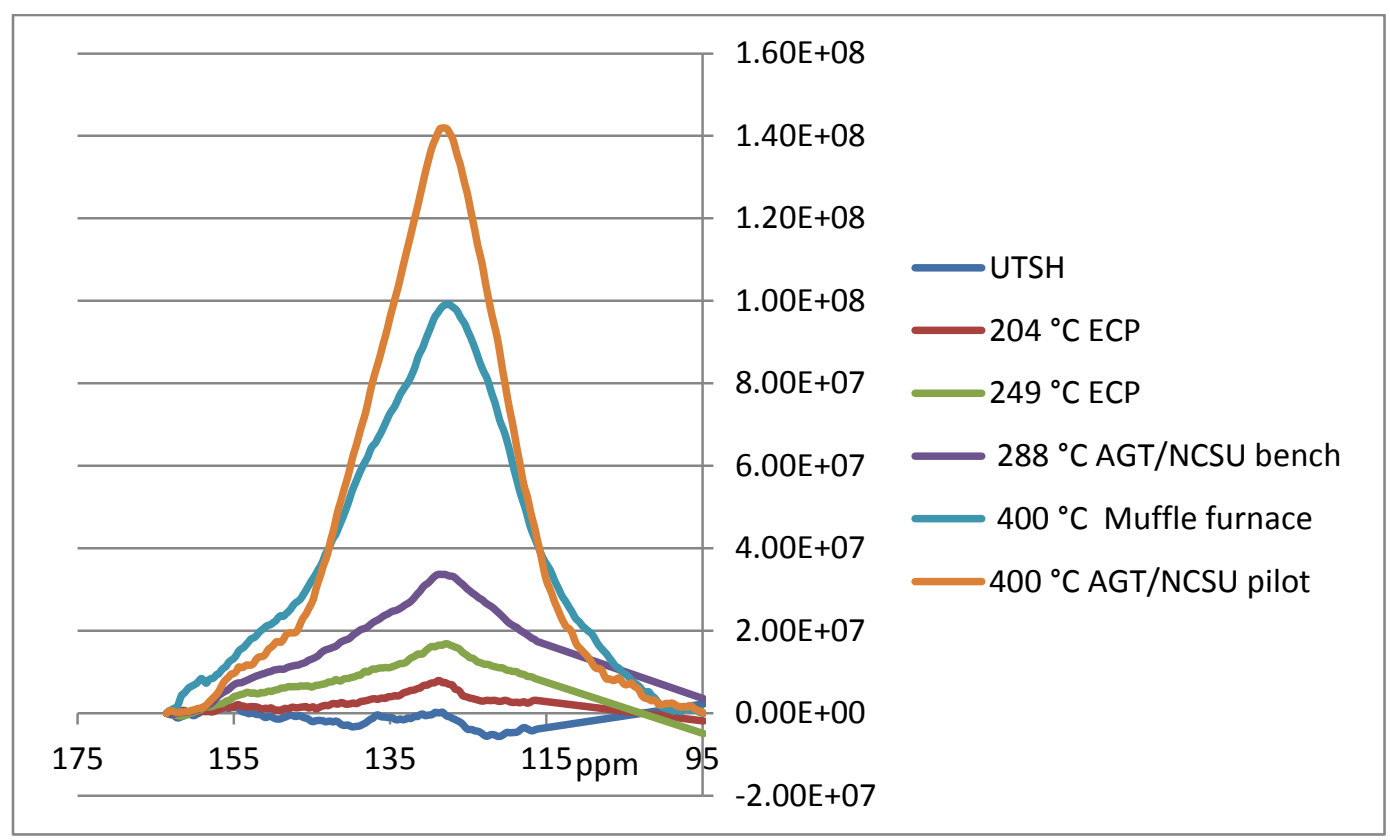

Figure 6.28: Baseline Adjusted Aromatic Region Region of SS ${ }^{13} \mathrm{C}$ NMR Spectra of Torrified Fillers

\subsection{FTIR Analysis of OTES Treated Fillers}

FTIR spectroscopy with ATR sampling was used to determine if any silane grafting had occurred during treatments. In Figure 6.29, the top spectra is untreated soy hulls (UTSH), the lower spectra is the A137 OTES liquid silane (OTES Silane) and the middle spectra is sample [3.7.3 a] soy filler slurry treated with the silane (OTES alurry treated filler). There was notable formation of absorptions in the 2800 to $3000 \mathrm{~cm}^{-1}$ range 
attributable to the silane. The broad hydroxyl absorbance at 3000 to $3600 \mathrm{~cm}^{-1}$ diminished in the treated sample, as well, indicating that grafting was successful.

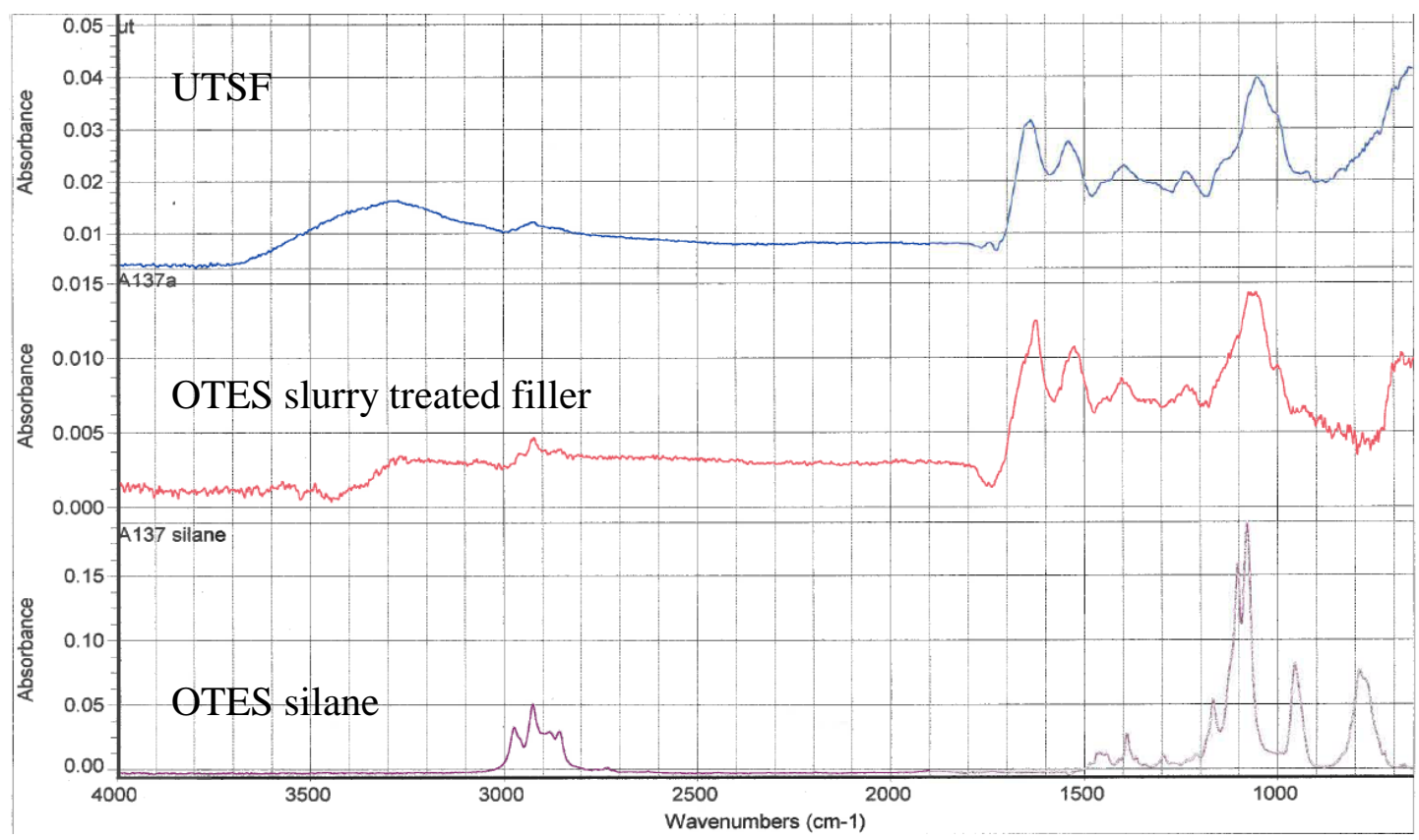

Figure 6.29: ATR FTIR Spectra of UTSH, OTES Treated Hulls \& OTES Silane

\subsection{FTIR Analysis of Esterified Fillers and Filtrates}

ATR FTIR spectroscopy is a good method to follow acetylation. The spectra of the dried solids from the filtered ambient temperature, pyridine catalyzed, acetylation soy flour sample [3.6.1 a] presented no notable differences from the untreated soy flour, indicating that the undissolved solids in the slurry were not successfully acetylated. The filtrate residue from this sample was dissolved in $3 \mathrm{ml}$ of toluene and was film cast on an IR $\mathrm{NaCl}$ salt plate. The transmission spectra, seen in Figure 6.30, indicates that the filtrate residue was a close match (88\%) to acetate fibers (cellulose acetate), confirming successful acetylation of the soluble portion of the flour. Subtraction of the cellulose 
ester spectra from the filtrate solids spectra resulted in a 55\% match to Soyamidopropyl ethyl ammonium ethosulfate \#1, a soy protein used in hair conditioners, indicating that in addition to the soluble cellulose that was acetylated, some soy protein was also solubilized. This is shown in Figure 6.31.

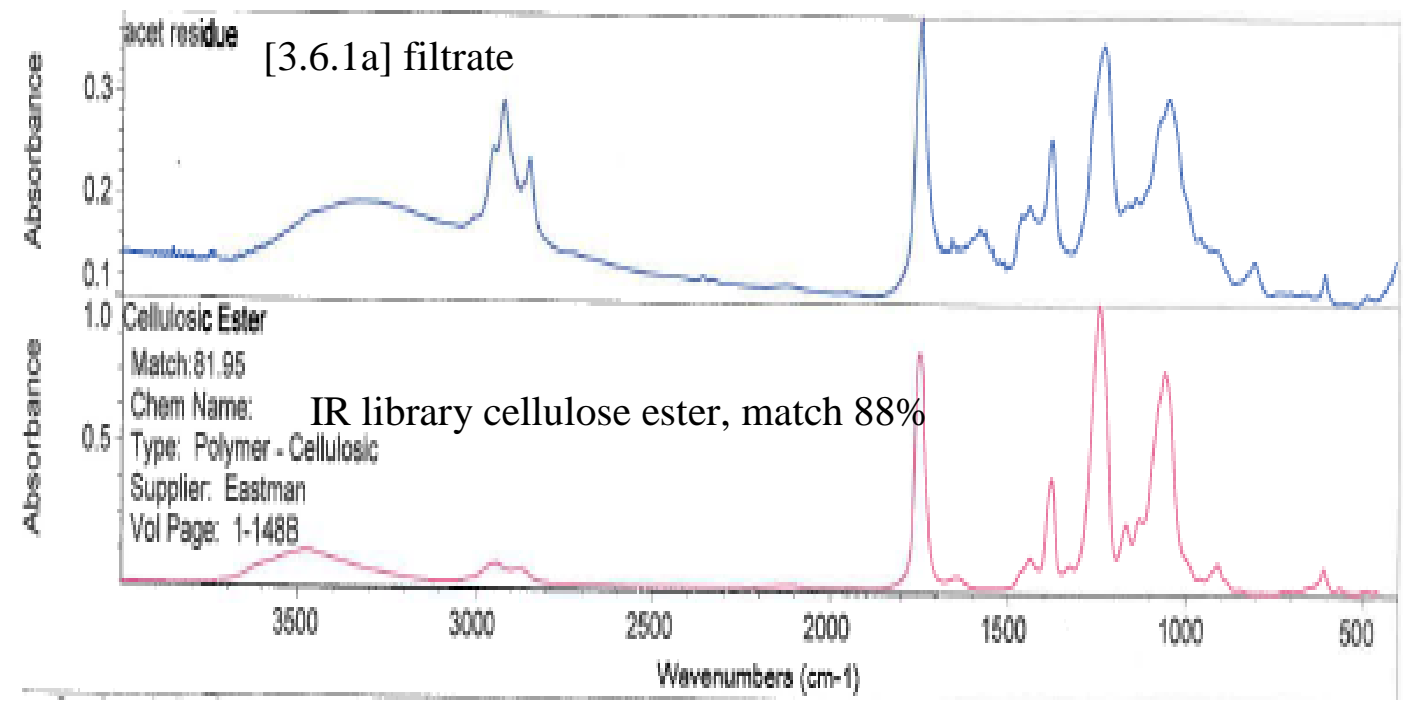

Figure 6.30: FTIR Match of Acetylated 3.6.1a Filtrate and Cellulose Acetate

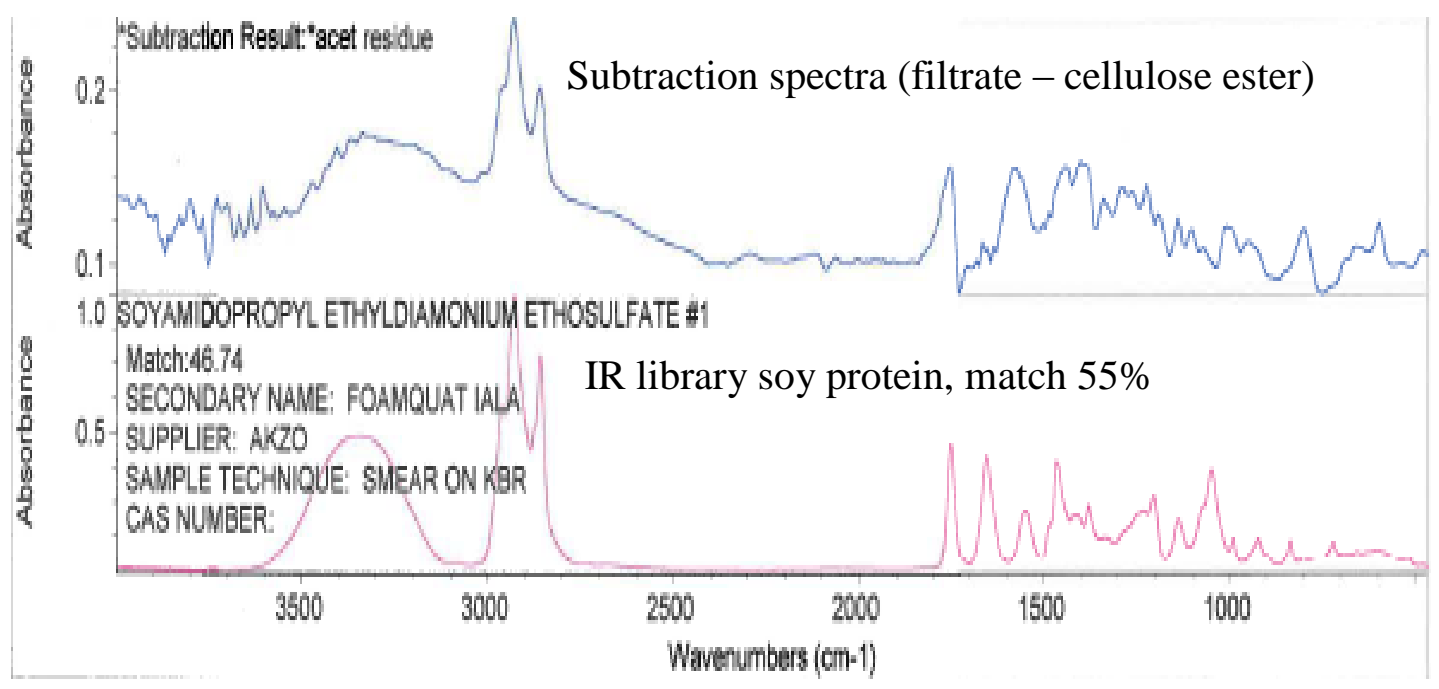

Figure 6.31: FTIR Match of Subtracted [3.6.1 a] Filtrate Spectra to Soy Protein 
Likewise, the filtered solids from the acetylation sample [3.6.1 b] attempted with DABCO catalysis at ambient temperature did not exhibit any changes in the ATR FTIR spectrum. The $110 \mathrm{ml}$ filtrate was allowed to dry in a hood and the oily residue was identified by IR spectroscopy as DABCO.

The spectrum for the acetylation soy flour sample [3.6.2 a] attempted using temperature assist without catalyst indicated significant changes relative to the untreated soy flour. In Figure 6.32, the upper spectrum is the untreated soy flour control and the lower spectrum is the dried acetylated solids from the sample. The broad hydroxyl absorbance at 3000 to $3700 \mathrm{~cm}^{-1}$ diminished and the absorption intensity shifted from $3410 \mathrm{~cm}^{-1}$ to $3300 \mathrm{~cm}^{-1}$, indicating more relative contribution of amide absorbances vs. hydroxyl. Instead of a single absorbance at $1680 \mathrm{~cm}^{-1}$, absorptions at 1620 and $1746 \mathrm{~cm}^{-1}$ appeared. The absorbances at $1680 \mathrm{~cm}^{-1}$ and $1620 \mathrm{~cm}^{-1}$ were amide absorptions from the soy proteins. The $1746 \mathrm{~cm}^{-1}$ absorbance due to the $\mathrm{C}=\mathrm{O}$ acetate stretch. Acetate absorbances for $\mathrm{C}_{-} \mathrm{CH}_{3}$ at $1383 \mathrm{~cm}^{-1}$ and $\mathrm{C}-\mathrm{O}$ at $1234 \mathrm{~cm}^{-1}$ also appeared. The amide absorbance at $1520 \mathrm{~cm}^{-1}$ was unaffected, with similar relative intensity to the alkane absorptions in the $2800 \mathrm{~cm}^{-1}$ to $3000 \mathrm{~cm}^{-1}$ range. These absorbances were therefore suitable for normalization for semi-quantitative analysis of degree of acetylation.

Toluene was added to the filtrate residue to dissolve it for casting onto a $\mathrm{NaCl}$ salt plate for transmission FTIR analysis. After drying, the slight reddish film with tan particulates had the spectra seen in Figure 6.33, which was a 93\% match to cellulose acetate, indicating the soluble portion of the flour was acetylated as well. 


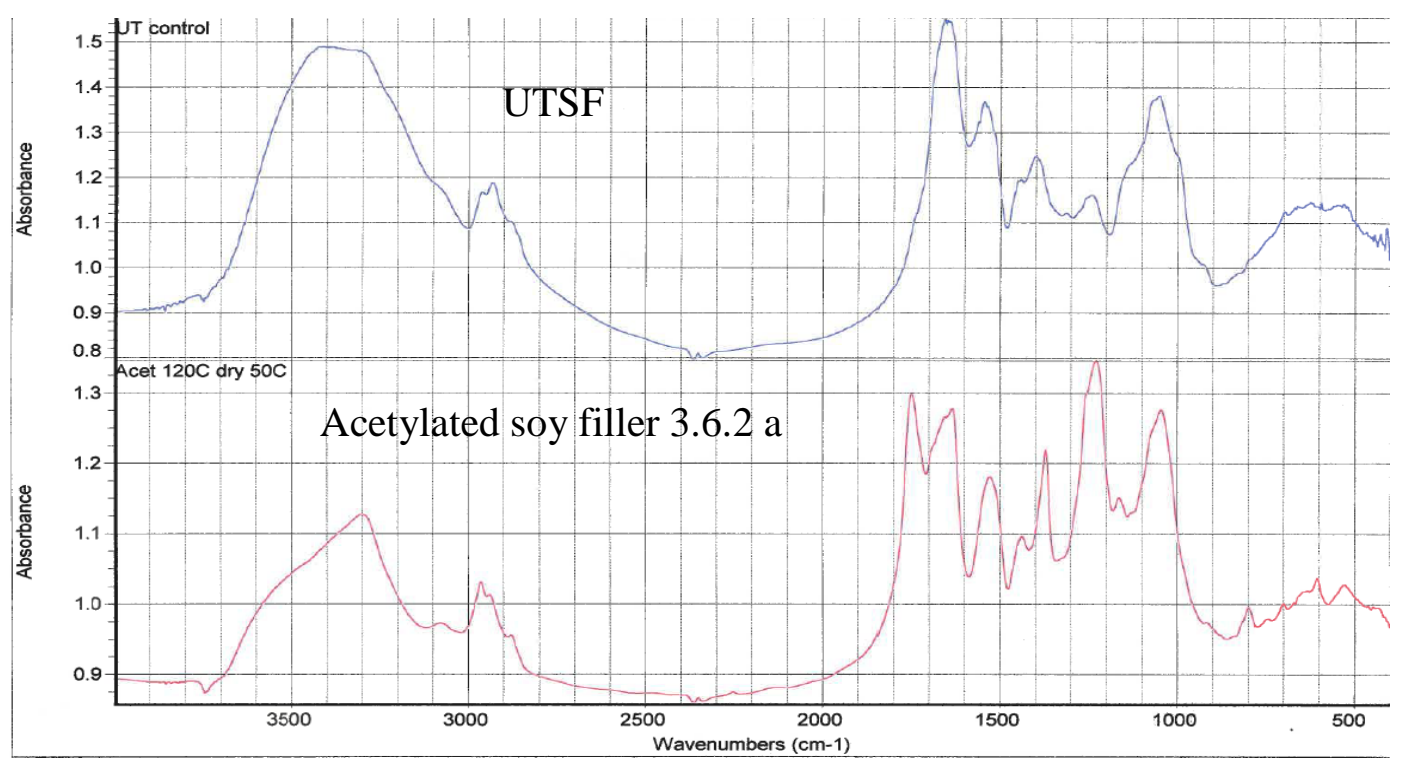

Figure 6.32: ATR FTIR of UTSF and Acetylated Soy Flour 3.6.2 a

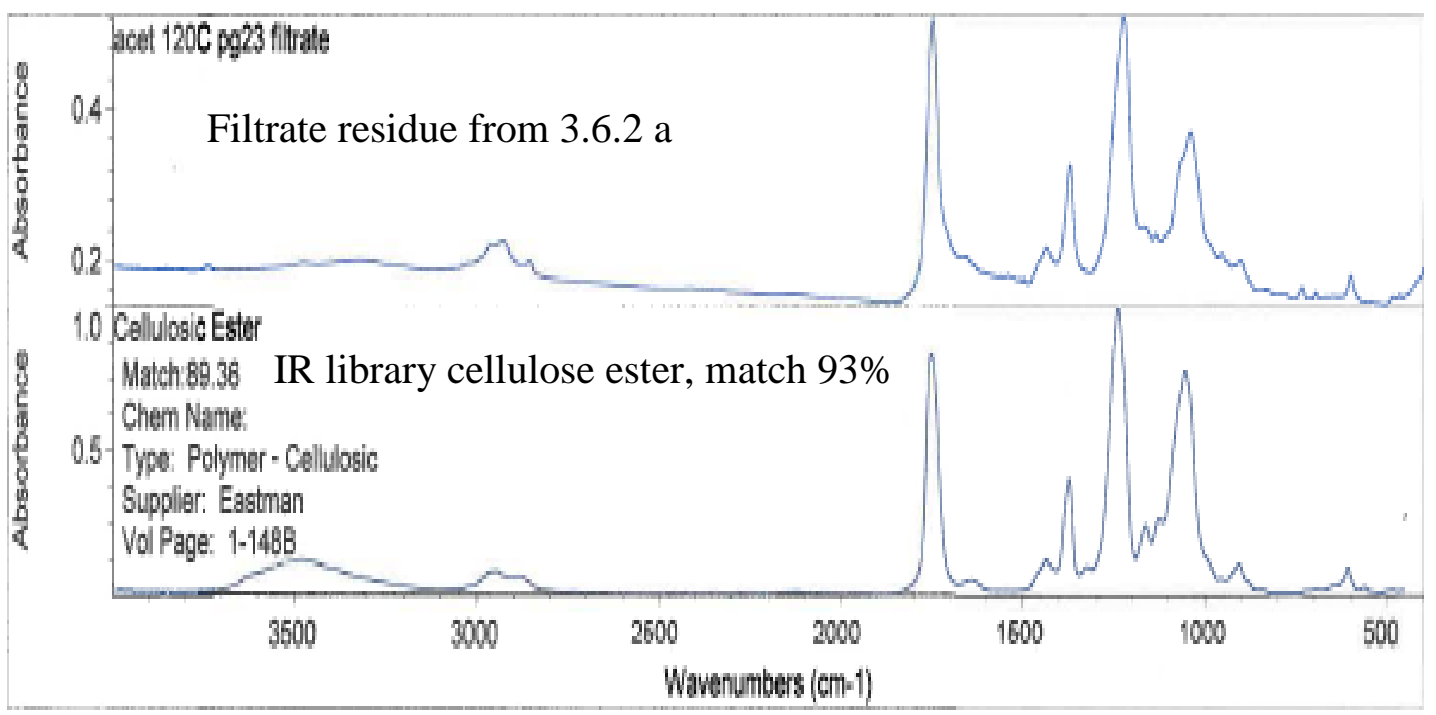

Figure 6.33: FTIR Spectra Match for Filtrate 3.6.2a Residue to Cellulose Acetate

Figure 6.34 compares the $10 \mathrm{~g}$ scale, temperature assist, slurry acetylated soy flour [3.6.2 b] (bottom) to the smaller scale $0.34 \mathrm{~g}$ processed [3.6.2 a] (middle) and the untreated precursor flour (top). At very small scale, a higher level of acetylation was 
achieved than seen with the $10 \mathrm{~g}$ scale-up. This is evidenced in the ester absorbances at $1746 \mathrm{~cm}^{-1}(\mathrm{C}=\mathrm{O}), 1383 \mathrm{~cm}^{-1}(\mathrm{C}-\mathrm{CH} 3)$ and $1234 \mathrm{~cm}^{-1}$ (-C-O-), which appear in both the slurry treated samples, although they are significantly larger in the smaller scale sample.

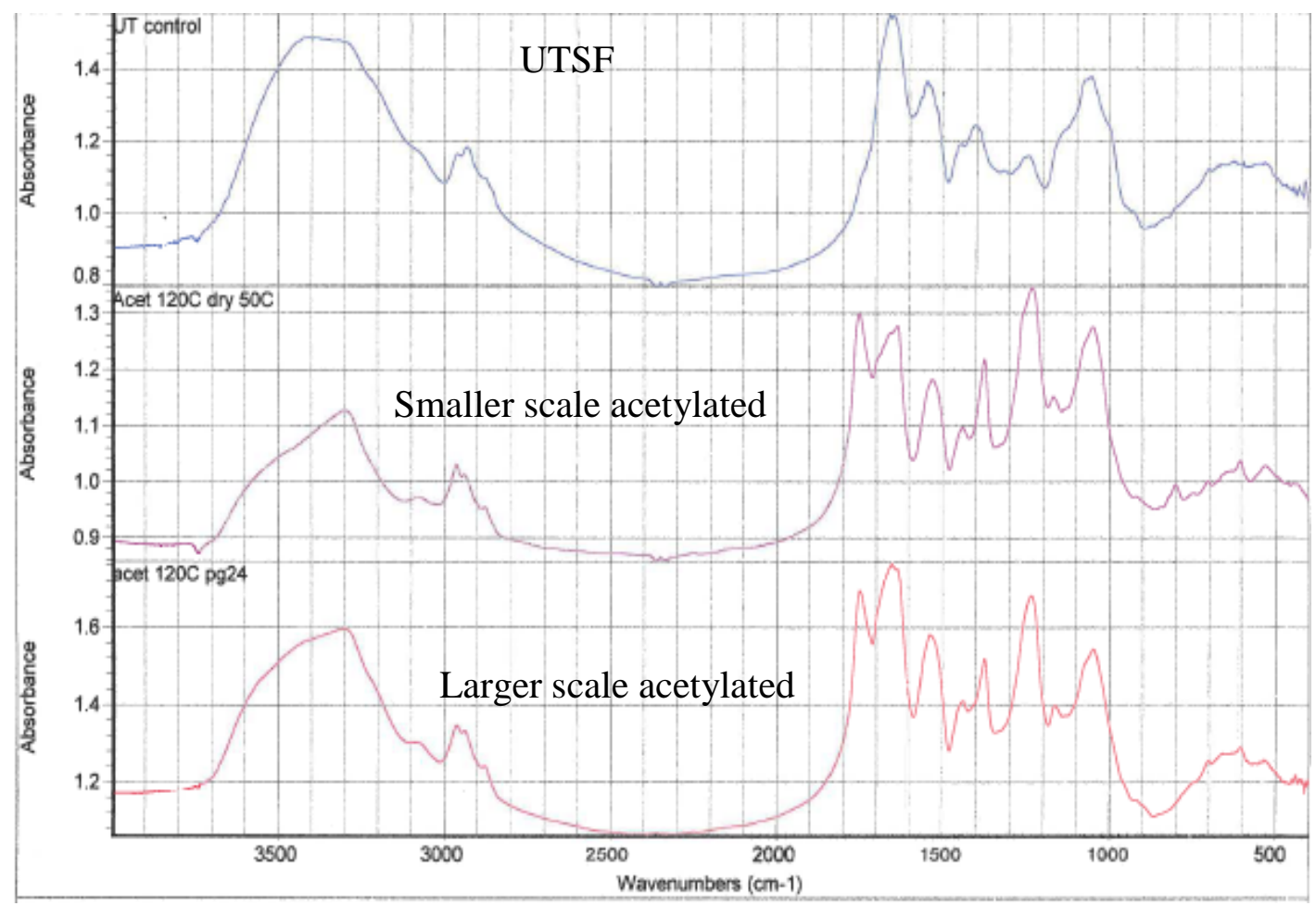

Figure 6.34: FTIR Spectra of UTSF and Slurry Acetylated Flour at Different Scales

Figure 6.35 compares the IR spectra of the UTSF (bottom) and samples from three areas of the $25 \mathrm{~g}$ sludge acetylated sample [3.6.3 a]. This sample, which was reacted in a round bottom flask with poor agitation, had differing coloration in the center (top), which was light brown; intermediate position (2nd from top), which was chocolate; and against the flask wall (3rd from top), which was a dark brown. Based on the evolution of the acetate absorptions, the color clearly correlated with the level of cetylation, with the darkest color indicating the greatest level of acetylation. 


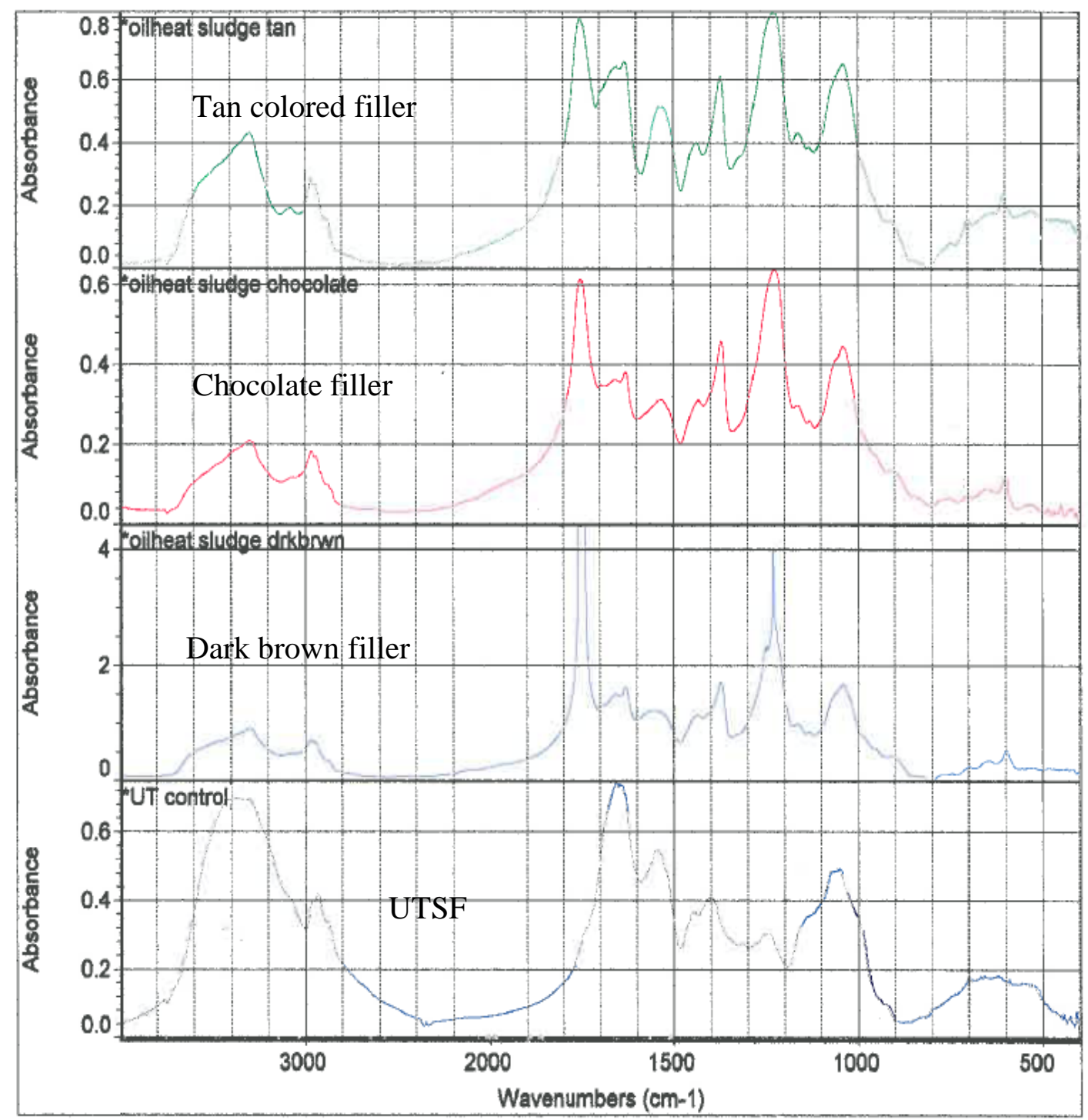

Figure 6.35: Different Areas of Acetylated Flour 6.6.3a with Different Coloration

Based on the large absorbance at $1746 \mathrm{~cm}^{-1}$, this longer duration sludge method was more effective than the shorter slurry method for acetylation. Figure 6.36 compares the FTIR spectra of the UTSF (middle), $5.5 \mathrm{~g}$ sludge acetylated [3.6.3 b] (bottom) and 15 g sludge acetylated[3.6.3 c] (top). 


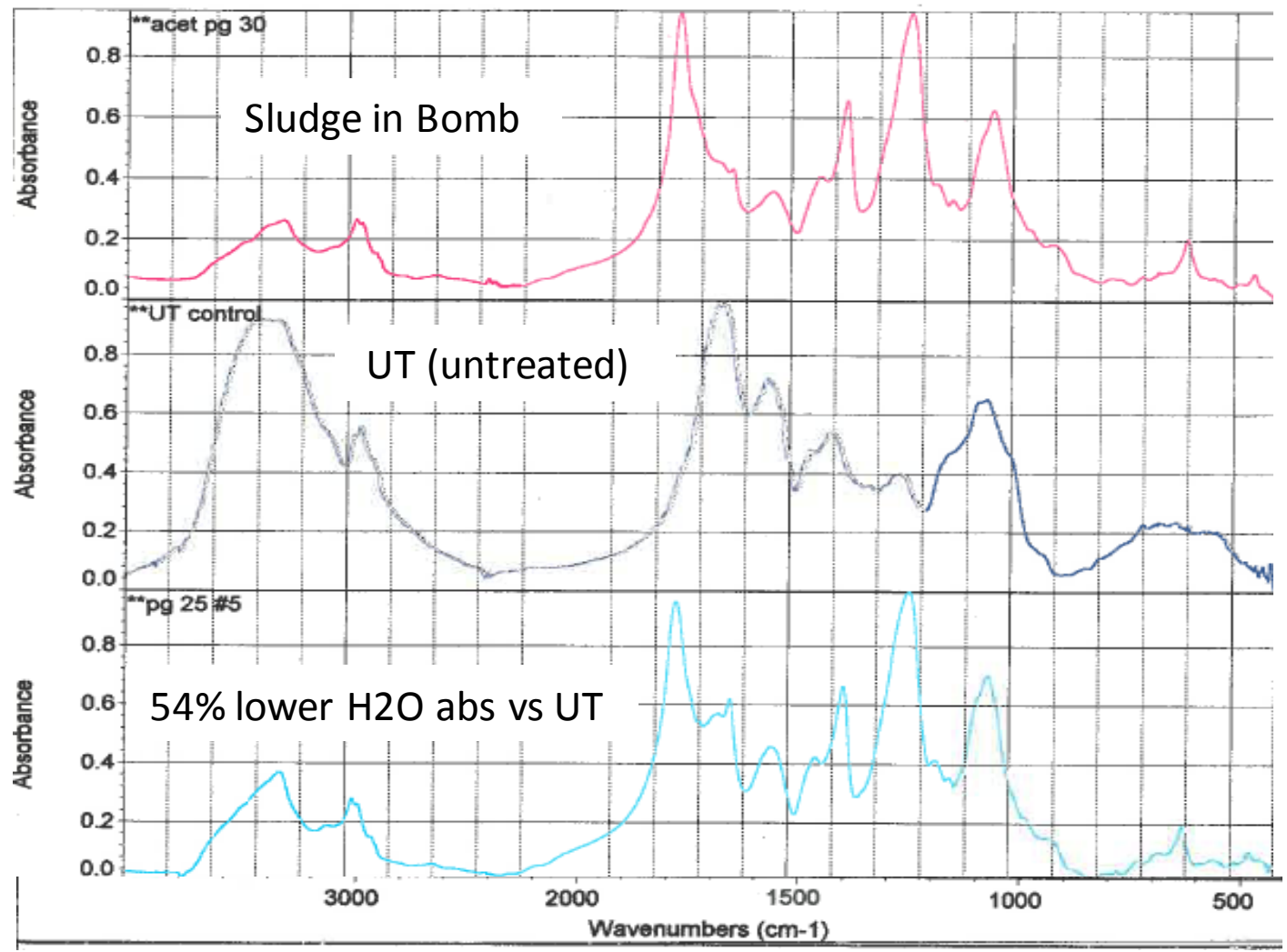

Figure 6.36: FTIR Spectra of the UTSF and Sludge Ttreated Acetylated Flours

In figure 6.37, FTIR spectra for untreated soy hulls UTSH (top), Carbon 20-24 alkenyl succicnc anhydride: ASA 2024 liquid (bottom) and ASA esterified sample [3.6.4c] (middle) are shown. There was development of alkane absorptions from the ASA, in the $2800-3000 \mathrm{~cm}^{-1}$ range, in the treated filler, indicating effective displacement of the hydroxyls. The amide absorptions were diluted relative to the untreated spectra and shifted to higher wave numbers. Additional features in the fingerprint region also appeared. Although not perfectly aligned directly with the ASA liquid absorptions, in general they are close in position, indicating additional functionality on the treated filler. 


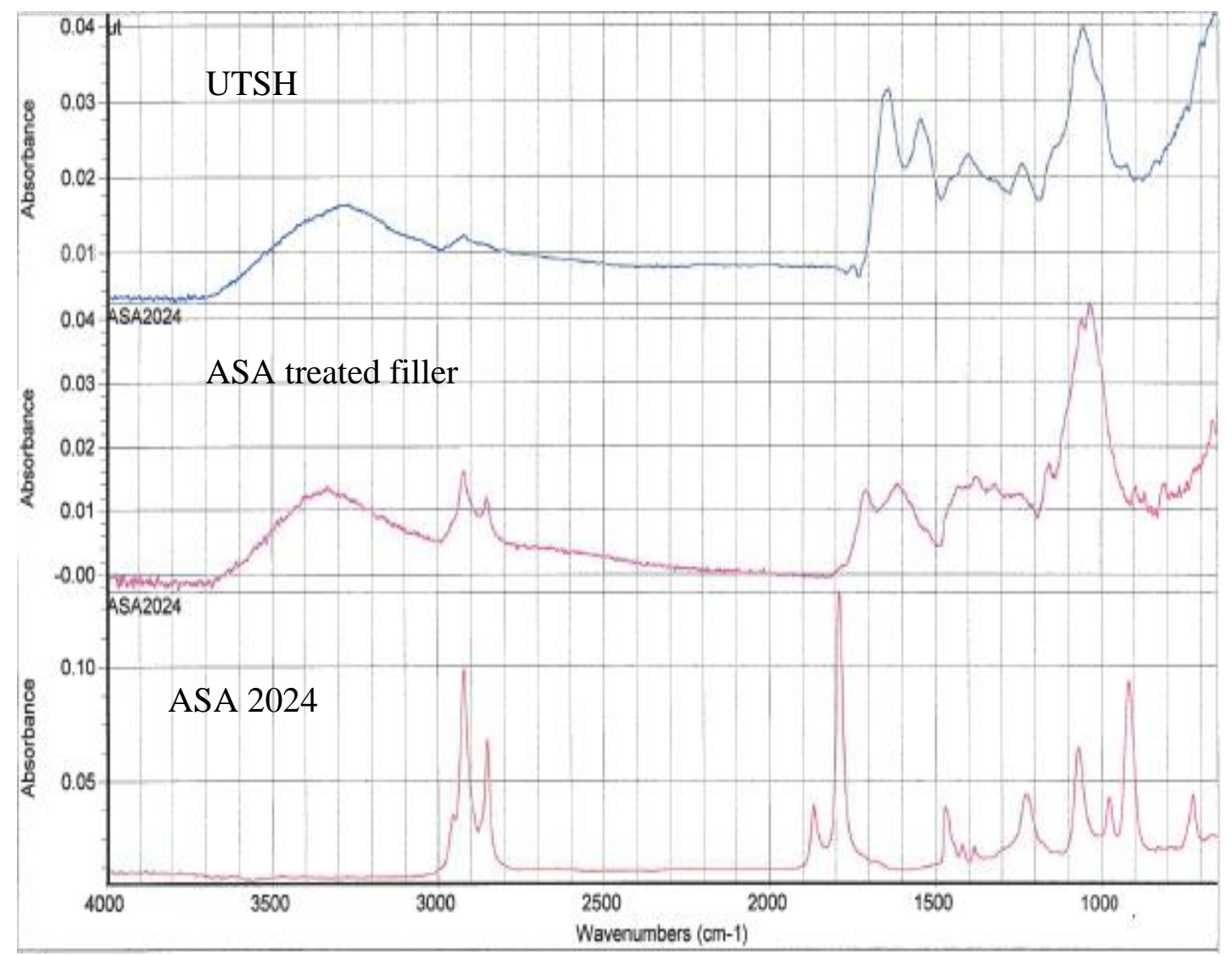

Figure 6.37: FTIR Spectra of UTSH, ASA 2024 Treated Hulls and ASA 2024 Liquid

Figure 6.38 compares the spectra for UTSH (top), acetylated flour [3.6.3 c] (2nd from top), ASA esterified hulls [3.6.4c] (3rd from top) and a sample treated with a 50/50 blend of acetic anhydride and ASA [3.6.4b] (bottom). The acetylated spectrum and mixed anhydride treated spectrum were very similar, indicating that the acetylation dominated, with less of the ASA reaction. An absorption at $1175 \mathrm{~cm}^{-1}$, however, was not in the acetylated only spectrum, but does align with an absorption in the ASA2024 only treated spectrum. An ASA2024 absorbance at $1600 \mathrm{~cm}^{-1}$ also appears to influence the spectrum, as a valley in the acetylated spectrum is bridged in the mixed anhydride treated spectra. 


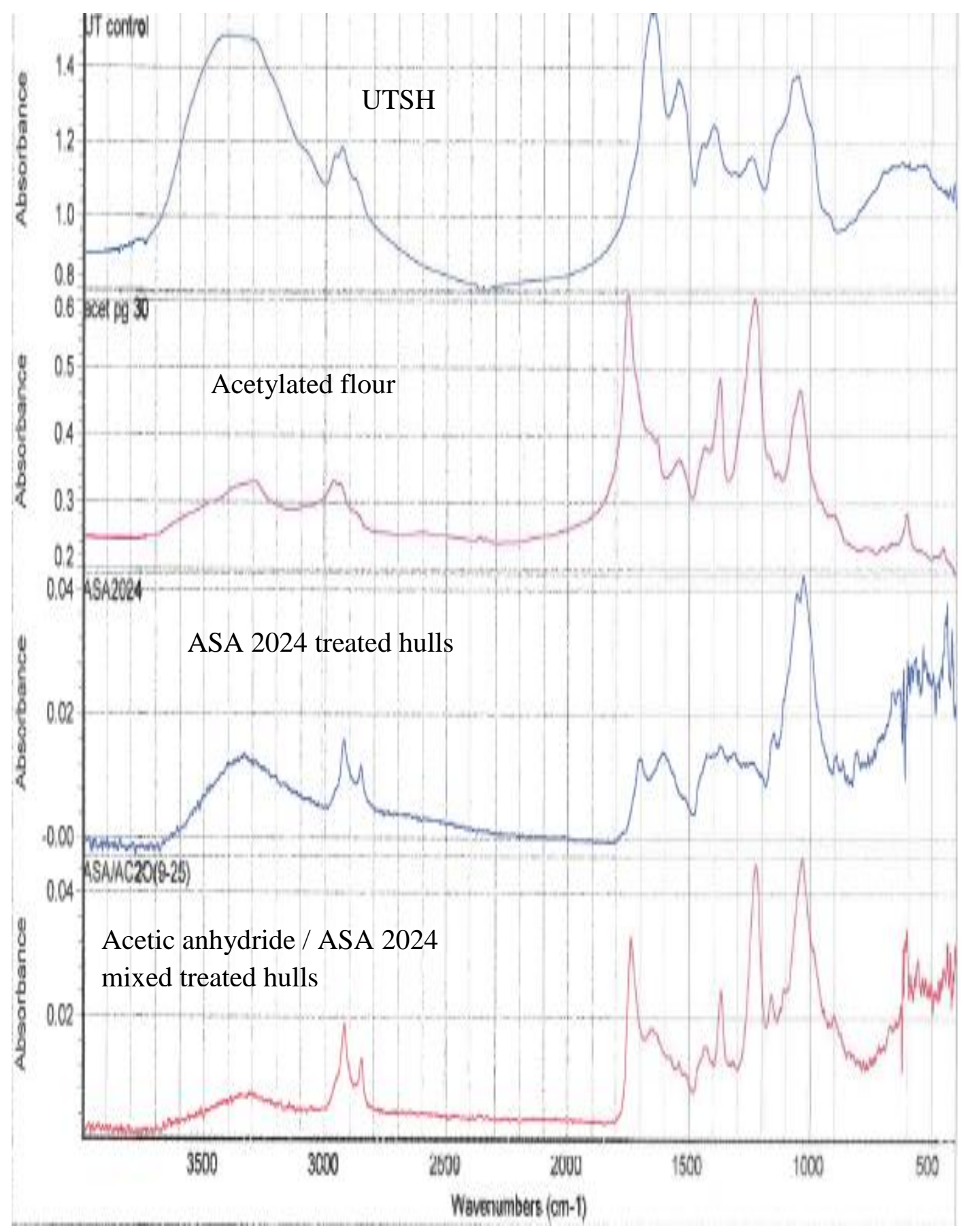

Figure 6.38: FTIR Spectra of UTSH, Acetylated Flour, ASA 2024 Treated Hulls and Mixed Treatment Hulls 


\section{CHAPTER VII}

\section{SUMMARY AND FUTURE DIRECTION}

\subsection{Scope of the Dissertation}

The intent of this research was to develop a bio-based filler suitable for thermoset composites. This filler would provide a low density alternative to mined mineral filler, such as $\mathrm{CaCO}_{3}$ or clay. Composites made with these fillers would be lighter in weight, which is desirable for many markets, particularly transportation. Cost parity to the mineral fillers, on a volume basis, was desirable and the use of green chemistry principles was a key objective of the project.

This dissertation reports the progress in the evaluation of soy-based fillers for thermoset composites. Various soy bio-mass precursors were evaluated. Resin casting studies were used to evaluate modifying treatments for effectiveness in the reduction of hydrophillicity. Promising fillers were evaluated in thermoset bulk molding compounds and sheet molding compounds. They were compared to conventional compounds for various performance attributes. Finally, promising fillers, and composites made with

them were probed analytically, for insight into changes induced by the treatments and behaviors impacting performance as a composite filler. 


\subsection{Precursors and Modifications}

Soy meal flour, ground soy hulls, soy protein concentrate and soy protein isolates were used as the basis of the soy filler samples. Treatments, included enzymatic refinement, merceration, torrefaction, application of coatings, silane grafting and esterifications. In addition, some combination treatments were evaluated for possible additive benefit.

\subsection{Water Absorption Experiments}

Resin casting experiments were used to screen the treated fillers. An analysis of the method indicated normal distributions of untreated weight gain results for castings with untreated soy fillers. The distribution was clearly distinguishable from the normal distribution for castings with $\mathrm{CaCO}_{3}$. The water absorption over time was non-linear and did not level to a plateau, in the 1-6 day time-scale evaluated. Because of the nonlinearity and differences in measurement times between sample sets, all data was normalized to an internal $\mathrm{CaCO}_{3}$ sample within each set. These normalized average \% weight gain per day values were used to compare sample sets. The following treatments reduced water absorption by roughly $50 \%$ and were further evaluated in composites.

- Enzymatic refinement of soy flour to soy isolate

- Torrefaction with a "temperature $\mathrm{x}$ time" factor of 4000 to $5000{ }^{\circ} \mathrm{C}$-min

- Either $4 \mathrm{hr}$ slurry or $15 \mathrm{~min}$ dry blend silane treatment with octyltriethoxysilane

- A $4 \mathrm{~h} 120{ }^{\circ} \mathrm{C}$ sludge acetylation of soy flour 


\subsection{Bulk Molding Compounds}

BMC studies were used to decide which of these treatments would be advanced in the evaluations. Enzyme-refined SPC and SPI fillers, torrefacted fillers, silane treated and aceltylated fillers were evaluated. With soy meal flour as the precursor, some silane treatments provided reduction in water absorption and retention of properties after water immersion. The improvements, however, were not as good as for acetylation, torrefaction and refinement. Issues with residual acetic anhydride and acetic acid by-product for the acetylated filler resulted in poor mechanical properties. This fact, along with the use of, and need to recover, chemicals in the process, resulted in a decision to not move forward with acetylation. The torrefaction process and enzyme refinement process were further studied. Both processes meet the target requirement of green chemical considerations.

\subsection{Cost Assessment : Torrefaction of Soy Hulls}

The price point for the soy filler volume cost parity to $\mathrm{CaCO}_{3}$ is $\$ 0.30 / \mathrm{lb}$. Soy hulls are approximately $\$ 0.10 / \mathrm{lb}$. and the torrefaction yield is $65 \%$ using the $250{ }^{\circ} \mathrm{C}$ process. The precursor cost per lb of filler is therefore $\$ 0.154$. Agri-tech projects the capital equipment costs with a 5 year amortization and operating costs to be roughly $\$ 0.22 / \mathrm{lb}$. The projected filler cost is $\$ 0.374 / \mathrm{lb}$, which is a $25 \%$ premium over $\mathrm{CaCO}_{3}$. Because the filler is only roughly $20 \%$ of the total formulation, the premium for the compound is only $5 \%$, which considering its benefit of lightweighting, is a good value relative to competitive offerings. 


\subsection{Sheet Molding Compounds}

Thickening studies of SMC paste indicated that much higher levels of thickener were required with refined SPI and with lightly torrefacted filler. With higher levels of torrefaction, conventional levels of thickener provided the desired effect.

In early SMC studies with torrefacted fillers, polymerization issues were encountered. This was first noted in poor mechanical integrity of moldings and verified by dielectric impedance testing. It was determined that there is a threshold heat treatment temperature, beyond which the free radical cure of the thermoset composite is inhibited, and in extreme cases, isretarded. Heat treatment below $250^{\circ}$, did not inhibit the cure and resulted in useful filler with reduced water absorption.

SMCs made with these fillers had rheological behavior similar to that of conventional SMC in terms of the stress required to flow and viscosity; however, they had a longer stress relaxation time and a lower power law index. Impedance curves and exotherms indicated no deleterious effects on cure, relative to the $\mathrm{CaCO}_{3}$ control compound. The mechanical properties were in line with those of commercial low density compounds. On a cost per volume basis, the soy-filled SMC was much more competitive than other low density compounds. .

\subsection{Analysis of Fillers}

Although the torrefacted fillers were the focus of the composite scaling evaluation, a number of the more promising treatments were selected for analytical 
examination. FTIR spectroscopy. DSC, TGA, EA and NMR spectroscopy were used to study the fillers.

FTIR was used to probe changes in chemical composition of the fillers. Silane absorbance provided evidence of successful grafting. Acetyl peaks provided a semiquantitative measure of the level of acetylation. Reduction of carbohydrates, with protein refinement, and of oxygen and hydrogen, with torrefaction, were also observed.

The DSC was used to study the inhibiting and retarding effects of the fillers. Extracted oil and tar from the filler resulted in inhibition, but retardation was only seen with the highly torrefacted solid filler. Stevenson's kinetic equations provided analysis results in line with literature findings.

The TGA of the fillers provided insight into the decomposition behavior of the precurusor material. EA and NMR results correlated well with each other in terms of apparent formation of aromatic structures at different process temperatures.

\subsection{Unique Contribution and Future Direction}

This work provides a basis from which further development of modified soy flours as fillers for thermoset composites will continue. Biomass has been evaluated as fillers for thermoset composites since the early 1980s but failed to gain commercial acceptance due to excessive water absorption and inhibition issues with free radical

curing. Biomass, with a large percentage of carbohydrates, are very hydrophilic due to their abundance of hydroxyl groups, while biomass, high in lignin, resulted in inhibition 
of the free radical cure of the unsaturated styrenated polyester matrix systems. Generally protein use as a filler is not desirable due to its food value.

Torrefaction has proved to be a good, cost effective, process to reduce hydrophilicity of high cellulose feedstock. Surprising, however, some levels of torrefaction were found to induce the inhibition effect of the filler. Scientific inquiry into this problem proved that aromatics form during the torrefaction process and can become problematic when threshold levels are reached. Studies to determine suitable levels and appropriate processes provided options for manufacture of suitable fillers.

Future work is needed to optimize the process and to scale-up to levels for commercial use. Likewise, soy protein concentration shows promise as a useful and cost effective filler when uses for the carbohydrate by-products are developed. This method has the added advantage of light color to facilitate molding compound pigmentation. Both these manufacturing methods are consistent in providing green chemistry processing of the fillers. 


\section{BIBLIOGRAPHY}

1. Anastas, P.; Warner, J., Green Chemistry: Theory and Practice; Oxford University Press: New York, 1998; p 30.

2. Kolybaba, M.; Tabil, L.; Panigrahi, S.; Crear, W.; Powell, T.; Wang, B., "Biodegradable Polymers: Past, Present, Future," CSAE/ASAE Annual Intersectional Meeting, Fargo, 2003; pp 1-15.

3. Bastioli, C., Handbook of biodegradable polymers; Smithers Rapra Technology, 2005.

4. International Biodegradable Polymers Association and Working Groups.

"Bioplastics-Facts and Figures," http://en.european-bioplastics.org/multimedia/ (accessed June 17, 2015).

5. Meier, M.; Metzger, J.; Schubert, U., "Plant Oil Renewable Resources as Green Alternatives in Polymer Science," Chem. Soc. Rev. 2007, 1788-1802.

6. Meir, M., "Metathesis with Oleochemicals: New Approaches for the Utilization of Plant Oils as Renewable Resources in Polymer Science," Macromol. Chem. Phys. 2009, 1073-1097.

7. Rhonda, J.; Lligadas, G.; Galia, M.; Cadiz, V., "Vegetable Oils as Platform Chemicals for Polymer Synthesis," Eur. J. Lipid Sci. Technol. 2011, 113 (1), 4658.

8. Montero de Esponosa, L.; Meier, M., "Plant Oils: The Perfect Renewable Resource for Polymer Science," European Polym. Journal 2011, 47 (5), 837-852.

9. Sloan, J., "Bio-Based Resins Begin to Grow," Comp. Tech. 2008, 14 (2), 33-36.

10. Ravenstijn, J., "Bio-Based Polymers: a Revolutionary Change," JEC Comp. Mag. 2010, 59, 17-20. 
11. Evans, J., "Alternative Feedstocks.Viable?," SPE Plas. Eng. 2011, No. Feb., 1218.

12. Clemens, C., "WOODFIBER-PLASTIC COMPOSITES IN THE UNITED STATES - HISTORY AND CURRENT AND FUTURE MARKETS", USDA Forest Service, Forest Products Laboratory, http://www.fpl.fs.fed.us/documnts/pdf2000/clemo00b.pdf (accessed June 17, 2015).

14. Zhan, M.; Wool, R., "Mechanical Properties of Chicken Feather Fibers," Polym. Compos. 2011, 32 (6), 937-944.

15. Ofem, M.; Umar, M., "Effect of Filler Content on the Mechanical Properties of Periwinkle Shell Reinforced CNSL Resin Composites," ARPN J. of Eng. and Appl. Sci. 2012, 7 (2), 212-215.

16. Lignotech Developments, http://www.lignotech-usa.com (accessed June 17, 2015).

17. Laural Biocomposites, LLC, http://laurelbiocomposite.com/ (accessed June 17, 2015).

18. New Polymer Systems, Inc., http://www.newpolymersystems.com/ (accessed June 17, 2015).

19. Kobayashi, S.; Makino, A., "Enzymatic Polymer Synthesis: An Opportunity for Green Polymer Chemistry," Chem. Rev. 2009, 109 (11), 5288-5353.

20. Polymer Ohio, Inc. OH!Polymer. http://www.polymerohio.org/index.php?option=com_content\&view=article\&id=9 $\underline{4 \& \text { Itemid=102 }}$ (accessed Aug June 17, 2015).

21. Ohio Soybean Association. "Ohio Soybean Industry Overview" http://associationdatabase.com/aws/OHSOY/pt/sp/osa_industryoverview (accessed June 17, 2015).

22. Stauffer, C., "Defatted Sou Flour Reference Guide," "http://www.wishh.org/aboutsoy/defatted_soy_flour_reference_guide.htm. (accessed June 17, 2015). 
23. Barman, B.; Hansen, J.: Mossey, A., "Modification of the Physical Properties of Soy Protein Isolates by Acetylation”, “J. Agric.Food Chem. 1977, 25 (3),638-641.

24. Middelbos, I.; Fahey, G., "Soybean Carbohydrates," In Soybeans: Chemistry, Production, Processing and Utilization”, 1st ed.; L. Johnson, P. W. R. G., Ed.; AOCS Press: Urbana, Il, 2008; pp 269-273.

25. Food and Agriculture Organization of the United Nations, "TECHNOLOGY OF PRODUCTION OF EDIBLE FLOURS AND PROTEIN PRODUCTS FROM SOYBEANS", http://www.fao.org/docrep/t0532e/t0532e05.htm (accessed June 17, 2015).

26. Lee, E., “UP Onya-10-LU” particle size analysis, 2012.

27. Lee, E., "UP Premix \#1” particle size analysis, 2013.

28. Mannberg, P.; Giannadakis, K.; Jakovics, A.; Varna, J., "Moisture Absorption and Degradation of Glass Fiber / Vinylester Composites," International Scientific Colloquium : Modeling for Material Processing, Riga, 2010; pp 157-162.

29. Watt, P., "USB Project \#2456 Final Report”, The United Soy Board, 2013.

30. Schultz, J.; Mehta, R., "Use of Soy-based and Bio-based Fillers in SMC," USB Thermoset Plastics Technical Advisory Board, Detroit, 2011.

31. Mangino, M.; Harper, J., "Soy, http://class.fst.ohiostate.edu/FST822/lectures/Soy.htm (accessed March 26, 2013).

32. Baker, E., "Preparation of Unheated Soy Protein Isolates with Low Trypson Inhibitor”, USDA 1986.

33. Liu, J.; Wang, F., "Influence of Mercerization on Micro-structure and Properites of Kapok Blended Yarns with Different Blending Ratios," J. Eng. Fibers and Fabrics 2011, 6, 63-68.

35. Van der Weyenberg, I.; Ivens, J.; De Coster, A.; Kino, B.; Baetens, E.; Verpoest, I., "Influence of Processing and Chemical Treatment of Flax Fibers on their Composites," Comp. Sci. and Tech. 2003, 63, 1241-1246. 
36. Valadez-Gonzalez, A.; Cervantes-Uc, J.; Olayo, R.; Herrera-Franco, P., "Chemical Modification of Henequen Fibers with an Organosilane Coupling Agent," Composites, Part B 1999, 30 (1), 321-331.

37. Agrawal, R.; Saxena, N.; Sharma, K.; Thomas, S.; Sreekala, M., "Activation Energy and Crystallization Kinetics of Untreated and Treated Oil Pam Fibre Reinforced Phenol Formaldehyde Composites," Materials Science and Engineering 2000, A277, 77-82.

38. Rangel-Vazquez, N.; Leal-Garcia, T., "Spectroscopy Analysis of Chemical Modification of Cellulose Fibers," J. Mex. Chem. Soc. 2010, 54, 192-197.

39. Yang, B.; Dai, Z.; Ding, S.-Y.; Wyman, C., "Enzymatic Hydrolysis of Cellulosic Biomass," Biofuels 2011, 2 (4), 421-450.

40. Zhang, Q.; Lo, C.-M.; Ju, L.-K., "Affinity Foam Fractionation of Trichoderma Cellulase," Applied Biochemistry and Biotechnology 2006, 129-132, 1051-1065.

41. Stromberg, B.; Rawls, J., "Method and System for the Torrefaction of Lignocellulosic Material," US 2011/0041392 A1, Feb 24, 2011.

42. Beekes, M.; Cremers, M., "Torrefaction Cracks the Biomass Challenge," Renewable Energy World Magazine, June 25, 2012, 7-12.

43. Nimlos, M.; Brooking, E.; Looker, M.; Evans, R., "Biomass Torrefaction Studies with a Molecular Beam Mass Spectrometer," Prepr. Pap. - Am. Chem. Soc., Div. Fuel Chem. 2003, 48 (2), 590-591.

44. "Soy Flour Products in Baking. Wiishh.org., http://www.wishh.org/nutrition/stauffer_baking_paper.pdf. (accessed June 17, 2015).

45. Dankovich, T.; Hsieh, Y., "Surface Modification of Cellulose with Plant Triglycerides for Hydrophobicity," Cellulose 2007, 14, 469-480.

47. Chen, F.; Zhang, J., "Effects of Plasticization and Shear Stress on Phase Structure Development and Properties of Soy Protein Blends," ACS Applied Materials and Interfaces 2010, 2 (11), 3324-3332. 
48. Mealey, S.; Thomas, B., "Past, Present and Future of Organosilane Treatments for Fillers," Rubber World 2005, 12, 32-35.

49. Sadler, E.; Vercere, A., "Silane Treatmetn of Mineral Fillers- Practical Aspects," Plas. Rub. and Comp. Proc. and Appl. 1995, 24, 271-275.

50. Lu, J.; Drzal, L., "Microfibrillated Cellulose/Cellulose Acetate Composites: Effect of Surface Treatment," J. of Polym. Sci.: Part B: Polym. Phys. 2009, 48, 153-161.

51. Abdelmouleh, M.; Boufi, S.; Salah, A.; Belgacem, M.; Gandini, A., "Interaction of Silane Coupling Agents with Cellulose," Langmuir 2002, 18, 3203-3208.

52. Salon, M.; Gerbaud, G.; Abdelmouleh, M.; Buzzese, C.; Boufi, S.; Belgacem, M., "Studies on Interactions Between Silane Coupling Agents and Cellulose Fibers with Liquid and Solid-State NMR," Magn. Reson. Chem. 2007, 45, 473-483.

53. BEl-Hassen, R.; Boufi, S.; Salon, M.; Abdelmouleh, M.; Belgacem, M., "Adsorption of Silane onto Cellulose Fibers. II. The Effect of $\mathrm{pH}$ on Silane Hydrolysis, Condensation, and Adsorption Behavior," J. Appl. Polym. Sci. 2008, 108, 1958-1968.

54. Heitner, C.; St. John Manley, R.; Ahvazi, B.; Wang, J., "The Effect of Acetylation on the Photodegradation of Milled Wood Lignin," Journal of Pulp and Paper Science 2001, 27 (10), 325-329.

55. Hill, C.; Khalil, A., "Effect of Fiber Treatments on Mechanical Properties of Coir or Oil Palm Fiber Reinforced Polyester Composites," J. of Appl. Polym. Sci. 2000, 78, 1685-1697.

56. Chand, N.; Verma, S.; Khazanchi, A., "SEM and Strength Characteristics of Acetylated Sisal Fibre," J. Mat. Sci. Letters 1989, 8, 1307-1309.

58. Secen, H.; Kalpar, A., "An Efficient Acetylation of Primary and Secondary Aliphatic Alcohols with Acetic Anhydride in the Presense of Graphite Bisulphate," Turk. J. Chem 1999, 23, 227-230.

59. Ch, R.; Tyagi, M.; Patil, P.; Ravindranathan Kartha, K., DABCO: an Efficient Promoter for the Acetylation of Carbohydrates and other Substances under Solvent-Free Conditions. Tetrahedron Letters 2011, 52, 5841-5846. 
60. Li, J.; Zhang, L.-P.; Peng, F.; Bian, J.; Yuan, T.-Q.; Xu, F.; Sun, R.-C., "Microwave-Assisted Solvent Free Acetylation of Cellulose with Acetic Anhydridein the Presense of Iodine as a Catalyst," Molecules 2009, 14, 35513566.

61. Simonson, R.; Rowell, R., "A New Process for Continuous Acetylation of Lignocellulosic Fiber," Proceedings of the 5th Pacific Rim Bio-based Composites Symposium, Canberra, Austrailia, 2000; pp 190-196.

62. Peterson, H.; Fleischmann, G., "Process for the Acetylation of Lignocelluloses, Hemicelluloses, and Celluloses with Ketene," 20110009610, Jan 13, 2011.

63. Kjeldahl, J., "A New Method for Determination of Nitrogen in Organic Bodies," Analytical Chemistry 1883, 22, 366.

64. AOCS. search methods results. AOCS.

http://search.aocs.org/methods/search_methods_results.cfm (accessed June 17, 2015).

65. Food and Agriculture Organization of the United Nations. "Food Energy -Methods of Analysis and Conversion Factors," FAO Corporate Document Repsository. http://www.fao.org/docrep/006/Y5022E/y5022e03.htm (accessed June 17, 2015).

66. McClements, D., "7. Analysis of Carbohydrates," http://people.umass.edu/ mcclemen/581Carbohydrates.html (accessed June 17, 2015).

67. Clemons, C.; Young, R.; Rowell, R., "Moisture Sorption Properties of Composite Boards From Esterified Aspen Fiber," Wood and Fiber Sci. 1992, 24 (3), 353-363.

68. Rousset, P.; Aguiar, C.; Labbe, M.; Commandre, J.-M., "Enhancing the Combustible Properties of Bamboo by Torrefaction," Biosource Technology 2011, 102, 8225-8231.

69. Lv, P.; Almeida, G.; Perre, P., "Torrefaction of Cellulose: Validity and Limitation of the Temperature/Duration Equivalence," BioResources 2012, 7 (3), 3720-3731. 
70. Barkakaty, B., "Some Structural Aspects of Sisal Fibers," J. Appl. Polym. Sci. 1976, 20, 2921-2940.

71. Rees, D.; Robertson, A., "Some Thermodynamic Implications for the Thermostability of Proteins," Protein Science 2001, 10 (6), 1187-1194.

72. Capouchova, I.; Petr, J.; Maresova, D., "Evaluation of Size Distribution of Starch Granules in Selected Wheat Varieties by the Low Angle Laser Light Scatterig Method," Plant Soil Environ. 2003, 49 (1), 12-17.

74. Coffman, A.; Li, Q.; Ju, L-K., "Effect of Natural and Pretreated Soybean Hulls on Enzyme Production by Trichoderma reesei", J. Am. Oil Chem. Soc. 2014, 91, 1331-1338.

75. Korte, H., "High Temperature Resistant Plastic Composite with Modified LignoCellulose". US Patent US2012/00835555 A1, 5 April 2012.

76. Watt, P,; Pugh, C., "Studies to Determine Characteristics of Thermally Treated Biomass Fillers Suitable for Thermoset Composites," Polymers from Renewable Resources, vol. 6, no. 1, 1-24, 2015.

77. Allen, P., Yeh, J., Collister, J. Meinecke, E., "Experimental Study of SMC Rheology Using Compression Techniques" $45^{\text {th }}$ Conference, Composites Institute, SPI 1 45, (11B:1-6), Feb 12-15, 1990.

78. Collister, J., and Allen, P., "Sheet Molding Compound Rheology" - book chapter in Hamid Kia's Sheet Molding Compounds, Hanser Publishers, 1993, 137-161.

79. Stevenson, J. "Free Radical Polymerization Models for Simulating Reactive Processing" Polym. Eng. and Sci.. 26, (11) (1986): 746-759.

80. Kamal, M., Sourour, S. and Ryan, M. SPE Tech Papers 19 (1973): 187. 
81. Putsatcioglu, S., Fricke, A. and Hassler, J. "Heats of Reaction and Kinetics of a Thermoset Polyester" J. Appl,. Polym. Sci. 24 (1979): 937-946.

82. Han, C. and Lee, D. "Analysis of the Curing Behavior of Unsaturated Polyester Resins Using the Approach of Free Radical Polymerization" J. of Appl. Polym. Sci.33 (1987): 2859-2876.

83. Muzumdar, S. and Lee, J. "Prediction of Gel-Time in the Cure of Unsaturated Polyester Resins: Phemonological Modeling vs. Statistical Analysis" Polym. Eng. Sci 31(23) (1991): 1647-1656. 